GERSON DE SOUZA FARIA

\title{
NOVOS ATAQUES DE CANAL SECUNDÁRIO A DISPOSITIVOS DE ENTRADA MANUAL DE DADOS CONFIDENCIAIS
}

Tese apresentada à Escola

Politécnica da Universidade de

São Paulo para obtenção do Título de

Doutor em Ciências

São Paulo

2017 
GERSON DE SOUZA FARIA

NOVOS ATAQUES DE CANAL SECUNDÁRIO A DISPOSITIVOS DE ENTRADA MANUAL DE DADOS CONFIDENCIAIS

Tese apresentada à Escola

Politécnica da Universidade de

São Paulo para obtenção do Título de

Doutor em Ciências

Área de Concentração:

Sistemas Eletrônicos

Orientador:

Prof. Dr. Hae Yong Kim 
Este exemplar foi revisado e corrigido em relação à versão original, sob responsabilidade única do autor e com a anuência de seu orientador.

São Paulo, de de

Assinatura do autor:

Assinatura do orientador:

Catalogação-na-publicação

Faria, Gerson de Souza

NOVOS ATAQUES DE CANAL SECUNDÁRIO A DISPOSITIVOS DE ENTRADA MANUAL DE DADOS CONFIDENCIAIS / G. S. Faria -- versão corr. -- São Paulo, 2017.

$181 \mathrm{p}$.

Tese (Doutorado) - Escola Politécnica da Universidade de São Paulo. Departamento de Engenharia de Sistemas Eletrônicos.

1.Redes de computadores (Segurança) 2.Processamento digital de sinais 3.Reconhecimento de padrões I.Universidade de São Paulo. Escola Politécnica. Departamento de Engenharia de Sistemas Eletrônicos II.t. 


\section{Agradecimentos}

Ao professor Hae Yong Kim pela amizade, seriedade e rigor no processo de orientação, pelo constante estímulo e pela parceria real de trabalho.

Ao Departamento de Engenharia de Sistemas Eletrônicos por me selecionar e à Capes, pela concessão de bolsa de estudo.

Aos professores Miguel Arjona Ramirez e Emilio Del Moral Hernandez pelas valorosas contribuições na banca de qualificação.

Ao professor Reinaldo Augusto da Costa Bianchi pela apresentação do artigo Identification of Pressed Keys by Acoustic Transfer Function em congresso internacional.

Ao professor Ross Anderson, cuja experiência, inteligência e afabilidade muito influenciaram esta tese.

Ao professor Claudio Garcia, pelas discussões profícuas.

À professora Roseli de Deus Lopes pela oportunidade de realizar supervisão no programa PAE.

À Secretaria do Departamento, nas pessoas de Eliana, Elisabete e Simone, sempre solícitas.

Aos meus pais Apparecida e Agenor, e irmãos Laercio e Alexandre.

À Ninoca Maria, Jolie Marie e Nina Luísa, que sempre estiveram presentes, em todos os momentos.

À equipe do LSITEC/LEA - Laboratório de Ensaios e Auditoria, que me incentivou à pesquisa da fascinante área de ensaios de segurança de sistemas.

E sempre, à Ana, pelo apoio constante, dedicação e carinho, sem os quais nada disso teria sido realizado. 
Que eu possa viver para te louvar, e tuas normas me auxiliem.

- Salmos 119:175 


\section{Sumário}

Introdução 1

Revisão da Literatura . . . . . . . . . . . . . . . . . . . . 2

Abordagem adotada . . . . . . . . . . . . . . . 3

Organização da tese . . . . . . . . . . . . . . . . . . . 5 5

Publicações ........................... 6

$\begin{array}{llr}1 & \text { Ataques invasivos e de canal secundário } & 8\end{array}$

1.1 Tráfego do PIN no padrão EMV . . . . . . . . . . . . . . . . 8

1.2 Ataques invasivos . . . . . . . . . . . . . . . . 9

1.3 Ataques de canal secundário . . . . . . . . . . . . . 12

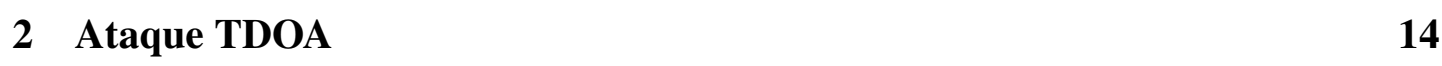

2.1 Vibração de uma placa . . . . . . . . . . . . . . . . . . 17

2.1 .1 Teoria . . . . . . . . . . . . . . . . . 17

2.1 .2 Dispersão em uma placa acrílica . . . . . . . . . . . . . . 18

2.2 Protótipo de teclado em placa acrílica . . . . . . . . . . . . 21

2.2 .1 Construção dos atributos e algoritmo de classificação . . . . . 23

2.3 Experimento com teclado numérico . . . . . . . . . . . . 25

2.3 .1 Atributos e classificação . . . . . . . . . . . . . 26

2.4 Experimento com PIN pad . . . . . . . . . . . . . . . . . 28

$2.4 .1 \quad$ Atributos e classificação . . . . . . . . . . . . . . . 29

2.5 Discussões e viabilidade do ataque . . . . . . . . . . . . 32

2.6 Estimativa da localização de origem da vibração . . . . . . . . . . . . 33

3 Ataque DAA

3.1 Modelo do ataque . . . . . . . . . . . . . . . . . . . . 37

$3.1 .1 \quad$ Caracterização do sistema acústico como sistema linear. . . . 37

3.1 .2 Resposta acústica impulsiva de um espaço tridimensional. . . 39

3.1.3 Métodos de estimação da resposta em frequência dos sistemas 41

3.1.3.1 Método baseado no periodograma suavizado de Welch 41 
3.1.3.2 Método baseado em sistema LIT racional . . . . . . 42

3.1.4 Ataque baseado na densidade espectral de potência (PSD) . . 43

3.2 Experimento com PIN pad Ingenico iPP320 . . . . . . . . . . . 44

3.2.1 Aquisição de dados de treino e teste . . . . . . . . . . . . 46

3.2 .2 Atributos e classificação . . . . . . . . . . . . . 47

3.2 .3 Comparação com o ataque via PSD . . . . . . . . . . . . . . . . . . . . . . . . . 40

3.2 .4 Análise dos resultados . . . . . . . . . . . . . 50

3.2.5 Experimento de posicionamento dos microfones . . . . . . . 51

3.2 .6 Experimento de ruído ambiental . . . . . . . . . . . 53

3.2 .7 Clonagem do ataque . . . . . . . . . . . . 55

3.3 Experimento com PIN pad Gertec PPC910 . . . . . . . . . . . . . 56

3.3 .1 Análise dos resultados . . . . . . . . . . . . 59

3.4 Discussões e viabilidade do ataque DAA . . . . . . . . . . . . . 59

4 Ataque utilizando células de carga $\quad 61$

4.1 Modelagem física do problema . . . . . . . . . . . . . . 62

4.2 Experimento inicial . . . . . . . . . . . . . . . . . . 64

4.3 Extração de atributos $\ldots \ldots \ldots 66$

4.3 .1 Atributo dados brutos de força . . . . . . . . . . . 66

4.3 .2 Atributo forças normalizadas . . . . . . . . . . . . . 66

4.3 .3 Atributo modelo de coordenadas . . . . . . . . . . . . 67

4.4 Mesa sensora I . . . . . . . . . . . . . . . . . . . . . 67

4.4.1 Resultados do experimento da Mesa I com PIN pad iPP320. . 68

4.5 Mesa sensora II . . . . . . . . . . . . . . . 71

$4.5 .1 \quad$ Resultados do experimento da Mesa II com PIN pad iPP320 . 72

4.6 Discussões e viabilidade do ataque . . . . . . . . . . . . . . 75

5 Normas e Processos de Certificação

5.1 A norma ISO $9564 \ldots \ldots \ldots 77$

5.2 Padrões de certificação . . . . . . . . . . . . . . . . . . . 77

$5.2 .1 \quad$ Payment Card Industry - PCI . . . . . . . . . . . . . . . . . . . . . . . . . 77

5.2 .2 Common Criteria - CC . . . . . . . . . . . . 78

5.2 .3 ITI/ICP-Brasil . . . . . . . . . . . . . . 78

5.3 Análise dos custos dos ataques desenvolvidos . . . . . . . . . . 79

5.4 Divulgação responsável de vulnerabilidades . . . . . . . . . . . 83

\begin{tabular}{lr}
\hline Conclusões & 86
\end{tabular}

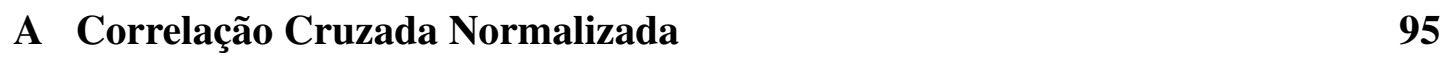


\begin{tabular}{|l|l|}
\hline B Principal Component Analysis (PCA) & 97
\end{tabular}

B.1 O algoritmo . . . . . . . . . . . . . . . . . . . 99

B.2 Aplicação . . . . . . . . . . . . . . . . . . . 100

\begin{tabular}{|lll}
\hline & Método do Periodograma Suavizado de Welch & 102
\end{tabular}

C.1 O algoritmo "tfestimate" . . . . . . . . . . . . . . . . . . 102

\begin{tabular}{|ll}
\hline D O classificador Naive Bayes & 104
\end{tabular}

D.1 O algoritmo Naive Bayes . . . . . . . . . . . . . . . . . . . . . . . 104

D.2 Aplicação . . . . . . . . . . . . . . . . . . 105

\begin{tabular}{|lll}
\hline E & Simulação do modelo DAA para uma caixa fechada & 107
\end{tabular}

\begin{tabular}{ll}
\hline Glossário & 111
\end{tabular}

\begin{tabular}{ll}
\hline Índice Remissivo & 115
\end{tabular} 


\section{Lista de Figuras}

2.1 Montagem do experimento para observar o fenômeno de dispersão em uma placa acrílica. . . . . . . . . . . . . . . . . 19

2.2 (Esq) Sinais de aceleração obtidos por toques na placa acrílica com o dedo nos pontos 'b', 'c' and 'd'. (Dir) Atraso relativo estimado utilizando-se a posição do maior pico na NCC entre $A 1_{z}$ and $A 2_{z} \cdot$. . 20

2.3 (Esq) Sinais de aceleração obtidos por toques com uma ponta metálica de uma lapiseira na placa acrílica, nos pontos 'b', 'c' and 'd'. (Dir) Atraso relativo estimado utilizando-se a posição do maior pico na NCC entre $A 1_{z}$ and $A 2_{z}$. . . . . . . . . . . . . . . . . 21

2.5 Uma janela Gaussiana é aplicada de modo a atenuar efeitos de reflexão, melhorando a estimação do atraso. (Cima) sinal original de aceleração do experimento com PIN pad, pressionando a tecla " 8 ". (Baixo) sinais

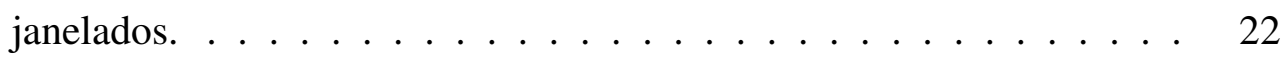

2.6 Atrasos obtidos do experimento de teclado em placa de acrílico. . . . 23

2.7 Cálculo das componentes principais dos 3 atrasos obtidos do experimento de teclado em placa acrílica mostram que apenas duas componentes são responsáveis por toda informação. . . . . . . . . . . . . . 24

2.9 Atrasos obtidos do experimento com teclado numérico. A abscissa corresponde ao número do pressionamento, i.e., $x=1$ a 10 correspondem à tecla " 1 ", $x=11$ a 20 à tecla "2" e $x=91$ a 100 à tecla

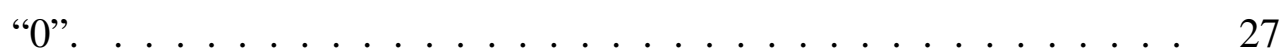

2.10 Cálculo das componentes principais dos 3 atrasos obtidos do experimento PIN pad mostram que apenas duas componentes são responsáveis por toda informação. . . . . . . . . . . . . . . . . . . 27

2.12 Atrasos obtidos do experimento PIN pad. A abscissa corresponde ao número do pressionamento, i.e., $x=1$ a 20 corresponde à tecla "1", $x=21$ a 40 à tecla "2" e $x=181$ a 200 à tecla " 0 ". . . . . . . . . . . 30 
2.13 Cálculo das componentes principais dos 3 atrasos obtidos do experimento PIN pad mostram que apenas duas componentes são responsáveis por toda informação. . . . . . . . . . . . . . . . . 30

2.14 Estimação das posições das teclas para o experimento PIN pad. . . . . 31

2.15 Diagrama do método de triangulação. . . . . . . . . . . . . . 33

3.1 O conjunto formado pelo espaço interno do dispositivo, a posição da tecla e dos microfones, compõe um sistema cuja resposta em frequência deve ser estimada. As teclas serão classificadas baseadas nas funções de transferência. . . . . . . . . . . . . . . . . . . . 37

3.2 (a) A resposta de cada microfone ao pressionamento é descrita por um sistema linear, com excitação comum, não diretamente observável.

(b) $\mathrm{O}$ sistema resultante independente do conhecimento do sinal de

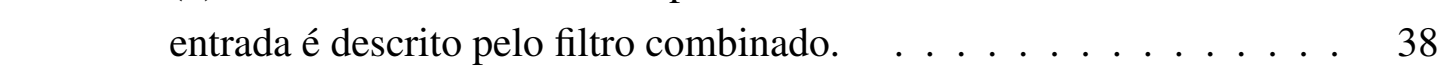

3.3 Sinais de um pressionamento do equipamento iPP320. A estimação da função de sistema linear que transforma o sinal de um microfone M1 (azul) em outro, M2 (vermelho) é utilizada para classificação das reclas. . . . . . . . . . . . . . . . . . . 39

3.4 (Esq) PIN pad Ingenico iPP320 utilizado no experimento. (Dir) Vista inferior mostrando o compartimento SAM com os microfones implantados. No canto superior direito do compartimento há a inserção da imagem de um módulo de aúdio estereofônico com comunicação Blu-

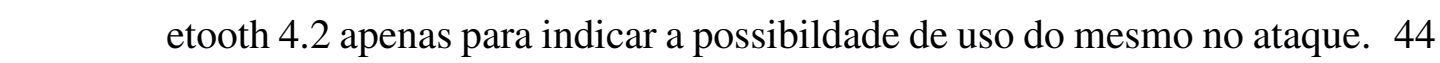

3.6 Pré-amplificadores Sparkfun BOB-12758 utilizados nos experimentos, - conectados aos microfones de eletreto. . . . . . . . . . . . . . . . 46

3.7 Magnitudes das funções de transferência estimadas obtidas do experi\begin{tabular}{|c|}
\hline mento com o PIN pad Ingenico. Cada cor corresponde a uma pessoa. \\
\hline
\end{tabular}

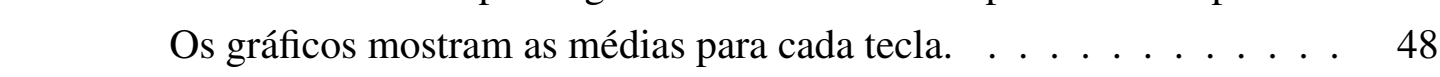

3.8 Atributos linLIT do experimento "B". Cada cor corresponde a um \begin{tabular}{|c|}
\hline atributo. A tecla "1" corresponde aos pressionamentos 1 a 50 e assim \\
\hline
\end{tabular}

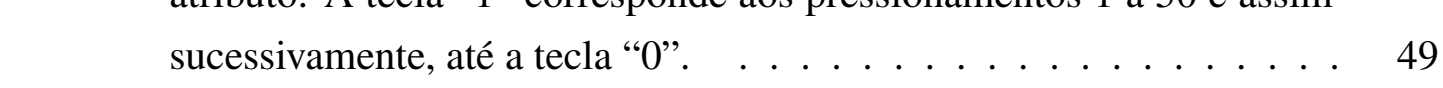

3.11 Percentagem de combinações de parâmetros que atingiram $100 \%$ de classificação correta versus par de microfones. . . . . . . . . . . . 52

3.12 Níveis sonoros medidos ao lado do PIN pad. O plateau à esquerda \begin{tabular}{|l|l|}
\hline corresponde ao nível ambiente sem música e o da direita com música. 53 & 53
\end{tabular}

3.13 Médias das magnitudes das funções de transferência dos experimentos "A" (vermelho) e "B" (azul) para a tecla "3". Ambas as funções são

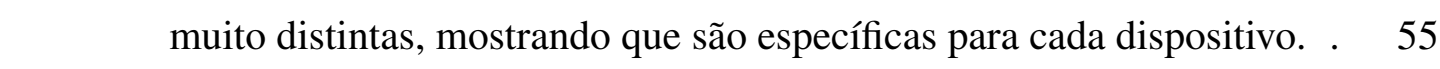


3.14 (Esq) PIN pad Gertec PPC910 utilizado no experimento. (Dir) A tampa inferior com os microfones implantados. . . . . . . . . . . 56

3.15 Funções de transferência obtidas neste experimento mostram visualmente uma concordância baixa entre diferentes pessoas. Cada cor corresponde a uma pessoa. Os gráficos são médias para cada tecla. . . . 57

3.16 Atributos logLIT para o experimento. Apenas os 4 principais atributos são apresentados. . . . . . . . . . . . . . . 58

$4.1 \quad$ Diagrama da mesa do experimento de células de carga. Os pontos $p_{i}$ correspondem às posições das células e $\mathbf{P}$ corresponde ao ponto de

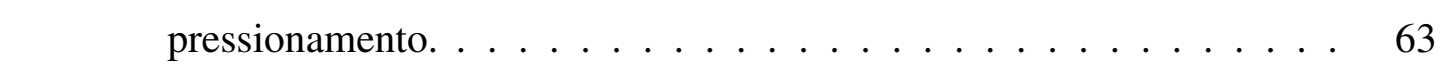

$4.2 \quad$ Primeiro experimento com células de carga. Os sinais do osciloscópio

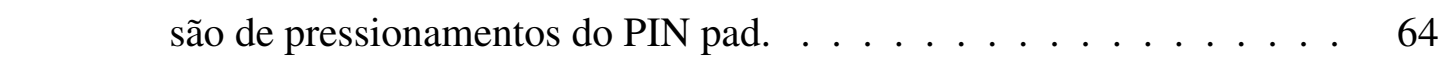

4.3 Diagrama do circuito amplificador do sinal das células de carga utili\begin{tabular}{|l}
\hline zado no experimento. $\mathrm{O}$ resistor de ganho $\mathrm{Rg} \approx 6 \Omega$ proporciona um \\
\hline
\end{tabular} ganho de $\approx 10.000 . \ldots \ldots \ldots \ldots \ldots 65$

4.4 Protótipo da mesa. As células de carga são afixadas na placa acrílica com uso de pequenos pés de borracha. . . . . . . . . . . . . . 67

4.5 (Acima) Sinais de força obtidos no pressionamento da teclas para as \begin{tabular}{|c|}
\hline quatro células de carga. (Abaixo) Atributos computados pela normali- \\
\hline
\end{tabular} zação euclideana $\left(\ell^{2}\right)$ dos valores das forças. . . . . . . . . . . 68

4.6 Atributos do tipo "forças normalizadas" após a PCA indicam que a informação necessária possui dimensão 3. . . . . . . . . . . . . . . 69

4.7 "Clusters" de coordenadas de pressionamentos de dois usuários para o - experimento iPP320. . . . . . . . . . . . . . 70

4.8 Protótipo da segunda mesa sensora com base de vidro. As tensões elétricas das células de carga de 500g são medidas diretamente por um

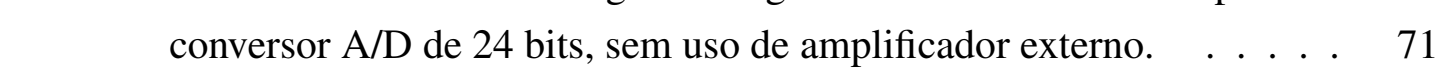

4.9 Atributos do tipo forças normalizadas após a PCA. . . . . . . . . . . 72

4.12 Kit de referência de projeto de interface de toque MAXREFDES82 da empresa Maxim. . . . . . . . . . . . . . . 75

5.1 Declaração de certificação PCI do equipamento iPP320. . . . . . . . . . 79

5.2 Declaração de certificação PCI do equipamento PP910. . . . . . . . . . 79

B.1 Autovalores da família de dados de treino para o experimento "B". . . 98 
E.1 Caixa utilizada na simulação do modelo entrada-saída. A linha azul sólida corresponde ao percurso da fonte sonora em que as funções de transferência foram calculadas. As posições dos microfones são M1 e M2. . . . . . . . . . . . . . . . . . . . . . 108

E.2 Representação da magnitude da resposta em frequência para valores

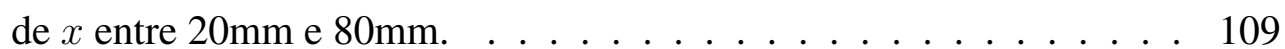

E.3 $\quad$ Funções de transferência simuladas para a caixa da Figura|E.1, para posições distintas de $x . \ldots \ldots$. . . . . . . . . . . . 110 


\section{Lista de Tabelas}

2.1 Matriz de Confusão do Experimento de Teclado Numérico . . . . . . 28

2.2 Matriz de Confusão do Experimento PIN pad . . . . . . . . . . . 31

3.1 Comparação entre os atributos do método PSD . . . . . . . . . . . . 50

3.2 Comparação entre os ataques - experimento Ingenico . . . . . . . . . 51

3.3 Comparação entre os métodos com ruído ambiental . . . . . . . . . . 54

$3.4 \quad$ Matriz de confusão do experimento Gertec - atributos logLIT . . . . 58

3.5 Comparacao entre os métodos - experimento Gertec . . . . . . . . . 58

4.1 Resultados de classificação - mesa sensora I . . . . . . . . . . . . 71

4.2 Resultados de classificação - mesa sensora II . . . . . . . . . . . . . 73

5.1 Cálculo do custo dos ataques TDOA e DAA para um PIN pad . . . 80 


\section{Lista de Abreviaturas e Siglas ${ }^{1}$}

ATM (Automatic Teller Machine ou Automated Teller Machine)

Caixa eletrônico de auto atendimento

CC (Common Criteria) Corpo normativo da área de segurança da informação

DAA (Differential Audio Analysis) Análise de áudio diferencial

EMSEC (Emission Security) Segurança de emissões

EMV (Europay, MasterCard e Visa) Padrão global para cartões com chip

GPS (Global Positioning System) Sistema de Posicionamento Global

HMI (Human Machine Interfacing) Interface Homem-Máquina

IIR (Infinite Impulse Response) Resposta ao Impulso Infinita propriedade de uma categoria de sistemas LIT

IoT (Internet of Things) Internet das Coisas

LIT (Linear e Invariante no Tempo) Categoria da teoria de sistemas

MEMS (Micro-Electro-Mechanical Systems) Sistemas Microeletromecânicos

MFCC (Mel Frequency Cepstral Coefficient) Representação do cepstrum de um sinal na escala mel

MLP (Multilayer Perceptron) Perceptron multicamadas

\footnotetext{
${ }^{1}$ Procuramos sempre que possível empregar as abreviações mais comumente encontradas na literatura especializada que, por esta razão, foram mantidas na língua inglesa.
} 
NCC (Normalized Cross Correlation) Correlação cruzada normalizada

NSA (National Security Agency) Agência Nacional de Segurança dos EUA

PCI (Payment Card Industry) Consórcio de empresas de meios de pagamento responsável pelo padrão de certificação de segurança homônimo

PIN (Personal Identification Number) Número de identificação pessoal

PIN pad Terminal de ponto de venda que utiliza cartão e onde o PIN é inserido

POS (Point of Sale) Terminal de ponto de venda

PSD (Power Spectral Density) Densidade Espectral de Potência

RNA Rede Neural Artificial

RSA (Rivest, Shamir e Adelman) Algoritmo criptográfico de chave pública

SAM (Secure Access Module) Módulo de Acesso Seguro

SCA (Side-channel Attack) Ataque de Canal Secundário

TDOA (Time Difference of Arrivals) Diferença de tempo de chegadas

TPR (True Positive Rate) Taxa de Positivos Verdadeiros 


\section{Resumo}

Esta tese apresenta três novos ataques a equipamentos de pagamento eletrônico que possuem teclado mecânico, conhecidos como "PIN pads". Mostramos de três formas distintas como tais equipamentos possuem vulnerabilidades de segurança na camada física que permitem o vazamento do PIN (Personal Identification Number) quando o mesmo é digitado. Demonstramos experimentalmente que é possível inferir com elevada taxa de acerto (100\% em um dos ataques) a senha digitada, de forma não-invasiva. Os ataques desenvolvidos são baseados na introdução de sensores nos próprios equipamentos ou em seu ambiente de operação: acelerômetros para análise de vibração, microfones para análise acústica e células de carga para medição de forças do pressionamento.

Devido à massificação no uso de sensores por dispositivos de consumo, o roubo de informação por meios não convencionais é atividade crescente. Os resultados dos ataques de baixo custo realizados expõem sérias deficiências no processo de certificação de segurança de tais equipamentos.

Palavras-chave: segurança da informação, ataque de canal secundário, PIN pad, smartcard, PCI, EMV, Common Criteria, Internet das Coisas, Big Data. 


\section{Abstract}

This thesis presents three new attacks on electronic payment equipment having mechanical keypads, known as "PIN pads". We show in three different ways how they have security vulnerabilities at the physical layer allowing the leak of the PIN (Personal Identification Number) when it is entered. We experimentally demonstrated that it is possible to infer with high success rate (100\% in one of the attacks) the password entered on the device, in a non-invasive way. The attacks are based on the placement of sensors inside the equipment itself or in its operating environment: accelerometers for doing vibration analysis, microphones for acoustic analysis and load cells for measuring the pressing force.

Due to massive deployment of sensors in consumer devices, information theft by unconventional means is increasing. The results of the low-cost attacks here developed expose serious shortcomings in the process of security certification of such equipment.

Keywords: information security, side-channel attack, PIN pad, smartcard skimming, PCI, EMV, PIN Entry Device, Common Criteria, PIN pad, Internet of Things, Big Data. 


\section{Introdução}

Equipamentos eletrônicos de pagamento como PIN pads foram introduzidos em meados dos anos 1970 ${ }^{2}$. Desde então, a tecnologia de dispositivos eletrônicos avançou de forma acentuada, com a redução de tamanhos, custos, consumo energético e, ao mesmo tempo, com a ampliação da capacidade de processamento, espectro de uso e mobilidade, como ocorreu na eletrônica de forma geral. A introdução de sensores avançados e de baixo custo, de tecnologia Micro-Electro-Mechanical Systems (MEMS) - giroscópios, acelerômetros, magnetômetros, microfones, câmeras etc. - no mercado de dispositivos de consumo (smartphones como o melhor exemplo), aliada à capacidade de processamento e comunicação cada vez maiores de sistemas microcontrolados e ao desenvolvimento de algoritmos poderosos de aprendizado de máquina, trazem uma nova ameaça à segurança de dados. Informação física que outrora era de difícil aquisição ou inacessível, hoje é parte de virtualmente todos os dispositivos móveis por meio de sensores de baixíssimo custo. Tais sensores podem ser componentes do próprio dispositivo ou podem ser introduzidos maliciosamente em um dispositivo para roubo de informação. Neste último caso são conhecidos na literatura de língua inglesa como skimmers, sendo que no Brasil é comum o uso do termo "chupa-cabras" em se tratando de roubo de dados em caixas eletrônicos.

Os três ataques desenvolvidos nesta tese são baseados na introdução maliciosa de sensores em PIN pads: acelerômetros - utilizados na análise de ondas mecânicas geradas no pressionamento das teclas; microfones - utilizados na análise acústica do interior do equipamento; e extensômetro@ ${ }^{3}$ - células de carga, utilizadas na triangulação de forças do pressionamento.

\footnotetext{
${ }^{2}$ Três são as empresas pioneiras na produção de terminais de pagamento: Hypercom (Austrália, 1978), Ingenico (França, 1980) e Verifone (Estados Unidos,1981).

${ }^{3}$ Também conhecidos pelo nome em inglês, strain gauges.
} 
A massificação de sensores de baixo custo abre um novo horizonte de ataques e origina-se do modelo tecnológico atualmente em voga, denominado Internet of Things (IoT) sendo este paradigma difundido em vários meios, sejam técnicos 4 , culturais, comportamentais etc., cujo intuito é o monitoramento (e controle, em determinados casos) de todos os objetos físicos existentes, atribuindo-lhes um modelo de operação e um endereço na rede. Esta cultura de generalização de sensores implantados em objetos outrora considerados triviais traz consigo novas questões de segurança de modo algum negligenciáveis5 5 Assim, a generalização do uso efetivo de sensores de quaisquer grandezas físicas em objetos do cotidiano leva diretamente à possibilidade de adquirir informações que possibilitem realizar inferências antes impossíveis, que podem ser, a princípio, portadoras de informação confidencial. Deste modo, terminais de pagamento, que já são alvos da criminalidade, continuarão a sê-lo, de forma ainda mais elaborada e eficiente. Segundo pesquisa do Gartner, Inc. 6 em 2020 o mercado negro de venda de dados de sensores e de vídeo movimentará mais de US\$5 bilhões, considerando-se também os investimentos em segurança em seu combate.

A motivação da pesquisa é o aprofundamento do exame de segurança física de PIN pads sob uma ótica de novas tecnologias de sensores de baixíssimo custo aliada a técnicas de processamento digital de sinais e classificação de sinais via aprendizado de máquina, investigação iniciada durante meu mestrado, "Identificação das teclas digitadas a partir da vibração mecânica”[2].

\section{Revisão da Literatura}

A literatura de ataques a teclados mecânicos utilizando canais secundários e processamento de sinais tem como um dos precursores Asonov e Agrawal [16], em estudo no

\footnotetext{
${ }^{4}$ Basta notar a quantidade de novas plataformas de desenvolvimento open source e open hardware como Arduino, MBed, Raspberry Pi etc. Nessas comunidades de desenvolvimento compartilhado, forma-se a educação técnica em que o controle de dispositivos quaisquer é objetivo comum, caminhando rapidamente do hobby à aplicação industrial.

${ }^{5} \mathrm{O}$ Pew Research Center publicou um relatório contendo entrevistas com mais de 1.400 especialistas com perguntas a respeito da "Vida Digital em 2025", sendo que a ubiquidade da Internet mediando todas as interações realizadas pelo ser humano é senso comum entre os entrevistados. O relatório pode ser acessado em http://www.pewinternet.org/2014/07/03/net-threats/

${ }^{6}$ Gartner Says By 2020, More Than Half of Major New Business Processes and Systems Will Incorporate Some Element of the Internet of Things. http://www.gartner.com/newsroom/id/3185623. Acesso em 2 Nov. 2016
} 
qual realizam análise de áudio emanado por teclados genéricos de computador pessoal e teclados de caixas eletrônicos. Seguem nessa mesma linha Berger [11] e Zhuang [8]. Ataques acústicos em outros dispositivos, tais como impressoras matriciais são encontrados em Backes et al. [10]. Tromer [12] apresenta uma criptanálise em que afirma ser possível identificar as operações matemáticas de uma assinatura RSA sendo executadas pela CPU, por meio da captura de emanações acústicas de um componente eletrônico específico da fonte de alimentação, um capacitor eletrolítico, operando na faixa de $20 \mathrm{kHz}$. Cai e Chen [14] descrevem um ataque que permite inferir os dígitos pressionados no teclado virtual de smartphones baseados no sistema Android analisando o movimento do aparelho capturado pelo acelerômetro interno do mesmo. Uma análise geral sobre a vulnerabilidade de sensores de telefones celulares é apresentada em Cai et al. [15]. Hussain et al. [7], apresentam um extenso levantamento da literatura sobre ataques dessa natureza em smartphones, também baseados no sistema Android. Wang et al. [13] demonstram a possibilidade de descobrir o PIN digitado em teclado de ATM com análise de sinais de movimento capturados por wearable devices, como smartwatches e outros, atingindo 80 a $90 \%$ de acertos.

Já a literatura que analisa ataques de tipo EMSEC (segurança de emissões) ou mesmo baseadas em análise de movimento ou força no pressionamento tendo como alvo terminais de tipo PIN pad não foi encontrada. É possível que tal fato se deva à política que envolve o universo da segurança do sistema financeiro. Informações importantes a respeito de ensaios realizados em dispositivos normalmente não são publicadas tendo o sigilo como justificativa.

Além das referências correlatas acima citadas, bibliografia específica é referenciada no capítulo em que é utilizada, de modo a preservar o sentido da menção no contexto correto.

\section{Abordagem adotada}

Vários aspectos se articulam na abordagem ora adotada, relativos à cultura técnica dos profissionais? tanto os que concebem o projeto do dispositivo quanto os que realizam

\footnotetext{
${ }^{7} \mathrm{O}$ termo "cultura" é aqui utilizado genericamente como sendo os hábitos mentais adquiridos pelas pessoas de uma determinada sociedade, comunidade, profissão etc.
} 
ensaios de segurança, bem como dos hábitos dos usuários que interagem com o dispositivo. A segurança é uma área multifacetada, não se limitando a este ou àquele aspecto isoladamente.

Talvez a tendência mais comum na avaliação de segurança seja a de se ater ao horizonte histórico de ataques, sem a antecipação de ataques potencialmente danosos e ainda desconhecidos dos registros policiais. Nesta concepção, restaria ao pesquisador apenas o estudo dessas ocorrências, de modo a eliminar as brechas a futuros ataques de mesmo tipo. No entanto, ainda que absolutamente necessário o conhecimento histórico dos ataques, é tarefa importante e possível antecipar tendências de novas gerações de ataques, dado o desenvolvimento corrente da tecnologia. Ainda que essa atividade prognóstica caiba perfeitamente à academia, a reação comum por parte de fabricantes e fornecedores, quando confrontados com ataques realizados na academia é a de considerá-los tautologicamente como "acadêmicos", no sentido que o adjetivo possui de "puramente teórico" e "laboratorial", ou seja, sem a possibilidade real de ser efetivado na prática diária do mundo do crime. Deste modo, acredito que os ataques aqui promovidos, com o uso de técnicas acessíveis e de baixo custo, podem servir como contra exemplo.

Um outro questionamento que se segue é sobre a existência de diferença entre pesquisa na área de segurança e "hacking”. O termo hacking é vulgarmente entendido e muitas vezes divulgado pelos meios de comunicação como portador de conteúdos filosóficos ("acesso livre à informação"), políticos (hack-activism), criminosos etc., fugindo do âmbito meramente tecnológico. Em um texto clássico, Bruce Schneier ${ }^{8}$ argumenta que hacking é trapaça e é como nos tornamos melhores em segurança somente após alguém inventar um novo ataque é que podemos elaborar uma defesa contra ele.9. Ainda segundo Schneier, hacking é um modo particular de observar o mundo, "pensando fora da caixa" 10 , i.e., imaginando situações em que os sistemas possam se comportar de forma não prevista e aperfeiçoando ferramental, teórico ou

\footnotetext{
${ }^{8}$ https://www.schneier.com/blog/archives/2006/09/what_is_a_hacke.html. Acesso em 28 Jul. 2015.

${ }^{9}$ Hacking is cheating, and it's how we get better at security. It's only after someone invents a new attack that the rest of us can figure out how to defend against it. NB: Na falta de termo melhor, uso aqui "trapaça” mas sem a acepção de causar prejuízo, presente no termo em língua portuguesa.

${ }^{10} \mathrm{O}$ clichê "thinking outside the box" é entendido como um convite a pensar fora de cânones, cultura ou padrões mentais em geral. Já outros autores simplesmente afirmam: "Esqueça a caixa. Apenas pense.", considerando "dentro da caixa/fora da caixa” também um modelo a ser ignorado.
} 
não, com vistas a este fim. Ao final, o autor conclui que tal postura é a única esperança para a segurança no universo tecnológico em que vivemos. Ross Anderson [18] utiliza o termo hacking também de forma neutra relativa a valores, apenas como um dado da realidade, muito próximo ao sentido de Schneier. Considero as acepções de ambos autores como válidas para a abordagem aqui proposta, ou seja, uma vez que os sistemas adquirem múltiplas faces, o profissional de segurança é obrigado a olhá-los a partir de perspectivas distintas. A diferenciação entre black hat hacking e white hat hacking é uma diferenciação entre fins (escolha entre agir do lado do crime ou do lado da sociedade) e não entre meios, pois estes últimos podem ser basicamente os mesmos, isto é, o conhecimento da tecnologia e suas possibilidades.

Em minha dissertação de mestrado [2], a hipótese de vazamento de informação da tecla pressionada surgiu sem um modelo físico explicativo. Ferramentas de aprendizado de máquina indicaram a existência de informação vazada pelos pressionamentos das teclas sem que soubéssemos ao certo qual fenômeno físico causava o vazamento. Aqui, em lugar de utilizar aprendizado de máquina diretamente sobre os dados adquiridos ou sobre transformações ad hoc destes, utilizamos aprendizado de máquina sobre dados transformados a partir de um modelo explicativo a priori .

Assim, de forma geral, a abordagem utilizada nos ataques aqui propostos segue uma sequência básica: vislumbre do fenômeno físico envolvido $\rightarrow$ modelagem do fenômeno físico $\rightarrow$ extração das características principais dos sinais adquiridos $\rightarrow$ classificação. Tal caminho torna possível a comprovação da origem do problema, pois é baseada em um modelo físico a priori .

\section{Organização da tese}

O Capítulo 1, 'Ataques invasivos e de canal secundário' discute o tratamento do PIN no padrão EMV e apresenta exemplos recentes de ataques a PIN pads e leitores de cartão de caixas eletrônicos (ATM), mostrando vulnerabilidades e sua exploração. Aborda diferenças entre tipos básicos de ataques: invasivos, não-invasivos e de canal secun-

\footnotetext{
${ }^{11}$ Black hat como sendo hackers do lado do crime (ou crackers) e white hat os hackers da área da segurança, também conhecidos como "hackers éticos". Talvez por ironia, a maior conferência de segurança de sistemas hoje em dia tem o nome "Black Hat".
} 
dário. O Capítulo 2, 'Ataque TDOA' desenvolve um ataque que utiliza diferenças de tempo de chegada entre sinais de vibração propagados no corpo do PIN pad, modelo análogo ao utilizado por geofísicos na estimativa do epicentro de um sismo. Já o Capítulo 3. 'Ataque DAA ${ }^{12}$ desenvolve um ataque utilizando dois microfones no interior do PIN pad, em que a propagação do som do pressionamento de cada tecla é modelada como um filtro dos sinais dos microfones. No Capítulo 4 'Ataque utilizando células de carga ' desenvolvo um ataque em que a descoberta da tecla que originou o pressionamento é realizada pela medida de forças exercidas em uma base em que o terminal é assentado. O Capítulo 5, 'Normas e Processos de Certificação]' analisa as normas criadas por consórcios de empresas que são utilizadas por laboratórios de certificação de segurança de PIN pads, no qual apenas os tópicos de segurança física aplicáveis aos ataques aqui desenvolvidos são analisados. Neste mesmo capítulo é apresentado o tópico de "divulgação responsável de vulnerabilidades" no qual descrevo como esse processo foi realizado para um dos ataques aqui apresentados. Na sequência, configuram o trabalho as Conclusões, os Apêndices, que detalham aspectos das técnicas empregadas, um Glossário - com termos originários da língua inglesa ou termos específicos e jargões de segurança - e, ao final, um Índice Remissivo.

\section{Publicações}

Minha dissertação de mestrado, "Identificação das teclas digitadas a partir da vibração mecânica" [2] e o doutorado constituem tema correlato de pesquisa.

As publicações associadas à minha pesquisa de mestrado são:

- “Identificação das teclas digitadas a partir da vibração mecânica," publicado nos Anais do XXX Simpósio Brasileiro de Telecomunicações [1];

- Identification of Pressed Keys From Mechanical Vibrations, publicado no periódico IEEE T. Information Forensics and Security [3] que trata de um ataque de canal secundário à PIN pad mediante análise de vibrações mecânicas;

\footnotetext{
${ }^{12}$ A sigla DAA e o nome do novo ataque Differential Audio Analysis foram sugeridos por Ross J. Anderson, Professor de Engenharia de Segurança do Laboratório de Computação da Universidade de Cambridge.
} 
O conteúdo desta tese deu origem às seguintes publicações ${ }^{13}$.

- Identification of pressed keys by time difference of arrivals of mechanical vibrations, publicado no periódico Computers \& Security [4], trata do conteúdo do Capítulo2,

- Identification of Pressed Keys by Acoustic Transfer Function, publicado nos anais da IEEE International Conference on Systems, Man, and Cybernetics SMC2015 [5], trata do conteúdo do Capítulo 3, reduzido para formato de conferência;

- Differential Audio Analysis: A New Side-Channel Attack on PIN-pads, submetido (e em processo de revisão) ao periódico Computers \& Security, trata do conteúdo do Capítulo 3 em formato extendido para revista.

\footnotetext{
${ }^{13}$ Anexadas ao final desta.
} 


\section{Capítulo 1}

\section{Ataques invasivos e de canal secundário}

Este capítulo apresenta uma síntese de dispositivos e técnicas recentes de roubo de dados encontrados em estabelecimentos comerciais. Algumas delas são consideradas invasivas, ou seja, há modificação do dispositivo alvo - como soldagens, anulação dos mecanismos de detecção de violação tamper detection etc. Outras são não-invasivas, como a inserção de elementos de interceptação entre cartão e leitora e ataques de canal secundário.

\subsection{Tráfego do PIN no padrão EMV}

EMV (Europay, MasterCard e Visa é um padrão global para cartões de débito e crédito equipados com microprocessadores (smartcards), bem como a tecnologia utilizada para autenticar transações com esse tipo de cartão, também conhecida como "chip and PIN". O dado confidencial que normalmente é inserido pelo usuário em um PIN pad é seu PIN, que deve ser autenticado pelo terminal para efetuar a transação financeira. Mas apenas com a posse do PIN um adversário não realiza muita coisa, sendo necessária informação adicional do cartão, que não vaza pelos canais secundários aqui desenvolvidos. É necessário que se possua também dados do cartão, que permitam a realização da clonagem do mesmo. Tais informações podem ser adquiridas de várias formas. Uma delas utiliza a leitora de tarja da porta de entrada do estabelecimento 
ou vestíbulo, em que se encontram os caixas eletrônicos de autoatendimento (ATM) Para cartões magnéticos, a operação de clonagem é trivial, não a sendo para os cartões com chip, que realizam operações criptográficas e transações dinâmicas de autenticação. Para operações com cartão no padrão EMV há três tipos básicos de autenticação de PIN e do cartão: SDA, DDA e CDA2 Das três, apenas o SDA trafega o PIN sem criptografia entre leitora e cartão [18, Sec. 10.6.1.1]. Tal fato limita as possibilidades de roubo do PIN, que deve ser realizado de outra forma. Deste modo, ataques de canal secundário para roubo de PIN tornam-se potencialmente danosos, cobrindo a maioria dos cenários.

Os cartões com chip que seguem o padrão EMV possuem um modo de operação denominado fallback, que permite o uso da tarja magnética agregada ao cartão, ignorando-se o processamento dinâmico do chip. Esse modo de operação é permitido de forma a manter interoperabilidade com sistemas de tarja. Um cenário possível é o de um cliente possuidor de cartão emitido por um banco brasileiro (obrigatoriamente EMV) realizando compras em um país em que opera predominantemente com tarja e assinatura, como os EUA ${ }^{3}$ Como dados do cartão estão presentes de forma não criptografada também na memória do chip, estes podem ser lidos para fins de criação de um cartão clonado de tarja magnética. Em suma, diferentes implementações do protocolo EMV permitem níveis distintos de segurança, fatores estes que não abordaremos aqui. O aspecto importante é que o fato do PIN ser utilizado em uma transação EMV imputa ao dono do cartão a responsabilidade pela operação, dificultando uma disputa legal em caso de fraude.

\subsection{Ataques invasivos}

Ataques invasivos requerem alteração física do dispositivo de modo a obter informação, como por exemplo decapagem do chip para permitir acesso a seus componentes internos, desativação dos mecanismos de segurança (tamper detection) de um PIN pad

\footnotetext{
${ }^{1}$ Door Skimmer + Hidden Camera $=$ Profit https://krebsonsecurity.com/2015/03/door-skimmerhidden-camera-profit/. Acesso em 7 Jul. 2016

${ }^{2}$ Static Data Authentication, Dynamic Data Authentication e Combined Data Authentication.

${ }^{3}$ O número de transações EMV com cartão (card present) nos EUA em 2015 foi de apenas $2 \%$ do total https://www.emvco.com/about_emvco.aspx?id=202. Acesso em 22 Ago. 2016
} 
e conexão de fios no barramento de dados para monitorar transferências dos mesmos.

Um ataque recente contra ATMs para roubo de dados de cartão (e em alguns casos também o PIN), foi descoberto no México em 2015, em que os criminosos inseriam dispositivos chamados de shimmers $\bigsqcup^{4}$ no próprio slot do cartão de máquinas de ATM (Figuras 1.1a e 1.1b ${ }^{5}$ onde o canal de comunicação é interceptado diretamente. Neste caso de ataque, o PIN nem sempre trafega no modo "texto claro", ou seja, sem estar criptografado, pois como mencionado acima, dependendo do tipo de cartão e implementação do protocolo EMV, pode haver criptografia na comunicação entre o cartão e a leitora. O PIN teria que ser obtido por outros meios, como câmeras ocultas, por exemplo, ou algum tipo de ataque via canal secundário.

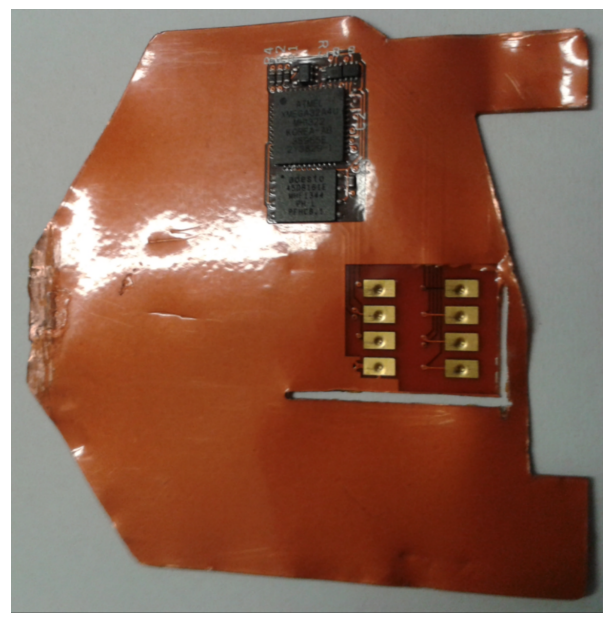

(a)

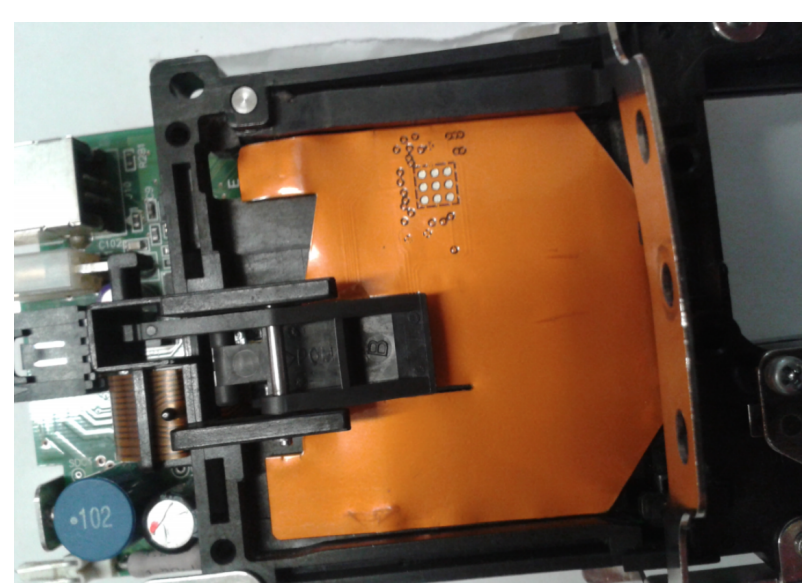

(b)

Figura 1.1: (a) Membrana flexível (shimmer) com os contatos elétricos e circuitos integrados de captura e armazenagem do tráfego entre o terminal e o cartão. (b) Shimmer já inserido na leitora de cartão de um terminal ATM.

Em 2014, a grande imprensa brasileira divulgou que estaria havendo clonagem de chips de smartcards no Brasil ${ }^{6}$ A hipótese foi deixada de lado devido a uma análise posterior: o que poderia ter ocorrido na verdade fora um ataque do tipo "replay", em que uma transação eletrônica verdadeira era copiada por meio de um PIN pad adul-

\footnotetext{
${ }^{4}$ O termo shimmer significa "calço", ou seja, um objeto normalmente delgado que é inserido em uma ranhura e empresta semelhança com skimmer, que é como esses aparatos de roubo de informação são conhecidos.

${ }^{5}$ Chip Card ATM “Shimmer” Found in Mexico: http://krebsonsecurity.com/2015/08/chip-card-atmshimmer-found-in-mexico/, Acesso em 27 Jan. 2016.

"Q"Quadrilha usa bluetooth para clonar cartões de chip e movimenta milhões": http: //g1.globo.com/fantastico/noticia/2014/11/quadrilha-usa-bluetooth-para-clonar-cartoes-de-chip-emovimenta-milhoes.html. Acesso em 18 Mai. 2015
} 
terado, armazenada e recuperada pelos criminosos via Bluetooth. Posteriormente, os dados da transação eram modificados e re-emitidos na rede de pagamentoß7. A transação financeira era então aprovada devido a implementações deficientes do protocolo EMV, que não realizavam verificações necessárias, possivelmente confiando no mantra de que "uma transação com chip não pode ser fraudada". Ficou evidente neste caso que o terminal foi completamente adulterado e o sistema de tamper detection burlado, deixando evidências físicas que serviram como prova material do crime.

A criatividade e, especialmente, a rápida adequação tecnológica utilizada no crime eletrônico, chegam a surpreender até mesmo experientes analistas de segurança. Ross Anderson[18] cita caso de 2005 em que os dados roubados de cartão de crédito utilizados em bombas de gasolina de autoatendimento são transmitidos via mensagens SMS. Telefones celulares são utilizados em roubo automatizado de informação bancária desde ao menos 2010 8 . Há registros de um ataque a PIN pad em 2013 para roubo de informações do cartão e PIN, de nível profissional, contendo sistema GSM e Bluetooth. Nesse aparato, as informações poderiam ser recuperadas pelo criminoso de duas formas: estando este a uma distância de até 100 metros, via Bluetooth, ou em qualquer parte do mundo, via SMS. Importante notar que todo o dispositivo malicioso foi introduzido no interior do terminal? mais precisamente, no compartimento dos cartões SAM. Tal compartimento é um dos principais itens de vulnerabilidade identificados nesta investigação, sendo explorado por dois de três ataques aqui desenvolvidos. A maioria dos ataques promovidos contra PIN pads com roubo de dados do cartão aproveitam-se de vulnerabilidades do mecanismo de detecção de violação, desabilitando-o ou permitindo acesso a conexões internas dos dispositivos sem ser detectado pelo mecanismo, como apresentam Drimer et al. [34]. Nesta investigação, esse tipo de análise de vulnerabilidade - tamper proofing - não é realizada pela razão de que os tipos de ataque aqui empreendidos - chamados de "canais secundários" prescindem da adulteração do dispositivo, podendo não deixar evidência de alterações.

\footnotetext{
7 “Replay” Attacks Spoof Chip Card Charges: http://krebsonsecurity.com/2014/10/replay-attacksspoof-chip-card-charges/. Acesso em 2 Nov. 2016

${ }^{8}$ Sophisticated ATM Skimmer Transmits Stolen Data Via Text Message. http://krebsonsecurity. com/2010/06/sophisticated-atm-skimmer-transmits-stolen-data-via-text-message/. Acesso em 12 Mar. 2015.

${ }^{9}$ Pro-Grade Point-of-Sale Skimmer: http://krebsonsecurity.com/2013/02/pro-grade-point-of-saleskimmer/, Acesso em 12 Mar. 2015.
} 


\subsection{Ataques de canal secundário}

Ataques de canal secundário são considerados não-invasivos pois somente exploram informação externamente disponível (emissão de algo que é frequentemente não intencional) como tempo de operação, consumo de energia, emissão acústica, vibração, emissão eletromagnética etc. Com "externamente", me refiro à parte do dispositivo em que não é possível o acesso direto aos circuitos que trafegam informação sigilosa, ou seja, partes consideradas críticas previamente protegidas.

O termo "ataque de canal secundário" ou "ataque de canal colateral" vem do inglês side-channel attack, convencionalmente utilizado na comunidade de segurança de hardware criptográfico e microeletrônica. Autor clássico na área de engenharia de segurança, como o já citado Ross Anderson [18, Sec. 17.6] utiliza o termo com maior abrangência, adequada ao uso aqui empregado, que não se relaciona nem à criptografia e, tampouco, à microeletrônica, mas sim ao meio físico pelo qual um dispositivo ou a interação humana com este gere sinais que, uma vez decodificados, forneçam informação imprevista no modelo a respeito desta interação.

A pesquisa que popularizou o termo side-channel attack foi relativa a "vazamentos" de informações de operações criptográficas realizadas por microprocessadores, aplicadas igualmente a cartões de crédito e débito, desenvolvida por Paul Kocher et al. [43] ${ }^{10}$. Uma breve descrição deste tipo de ataque é importante, pois este introduz técnicas de processamento digital de sinais em ataques. Os autores descobriram que as flutuações na corrente elétrica que alimenta o cartão estavam correlacionadas com a instrução sendo executada e também com seus operandos, isto é, com o material criptográfico (dados e chaves). Tal técnica ficou conhecida como power analysis, ou análise de consumo de energia. Simplificando drasticamente a explicação da técnica: um circuito eletrônico implementando, por exemplo, a operação lógica XOR pode consumir corrente elétrica distinta quando os operandos são iguais ou não. Desta forma, por criptanálise da variação do consumo e com informação a priori do algoritmo sendo executado, descobriram quais operações e dados eram operados pelo algoritmo crip-

\footnotetext{
${ }^{10}$ É provável que a descoberta desta vulnerabilidade e o desenvolvimento do ataque explorando-a tenha tornado o termo side-channel attack quase sinônimo de "ataque a microprocessadores", como percebe-se na literatura e em conferências como a CHES - Conference on Cryptographic Hardware and Embedded Systems.
} 
tográfico, o que lhes permitiu descobrir as chaves envolvidas, configurando brecha de segurança extrema. Recentemente, descobriu-se que tal técnica tornou-se ferramenta de espionagem da própria National Security Agency (NSA), informação esta revelada pelo vazamento de documentação dos serviços de inteligência americanos e britânicos realizado por Edward Snowden 11 .

Desta maneira, dado que a interação física com dispositivos pode envolver trocas de energia de várias naturezas (elétrica, mecânica, térmica, acústica, óptica etc.), o problema da segurança do projeto e do uso dos equipamentos se torna ainda mais complexo, exigindo uma visão constantemente ampliada da natureza da questão. Como supracitado, tal problema é intensificado com a massificação de dispositivos sensores das mais variadas grandezas físicas e sistemas completos de comunicação integrados e miniaturizados.

Como consequência de estarmos lidando com dispositivos físicos, é razoável que nem todo ataque funcione em qualquer alvo. Por exemplo, um ataque bem sucedido a um PIN pad Ingenico pode não funcionar em um Verifone ou mesmo em um Ingenico de modelo distinto, não possuindo a vulnerabilidade específica daquele. No entanto, a distribuição de centenas de milhares de unidades de um mesmo modelo vulnerável é motivo o bastante de preocupação.

\footnotetext{
11 "Power analysis, a side channel attack, can be used against secure devices to non-invasively extract protected cryptographic information such as implementation details or secret keys. We have employed a number of publically known attacks against the RSA cryptography found in TPMs from five different manufacturers. We will discuss the details of these attacks and provide insight into how private TPM key information can be obtained with power analysis. In addition to conventional wired power analysis, we will present results for extracting the key by measuring electromagnetic signals emanating from the TPM while it remains on the motherboard. We will also describe and present results for an entirely new unpublished attack against a Chinese Remainder Theorem (CRT) implementation of RSA that will yield private key information in a single trace". Trecho extraído de http://cryptome.org/2015/03/nsaappledpa-intercept-15-0309.zip, arquivo tpm-vulnerabilities-to-power-analysis-and-an.pdf. Acesso em 13 Dez. 2015.
} 


\section{Capítulo 2}

\section{Ataque TDOA}

Quando pressionamos uma tecla, a energia gerada pelo pressionamento propaga-se como onda mecânica por todo o equipamento. Neste caso, o meio físico do equipamento torna-se um canal secundário, i.e., não protegido, de transmissão da informação digitada - isso, obviamente, se pudermos extrair informações úteis a partir de tais vibrações. Se conseguirmos estimar a posição das teclas por meio da medida dos atrasos em alguns pontos distintos ou, se pudermos classificar tais atrasos em classes distintas, obteremos a informação desejada, ou seja, o que foi pressionado.

A analogia deste fenômeno com um sismo é direta: terremotos originam-se no interior da Terra e sua origem pode ser inferida a partir de medidas de atraso de chegadas das oscilações, realizadas em estações fixas de sensoreamento, localizadas na superfície terrestre. O meio terrestre é geralmente complexo, heterogêneo. O corpo de um dispositivo como um PIN pad também o é, composto de agregados de materiais distintos, como plásticos, metais, borrachas etc. Em ambos os casos, há fenômenos de onda como reflexões, refrações, dentre outros. Não obstante, por meio desta analogia sismológica, tratamos da possibilidade da classificação da tecla pressionada por meio da triangulação dos atrasos na propagação das vibrações que são geradas pelo pressionamento. Neste ataque, a vibração é capturada na forma de aceleração mecânica, com o uso de acelerômetros de tecnologia Micro-Electro-Mechanical Systems (MEMS).

Em trabalho anterior, realizado durante as investigações de meu mestrado, mostramos ser possível identificar a tecla pressionada com alta taxa de acertos via vibração mecânica, para dois tipos de dispositivos distintos, um PIN pad e um teclado de caixa 
eletrônico (Faria e Kim [3]). Utilizamos acelerômetros no corpo dos dispositivos e classificamos as vibrações por meio de valores de correlações cruzadas normalizadas via NCC (Apêndice A). Os resultados obtidos foram de até $\approx 80 \%$ de acertos para o PIN pad e $\approx 98 \%$ para o teclado de ATM.

A técnica aqui utilizada é conhecida em várias áreas, pelo nome de Time Difference of Arrivals (TDOA), ou "Diferença de tempo de chegadas", divergindo quanto à origem e tipo dos sinais. Por exemplo, a estimativa precisa destes atrasos é a base do Sistema de Posicionamento Global (GPS) e outros sistemas de localização geográfica. Geofísicos e sismólogos também usam-na, a fim de localizar o epicentro de terremotos e de outros eventos sísmicos [20]. No ataque aqui desenvolvido, a posição da tecla é análoga à do epicentro de um sismo.

À semelhança de emissão acústica, cada tecla pode emitir uma vibração mecânica característica quando pressionada. No entanto, a vibração mecânica tem sido muito menos explorada na literatura. Marquardt e Verma [6] usam-na para reconhecer as teclas digitadas em um teclado de computador. Utilizam o acelerômetro de um smartphone colocado próximo ao teclado de um computador para captar as vibrações. A classificação das teclas digitadas é categorizada em "esquerda" ou "direita" e pares de teclas digitadas em "próximas" e "distantes". Tais atributos são as entradas para consulta em um dicionário pré-existente. Na abordagem dos autores, sem uso de TDOA pois apenas um acelerômetro é utilizado, alcançaram taxas de classificação de até $80 \%$, tomando essas decisões binárias.

O fenômeno explorado no ataque aqui desenvolvido é de natureza diferente da explorada por Marquardt e Verma [6] e por Faria e Kim [3], não dependendo da diferenciação das vibrações entre teclas, ou seja, mesmo que todas as teclas emitam exatamente a mesma vibração mecânica, ainda seria possível identificar a tecla pressionada pelos atrasos de chegada da onda mecânica propagada.

O objetivo principal deste experimento é mostrar que tal fenômeno físico pode ser utilizado para identificar a tecla pressionada, de forma maliciosa ou não. Nesse sentido, medidas de mitigação dessas vibrações devem ser tomadas quando a confidencialidade é um fator crucial.

A literatura sobre TDOA vem de diversos campos de pesquisa. Em [23, 24], M. Ge 
discute as teorias clássicas de localização de origem de frente de onda que são usadas em emissão sísmica e emissão acústica. Ele analisa os princípios dos métodos de localização de fontes e menciona as principais causas de imprecisão, entre elas, a imprecisão nas posições dos sensores e erros na medição do instante de chegada. Métodos de geolocalização baseados na medição da diferença de tempos de chegada dos sinais recebidos de vários satélites geoestacionários são apresentados em [25, 26, 27]. Ho e Chan [25] apresentam um método que resolve um conjunto de equações nãolineares para estimar a localização da fonte. Gustafsson e Gunnarsson [26] comparam um método de Monte Carlo e um algoritmo de busca por gradiente. Schumacher et al. propõe uma abordagem paramétrica Bayesiana para o problema do local de origem da onda na pesquisa de materiais [9].

Esse ataque utiliza a classificação dos atrasos entre pares de acelerômetros, via aprendizado de máquina. Deste modo, a estimação das coordenadas geométricas da origem da vibração não é necessária, como veremos nas Seções 2.3 e 2.4, diferentemente das aplicações de posicionamento via TDOA das referências citadas. No entanto, como os atributos ${ }^{1}$ escolhidos (os atrasos em si) possuem significado físico relacionado às posições das teclas (afinal esse é o modelo físico proposto), a visualização das posições dá uma indicação qualitativa da qualidade desses mesmos atributos, como veremos adiante.

Até onde nossa pesquisa bibliográfica avançou, não encontramos a aplicação de tal técnica a ataques de segurança a teclados mecânicos.

O capítulo está organizado da seguinte forma. A teoria básica de ondas transversais é apresentada na Seção 2.1. Três experimentos utilizando três teclados mecânicos diferentes são apresentados: um teclado maquete simples na Seção 2.2, um teclado numérico normal na Seção 2.3 , e um PIN pad comercial na Seção 2.4 .

\footnotetext{
${ }^{1}$ No jargão da área de aprendizado de máquina, o termo "atributo" ou "característica" (feature em inglês) são dados de entrada de um algoritmo classificador que represente os dados originais de forma a serem classificados eficientemente. Ver definição mais detalhada no Glossário.
} 


\subsection{Vibração de uma placa}

\subsubsection{Teoria}

O comportamento de uma onda transversal em uma barra ou placa (com espessura) é consideralvelmente mais complexo do que o comportamento de uma onda transversal em um fio ou membrana bidimensional de espessura negligenciável. Placas e barras possuem espessura, conferindo propriedades como rigidez à flexão, definida como a resistência oferecida pelo material à flexão. A equação diferencial que rege a deflexão de uma corda uni-dimensional ou fio é [28]:

$$
\nabla^{2} y(x, t)=\frac{1}{c^{2}} \frac{\partial^{2} y(x, t)}{\partial t^{2}}, \quad c^{2}=\frac{T}{\rho}
$$

onde $T$ é a tensão e $\rho$ é a densidade do material. Todas as funções da forma $y(x, t)=$ $F_{1}(x-c t)+F_{2}(x+c t), \forall F_{1}, F_{2}$, são suas soluções, onde $c$ é a velocidade constante da onda (também chamada "velocidade de fase"), viajando sem deformação. Por outro lado, a equação simplificada de onda da vibração transversal de uma barra uniforme é [29. Seção 8.7]:

$$
\nabla^{4} y(x, t)=-\frac{1}{a^{2}} \frac{\partial^{2} y(x, t)}{\partial t^{2}}, \quad a^{2}=\frac{E I}{m}
$$

onde $E$ é o módulo de elasticidade do material, $I$ é o seu momento de inércia e $m$ sua massa total. Suponhamos que uma solução das equações $2.1 \mathrm{e} 2.2$ seja uma onda harmônica simples viajando com velocidade $v$ :

$$
y(x, t)=A \cos \frac{2 \pi}{\lambda}(x-v t)
$$

Substituindo a Equação 2.3 na Equação 2.1, obteremos $v=c$. Já para a Equação 2.2, obteremos uma velocidade que depende do comprimento de onda, $v=a \frac{2 \pi}{\lambda}$. Na Equação 2.2, o termo $a$ não possui dimensões de velocidade, por isso não representa uma velocidade, ao passo que $c$ na Equação 2.1 é de fato uma velocidade.

Em resumo, a velocidade de uma onda é constante em um fio "ideal” (de espessura negligenciável) e também em uma membrana. Por outro lado, em uma barra, ela de- 
pende do comprimento de onda e consequentemente da frequência. Isto se dá porque a barra é um meio dispersivo. Uma onda senoidal pode viajar em um meio dispersivo sem sofrer alteração em sua forma, mas um pacote de ondas será deformado pois os seus componentes possuem, por definição, comprimentos de onda distintos. Neste caso, cada componente irá viajar a uma velocidade distinta, causando assim alteração em sua forma [28, Cap. 12], [29, Seção 8.7]. O mesmo fenômeno ocorre em placas, como a placa acrílica na qual fizemos os dois experimentos iniciais (Seções 2.1.2 e 2.2) e, obviamente, nos dispositivos testados (Seções 2.3 e 2.4).

Fenômenos de dispersão e reflexão tornam difícil medir com precisão os atrasos na chegada de vibrações mecânicas, porque as diferentes formas de pressionar teclas geram vibrações com espectros de frequência distintos, causando diferentes atrasos entre frentes de onda e ocorrências de reflexões. Medimos os atrasos de frentes de onda considerando-os como pacotes viajando com uma velocidade de grupo. A velocidade de grupo de uma onda é a velocidade com que a forma global da amplitude da onda se propaga.

\subsubsection{Dispersão em uma placa acrílica}

De modo a observar na prática o efeito de dispersão e velocidade de grupo apresentados na Seção 2.1.1, realizamos um experimento simples em uma placa acrílica utilizando duas fontes distintas de excitação: (i) tocando a placa com o dedo e (ii) tocando a placa com a ponta metálica de uma lapiseira. A Figura 2.1 mostra a montagem do experimento. As dimensões da placa de acrílico são aproximadamente $3 \times 640 \times 670 \mathrm{~mm}$. Os acelerômetos foram montados sobre pequenos postes metálicos e colados na superfície da placa acrílica, nas posições indicadas por $A_{1}$ e $A_{2}$.

Em todos os experimentos, utilizamos acelerômetros Freescale MMA7361, analógicos e triaxiais [31] operando na faixa de aceleração de $\pm 1,5 \mathrm{~g}$ e um osciloscópio digital Tektronix TDS-2004B para aquisição de dados. Cada vetor de sinal adquirido compreende 2500 pontos, o máximo permitido pelo osciloscópio. A taxa de amostragem varia de experimento para experimento. Neste caso, a taxa de amostragem é $100 \mathrm{kS} / \mathrm{s}$ para o experimento de tocar a placa com o dedo e $500 \mathrm{kS} / \mathrm{s}$ para tocá-lo com a lapiseira. Tal diferença de taxas foi necessária, como veremos a seguir, devido ao fato 


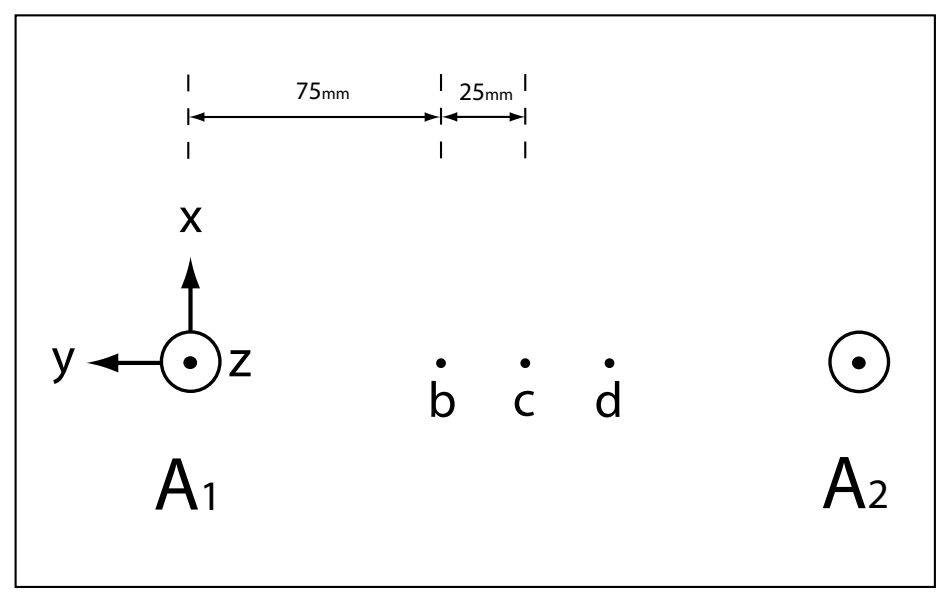

Figura 2.1: Montagem do experimento para observar o fenômeno de dispersão em uma placa acrílica.

de que a velocidade de propagação do sinal de um experimento ser maior do que de outro.

Ondas longitudinais nas direções $\vec{x}$ e $\vec{y}$ são muito mais rápidas do que as ondas transversais porque viajam dentro do material e não na sua superfície. Assim, ignoramos os sinais longitudinais, processando apenas sinais transversais da superfície, ou seja, na direção $\vec{z}$.

A Figura 2.2 (esquerda) apresenta os sinais de aceleração transversais $\vec{z}$ adquiridos pelos acelerômetros, ao tocar a placa com o dedo nos pontos "b", "c" e "d". A Figura 2.2 (direita) apresenta os gráficos da correlação cruzada normalizada (NCC) dos sinais, técnica utilizada nas estimativas de atraso entre os mesmos, apresentado no Apêndice A.

Evidentemente, uma frente de onda em um meio homogêneo e isotrópico chega primeiro ao acelerômetro mais próximo. Assim sendo, a frente de onda chega inicialmente em $A_{1}$ ao tocar o ponto "b", em $A_{2}$ ao tocar o ponto "d" e atinge quase simultaneamente os dois acelerômetros quando pressionando o ponto médio "c".

Utilizando apenas as posições dos picos da NCC calculamos a velocidade de grupo, que foi estimada $\mathrm{em} \approx 45 \mathrm{~m} / \mathrm{s}$. A Figura 2.3 apresenta os sinais obtidos e a NCC quando a placa é tocada com a ponta de uma lapiseira. A velocidade de grupo para este modo é mais que dobro da anterior, $\approx 95 \mathrm{~m} / \mathrm{s}$, porque a frequência principal gerada ao tocar a placa com a lapiseira é maior do que ao tocá-la com o dedo. Um cálculo aproximado mostra que a duração do primeiro semi-ciclo do sinal $A 1_{z}$ tocando com o dedo 

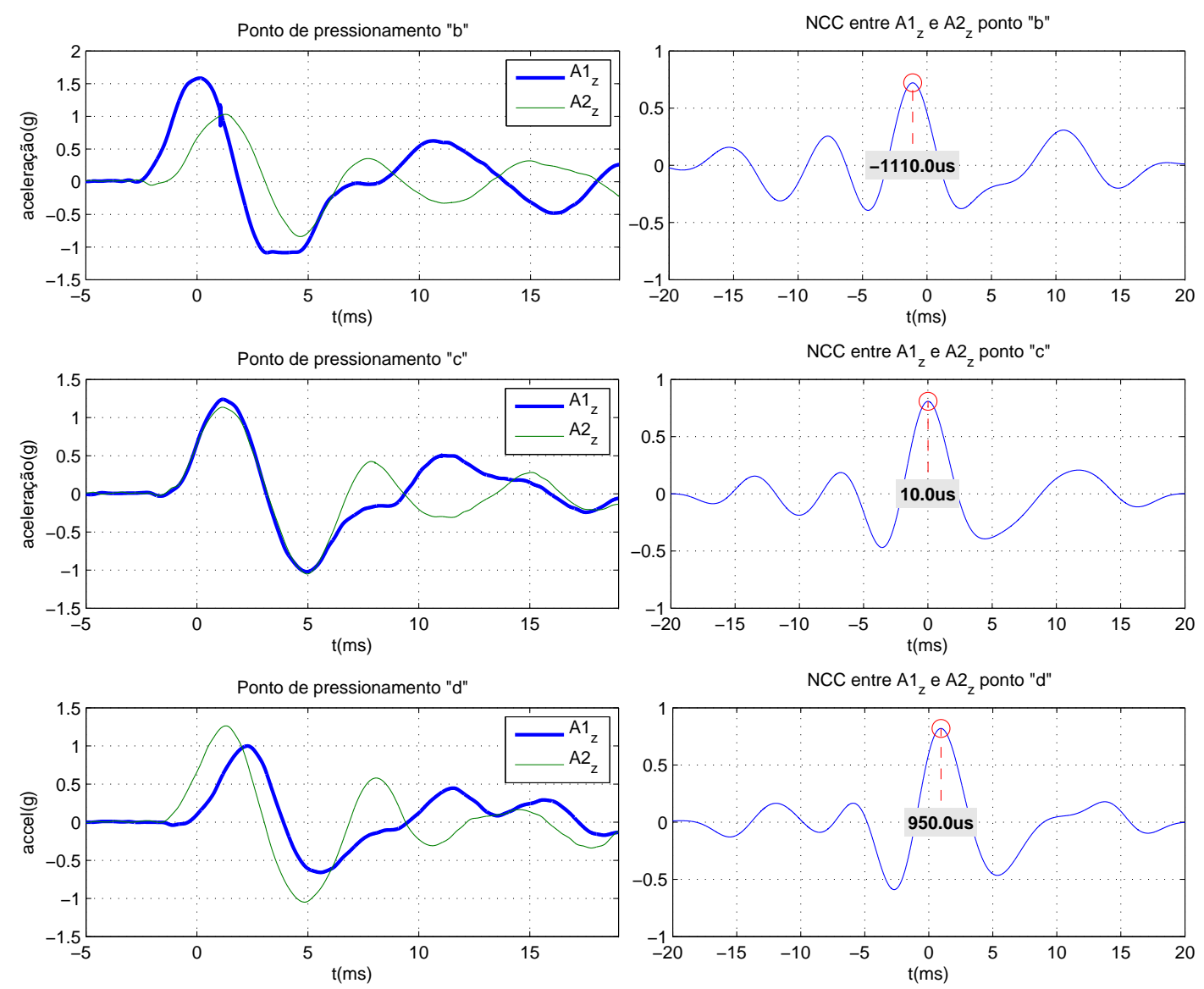

Figura 2.2: (Esq) Sinais de aceleração obtidos por toques na placa acrílica com o dedo nos pontos 'b', 'c' and 'd'. (Dir) Atraso relativo estimado utilizando-se a posição do maior pico na NCC entre $A 1_{z}$ and $A 2_{z}$.

(Fig 2.2 é de $\approx 5 \mathrm{~ms}$, correspondendo a uma frequência de $\approx 100 \mathrm{~Hz}$ (se considerado cíclico). Já a duração do primeiro semi-ciclo do sinal $A 1_{z}$ tocando com a lapiseira (Figura 2.3 ) é de $\approx 1 \mathrm{~ms}$, correspondendo a uma frequência de $\approx 500 \mathrm{~Hz}$ (se considerado cíclico).

Utilizamos a medida de correlação cruzada normalizada (NCC), detalhado no Apêndice A, para calcular o atraso relativo entre os sinais adquiridos pelos dois acelerômetros. Sua operação é a seguinte: suponha que a frente de onda gerada por um pressionamento leve $n_{1}$ intervalos de amostragem para chegar ao acelerômetro $A_{1}$ e leve $n_{2}$ intervalos de amostragem para atingir o acelerômetro $A_{2}$ (ver p.e. Figura 2.2). Neste caso, observamos um pico na NCC entre os valores obtidos por $A_{1}$ e aqueles obtidos por $A_{2}$, quando este último é deslocado para a direita $n_{1}-n_{2}$ posições. Esta diferença é o atraso estimado. 

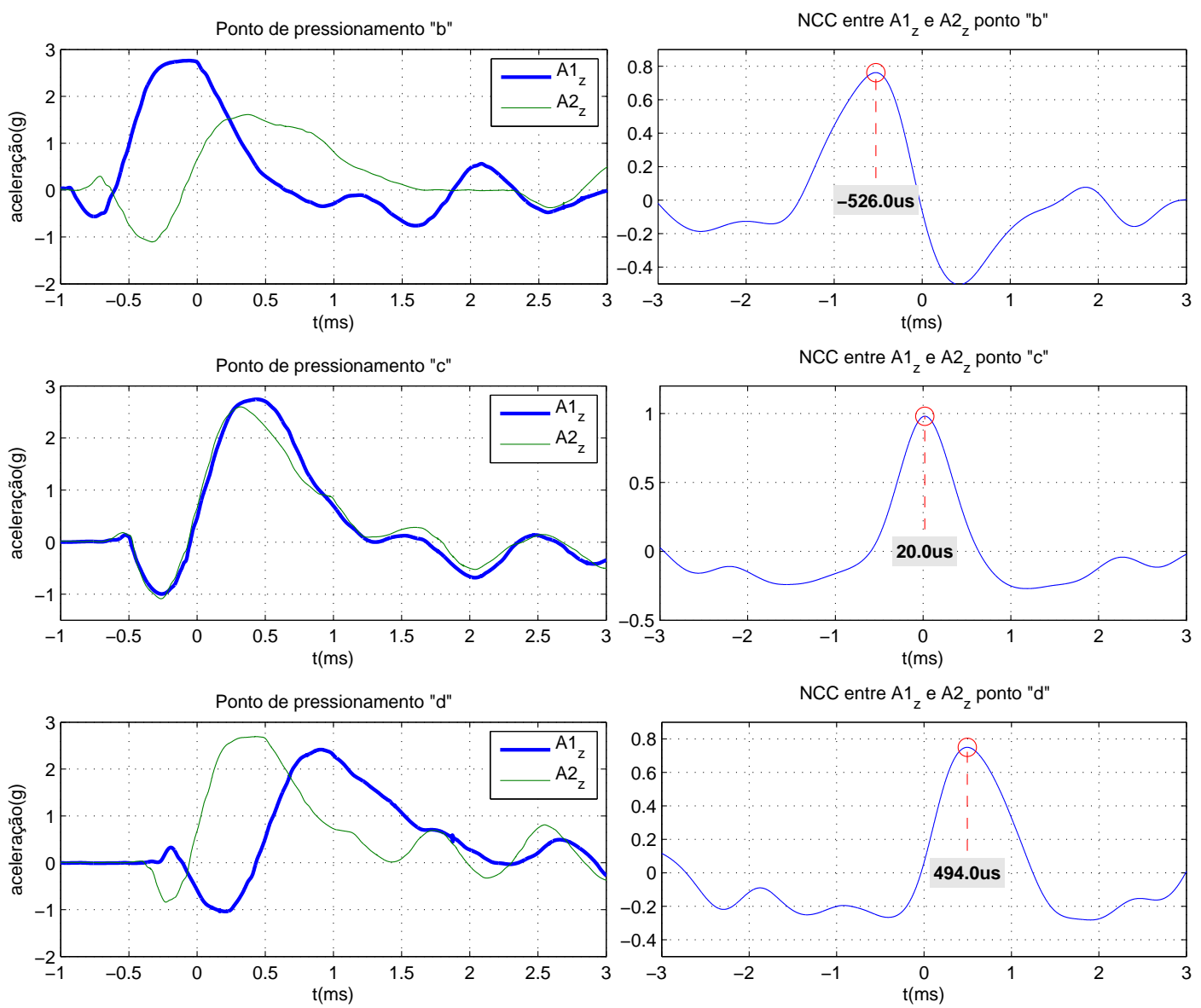

Figura 2.3: (Esq) Sinais de aceleração obtidos por toques com uma ponta metálica de uma lapiseira na placa acrílica, nos pontos 'b', 'c' and 'd'. (Dir) Atraso relativo estimado utilizando-se a posição do maior pico na NCC entre $A 1_{z}$ and $A 2_{z}$.

\subsection{Protótipo de teclado em placa acrílica}

Construímos um protótipo de teclado utilizando uma placa acrílica para verificar se os atrasos de vibração podem ser utilizados para identificar a tecla pressionada. Fixamos uma impressão em papel de um teclado na placa (Figura 2.4a), afixamos três acelerômetros e tocamos dentro de cada região emulando as teclas. O sucesso neste experimento seria uma boa indicação da validade do método, indicando a plausibilidade de se aplicar a técnica como um ataque em dispositivos reais. Pressionando 10 vezes cada uma das teclas "virtuais" de "0" a "9", geramos 100 aquisições do eixo $\vec{z}$ dos 3 acelerômetros. Os dados foram gerados por pressionamento de uma mesma pessoa.

A Figura 2.5 (cima) mostra um pressionamento típico capturado pelos três acelerômetros da montagem da Figura 2.4a Estes sinais são não-triviais devido à dispersão, 


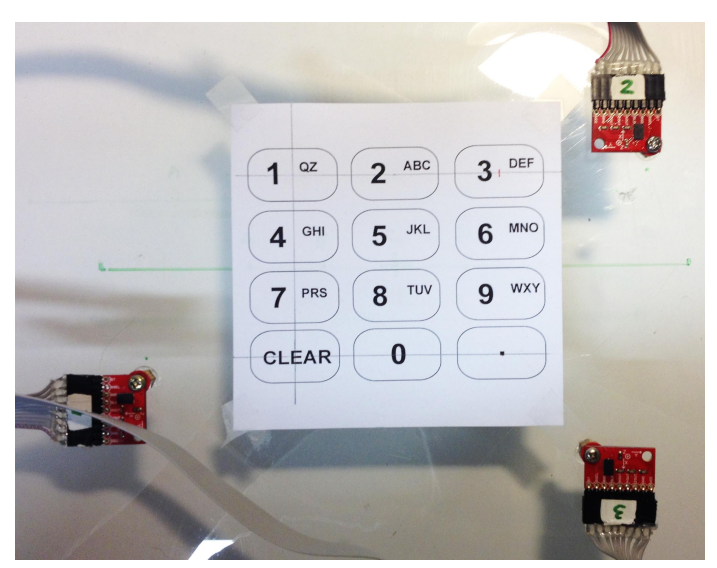

(a)

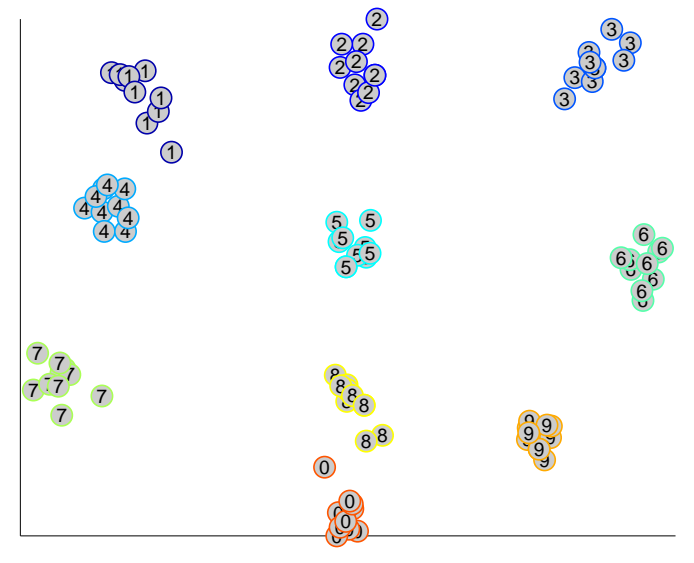

(b)

Figura 2.4: (a) Protótipo de teclado em placa acrílica. O toque dentro das áreas demarcadas é feito para simular os pressionamentos. (b) Estimação das posições das teclas no experimento do teclado acrílico.
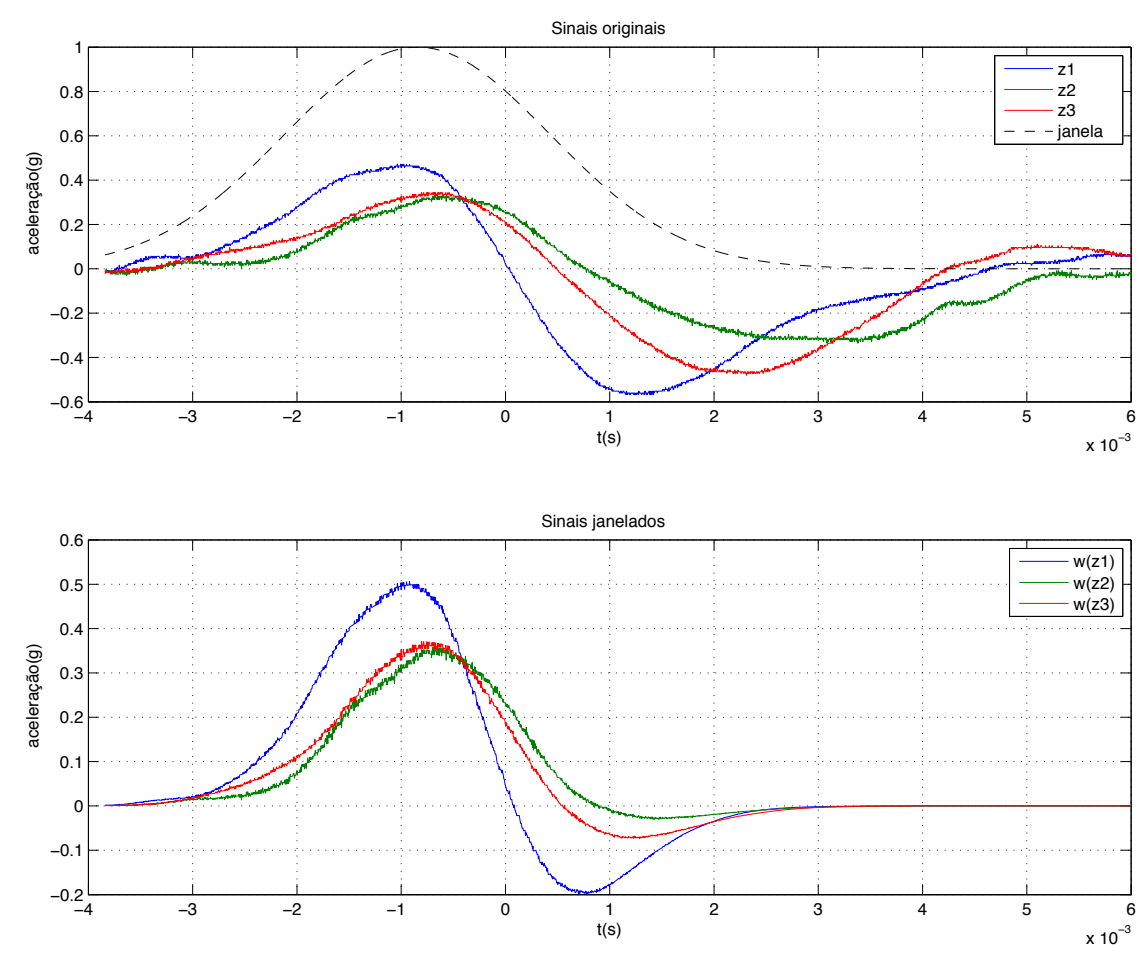

Figura 2.5: Uma janela Gaussiana é aplicada de modo a atenuar efeitos de reflexão, melhorando a estimação do atraso. (Cima) sinal original de aceleração do experimento com PIN pad, pressionando a tecla " 8 ". (Baixo) sinais janelados.

reflexões e outros fenômenos. Portanto, se nós simplesmente calcularmos a NCC entre um par desses sinais, o maior pico pode não corresponder ao atraso relativo. É possível remover os artefatos introduzidos pelas reflexões analisando apenas os primeiros 
pontos do sinal no tempo, antes da chegada das reflexões. Para este fim, multiplicamos os sinais por uma janela normal de média $\mu$ e desvio-padrão $\sigma$, posicionada em $\mu$. Calculamos o maior pico nos primeiros $M$ pontos em cada um dos três sinais originais e, em seguida, definimos $\mu$ como a posição média dos três picos, como mostrado na Figura 2.5. Os parâmetros $\sigma$ e $M$ dependem do experimento.

Neste experimento, a taxa de amostragem é $25 \mathrm{kS} / \mathrm{s}$ ou $50 \mathrm{kS} / \mathrm{s}$. Usamos $\sigma=\frac{200}{\sqrt{2}}$ para taxa de amostragem de $25 \mathrm{kS} / \mathrm{s}$ e $\sigma=\frac{100}{\sqrt{2}}$ para $50 \mathrm{kS} / \mathrm{s}$, e $M=1500$ para ambos.

\subsubsection{Construção dos atributos e algoritmo de classificação}

Depois de multiplicar os três sinais originais pela janela, tomamos os pares dos sinais envelopados e calculamos a NCC entre cada par. A posição do maior pico da NCC é considerada como o atraso relativo entre os sinais do par. Como temos três sinais originais, temos três atrasos relativos.

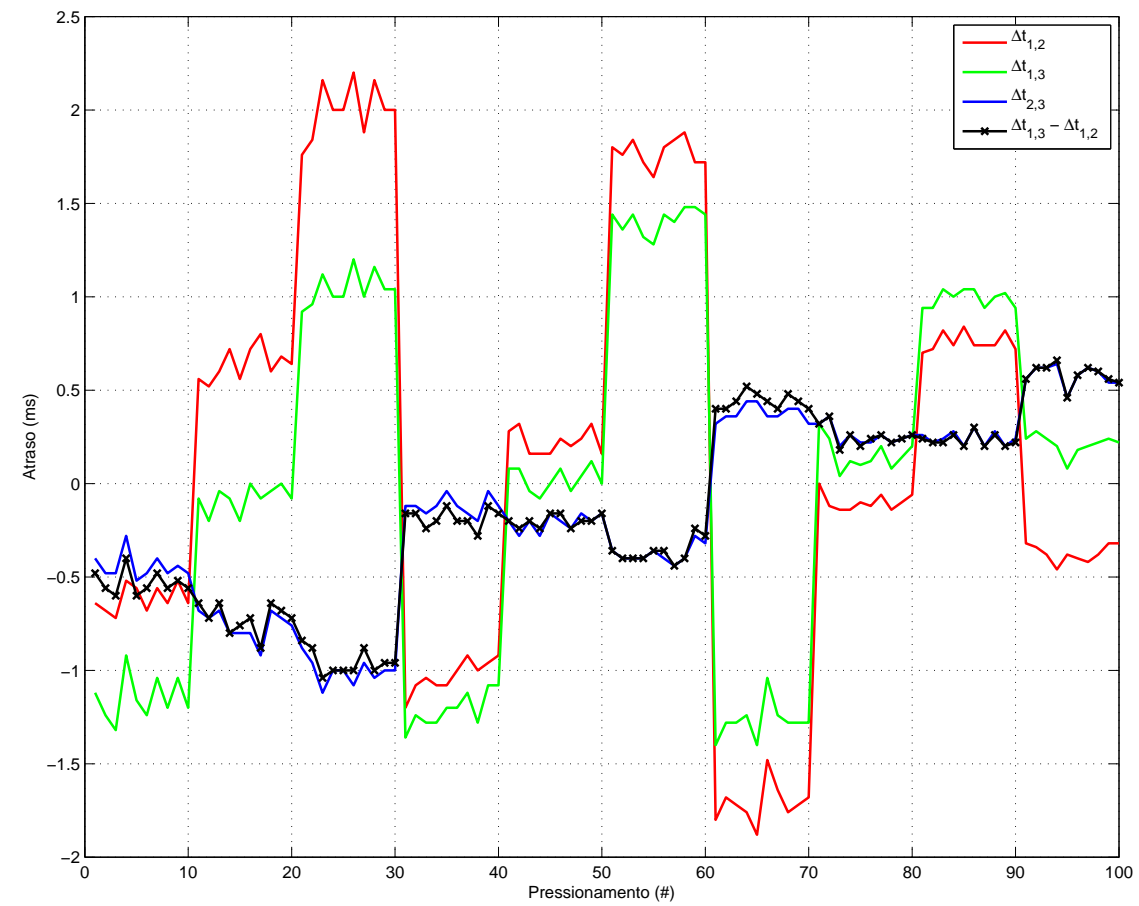

Figura 2.6: Atrasos obtidos do experimento de teclado em placa de acrílico.

Estes três atrasos relativos são os atributos utilizados, tanto para identificar a tecla pressionada como para estimar a posição espacial da mesma por triangulação 2-D. No entanto, observamos que apenas duas diferenças de tempo, ou atrasos, possuem 
informação útil, sendo que a terceira é combinação linear das demais. Na Figura 2.6. que mostra os atrasos calculados para o experimento do protótipo de teclado em placa acrílica, sobrepusemos $\Delta t_{2,3}$ (em azul) à $\Delta t_{1,3}-\Delta t_{1,2}$ (em preto) e vemos que são praticamente idênticos, a menos de algum ruído. Este tópico é explicado na Seção 2.6 . A Figura 2.7 apresenta os atributos calculados via análise de componentes principais (Principal Component Analysis - PCA), na qual se observa, ainda que visualmente, que apenas duas componentes trazem a maior parte da informação - a terceira corresponde a apenas $0.03 \%$ da variância total dos dados ${ }^{2}$, ou seja, basicamente ruído. Os degraus observados na $1^{\text {a }}$ componente da Figura 2.7, "c1", correspondem principalmente às variações das colunas (a sequência de pressionamentos é ascendente de "1" a "9" e depois “ 0 ”). A 2 a componente, “c2” fornece o restante da informação para codificar as linhas.

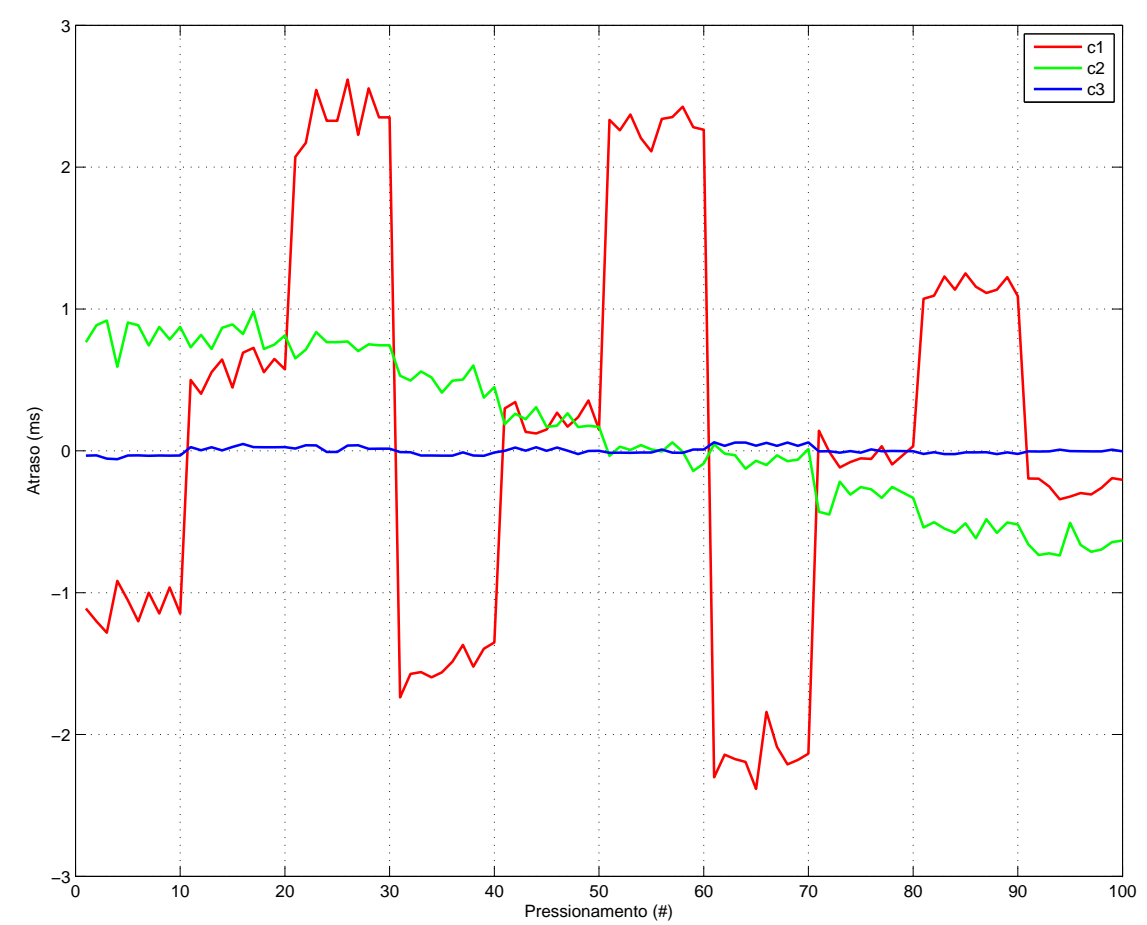

Figura 2.7: Cálculo das componentes principais dos 3 atrasos obtidos do experimento de teclado em placa acrílica mostram que apenas duas componentes são responsáveis por toda informação.

Em todos os experimentos deste capítulo, utilizamos o mesmo procedimento de

\footnotetext{
${ }^{2}$ Para o significado de variância no contexto da redução de dimensionalidade via PCA, veja Apêndice $\mathrm{B}$.
} 
extração de atributos descrito acima, bem como adotamos o classificador Naive Bayes $3^{3}$ com distribuição normal. O intuito de utilizar um classificador simples é o de investigar se os atributos escolhidos tem bom poder de discriminação, de modo a não depender excessivamente da capacidade do classificador.

Para cada teste, tomamos aleatoriamente $80 \%$ dos dados como conjunto de treino e $20 \%$ como conjunto de teste, realizando assim a classificação. Repetimos este procedimento de reamostragem 100 vezes, cada vez obtendo conjuntos distintos de treino e teste.

Neste experimento, obtivemos $100 \%$ de classificação correta. Realizando uma triangulação 2-D sobre os valores de atraso (o método é descrito na Seção 2.6 localizamos espacialmente as teclas, representadas na Figura 2.4b. Os locais estimados das teclas se assemelham bem à suas posições reais, apresentando conjuntos de teclas claramente separados.

\subsection{Experimento com teclado numérico}

Após os resultados satisfatórios do experimento no teclado de placa acrílica, decidimos atacar um teclado real utilizando o mesmo método. A Figura $2.8 \mathrm{a}$ mostra o teclado numérico testado, e os três acelerômetros colados sobre seu chassi interior. A escolha das posições dos acelerômetros no teclado foi feita de modo a que o triângulo formado pelos mesmos cubra maximamente a área onde as teclas são localizadas.

É inegável que tal teclado não é um dispositivo seguro, não possuindo mecanismo algum à prova de abertura. Igualmente é claro que um ataque razoável a esse tipo de teclado seria simplesmente realizado por meio de conexões com fios. Mas também é notório que esse tipo de teclado é inadequado para operações de entrada de dados confidenciais. A escolha deste teclado é etapa intermediária ao ataque de um PIN pad, por assemelhar-se mais a um PIN pad do que o teclado virtual da Seção 2.2 .

Neste experimento, teclamos 10 vezes cada uma das teclas "0" a "9". Os sinais originais foram multiplicados por uma janela Gaussiana de parâmetros $\sigma=\frac{650}{\sqrt{2}} \mathrm{e}$ $M=1000$. Usamos taxa de amostragem de $100 \mathrm{kS} / \mathrm{s}$.

\footnotetext{
${ }^{3}$ Teoria e aplicação são apresentadas no Apêndice D.
} 

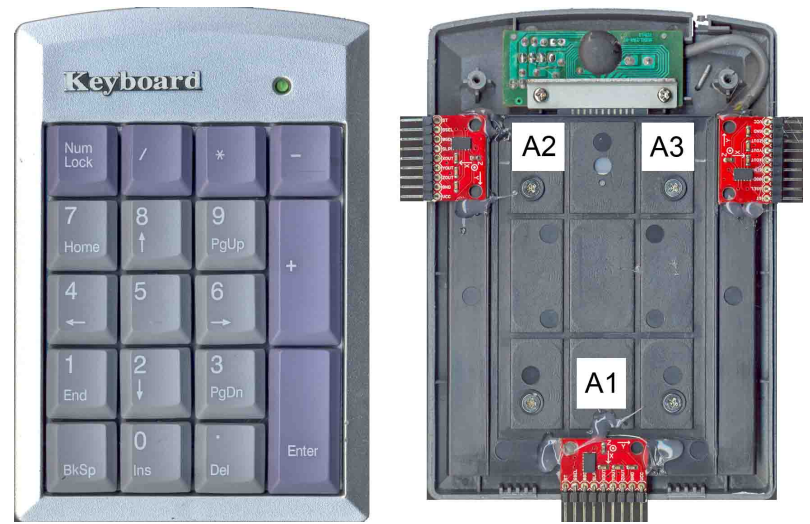

(a)

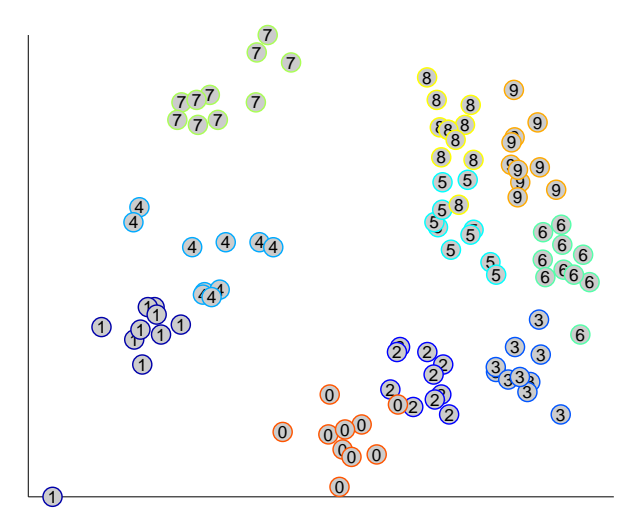

(b)

Figura 2.8: (a) Teclado numérico testado com os três acelerômetros colados. (b) Estimação das localizações das teclas do experimento de teclado numérico, utilizando a informação dos tempos de chegada das ondas de vibração.

\subsubsection{Atributos e classificação}

A Figura 2.9 mostra os atrasos calculados para o experimento. A Figura 2.10 apresenta os atributos calculados via PCA que, como no experimento anterior, observa-se que apenas duas componentes trazem a maior parte da informação - a terceira corresponde a apenas $0.19 \%$ da variância total dos dados. É difícil, neste caso, identificar a correspondência espacial dos atributos, isto é, qual componente corresponde às linhas ou colunas, como feito no experimento anterior, a partir do número de "patamares" de cada componente.

A Tabela 2.1 apresenta a matriz de confusão obtida. A medida de sucesso de classificação adotada é a proporção de entidades corretamente classificadas em uma categoria. É dada por: TPR = corretamente classificadas / (corretamente classificadas + incorretamente classificadas). A taxa de acertos geral é bastante elevada (93 $\pm 5 \%)$, onde $5 \%$ é o desvio padrão de 100 testes. Do mesmo modo, os testes deste experimento foram realizados por reamostragem dos dados de um mesmo usuário, tomando $80 \%$ para treino e $20 \%$ para teste. Nota-se que os erros ocorrem apenas entre as teclas vizinhas.

A estimativa de localização apresentada na Figura $2.8 \mathrm{~b}$ mostra uma distribuição não uniforme das teclas na direção horizontal, com maior densidade na parte direita e menor na parte esquerda. Provavelmente, isto sugere que a velocidade de grupo não é 


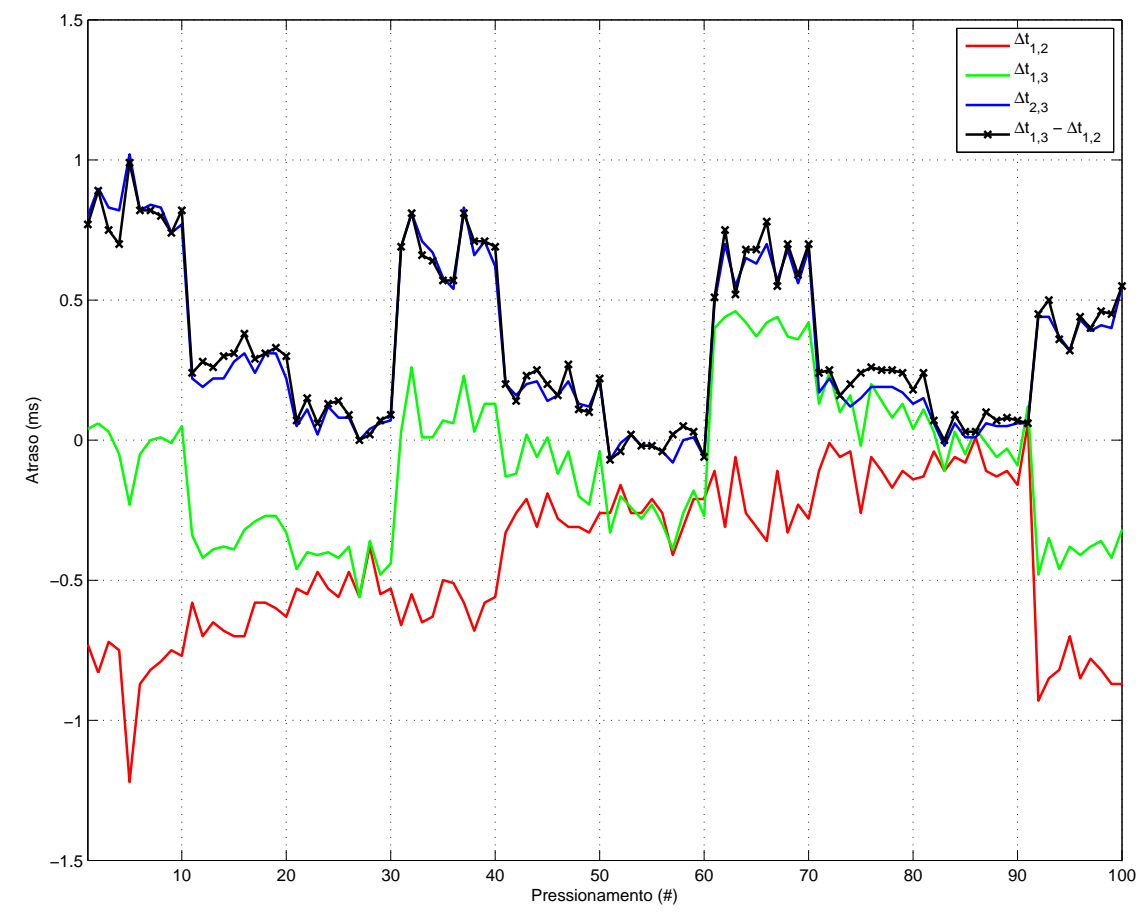

Figura 2.9: Atrasos obtidos do experimento com teclado numérico. A abscissa corresponde ao número do pressionamento, i.e., $x=1$ a 10 correspondem à tecla " 1 ", $x=11$ a 20 à tecla " 2 " e $x=91$ a 100 à tecla " 0 ".

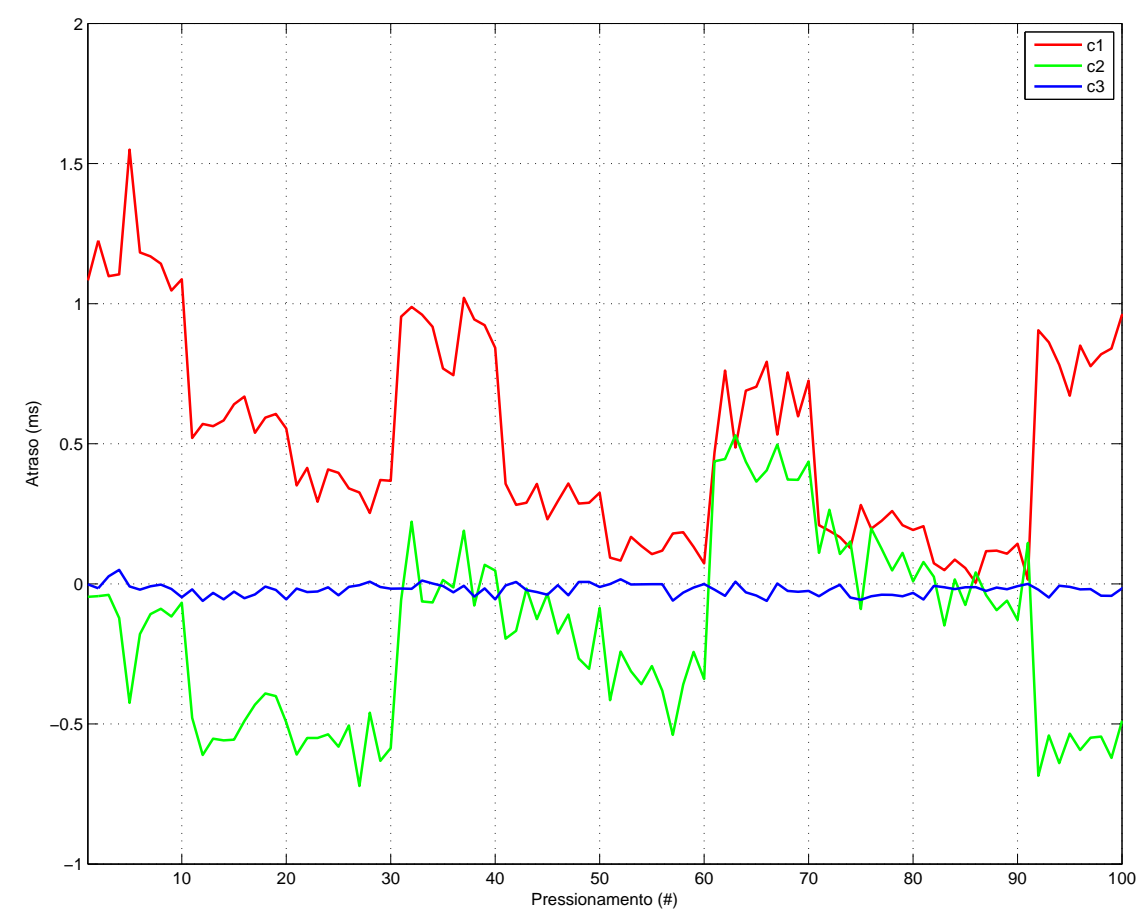

Figura 2.10: Cálculo das componentes principais dos 3 atrasos obtidos do experimento PIN pad mostram que apenas duas componentes são responsáveis por toda informação. 
Tabela 2.1: Matriz de Confusão do Experimento de Teclado Numérico

\begin{tabular}{|c|c|c|c|c|c|c|c|c|c|c|c|}
\hline $\begin{array}{c}\frac{\text { Classificado } \rightarrow}{\text { Real } \downarrow} \\
\end{array}$ & 1 & 2 & 3 & 4 & 5 & 6 & 7 & 8 & 9 & 0 & $\operatorname{TPR}(\%)$ \\
\hline 1 & 180 & & & 19 & & & & & & 1 & 90.0 \\
\hline 2 & & 189 & & & & & & & & 11 & 94.5 \\
\hline 3 & & & 195 & & & 5 & & & & & 97.5 \\
\hline 4 & 11 & & & 189 & & & & & & & 94.5 \\
\hline 5 & & & & & 186 & & & 14 & & & 93.0 \\
\hline 6 & & & 23 & & & 177 & & & & & 88.5 \\
\hline 7 & & & & & & & 200 & & & & 100.0 \\
\hline 8 & & & & & 14 & & & 169 & 17 & & 84.5 \\
\hline 9 & & & & & & & & & 200 & & 100.0 \\
\hline 0 & & 23 & & & & & & & & 177 & 88.5 \\
\hline TPR Médio & & & & & & & & & & & $93 \pm 5$ \\
\hline
\end{tabular}

constante em todas as áreas deste dispositivo, ou que outros fenômenos como reflexões ocorreram prejudicando a estimativa de atrasos calculada via NCC. Além disso, os agrupamentos de teclas apresentaram variância bem maior do que o experimento com teclado de placa acrílica.

\subsection{Experimento com PIN pad}

Após atacar um teclado numérico não seguro, aplicamos o ataque em um PIN pad, equipamento projetado para lidar com informações confidenciais de forma segura. A Figura 2.11a mostra o dispositivo, um PIN pad Ingenico iPP320 e a Figura $2.11 \mathrm{~b}$ a montagem laboratorial do experimento, onde os três acelerômetros foram colados no interior do compartimento de acesso ao cartão SAM. Tal equipamento é um modelo internacional, muito comum no mercado brasileiro e pode ser facilmente adquirido ${ }^{4}$.

O espaço limitado do compartimento SAM não nos permite colocar os acelerômetros (da forma como estão montados em suas placas de circuito impresso) onde quisermos. Como consequência, o triângulo formado pelos acelerômetros cobre apenas uma pequena parte da área onde as teclas estão localizadas. A Figura 2.11a apresenta a projeção frontal das posições aproximadas dos acelerômetros. Usamos espaçadores entre o chassi do dispositivo e as placas de circuito impresso dos acelerômetros (Figura 2.11b, de modo a delimitar a operação dos acelerômetros a uma pequena área,

\footnotetext{
${ }^{4}$ Dois modelos foram comprados ao custo individual aproximado de $\mathrm{R} \$ 550$.
} 


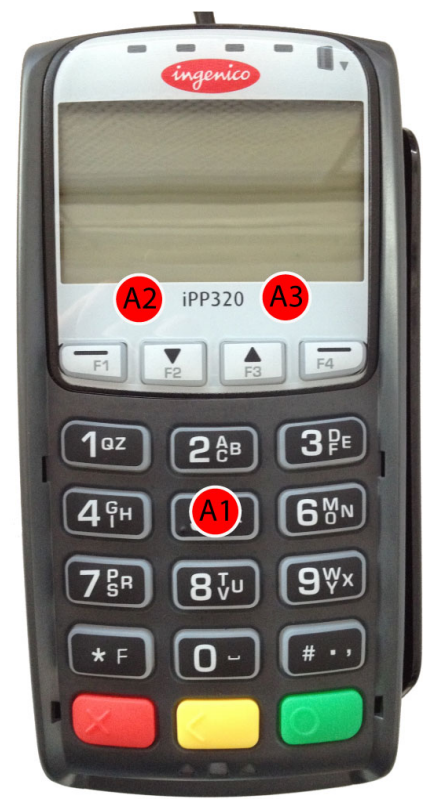

(a)

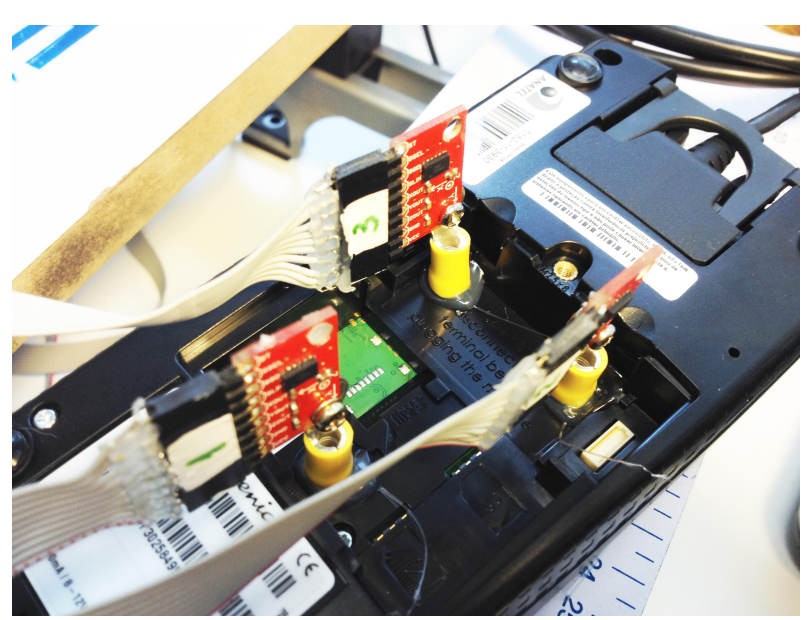

(b)

Figura 2.11: (a) PIN pad utilizado no experimento, com projeções das posições dos acelerômetros. (b) Vista inferior mostrando o compartimento SAM com os acelerômetros implantados.

na expectativa de que isso pudesse melhorar os resultados.

\subsubsection{Atributos e classificação}

Foram pressionadas cada uma das teclas na sequência de "1" a "9" e "0", por apenas uma pessoa. Como nos experimentos anteriores, os sinais foram multiplicados por uma janela Gaussiana, neste caso com $\sigma=\frac{450}{\sqrt{2}}$ e $M=1500$. Usamos taxa de amostragem de $250 \mathrm{kS} / \mathrm{s}$.

A Figura 2.12 mostra os atrasos entre os sinais dos acelerômetros. A Figura 2.13 apresenta os atributos calculados via PCA - a terceira componente, "c3" corresponde a apenas $0.09 \%$ da variância total dos dados. Como nos experimentos anteriores deste capítulo, observamos que a dimensão dos dados representados pelos atributos é 2 .

Os degraus observados na $1^{\mathrm{a}}$ componente correspondem principalmente às variações das colunas. A $2^{\text {a }}$ componente fornece o restante da informação para codificar as linhas, com patamares um pouco mais discerníveis do que no experimento de teclado acrílico. O eixo $x$ indica o número do pressionamento, sendo que $x=1$ a 20 correspondem aos 20 pressionamentos da tecla “ 1 ", $x=21$ a 40 correspondem à tecla " 2 " 


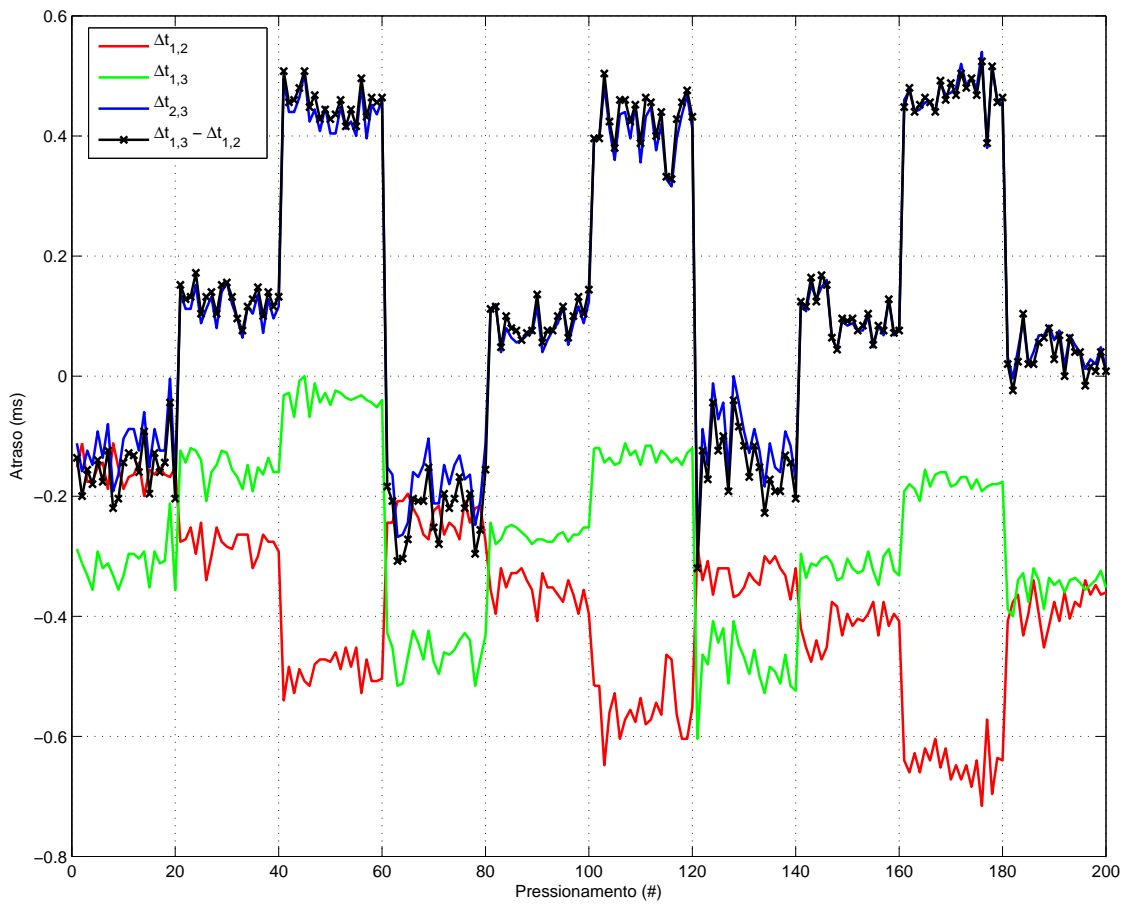

Figura 2.12: Atrasos obtidos do experimento PIN pad. A abscissa corresponde ao número do pressionamento, i.e., $x=1$ a 20 corresponde à tecla "1", $x=21$ a 40 à tecla " 2 " e $x=181$ a 200 à tecla " 0 ".

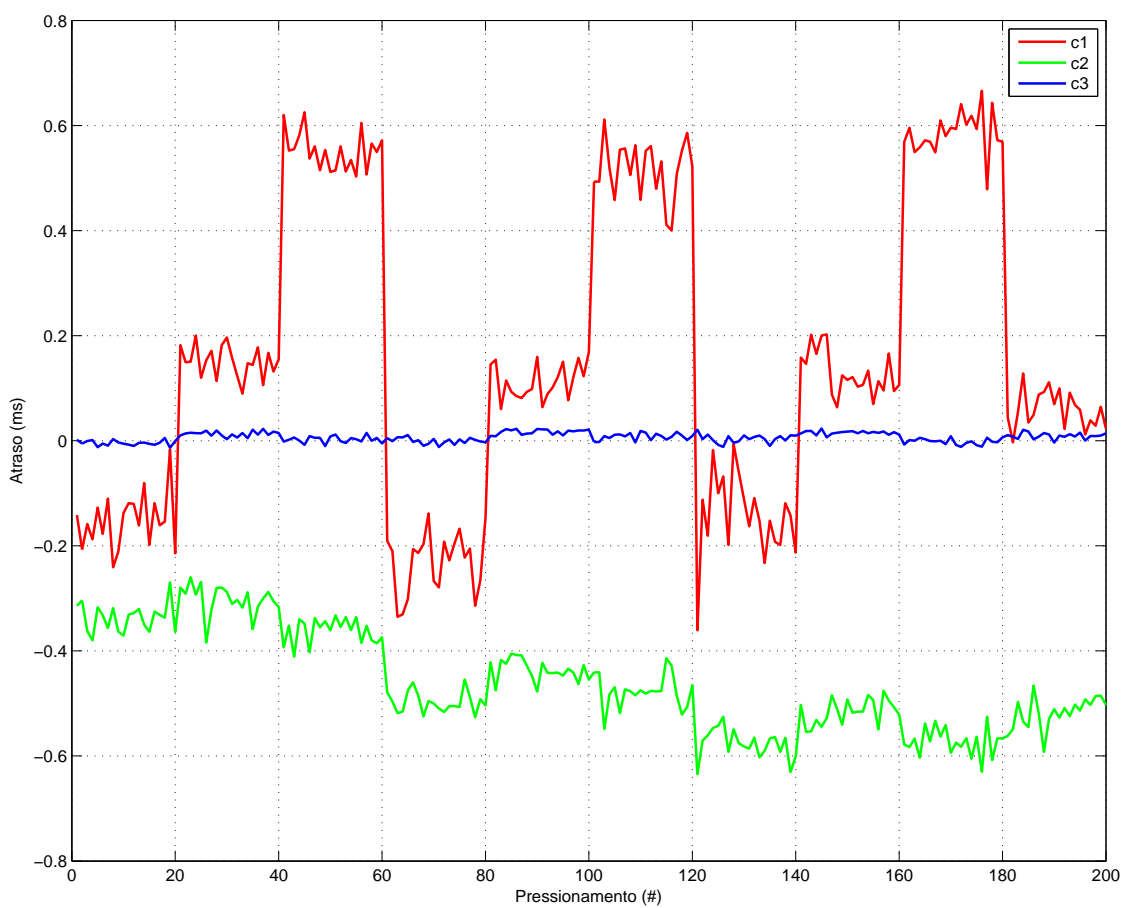

Figura 2.13: Cálculo das componentes principais dos 3 atrasos obtidos do experimento PIN pad mostram que apenas duas componentes são responsáveis por toda informação. 
e $x=181$ a 200 à tecla “0”.

A Tabela 2.2 apresenta a matriz de confusão da classificação. A taxa de acertos é bastante elevada ( $92 \pm 8 \%$ ), sendo 8 o desvio padrão dos 100 testes por reamostragem. Os erros ocorrem principalmente entre as teclas vizinhas. Com exceção das teclas "7" e "0" os erros ocorrem apenas entre teclas vizinhas que pertencem à mesma coluna. Observam-se resultados semelhantes em [3].

Tabela 2.2: Matriz de Confusão do Experimento PIN pad

\begin{tabular}{|c|c|c|c|c|c|c|c|c|c|c|c|}
\hline$\frac{\text { Classificado } \rightarrow}{\text { Real } \downarrow}$ & 1 & 2 & 3 & 4 & 5 & 6 & 7 & 8 & 9 & 0 & $\mathrm{TPR}(\%)$ \\
\hline 1 & 400 & & & & & & & & & & 100.0 \\
\hline 2 & & 376 & & & 24 & & & & & & 94.0 \\
\hline 3 & & & 396 & & & 4 & & & & & 99.0 \\
\hline 4 & & & & 400 & & & & & & & 100.0 \\
\hline 5 & & & & & 354 & & & 46 & & & 88.5 \\
\hline 6 & & & & & & 374 & & & 26 & & 93.5 \\
\hline 7 & & & & & & & 370 & & & 30 & 92.5 \\
\hline 8 & & & & & 13 & & & 318 & & 69 & 79.5 \\
\hline 9 & & & & & & 25 & & & 375 & & 93.8 \\
\hline 0 & & & & & 2 & & 9 & 87 & & 302 & 75.5 \\
\hline TPR Médio & & & & & & & & & & & $92 \pm 8$ \\
\hline
\end{tabular}

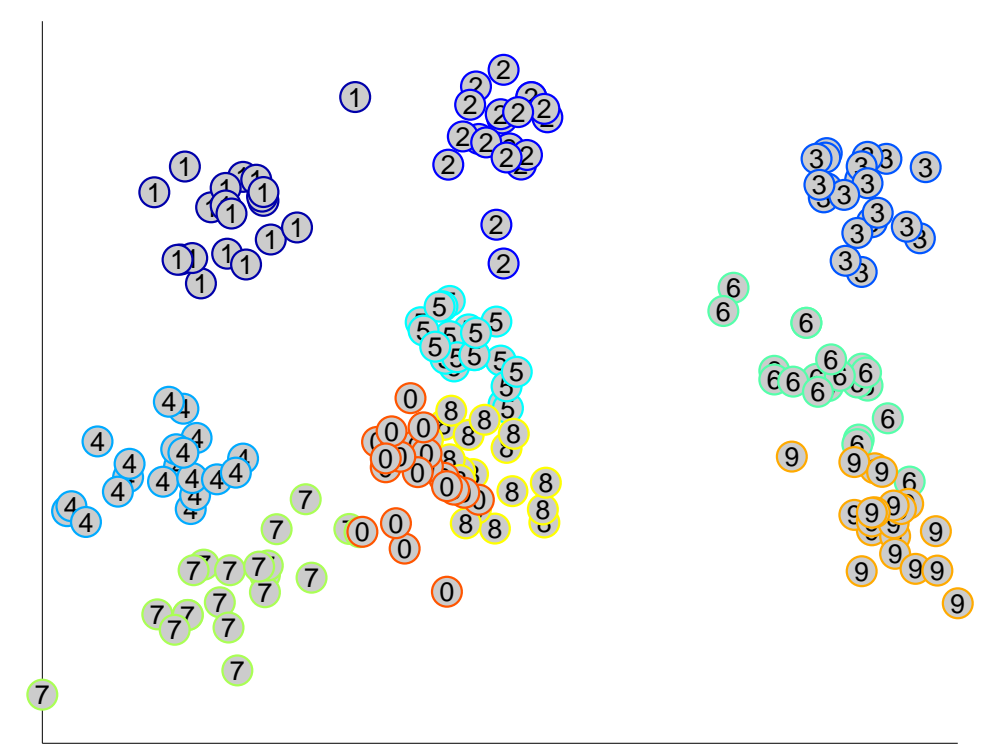

Figura 2.14: Estimação das posições das teclas para o experimento PIN pad.

Neste experimento, a reconstrução das posições das teclas foi também razoável (Figura 2.14), embora os agrupamentos de teclas não estejam tão claramente separados, 
como no caso do teclado em placa acrílica (Seção 2.2). As teclas aparecem distribuídas com razoável separação espacial entre grupos, com exceção de "0", “5” e "8”, pertencents à coluna central do teclado, que se encontram parcialmente sobrepostas. Tais resultados estão de acordo com a matriz de confusão da Tabela 2.2 e também com a visível proximidade de alguns dos atributos, como nos pressionamentos 80-100, 141-160 e 181-200 da Figura 2.13. Estes resultados mostram que a suposição de velocidade de grupo constante utilizada no método de localização de origem das fontes de vibração (Anexo 2.6) é razoável, apesar da evidente complexidade do meio físico. Os erros de localização observados podem ser devidos a: (a) o triângulo formado pelos acelerômetros abrange apenas uma pequena parte do teclado; (b) a velocidade de grupo não ser constante ao longo de todo o dispositivo; (c) a dispersão do meio leva a estimativas imprecisas dos atrasos via NCC, pois as ondas mecânicas se propagam de forma dependente do modo como as teclas são pressionadas.

\subsection{Discussões e viabilidade do ataque}

Os resultados do ataque apresentado mostram que é possível o roubo de informação digitada a partir da vibração, ainda que ensaiado com apenas um usuário. Para o caso do PIN pad, dispositivo que não deveria permitir a inferência do conteúdo introduzido pelo usuário, os resultados são indicativos de necessidade de revisão de projeto. Um aspecto bastante crítico deste modelo (e não apenas dele) é o compartimento de cartão SAM, onde os acelerômetros foram instalados. Tal abertura aumenta a vulnerabilidade ao ataque TDOA, principalmente porque:

1. fornece espaço para a implantação de skimmers que podem ficar ocultos dentro do compartimento;

2. o compartimento é normalmente localizado logo abaixo do teclado, lugar ideal para capturar as vibrações dos pressionamentos de teclas;

3. os conectores dos cartões SAM podem, eventualmente, fornecer energia elétrica para o skimmer. 
Desta forma, o ataque poderia ser executado em um cenário real e de maneira de difícil detecção, sem baterias e fios, em que skimmers miniaturizados operando sem fio podem ser introduzidos neste compartimento. Não foram realizados outros experimentos de posicionamento de acelerômetros, mas os resultados para acelerômetros posicionados a uma menor distância entre si indicam que mesmo fora do compartimento SAM seria possível adquirir vibrações do corpo do dispositivo e classificá-las em teclas, via TDOA.

\subsection{Estimativa da localização de origem da vibração}

Esta seção apresenta a técnica utilizada de estimativa de localização da tecla. No entanto, como demonstrado nos experimentos, não é necessário conhecer a localização (2-D) da tecla pressionada de modo a classificá-la. Supomos que a velocidade de grupo é constante por toda a superfície em que os acelerômetros estão afixados. Consequentemente, as distâncias relativas são aproximadamente proporcionais aos atrasos relativos medidos $(\Delta d \approx k \Delta t)$. Por exemplo, podemos considerar que a distância $d_{1}-d_{2}$ é aproximadamente igual ao atraso relativo medido $\Delta t_{1,2}$ entre acelerômetros $A_{1}$ e $A_{2}$ (Figura 2.15).

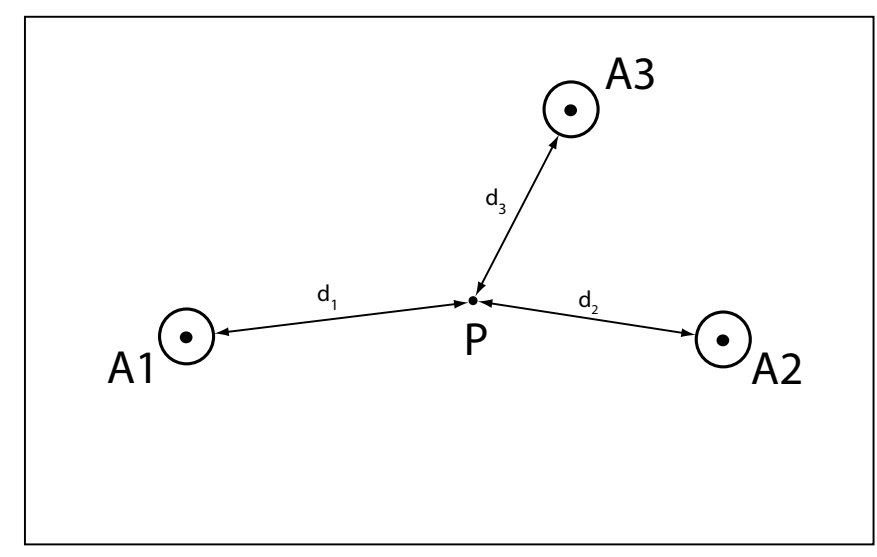

Figura 2.15: Diagrama do método de triangulação.

Da mesma forma, assumimos que $d_{1}-d_{3} \approx \Delta t_{1,3}$ e $d_{2}-d_{3} \approx \Delta t_{2,3}$. Entretanto, observamos que apenas duas diferenças de tempo possuem informação útil, sendo que a terceira é combinação linear das outras duas. Considere $\Delta t_{1,2}=t_{1}-t_{2}$. Fazendo o mesmo para $\Delta t_{1,3}$ e $\Delta t_{2,3}$, é simples verificar que $\Delta t_{2,3}=\Delta t_{1,3}-\Delta t_{1,2}$ é combinação 
linear dos outros dois atributos, não possuindo informação nova. Tal fato é comprovado no processo de redução de dimensionalidade via PCA, no qual a dimensão real de representação dos atributos é 2 .

A posição de origem da frente de onda $P$ é obtida por otimização numérica, na qual a seguinte função custo deve minimizada:

$$
f=c_{1,2}+c_{1,3}
$$

onde $c_{1,2}$ é:

$$
c_{1,2}= \begin{cases}{\left[d_{1}^{2}-\left(d_{2}+\Delta t_{1,2}\right)^{2}\right]^{2}} & \text { se } \Delta t_{1,2} \geq 0 \\ {\left[d_{2}^{2}-\left(d_{1}+\Delta t_{1,2}\right)^{2}\right]^{2}} & \text { se } \Delta t_{1,2}<0 .\end{cases}
$$

O custo $c_{1,3}$ é definido de modo similar. A distância $d_{i}$ do acelerômetro $A_{i}=\left(A_{i}^{x}, A_{i}^{y}\right)$ ao ponto $P=\left(P^{x}, P^{y}\right)$ é:

$$
d_{i}=\left\|A_{i}-P\right\|=\sqrt{\left(A_{i}^{x}-P^{x}\right)^{2}+\left(A_{i}^{y}-P^{y}\right)^{2}}
$$

Substituindo a Equação 2.5 e 2.6 na Equação 2.4 e minimizando $f$, obtemos a posição 2-D aproximada do ponto $P$ (Figura 2.15). Em nossos experimentos, a função fminunc do MATLAB foi utilizada para realizar a minimização. 


\section{Capítulo 3}

\section{Ataque DAA}

Quando escutamos um som oriundo de alguma fonte externa, as características do mesmo como intensidade e percepção do espectro de frequências alteram-se dependendo de nossa orientação e posição relativas à fonte de som. Isto ocorre porque captamos o som vindo de direções diferentes, sendo o mesmo alterado por essa razão, devido a fenômenos ondulatórios, como reflexão, ressonância, absorção, reverberação etc. dependendo das características do meio e da fonte de som. Sistemas de equalização de som ambiente realizam a tarefa de tornar a audição mais apurada, visando a correção dos fenômenos ambientais descritos, pois as características sonoras percebidas são dependentes da posição da origem da fonte e da posição de quem ouve. Este foi o fenômeno explorado neste ataque, denominado DAA (Differential Audio Analysis / Análise Diferencial de Áudio). Em síntese, os fenômenos acústicos existentes no ato de pressionar uma tecla trazem informação distintiva da tecla, pois as mesmas são distinguíveis por sua localização fixa.

$\mathrm{Na}$ literatura, existem artigos que identificam a tecla pressionada pelo som, pois cada tecla, de forma geral, emite um som característico quando pressionada. Asonov e Agrawal [16] obtiveram uma taxa de reconhecimento de $79 \%$ ao identificar uma de 30 teclas em um teclado de PC. Berger et al. [11] utilizam emanações acústicas de teclado e um dicionário da língua inglesa para reconhecer palavras digitadas em um teclado de PC obtendo acerto de 73\%. Especificamente, teclas como "Q", "W" e "E" são próximas entre si, fazendo com que o som de seu pressionamento tenha maior correlação cruzada do que entre as teclas mais distantes entre si como "Z" e "P", por exemplo. 
Zhuang et al. [8] tomam como entrada a gravação de som de 10 minutos de um usuário digitando um texto em inglês e recuperam com até $96 \%$ de acerto os caracteres digitados, com uso de um modelo de linguagem implementado via HMM (Hidden Markov Model), utilizando cepstrum como atributos, testando com dois usuários. Halevi [21] utiliza emanações acústicas de um teclado para descobrir senhas aleatórias, sem o uso de dicionário, alcançando taxa de acerto de $40 \%$ a 64\%, aplicando uma técnica denominada time-frequency, que explora características temporais (correlações) e espectrais (MFCC).

Embora a natureza do vetor de ataque seja a mesma, quer dizer, emissões acústicas, a abordagem do ataque aqui proposto é de natureza diferente das anteriormente descritas: mesmo que todas as teclas emitissem exatamente o mesmo som e vibração, ainda assim seria possível identificar a tecla pressionada, por meio da estimativa da resposta em frequência do sistema acústico do dispositivo. Isso porque a função de sistema acústica depende do espaço vazio do dispositivo, do local de origem do áudio (a tecla pressionada) e da localização de microfones de escuta.

Pesquisadores em engenharia acústica [36, p. 1381] utilizam a resposta em frequência e/ou a resposta impulsiva para estimar caracterísitcas acústicas de ambientes, como tempo de reverberação e outras características. No nosso caso, o "ambiente" é o compartimento SAM localizado logo abaixo do teclado do PIN pad, onde as ondas sonoras interagem.

Em teoria, uma vez que a resposta em frequência é uma característica do sistema e não do sinal de excitação, o ataque DAA seria independente do usuário - não importando quem pressionasse a tecla, a mesma seria corretamente identificada. É importante observar que o mesmo usuário tem a liberdade de teclar de modo distinto uma mesma tecla, obtendo sinais que podem ser bastante diversos entre si.

Neste capítulo, apresentamos o modelo do ataque e desenvolvemos a teoria básica na (Seção 3.1), testamos o ataque em dois PIN pads de modelos diferentes nas Seções $3.2 \mathrm{e} 3.3$, comparando técnicas convencionais com nossa abordagem. Um experimento de posicionamento dos microfones é apresentado na Seção 3.2 .5 e experimentos de operação em bases distintas e com ruído de fundo na Seção 3.2.6. A possibilidade de clonagem do ataque é analisada na Seção 3.2.7. A discussão dos resultados é apre- 
sentada na Seção 3.4. Uma simulação para demonstar o comportamento da resposta acústica impulsiva de um espaço fechado, fundamento deste ataque, é apresentada no Apêndice E

\subsection{Modelo do ataque}

Em linhas gerais, o ataque é baseado na captura de som de dois pontos distintos dentro de um compartimento do dispositivo. A hipótese é a de que a estimação do sistema linear (filtro) que transforma o sinal de um microfone no sinal do outro microfone nos fornece informação suficiente para classificação da tecla. Trata-se de um ataque baseado em identificação e classificação de sistemas lineares.
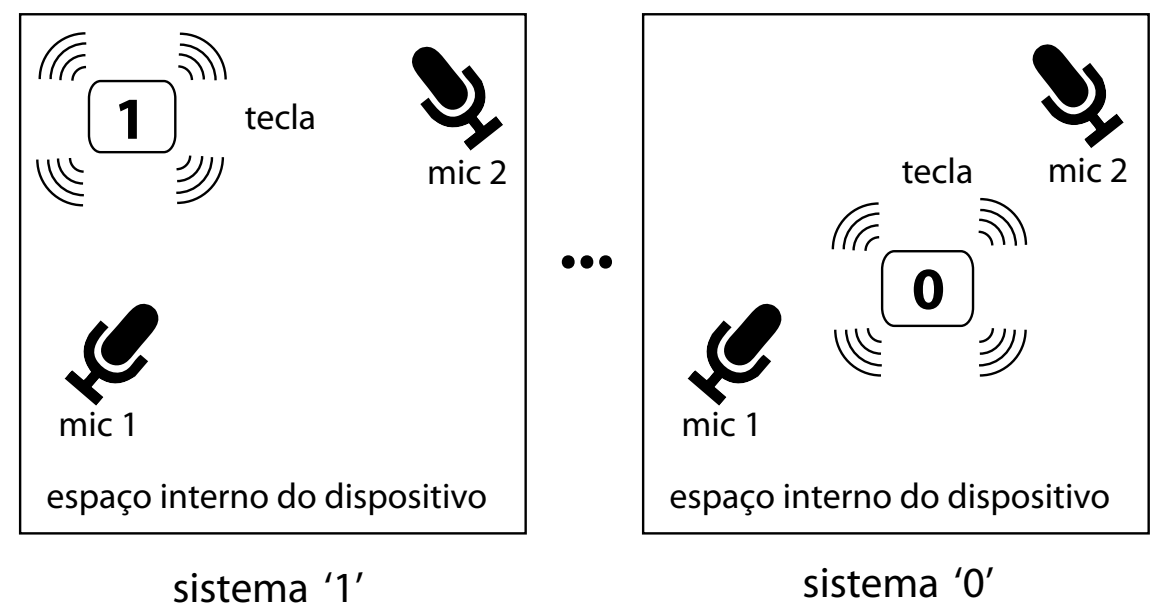

Figura 3.1: O conjunto formado pelo espaço interno do dispositivo, a posição da tecla e dos microfones, compõe um sistema cuja resposta em frequência deve ser estimada. As teclas serão classificadas baseadas nas funções de transferência.

\subsubsection{Caracterização do sistema acústico como sistema linear}

A Figura 3.1 apresenta o modelo de ataque proposto. As posições das teclas definem cada sistema, uma vez que outros fatores são mantidos fixos (espaço interno do dispositivo, características dos microfones e posições destes). A Figura 3.2 (a) ilustra o modelo acústico LIT (linear e invariante no tempo) de uma tecla.

A entrada $s(n)$ é comum a ambos os microfones (embora não mensurável diretamente), e cada microfone responde de acordo com a função de sistema correspondente, 


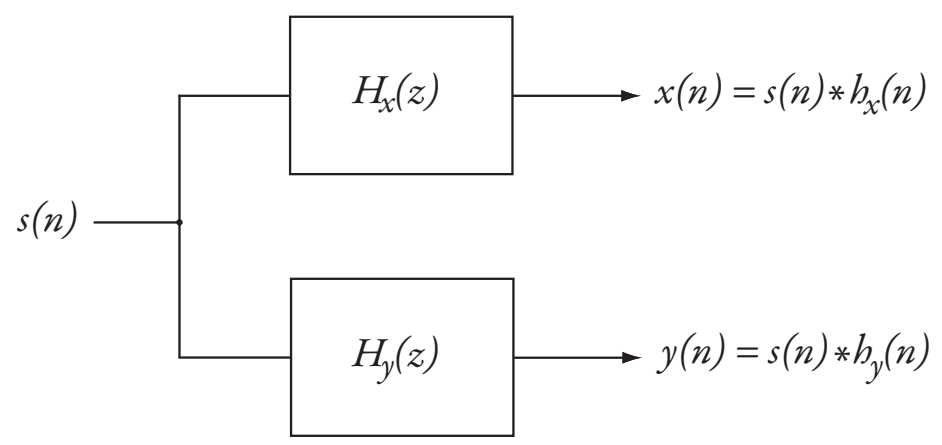

(a)

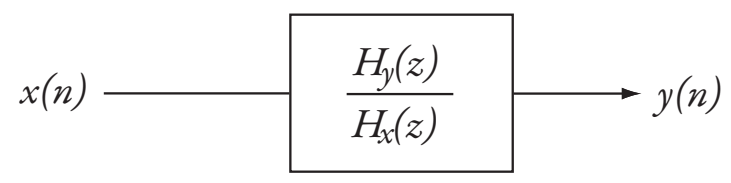

(b)

Figura 3.2: (a) A resposta de cada microfone ao pressionamento é descrita por um sistema linear, com excitação comum, não diretamente observável. (b) O sistema resultante independente do conhecimento do sinal de entrada é descrito pelo filtro combinado.

designadas $H_{x}(z)$ e $H_{y}(z)$. A Figura 3.2 (b) descreve o modelo entrada-saída adotado, dado pela função de sistema combinada, que transforma o sinal de um microfone $x(n)$ no sinal do outro, $y(n)$. Uma amostra de ambos os sinais de um pressionamento é apresentada na Figura 3.3 .

A adoção do modelo de identificação do sistema acústico via abordagem entradasaída é mais adequada do que a identificação e classificação dos sistemas de forma independente. Isto porque ela descreve o sistema acústico com razoável independência do sinal de excitação. A abordagem de classificação da resposta em frequência de um único sistema foi experimentada por Asonov [16], em que apenas um microfone é utilizado e os resultados se mostraram bastante inferiores e dependentes do modo de pressionamento das teclas. Reproduzimos a ideia de Asonov no experimento da Seção 3.2 .3 , bem como aplicamos a ele algumas técnicas que melhoram sua abordagem "clássica" de ataque via espectro de frequência.

Há várias formas de estimar a resposta em frequência ${ }^{1}$ de um sistema linear acústico [35, p. 66]. Estas normalmente utilizam fontes de excitação determinísticas ou

\footnotetext{
${ }^{1}$ A resposta em frequência de um sistema digital $H(z)$ é obtida tomando-se $z=e^{i \omega}$.
} 


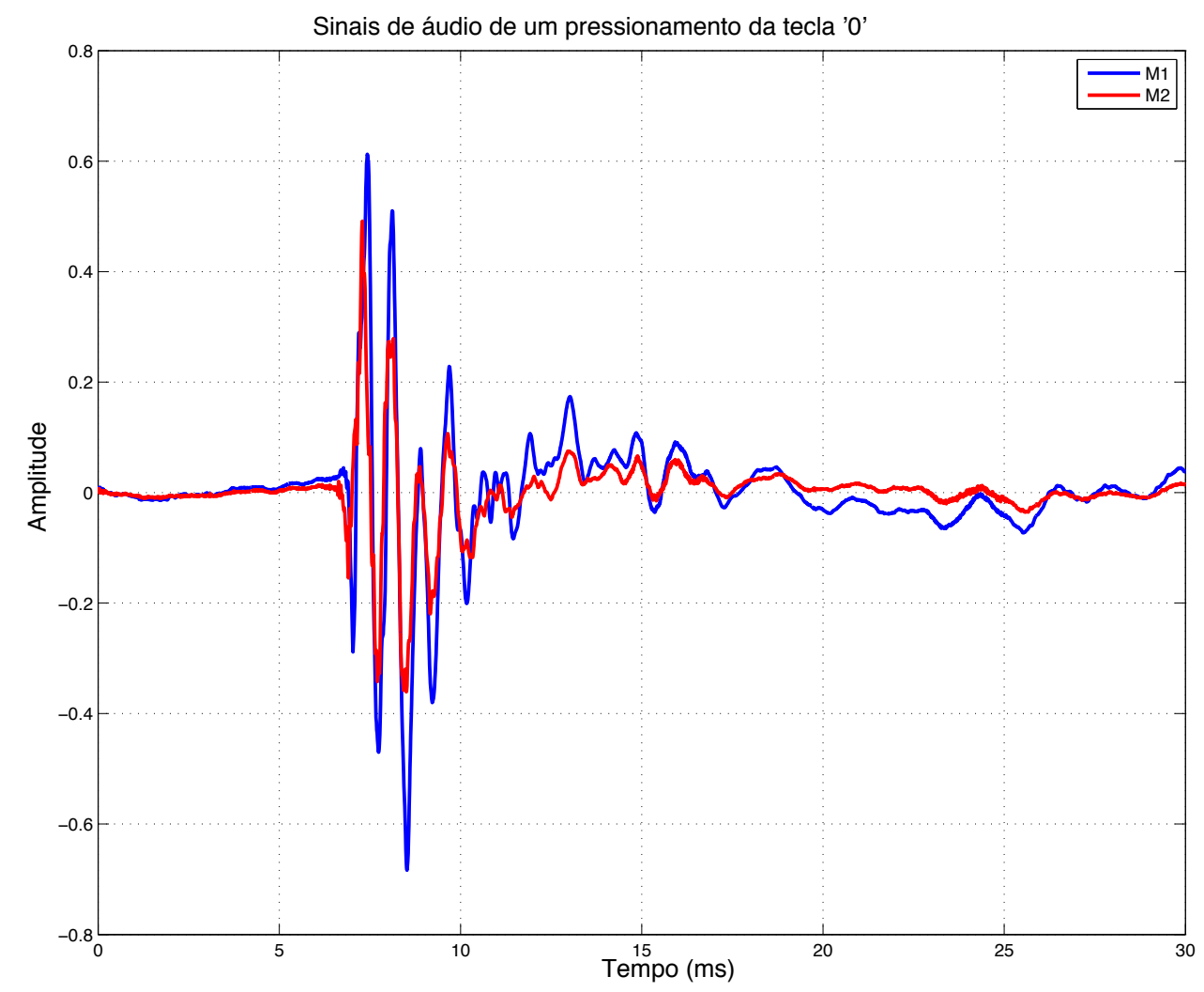

Figura 3.3: Sinais de um pressionamento do equipamento iPP320. A estimação da função de sistema linear que transforma o sinal de um microfone M1 (azul) em outro, M2 (vermelho) é utilizada para classificação das teclas.

ruído de espectro amplo, de modo a cobrir uma faixa desejada do espectro de frequências. Em nosso ataque, as fontes de excitação não são controláveis, pois são os sons gerados pelo pressionamento das teclas por pessoas diferentes. Na realidade, nosso problema não é o de estimar as funções de transferência ou respostas em frequência para a descrição completa dos sistemas em uma faixa ampla, mas sim o de procurar distinguir os diversos sistemas em suas faixas de operação usuais, com interesse em classificá-los em um número de categorias pré-definido, neste caso, igual à quantidade de teclas.

\subsubsection{Resposta acústica impulsiva de um espaço tridimensional}

O comportamento do som dentro de uma região fechada pode ser descrito pela solução da equação de Helmholtz, sendo esse um problema clássico de acústica, embora longe de ser trivial. Allen e Berkley [54] apresentam uma solução para este problema, 
pelo método conhecido como "método das imagens". Tal solução fornece a resposta impulsiva de um ambiente retangular, em cujo interior encontra-se uma fonte de som e um receptor, como um microfone. Partindo da solução desenvolvida pelos autores, a equação que descreve a resposta impulsiva para um espaço tridimensional, retangular, fechado e reflexivo é:

$$
h\left(t, \mathbf{x}, \mathbf{x}^{\prime}\right)=\sum_{\mathbf{p}=0}^{1} \sum_{\mathbf{r}=-\infty}^{\infty} \frac{\delta\left[t-\left(\left|R_{\mathbf{p}}+R_{\mathbf{r}}\right| / c\right)\right]}{4 \pi\left|R_{\mathbf{p}}+R_{\mathbf{r}}\right|} \beta_{x_{1}}^{|n-q|} \beta_{x_{2}}^{|n|} \beta_{y_{1}}^{|l-j|} \beta_{y_{2}}^{|l|} \beta_{z_{1}}^{|m-k|} \beta_{z_{2}}^{|m|}
$$

Onde:

$\mathbf{t}=$ tempo, medido em intervalos de amostragem;

$\mathrm{x}=$ posição da origem da fonte de áudio;

$\mathbf{x}^{\prime}=$ posição do microfone;

$\mathbf{p}=(q, j, k)$, indicando uma somatória tripla;

$\mathbf{r}=(n, l, m)$, indicando uma somatória tripla;

$R_{\mathbf{p}}=\left(x-x^{\prime}+2 q x^{\prime}, y-y^{\prime}+2 j y^{\prime}, z-z^{\prime}+2 k z^{\prime}\right)$;

$R_{\mathrm{r}}=2\left(n L_{x}, l L_{y}, m L_{z}\right)$, sendo $L_{x}, L_{y}$ e $L_{z}$ as dimensões da caixa;

$c=$ velocidade do som;

$\beta_{a_{b}}=$ coeficientes de reflexão das paredes $(0$ a 1.0$)$. O índice "a" corresponde à coordenada e "b" ao plano ( 1 = parede adjacente à origem, 2 = parede oposta $)$

A Equação 3.1 indica que a resposta ao impulso é diretamente dependente da localização da origem do sinal $\mathbf{x}$ e da localização da medida realizada $\mathbf{x}^{\prime}$. Tal característica é explorada no ataque, uma vez que a origem do sinal (as diferentes teclas) é a principal variável do modelo. Ou seja, mantendo-se os microfones fixos no espaço, a resposta ao impulso pode ser utilizada como uma "assinatura" da posição da fonte de áudio, contanto que a mesma possa ser estimada com robustez razoável. No ataque proposto, as respostas ao impulso de dois microfones combinadas em um único filtro são utilizadas para descrever o sistema, o que será explicado adiante. O Apêndice E traz uma simulação da resposta acústica de uma caixa utilizando a Equação 3.1, de modo a termos uma ideia melhor da capacidade discriminante que a análise diferencial de 
áudio possui. Pela simulação é possível observar que tal análise é bastante sensível espacialmente, o que indica em tese que a classificação dos sistemas é beneficiada.

\subsubsection{Métodos de estimação da resposta em frequência dos siste- mas}

De acordo com o modelo da Figura 3.2 (b), em que o sinal de um microfone é considerado como entrada e o sinal de outro microfone como saída de um sistema linear, teremos que estimar $K$ funções de sistemas SISO (single input single output), uma para cada tecla. As respostas em frequência das estimativas destas funções serão utilizadas na geração dos atributos para classificação. Como afirmado anteriormente, há vários métodos para sua estimação. Utilizamos aqui dois métodos: um não-paramétrico baseado no periodograma suavizado de Welch e outro baseado na estimação de sistemas autoregressivos (AR) de Yule-Walker. Um terceiro método foi parcialmente testado, de identificação de um modelo ARMA (autoregressive moving average), via função armax do MATLAB. Resultados iniciais do modelo ARMA com parâmetros adequados mostraram taxas de classificação inferiores comparadas aos dois métodos supracitados, com tempos de processamento muito superiores, o que levou ao abandono da análise via modelo ARMA.

\subsubsection{Método baseado no periodograma suavizado de Welch}

A resposta em frequência estimada via periodograma suavizado de Welch [37, 38] pode ser descrita por:

$$
\hat{H}(\omega)=\frac{\hat{S}_{y x}(\omega)}{\hat{S}_{x x}(\omega)}
$$

onde $\hat{S}_{y x}(\omega)$ é a densidade espectral de potência cruzada entre os sinais de entrada e saída e $\hat{S}_{x x}(\omega)$ é a densidade espectral de potência da entrada. A Equação 3.2 pode ser estimada com a função tfestimate do MATLAB. Uma análise mais detalhada deste método é apresentada no Apêndice C. As magnitudes dos vetores complexos resultantes $\left|\hat{H}_{i}\right|$ são utilizadas como atributos, após redução de dimensionalidade via PCA. Foram comparados dois atributos, $P C A(|\hat{\mathbf{H}}|, n)$ e $P C A(\log (|\hat{\mathbf{H}}|), n)$, sendo $n$ o número de componentes principais adotado e $\hat{\mathbf{H}}$ a matriz formada por todos os veto- 
res linha $\hat{H}_{i}$ estimados. Chamamos a esses atributos respectivamente linWELCH e $\log \mathrm{WELCH}$.

\subsubsection{Método baseado em sistema LIT racional}

Considere uma fonte de excitação $s(n)$ comum a ambos os microfones mas não mensurável diretamente (Ver Figura 3.2(a)). Considere também dois sistemas lineares, $x$ e $y$ descritos por suas funções, $H_{x}(z)$ e $H_{y}(z)$ que transformam a excitação capturada pelos dois microfones e os entregam como sinais $x(n)$ e $y(n)$.

Podemos modelar ambos os sistemas como processos autorregressivos (AR), i.e., representando-os como filtros IIR ("resposta ao impulso infinita") cuja entrada seja ruído branco ${ }^{2}$ Em princípio, outros métodos de estimação de um modelo AR, como o método de Burg ou mínimos quadrados poderiam ser utilizados, embora não o façamos aqui. Deste modo, um filtro será dado por $H_{x}(z)=1 / A_{x}(z)$ e o outro por $H_{y}(z)=$ $1 / A_{y}(z)$. De forma a identificar a função do sistema acústico que relaciona os dois, consideramos um sistema LIT ${ }^{3}$ racional $H(z)$ descrito por:

$$
H(z)=\frac{Y(z)}{X(z)}=\frac{A_{x}(z)}{A_{y}(z)}
$$

Os filtros autorregressivos $A_{x}(z)$ e $A_{y}(z)$ podem ser estimados pela função do MATLAB aryule (x, order), obtendo os filtros $\hat{A}_{x}$ e $\hat{A}_{y}$, estáveis por construção, garantindo a estabilidade de $H$. A resposta em frequência do sistema é obtida quando $z=e^{i \omega}$ :

$$
H\left(e^{i \omega}\right)=\frac{A_{x}\left(e^{i \omega}\right)}{A_{y}\left(e^{i \omega}\right)}
$$

A função do MATLAB utilizada para calcular a função de transferência com base nos filtros estimados é $\hat{H}=$ freqz $\left(\hat{A}_{x}, \hat{A}_{y}, \mathrm{n}\right)$, que retorna um vetor complexo. Em nossos experimentos, $n=512$. Este valor corresponde ao número de divisões na escala de frequência, cada divisão correspondendo à frequência de Nyquist dividida por 512.

Assim como no método anterior, as magnitudes dos vetores resultantes $\left|\hat{H}_{i}\right|$ são utilizadas como atributos, após redução de dimensionalidade via PCA. Foram com-

\footnotetext{
${ }^{2}$ Os filtros de processos AR são uma subclasse de filtros IIR, que possuem zeros triviais na origem.

${ }^{3}$ Linear e invariante no tempo.
} 
parados dois atributos, definidos anteriormente, $P C A(|\hat{\mathbf{H}}|, n)$ e $P C A(\log (|\hat{\mathbf{H}}|), n)$. Chamamos a esses atributos respectivamente linLIT e logLIT.

\subsubsection{Ataque baseado na densidade espectral de potência (PSD)}

Em seu artigo clássico, Asonov e Agrawal [16] utilizam como atributos a magnitude da FFT (Fast Fourier Transform) do sinal de apenas um microfone, tomando valores de magnitude a cada $20 \mathrm{~Hz}$. Operando com frequência de até $4 \mathrm{kHz}$, a dimensão do vetor de atributos será 200. Os autores não realizam nenhum procedimento de redução de dimensão, utilizando 200 pontos diretamente como entrada de uma rede neural artificial. Em trabalho posterior Zwang et al. [8] argumentam a respeito desses atributos, considerando-os inadequados, propondo o uso do cepstrum como alternativa, além de afirmar que puderam apenas realizar um experimento aproximado ao de Asonov e Agrawal. A mesma abordagem foi adotada aqui. De modo a comparar o método DAA com o modo convencional baseado em espectro de frequências, testamos o periodograma convencional, mais próximo do método de Asonov e Agrawal, porém, com as seguintes alterações:

- Cálculo do logaritmo da magnitude do periodograma, mais adequado ao tratamento de sinais de áudio, de elevada faixa dinâmica;

- Uso de redução de dimensionalidade via PCA;

- Uso de classificador Naive Bayes em vez de RNA;

A estimação do periodograma de um sinal $x(n)$ via DFT, em sua forma convencional [30, p.542] é dada por:

$$
P(\omega)=\frac{1}{N}\left|\sum_{n=0}^{N-1} w(n) x(n) e^{-i \omega n}\right|^{2}
$$

A função periodogram (x,w), do MATLAB, é utilizada para calcular o periodograma, onde $w$ é um vetor correspondente à janela utilizada; em nosso caso, a janela de Hamming, definida como $w(n)=0.54-0.46 \cos (2 \pi n / N)$. Os atributos utilizados serão computados da forma $\operatorname{PCA}(\operatorname{Norm}(\hat{\mathbf{P}}), n)$ para o modo linear 
e $P C A(\operatorname{Norm}(\log (\hat{\mathbf{P}})), n)$ para o modo logarítmico, sendo "Norm" a normalização pela soma dos valores absolutos e $\hat{\mathbf{P}}$ a matriz formada por todos os vetores linha $P_{i}$ estimados. Chamamos a esses atributos respectivamente linPSD e logPSD.

\subsection{Experimento com PIN pad Ingenico iPP320}

A Figura 3.4 mostra o primeiro PIN pad testado, modelo Ingenico iPP320, e a montagem do experimento, onde dois microfones foram colados dentro do compartimento de acesso aos cartões SAM.
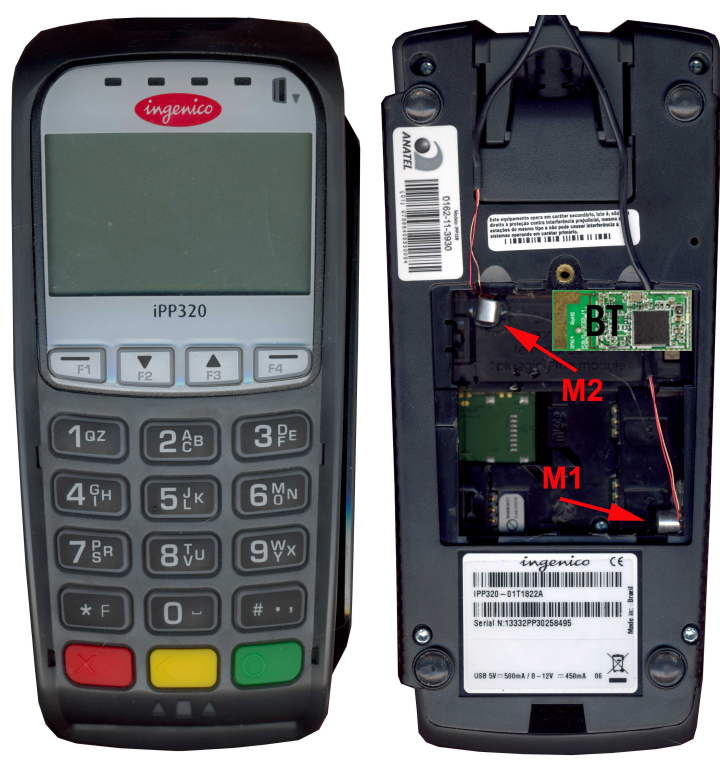

Figura 3.4: (Esq) PIN pad Ingenico iPP320 utilizado no experimento. (Dir) Vista inferior mostrando o compartimento SAM com os microfones implantados. No canto superior direito do compartimento há a inserção da imagem de um módulo de aúdio estereofônico com comunicação Bluetooth 4.2 apenas para indicar a possibildade de uso do mesmo no ataque.

É importante frisar que um PIN pad é um dispositivo à prova de abertura e alterações (tamper proof) e desabilita-se permanentemente se detectada uma tentativa de abertura ou violação, isto quer dizer, se aberto mediante a extração dos 4 parafusos que fecham o dispositivo, no caso do modelo testado. No entanto, o espaço do compartimento SAM (Figura 3.4, direita) é projetado para ser livremente acessível, de modo a permitir a inserção do cartão SAM pelo lojista. Deste modo, é possível que um adversário instale os microfones ou o skimmer no equipamento sem que o mesmo detecte 
intrusão e se desabilite.

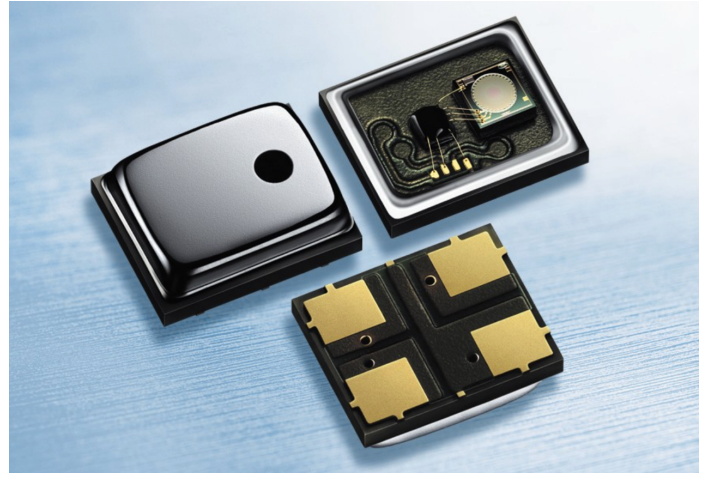

(a)

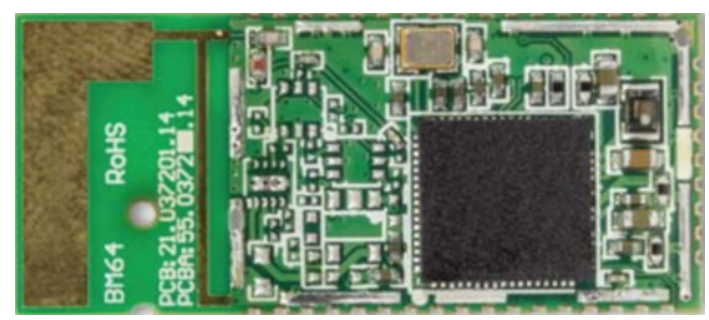

(b)

Figura 3.5: (a) Microfone MEMS poderia ser utilizado, pois suas dimensões são extremamente reduzidas $(4 \times 3 \times 1 \mathrm{~mm})$. Foto: Infineon. (b) Módulo Bluetooth Microchip BM64 poderia ser instalado para realizar a transmissão do áudio para processamento externo. Dimensões $=(32 \times 15 \times 2,5 \mathrm{~mm})$. Foto: Microchip.

O compartimento SAM expõe a vulnerabilidade ao ataque DAA principalmente pelos seguintes motivos:

1. fornece espaço para implantação dos "bugs" (escutas) e hardware auxiliar, de forma oculta dentro do compartimento. É possível o uso de microfones de tecnologia MEMS, de tamanho muito reduzido (Figura 3.5a). A maior dimensão deste microfone é $\approx 4 \mathrm{~mm}$.

2. o compartimento é normalmente localizado logo abaixo do teclado, local ideal para captura de áudio emanado pelos pressionamentos;

3. os slots dos cartões SAM podem prover energia elétrica para o skimmer, podendo este inclusive enviar os dados de forma wireless. Na Figura 3.4 (Dir), foi sobreposta uma imagem na mesma escala de um módulo Bluetooth de áudio estereofônico, da marca Microchip, modelo BM64 ampliado na Figura 3.5b. Segundo as especificações do fabricante, tal módulo permite a aquisição de áudio a uma taxa de $96 \mathrm{kS} / \mathrm{s}$, plenamente suficiente para o ataque. Possui ainda interface digita $5^{5} \mathrm{I}^{2} \mathrm{~S}$ que permite conexão com os microfones MEMS de forma direta, com resolução de 24-bits.

\footnotetext{
${ }^{4}$ http://ww1.microchip.com/downloads/en/DeviceDoc/60001403A. Acesso em 4 Mar. 2015.

${ }^{5}$ Integrated Interchip Sound, IIS ou I ${ }^{2} S$ é um padrão de interface serial utilizado na conexão de dispositivos de áudio desenvolvido pela Phillips em 1986.
} 
Em suma, o ataque pode ser realizado em um cenário real, de forma a não alterar o dispositivo - o skimmer poderia ser retirado do compartimento e recolocado quando necessário - e de difícil detecção. Importante frisar que em um ataque real, a etapa de treino deve ser realizada após a montagem de todo o aparato de escuta, de modo a levar em consideração as alterações no ambiente do compartimento SAM provocado pela inclusão do skimmer.

\subsubsection{Aquisição de dados de treino e teste}

Dois equipamentos de mesmo modelo, Ingenico iPP320, foram utilizados, sendo nomeados "Ingenico A" e "Ingenico B", seguindo-se o mesmo procedimento de aquisição para ambos. A obtenção dos conjuntos de dados para treino e teste foi segregada e realizada por duas pessoas.

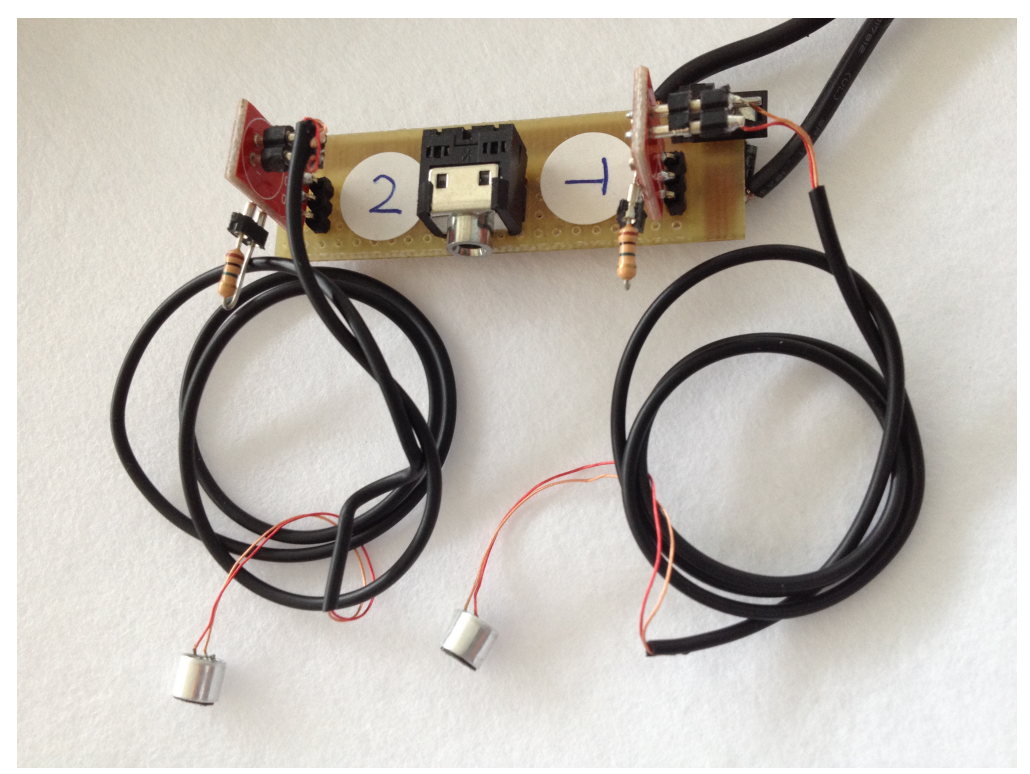

Figura 3.6: Pré-amplificadores Sparkfun BOB-12758 utilizados nos experimentos, conectados aos microfones de eletreto.

Como microcomputadores normalmente não possuem entrada estereofônica para microfones, dois pré-amplificadores foram utilizados para permitir o uso da entrada auxiliar, ou de linha, esta sim estéreo (Figura 3.6). Para o treino, uma das pessoas pressionou 50 vezes cada uma das teclas de "0" a "9", tendo ambos sinais dos microfones sido gravados em um único arquivo de áudio estéreo no formato “.wav”, a uma taxa de amostragem de $96 \mathrm{kS} / \mathrm{s}$. Para teste, outra pessoa pressionou as mesmas teclas 
50 vezes. O experimento foi realizado com o PIN pad desligadd ${ }^{6}$.

\subsubsection{Atributos e classificação}

A Figura 3.7 apresenta os gráficos das funções de transferência obtidas, antes da redução de dimensionalidade e criação dos atributos. Cada cor representa a magnitude média das funções para os pressionamentos de cada usuário.

Percebemos, ainda que visualmente, que as funções de tranferência são muito parecidas para ambos os usuários, ao mesmo tempo em que são bastante diferentes para teclas distintas, tornando-as, em princípio, adequadas para classificação. A Figura 3.8 exibe os gráficos dos atributos linLIT obtidos do conjunto de treino do experimento “B”, estas sim já com dimensionalidade reduzida via PCA, sendo utilizadas como entradas do classificador. No gráfico, cada tecla possui 50 pressionamentos, sendo que à tecla " 1 " correspondem os pressionamentos de 1 a 50 e assim sucessivamante, até a tecla " 0 ".

Cada gráfico da Figura 3.8 corresponde a uma componente do vetor reduzido. A redução de vetores de 512 pontos, gerados a partir de funções de transferência de ordem 22 (ambos polinômios de ordem 11), para apenas 4 pontos, via PCA, foi suficiente para garantir uma taxa de acertos de classificação de $100 \%$ utilizando-se o classificador Naive Bayes, com conjuntos de treino e teste separados, cada um de um usuário. Mesmo visualmente, percebe-se que há grande diferença nos valores dos atributos para teclas distintas, e uma grande regularidade destes para os pressionamentos da mesma tecla.

\subsubsection{Comparação com o ataque via PSD}

De modo a comparar o ataque DAA proposto com a abordagem em frequência convencional, utilizamos como atributos estimativas dos periodogramas com normalização, descrito na Seção 3.1.4. O procedimento para redução de dimensionalidade e classificação foi o mesmo utilizado para a abordagem DAA, com 50 pressionamentos por

\footnotetext{
${ }^{6}$ A maioria dos PIN pads emitem um "bip" de feedback ao usuário quando uma tecla é pressionada. Isto não interfere no ataque, uma vez que o "bip" inicia somente após o término do clique mecânico da tecla. Normalmente há configurações do dispositivo permitindo que o "bip” seja desabilitado.
} 

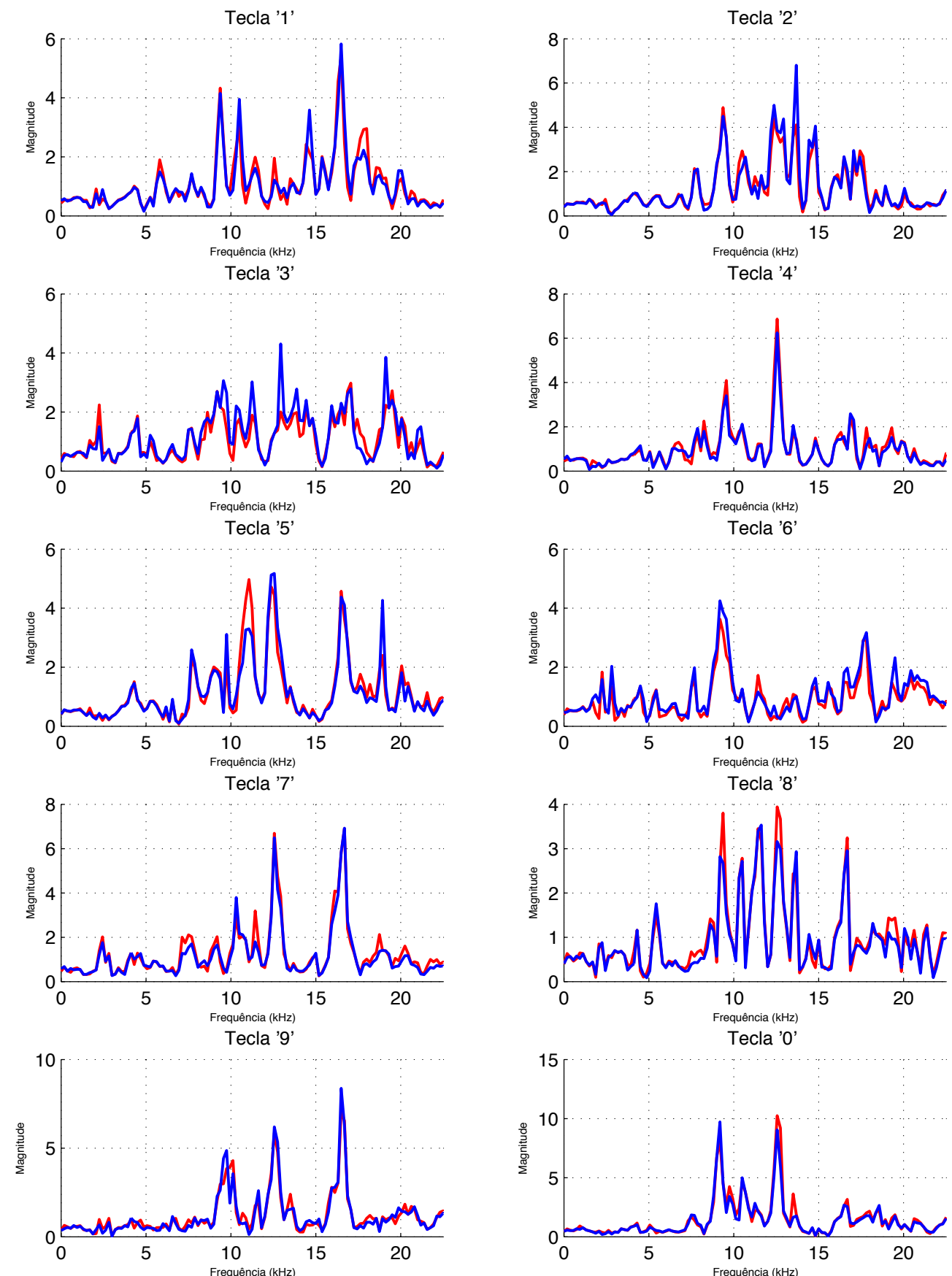

Figura 3.7: Magnitudes das funções de transferência estimadas obtidas do experimento com o PIN pad Ingenico. Cada cor corresponde a uma pessoa. Os gráficos mostram as médias para cada tecla.

tecla, treino e teste com 2 usuários distintos. Nesta abordagem, o sinal de apenas um microfone é utilizado. A Figura 3.9a apresenta os atributos linPSD estimados para o Experimento "B". A Figura 3.9b apresenta os atributos logPSD, quando o logaritmo é aplicado ao PSD antes da redução de dimensionalidade. É visível a maior qualidade 


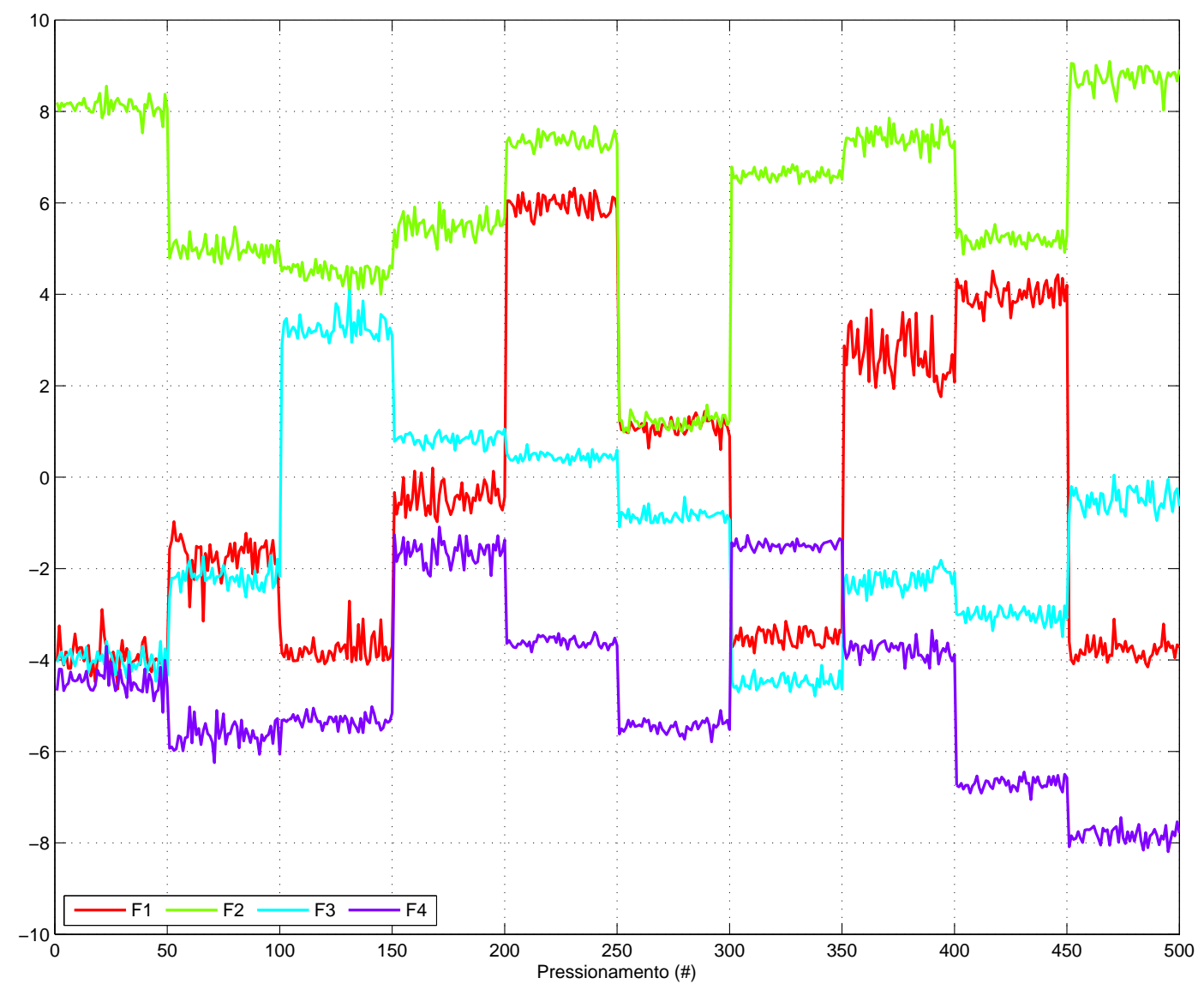

Figura 3.8: Atributos linLIT do experimento "B". Cada cor corresponde a um atributo. A tecla " 1 " corresponde aos pressionamentos 1 a 50 e assim sucessivamente, até a tecla " 0 ".

dos atributos para o segundo caso, com patamares bastante regulares e distintos entre estes.

Os resultados apresentados na Tabela 3.1 mostram que o uso do logaritmo do periodograma normalizado é fundamental para se obter bons atributos, levando a uma alta taxa de acertos, que neste caso chegou a 100\%. A explicação para esse resultado superior é que a aplicação do logaritmo transforma componentes de frequência com baixa magnitude em componentes com magnitude comparável, mas de valor negativo quando $<1$. Por exemplo, uma amplitude de valor 100 passa a estar na mesma ordem de grandeza de uma amplitude 1/100 quando comparamos seus logaritmos, p.e. na base 10, sendo 2 e -2. Isto é importante pois quando o cálculo das covariâncias é realizado no procedimento de redução de dimensionalidade via PCA, tais características de baixa magnitude não se perdem como ruído. 


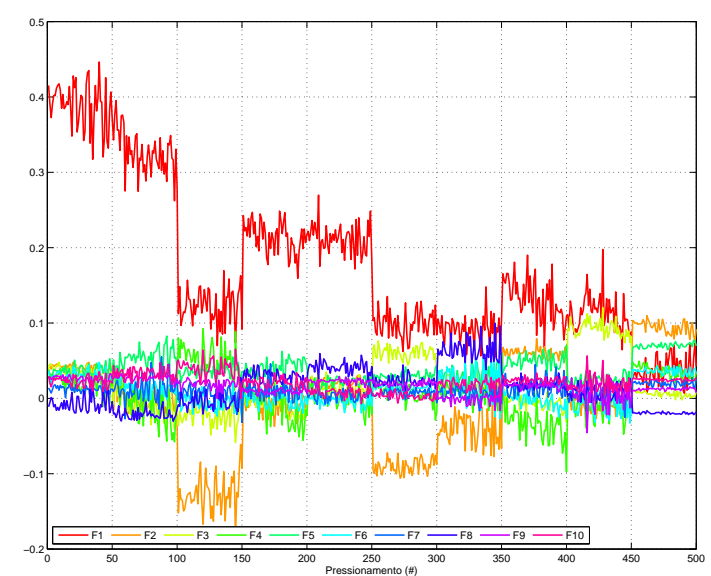

(a)

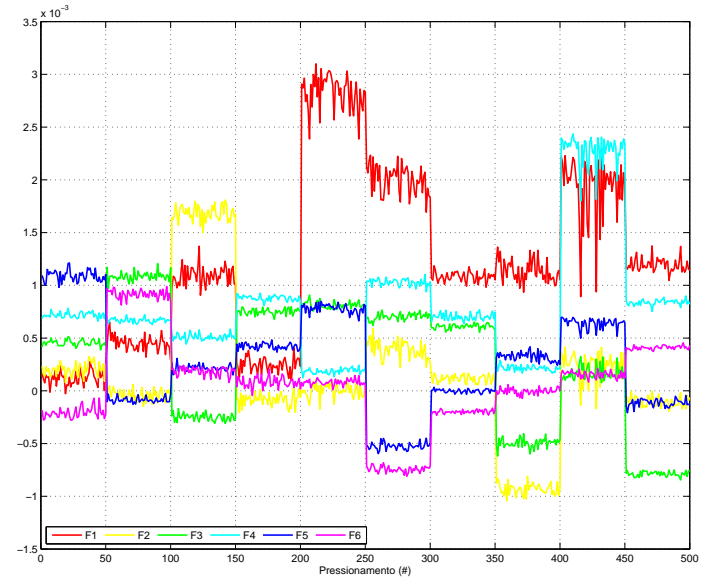

(b)

Figura 3.9: (a) Atributos linPSD. É perceptível a falta de regularidade dos atributos, com degraus pouco definidos e muita variância para a mesma tecla (b) $\mathrm{O}$ mesmo não ocorre com os atributos logPSD.

Tabela 3.1: Comparação entre os atributos do método PSD

\begin{tabular}{lcc}
\hline & $\operatorname{linPSD}$ & $\log P S D$ \\
\hline Acerto & $81 \pm 25 \%$ & $100 \%$ \\
\hline Autovalores & $98 \%$ & $50 \%$ \\
\hline Autovetores & 10 & 6 \\
\hline
\end{tabular}

As taxas médias de reconhecimento obtidas para o PSD linear estão de acordo com os resultados obtidos por Agrawal e Asonov para teclado de PC $(\approx 79 \%$, sem informação de incerteza), ainda que os autores tenham realizado treino e teste com apenas um usuário.

\subsubsection{Análise dos resultados}

A Tabela 3.2 apresenta os resultados para os experimentos com os equipamentos Ingenico "A" e "B". A coluna Treino/Teste faz a distinção entre qual dos dois usuários teve seus dados utilizados para treino ou teste.

Para ambos os experimentos o atributo $\log$ PSD foi muito superior ao linPSD, com maior taxa de acertos de classificação e menor desvio. Os atributos linWELCH e $\log$ WELCH obtiveram resultados equivalentes, já os atributos linLIT e logLIT obtiveram resultados superiores aos demais, com $100 \%$ de acertos. Para estes experi- 
Tabela 3.2: Comparação entre os ataques - experimento Ingenico

\begin{tabular}{ccccccccccc}
\hline & & \multicolumn{2}{c}{ PSD } & & \multicolumn{2}{c}{ DAA Welch } & & \multicolumn{2}{c}{ DAA LIT } \\
Experimento & Treino/Teste & $\operatorname{lin}$ & $\log$ & & $\operatorname{lin}$ & & $\log$ & & $\operatorname{lin}$ & $\log$ \\
\hline \multirow{2}{*}{ Ingenico A } & $1 / 2$ & $62 \pm 42$ & 100 & & $99.7 \pm .9$ & 100 & & 100 & 100 \\
& $2 / 1$ & $67 \pm 37$ & $95 \pm 9$ & & $99 \pm 3$ & $96 \pm 6$ & & 100 & 100 \\
Ingenico B & $1 / 2$ & $72 \pm 35$ & 100 & & 100 & 100 & & 100 & 100 \\
& $2 / 1$ & $86 \pm 24$ & 100 & & 100 & & 100 & & 100 & 100 \\
\hline
\end{tabular}

mentos, os resultados do ataque DAA (Welch ou LIT) foram praticamante indiferentes com relação aos atributos com logaritmo. Isto pode ser devido ao fato de que o DAA é, grosso modo, um quociente entre as respostas em frequência, mantendo assim os atributos em uma escala já proporcional.

\subsubsection{Experimento de posicionamento dos microfones}

Um experimento foi realizado para verificar a dependência das taxas de classificação com a posição dos microfones implantados no PIN pad. Inserimos 4 microfones no compartimento SAM do equipamento "B", como mostrado na Figura 3.10a, conectando-os aos pré-amplificadores da Figura 3.10b. A aquisição de sinais de 4 canais simultâneos foi realizada com um sistema de aquisição de 8 canais baseado no conversor A/D de 24 bits ADS1278, da Texas Instruments, operando a uma taxa de amostragem de 50kS/s. Foram adquiridos o áudio de pressionamento de 4 pessoas, pressionando 30 vezes cada tecla e treinado o sistema para os 6 pares possíveis formados pelos 4 microfones. O treino foi realizado tomando-se dados de 3 das 4 pessoas, deixando uma para teste. Este procedimento foi realizado 4 vezes, uma para cada pessoa cujos dados foram usados para teste.

A performance do sistema foi validada variando-se 3 parâmetros: ordem dos filtros AR (10 a 250), dimensão dos vetores de atributos (4 a 20) e o par de microfones $\{(1,2) ;(1,3) ;(1,4) ;(2,3) ;(2,4) ;(3,4)\}$. O número total de testes por par de microfones é $16.388(241 \times 17 \times 4)$. A Figura. 3.11 mostra a percentagem de testes que atingiram $100 \%$ de classificação correta. Por exemplo, o par $(1,2)$ para o atributo logLIT obteve 15.453 classificações exatas em 16.388 testes, aproximadamente $94 \%$. Para o 


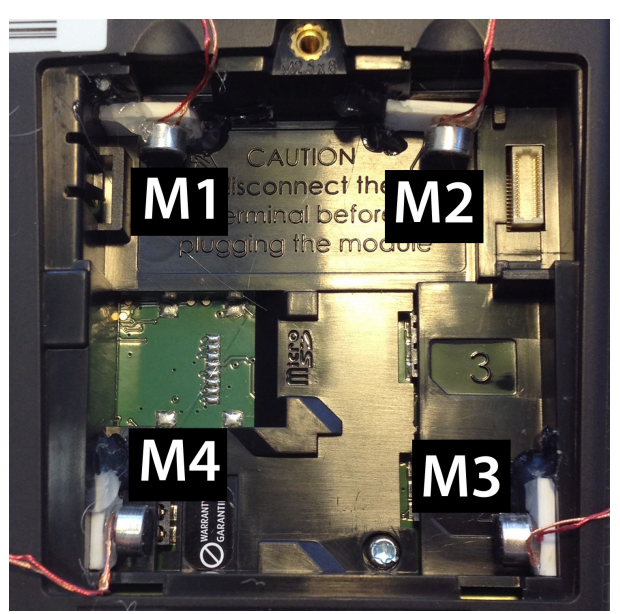

(a)

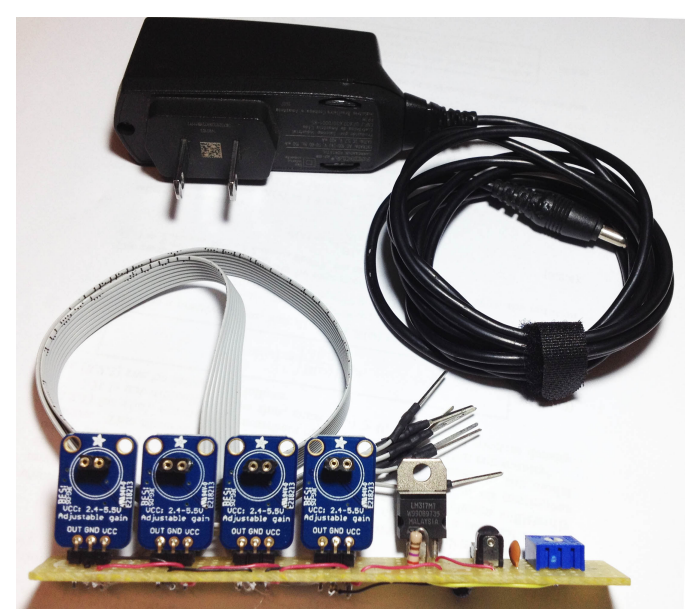

(b)

Figura 3.10: (a) Vista inferior do PIN pad Ingenico iPP320 utilizado no experimento mostrando o compartimento SAM com os 4 microfones implantados. (b) Préamplificadores Adafruit MAX4466 com ganho ajustável utilizados nos experimentos.

atributo linLIT, o mesmo par obteve 11.967 classificações exatas, aproximadamente $73 \%$.

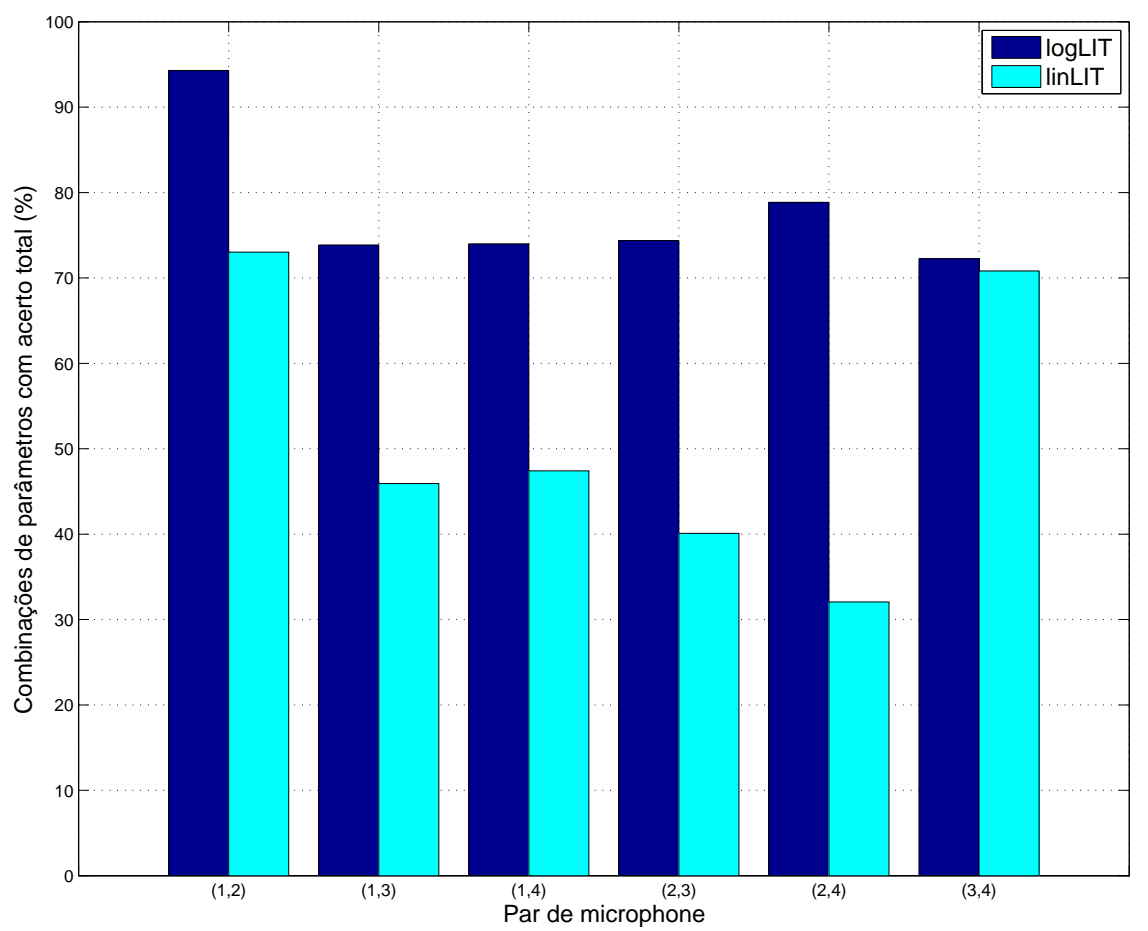

Figura 3.11: Percentagem de combinações de parâmetros que atingiram 100\% de classificação correta versus par de microfones.

Deste experimento, algumas observações se seguem: (i) todos os pares de microfo- 
nes produzem classificação com 100\% de acerto utilizando-se parâmetros adequados e (ii) o atributo logLIT produz classificação exata dentro de uma maior gama de parâmetros para todos os pares, sendo que (iii) há um par preferencial, o par (1,2). Os resultados observados na Seção 3.2 .4 indicaram que os resultados com os atributos linLIT e $\log L I T$ eram semelhantes quanto à taxas de classificação. O que observamos neste experimento é que os atributos logLIT aumentam, na média entre usuários, a faixa de parâmetros em que o ataque é bem sucedido.

\subsubsection{Experimento de ruído ambiental}

Para aferir a robustez do ataque em situações reais, realizei alguns experimentos com ruído de fundo. O equipamento Ingenico "B" foi testado com a melhor configuração de microfones de acordo com a Seção 3.2.5, i.e., o par $(1,2)$. A pessoa “1" pressionou cada uma das teclas 50 vezes em um ambiente ruidoso. A pessoa " 2 " também pressionou 50 vezes cada tecla em duas situações distintas, em um ambiente silencioso e em um ambiente ruidoso. Para ambas as pessoas, o ruído consistiu de música pop/rock contínua e distinta sendo reproduzida próximo ao PIN pad.

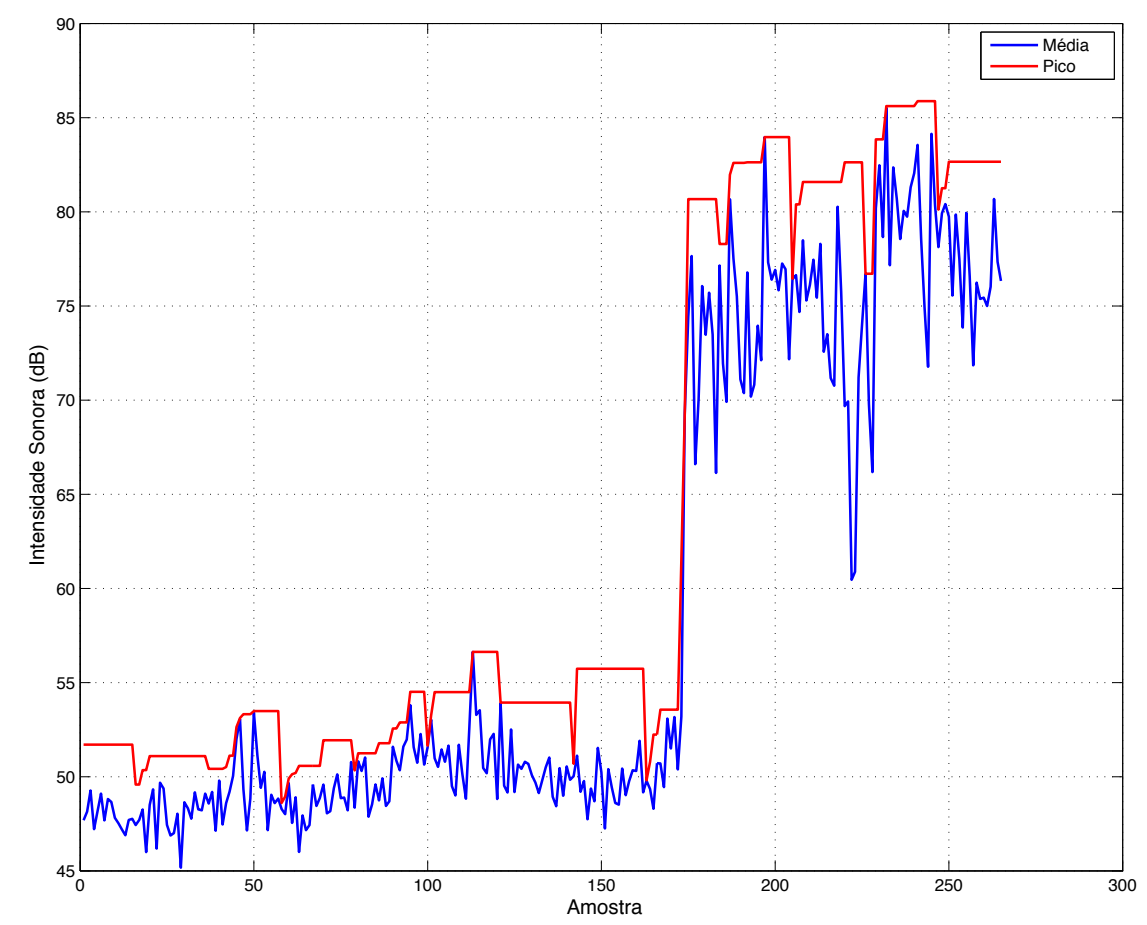

Figura 3.12: Níveis sonoros medidos ao lado do PIN pad. O plateau à esquerda corresponde ao nível ambiente sem música e o da direita com música. 
O gráfico da Figura 3.12 mostra os níveis de intensidade sonora medidos sem e com música7. O nível sonoro do ruído ambiente (70 80 dB na média) é normalmente considerado "moderado". A Tabela 3.3 apresenta os resultados de classificação dos experimentos. A coluna Treino / Teste corresponde à família de dados utilizada para treino e para teste, sendo que os números correspondem à pessoa que teclou.

Tabela 3.3: Comparação entre os métodos com ruído ambiental

\begin{tabular}{|c|c|c|c|c|c|c|c|}
\hline & \multirow[b]{2}{*}{ Treino / Teste } & \multicolumn{2}{|c|}{ PSD } & \multicolumn{2}{|c|}{ DAA Welch } & \multicolumn{2}{|c|}{ DAA LIT } \\
\hline & & $\operatorname{lin}$ & $\log$ & $\operatorname{lin}$ & $\log$ & lin & $\log$ \\
\hline Ensaio 1 & $\begin{array}{l}\text { ruído } 1 \text { / silêncio } 2 \\
\text { silêncio } 2 \text { / ruído } 1\end{array}$ & $\begin{array}{l}52 \pm 39 \\
25 \pm 36\end{array}$ & $\begin{array}{c}100 \\
83 \pm 31\end{array}$ & $\begin{array}{l}84 \pm 26 \\
73 \pm 39\end{array}$ & $\begin{array}{c}100 \\
89 \pm 25\end{array}$ & $\begin{array}{c}99.6 \pm .5 \\
88 \pm 21\end{array}$ & $\begin{array}{c}100 \\
99 \pm 1\end{array}$ \\
\hline Ensaio 2 & $\begin{array}{l}\text { ruído } 1 \text { / ruído } 2 \\
\text { ruído } 2 \text { / ruído } 1\end{array}$ & $\begin{array}{l}43 \pm 35 \\
31 \pm 33\end{array}$ & $\begin{array}{l}70 \pm 38 \\
85 \pm 32\end{array}$ & $\begin{array}{l}77 \pm 34 \\
87 \pm 30\end{array}$ & $\begin{array}{l}96 \pm 7 \\
99 \pm 2\end{array}$ & $\begin{array}{l}94 \pm 9 \\
99 \pm 1\end{array}$ & $\begin{array}{c}99 \pm 2 \\
99.8 \pm .6\end{array}$ \\
\hline
\end{tabular}

As conclusões do experimento foram as seguintes:

- Para todos os ensaios e combinações Treino/Teste, os atributos logarítmicos se mostraram superiores;

- Do "Ensaio 1", observamos que um treino com dados de silêncio não generaliza de forma adequada um ambiente ruidoso (silêncio 2 / ruído 1), exceto para o atributo logLIT. Já um treino com ruído (ruído 1 / silêncio 2) generaliza perfeitamente bem um ambiente silencioso, para todos os métodos com atributos logarítmicos;

- Do "Ensaio 2", observamos que treinos com dados de ruído generalizam de forma adequada um ambiente também ruidoso, mas apenas para o método DAA $\log (\log$ WELCH e $\log \mathrm{LIT})$;

- De todos os atributos testados, logLIT se mostrou superior aos demais.

Em suma, o ataque tem maiores chances de ser bem sucedido quando o treino é realizado em ambiente ruidoso e com atributos logLIT.

\footnotetext{
${ }^{7} \mathrm{O}$ nível sonoro foi medido com o uso do um aplicativo para iPhone "Decibel 10th" https://itunes. apple.com/br/app/decibel-10th-professional/id448155923?mt=8. Acesso em 14 Set. 2016
} 


\subsubsection{Clonagem do ataque}

Uma característica importante de um ataque é sua escalabilidade, i.e., se o mesmo pode ser replicado em escala a outros dispositivos com pouco ou nenhum retrabalho. Testamos se o ataque DAA pode ser clonado utilizando dados de treino em um equipamento e implantando a outro equipamento de mesmo modelo sem retreino dos algoritmos de aprendizado de máquina. Em vista disso, treinamos os algoritmos utilizando os pressionamentos no equipamento Ingenico " $\mathrm{A}$ " e utilizamos o mesmo para classificar os pressionamentos realizados no Ingenico "B". Os resultados obtidos foram bastante insatisfatórios de $6 \pm 7 \%$. Observamos que os pressionamentos para teclas equivalentes geram funções de transferência muito distintas.

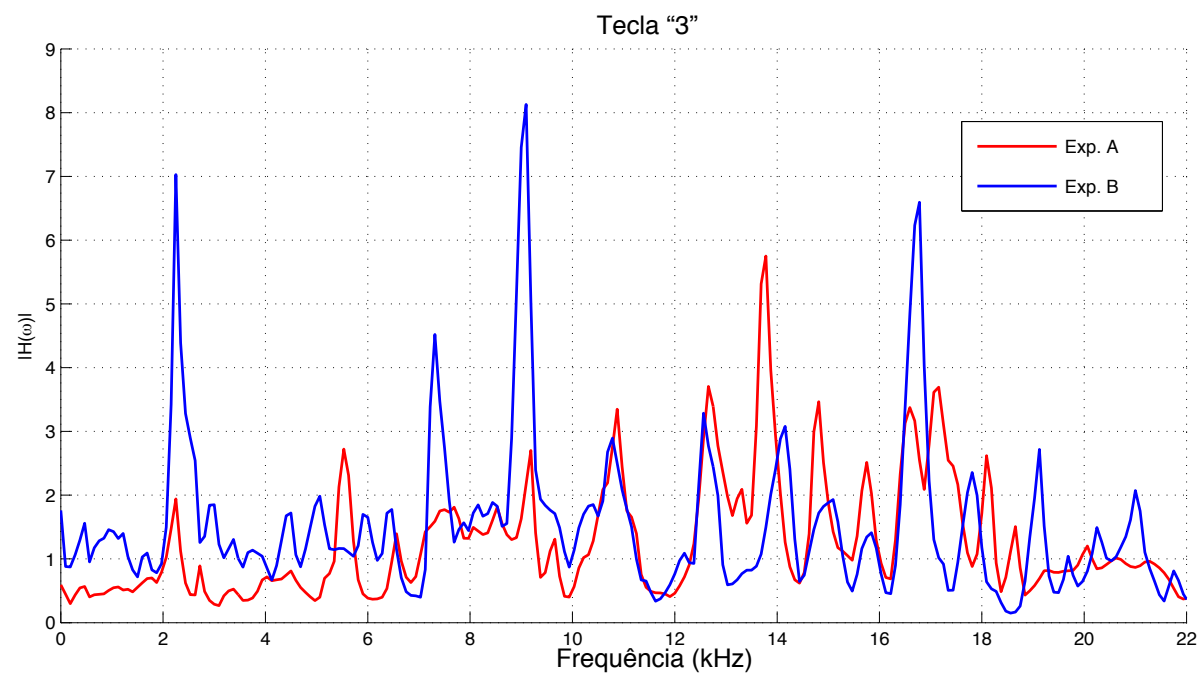

Figura 3.13: Médias das magnitudes das funções de transferência dos experimentos "A" (vermelho) e "B" (azul) para a tecla "3". Ambas as funções são muito distintas, mostrando que são específicas para cada dispositivo.

A Figura 3.13 apresenta as respostas em frequência da tecla "3" no Ingenico "A" (vermelho) e "B" (azul), que se mostraram bastante diferentes. As principais causas podem ser diferenças entre microfones e suas posições e diferenças nas teclas. De acordo com a simulação do modelo DAA apresentada no Apêndice E, percebemos que pequenas variações espaciais podem causar diferenças consideráveis nas funções de transferência. Tais especificidades impedem que o ataque seja clonado, necessitando de treino para cada terminal alvo. 


\subsection{Experimento com PIN pad Gertec PPC910}

A Figura. 3.14 apresenta outro equipamento testado, modelo Gertec PPC910 e a montagem do experimento, onde os microfones foram colados na parte interna da tampa traseira do compartimento SAM, na parte inferior do equipamento.

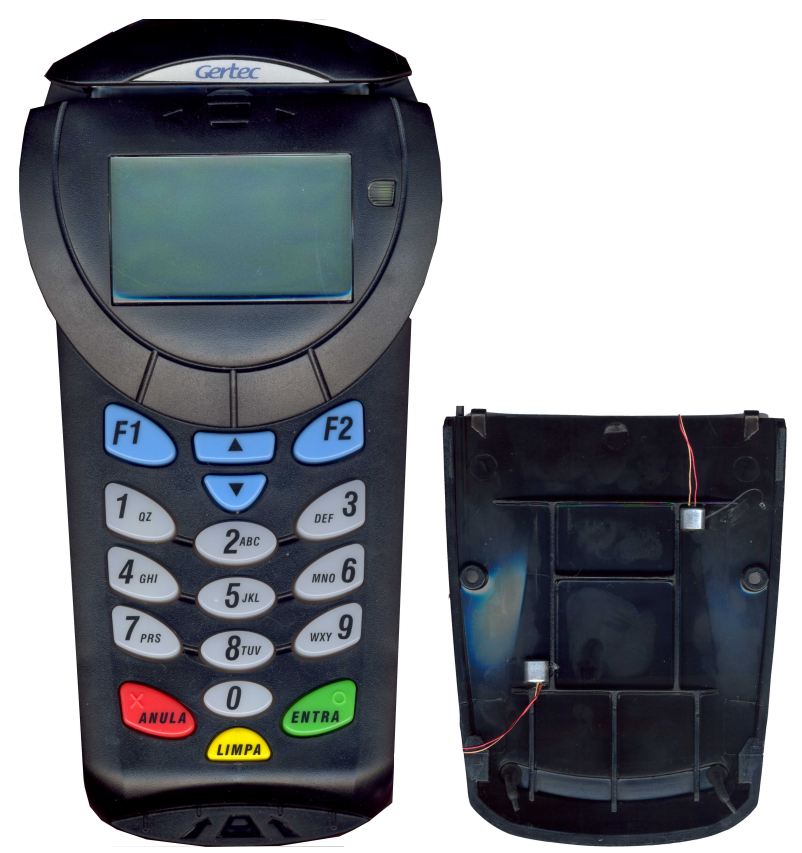

Figura 3.14: (Esq) PIN pad Gertec PPC910 utilizado no experimento. (Dir) A tampa inferior com os microfones implantados.

Para a etapa de treino, uma pessoa pressionou 70 vezes cada uma das teclas " 0 " a "9" e o aúdio de ambos os microfones foi gravado como um arquivo stéreo, com taxa de amostragem de $96 \mathrm{kS} / \mathrm{s}$. Para teste, uma outra pessoa pressionou as mesmas teclas 50 vezes.

Neste experimento, nem todos os pressionamentos puderam ser adquiridos, pois percebemos que é possível pressionar algumas teclas de modo a que a emissão acústica seja mínima, de forma que o processo de segmentação trivial utilizado não consiga capturar um pressionamento. A Figura 3.15 apresenta os módulos das funções de transferência obtidas pelo método LIT. Ainda que visualmente, observamos que as funções de transferência para uma mesma tecla apresentam uma disparidade muito maior entre os usuários do que as observadas no experimento anterior (Figura 3.7). A Figura 3.16 mostra 4 de 17 componentes principais que geraram o melhor resultado obtido, descrito a seguir. É difícil de se observar patamares distintos, como os obtidos 

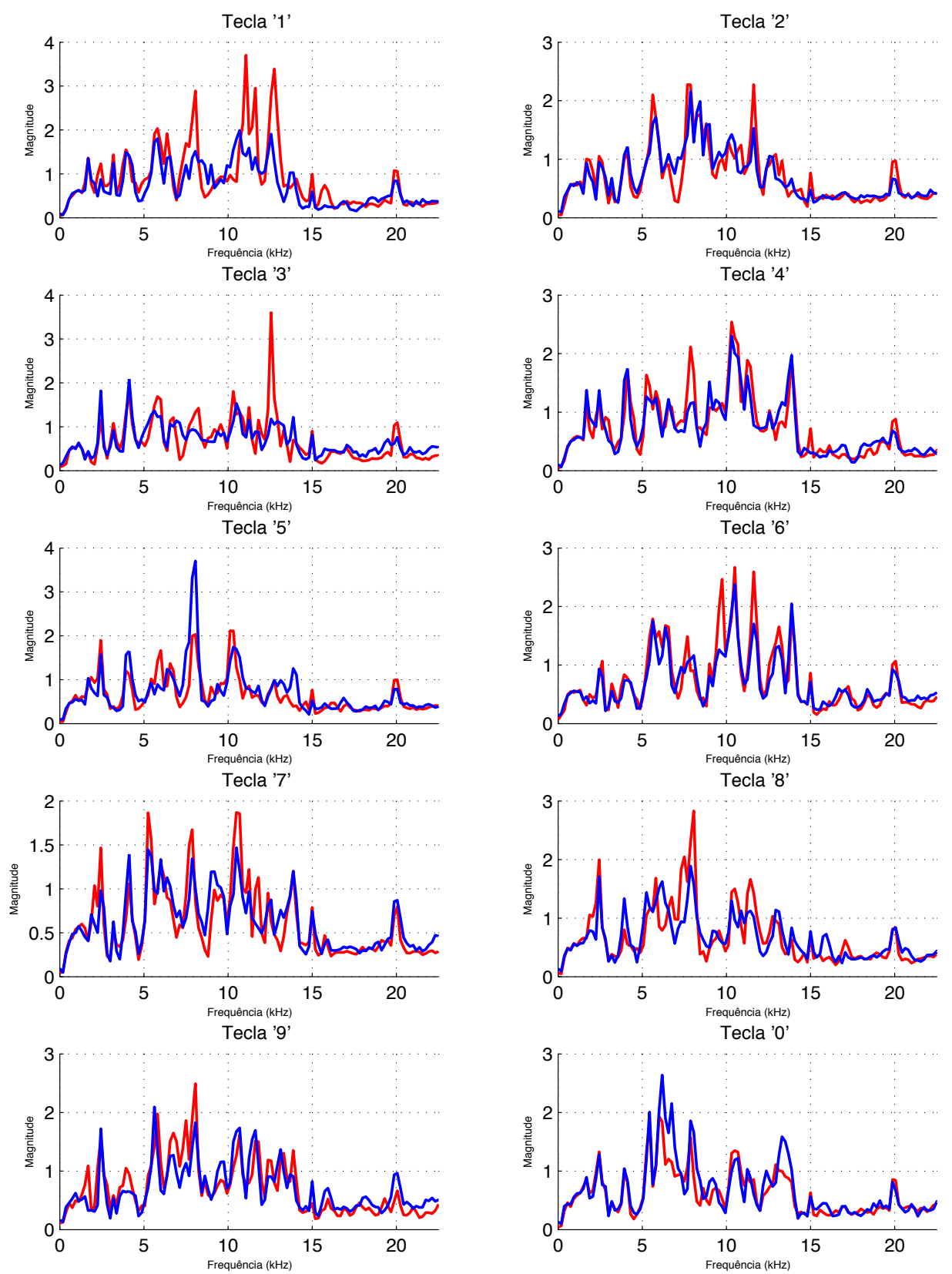

Figura 3.15: Funções de transferência obtidas neste experimento mostram visualmente uma concordância baixa entre diferentes pessoas. Cada cor corresponde a uma pessoa. Os gráficos são médias para cada tecla.

no experimento anterior (Figura 3.8). Não é razoável imaginar que, com atributos pouco discerníveis como estes, um outro algoritmo de classificação obtenha resultados muito superiores. 


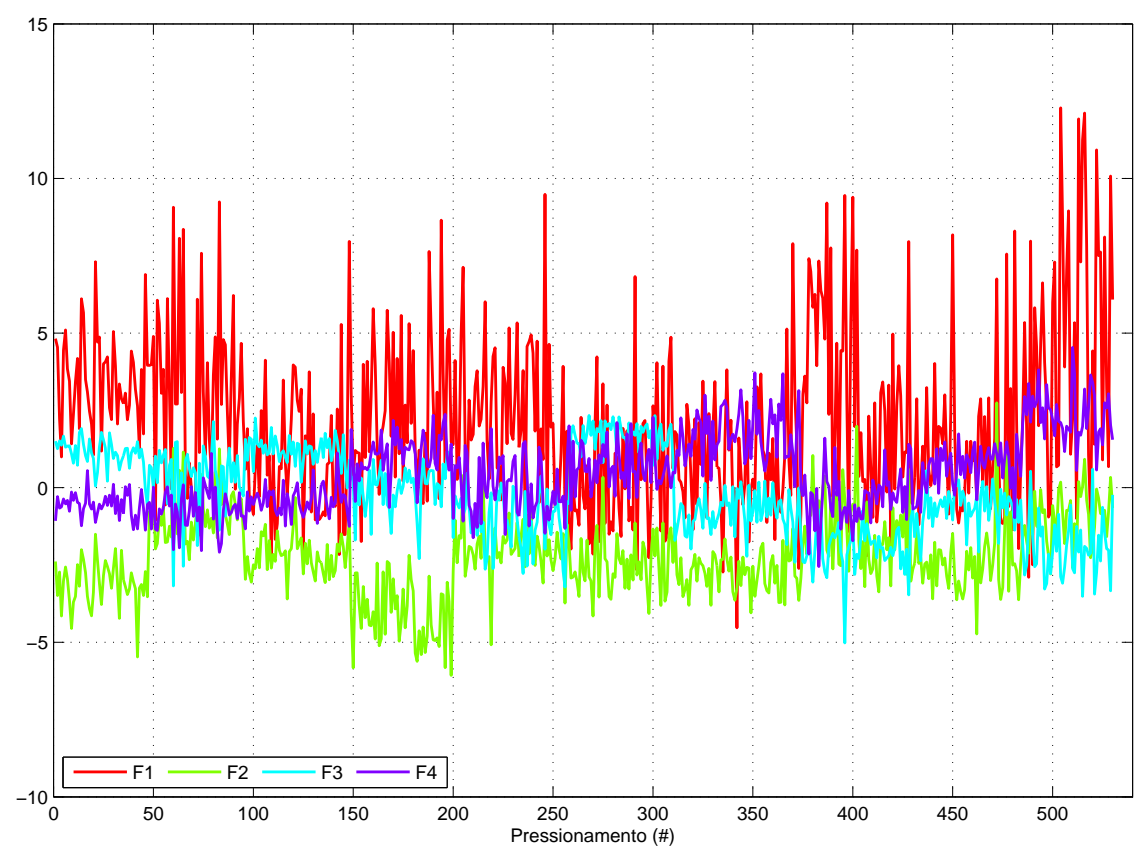

Figura 3.16: Atributos logLIT para o experimento. Apenas os 4 principais atributos são apresentados.

Tabela 3.4: Matriz de confusão do experimento Gertec - atributos logLIT

\begin{tabular}{|c|c|c|c|c|c|c|c|c|c|c|c|}
\hline$\frac{\text { Classificado } \rightarrow}{\text { Real } \downarrow}$ & 1 & 2 & 3 & 4 & 5 & 6 & 7 & 8 & 9 & 0 & $\operatorname{TPR}(\%)$ \\
\hline 1 & 47 & & & & & & & & & & 100.0 \\
\hline 2 & & 46 & & & & & & 2 & & & 95.8 \\
\hline 3 & 2 & & 51 & & & & & & & & 96.2 \\
\hline 4 & & & 2 & 35 & 5 & & 9 & & & & 68.6 \\
\hline 5 & & 11 & & 1 & 26 & & 8 & 11 & & 2 & 44.1 \\
\hline 6 & & 1 & 3 & & & 46 & & & & 2 & 88.5 \\
\hline 7 & & & & & 1 & & 57 & 5 & & & 90.5 \\
\hline 8 & & 11 & 2 & & 21 & & & 23 & & 4 & 37.7 \\
\hline 9 & 1 & 3 & 7 & 1 & 5 & 2 & & & 22 & 9 & 44.0 \\
\hline 0 & & & & & & & 1 & 3 & & 42 & 91.3 \\
\hline TPR Médio & & & & & & & & & & & $76 \pm 25$ \\
\hline
\end{tabular}

Tabela 3.5: Comparacao entre os métodos - experimento Gertec

\begin{tabular}{|c|c|c|c|c|c|c|c|}
\hline & \multirow[b]{2}{*}{ Treino/Teste } & \multicolumn{2}{|c|}{ PSD } & \multicolumn{2}{|c|}{ DAA Welch } & \multicolumn{2}{|c|}{ DAA LIT } \\
\hline & & $\operatorname{lin}$ & $\log$ & $\operatorname{lin}$ & $\log$ & $\operatorname{lin}$ & $\log$ \\
\hline \multirow{2}{*}{ Gertec } & $1 / 2$ & $20 \pm 28$ & $55 \pm 33$ & $58 \pm 29$ & $52 \pm 31$ & $70 \pm 22$ & $76 \pm 25$ \\
\hline & $2 / 1$ & $22 \pm 29$ & $42 \pm 19$ & $46 \pm 29$ & $43 \pm 29$ & $55 \pm 23$ & $53 \pm 29$ \\
\hline
\end{tabular}




\subsubsection{Análise dos resultados}

A Tabela 3.4 apresenta a matriz de confusão para o teste de maior taxa média de acertos, utilizando atributos logLIT. A taxa de reconhecimento média $(76 \pm 25 \%)$ é bastante baixa, comparada ao experimento anterior. Na verdade, a taxa real de classificação seria ainda menor se considerássemos que nem todos os pressionamentos realizados foram adquiridos na segmentação. A Tabela 3.5 mostra a acentuada superioridade do atributo logPSD sobre o linPSD, fato também observado no experimento com o PIN pad Ingenico. Os resultados dos atributos logarítmicos já não são tão proeminentes para os ataques DAA, comparados aos não logarímicos.

\subsection{Discussões e viabilidade do ataque DAA}

Os experimentos demonstram que o equipamento Ingenico iPP320 é muito mais vulnerável ao ataque DAA que o equipamento Gertec PPC910. Na verdade, o modelo Ingenico é vulnerável até ao ataque mais convencional utilizando apenas um microfone, embora aperfeiçoado via atributos logPSD. Mesmo assim, algumas teclas tiveram alta taxa de acertos no modelo Gertec. Seguem-se observações qualitativas sobre ambos equipamentos, que podem auxiliar no entendimento dos resultados obtidos:

- as teclas do Ingenico têm uma operação muito mais regular do que as do Gertec. A força usada para pressionar uma tecla no Gertec é maior e o movimento da tecla é muito instável;

- as teclas do Ingenico vazam um sonoro e inevitável clique. Se, por um lado, isso é útil como feedback acústico e mecânico para o operador (dando a certeza de que a tecla foi de fato pressionada), por outro lado, também fornece informação acústica. No entanto, o modelo Gertec pode ser pressionado de modo a que nenhum clique seja ouvido, reduzindo assim a energia do sinal de áudio, ou seja, não há informação suficiente para análise da resposta em frequência. Acredito ser esta a principal causa das baixas taxas médias de classificação para o Gertec;

- o espaço vazio do Gertec é muito mais irregular, não é quase uma caixa perfeita como o Ingenico (ver Figura 3.14 direita) e é estruturalmente mais complexa 
do que Ingenico, possuindo ranhuras. Tais características podem ter introduzido não-linearidades que afetam negativamente o modelo DAA, que é essencialmente linear.

Em todos os experimentos, o ataque DAA obteve taxas de acerto na classificação consideravelmente maiores do que o ataque por espectro de frequência, embora em certos casos os atributos logPSD tenham sido igualmente bons. Comparando-se os dois ataques DAA, o método paramétrico de estimação da resposta em frequência via Yule-Walker sempre apresentou melhores resultados que o de Welch (exceto quando ambos resultam em 100\%). Adicionalmente, o método paramétrico obteve $100 \%$ de acertos em um número de testes bastante grande e utilizando uma faixa ampla de parâmetros, como mostrado na Seção 3.2.5. Também o ataque DAA mostrou-se superior ao método espectral clássico aperfeiçoado.

Algumas sugestões de projeto, no intuito de mitigar as vulnerabilidades aos ataques acústicos podem ser adotadas. Um projeto seguro deve eliminar completamente este compartimento, utilizando outro modo de acesso aos cartões SAM. Adicionalmente, um teclado seguro não deve emitir qualquer som audível quando pressionado. É notável que muitos outros modelos de PIN pad possuam as mesmas características de projeto que levam às vulnerabilidades aqui descritas. Por exemplo, os modelos da marca Ingenico Desk/3200, iCT220, iCT250 e toda a série iPP300 8 aparentemente possuem o tipo de teclado muito semelhente ao aqui atacado, bem como possuem o compartimento SAM, fundamental para o ataque DAA.

Igualmente, cabe ressaltar que os processos de certificação ignoraram os ataques acústicos em sua análise. Como os relatórios de análise são confidenciais, não se sabe quais testes foram efetivamente realizados. Tais aspectos, relativos a normas e processos de certificação são abordados no Capítulo5

Em vista dos resultados obtidos e dos reduzidos custos envolvidos, considero o ataque DAA perfeitamente factível, indicando ainda como sistemas críticos em termos de segurança podem ter sido considerados seguros de forma não completamente justificada.

${ }^{8}$ Os dispositivos citados foram analisados apenas visualmente do website https://www. pcisecuritystandards.org/assessors_and_solutions/pin_transaction_devices. Acesso em 25 Set. 2016. 


\section{Capítulo 4}

\section{Ataque utilizando células de carga}

Diferentemente dos demais ataques abordados nesta tese, este não explora vulnerabilidades específicas dos dispositivos em si. Seu foco é em um aspecto comum a todos: a força exercida pela pessoa no ato do pressionamento. A possibilidade de um ataque dessa natureza foi sugerida por Kuhn [17]:

É improvável que roubo de informação através de canais secundários não convencionais permaneça restrito aos domínios eletromagnético, óptico e acústico. Por exemplo, um canal secundário mecânico poderia ser explorado instalando-se sensores de pressão sob os pés de um teclado, ou a mesa em que ele se encontra. O modo como os vetores das forças de cada pressionamento serão compostos irá depender da localização da respectiva tecla. Dois ou três transdutores deverão ser suficientes para distinguir e armazenar a sequência de pressionamentos, um ataque que pode ser de preocupação especial em equipamentos de inserção do PIN.$^{1}$

Kuhn levanta a possibilidade de que a natureza dos ataques poderia migrar para o que considera "forma não-convencional", sendo consideradas convencionais as pertencentes aos domínios eletromagnético, óptico e acústico ${ }^{2}$. No entanto, até onde foi a

\footnotetext{
${ }^{1}$ Information theft through unconventional side-channels is unlikely to remain restricted to the electromagnetic, optical, and acoustic domain. For example, a mechanical side-channel could be exploited by installing pressure sensors underneath the feet of a keyboard, or the table on which it rests. How the force vector of each keystroke will be split up among these anchor points will depend on the location of the respective key. Two or three attached transducers should suffice to distinguish and record keystroke sequences, an attack that may be of particular concern with trusted PIN-entry devices.

2 Conhecidos pela comunidade de inteligência militar como "EMSEC" (Segurança de Emissões).
} 
pesquisa bibliográfica, o possível ataque sugerido pelo autor não foi realizado experimentalmente. $\mathrm{O}$ ataque aqui apresentado adota a sugestão de medida de força na base em que o equipamento é colocado, e não diretamente sob os pés do mesmo. Considero que sua importância reside principalmente nos seguintes aspectos:

- Apresenta uma vulnerabilidade fracamente dependente do modelo de equipamento em si. Na verdade, a operação mesma de pressionar uma tecla é a principal vulnerabilidade do sistema;

- Mostra que uma grandeza de fácil medida como a força, uma vez decomposta, permite identificar a localização da origem da mesma;

- Demonstra que aparatos de baixíssimo custo permitem a quebra da confidencialidade da informação nesse tipo de operação, mediante técnicas adequadas de análise e classificação de sinais.

\subsection{Modelagem física do problema}

O modelo idealizado do dispositivo que realiza as medidas de força é uma pequena base retangular em que o terminal é apoiado. Em sua parte inferior, quatro medidores de força são posicionados, dando sustentação à base, como no diagrama da Figura 4.1 . O modelo físico concebido para o ataque considera as seguintes idealizações:

1. A placa é rígida, não sofrendo deflexões devido à força aplicada;

2. O pressionamento é considerado como se ocorresse na própria superfície da placa, quando na verdade ocorre no PIN pad sobre ela;

3. Apenas a força na direção normal é considerada.

A partir deste modelo, a condição de estabilidade da estrutura é dada pelas Equações 4.1 .

$$
\sum \vec{F}_{i}=\vec{F}_{p} \quad, \quad \sum\left(\vec{r}_{i} \times \vec{F}_{i}\right)=\mathbf{0}
$$


A primeira equação de 4.1 garante que a base não se desloque linearmente e a segunda equação garante que a base não rotacione, pela anulação do torque resultante. Nas equações, $\vec{F}_{i}$ são as forças medidas pelas células de carga, $\vec{F}_{p}$ é a força de pressionamento, $\overrightarrow{r_{i}}=\vec{P}-\overrightarrow{p_{i}}$ é o vetor da posição de $\overrightarrow{F_{p}}$ aos pontos de apoio da base $\overrightarrow{p_{i}}$ em que as forças $\vec{F}_{i}$ são medidas e $\vec{P}$ é o ponto de pressionamento. A origem das coordenadas adotada é o centro geométrico dos pontos de medida das células de carga (Figura 4.1).

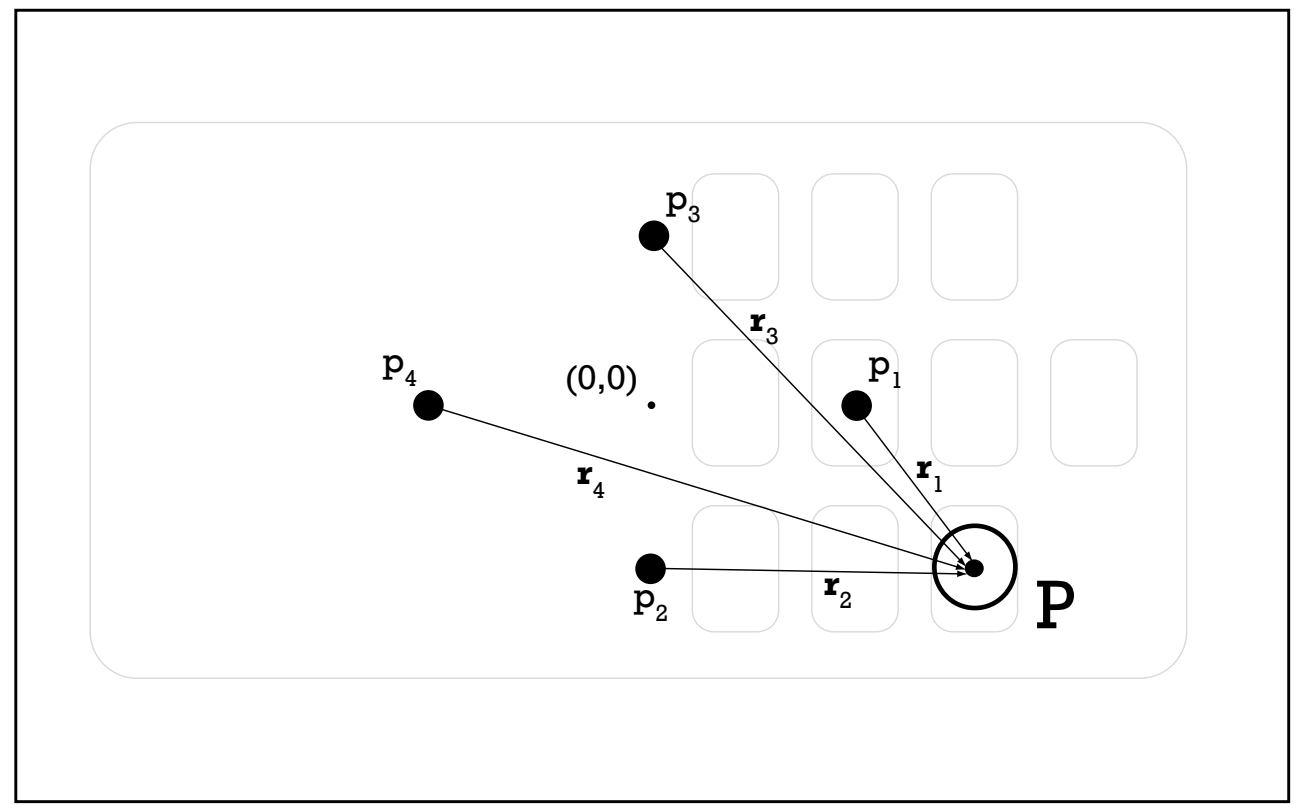

Figura 4.1: Diagrama da mesa do experimento de células de carga. Os pontos $p_{i}$ correspondem às posições das células e $\mathbf{P}$ corresponde ao ponto de pressionamento.

Assim, a posição de pressionamento $\vec{P}$ pode ser encontrada pela solução das equação dos momentos para a condição estática (sem deslocamentos e sem giros). Essa condição ocorre porque a placa reage contra o pressionamento. Na realidade, apenas a condição de anulação de torques é necessária.

Como a força de pressionamento é medida apenas na direção normal ao plano $(\vec{z})$, a solução na forma escalar é determinada por:

$$
\sum_{i} F_{i} r_{i}^{x}=0 \quad, \quad \sum_{i} F_{i} r_{i}^{y}=0 .
$$


A solução das equações acima é exata e fornece a posição em que houve o pressionamento, ou seja, o "centro de força", análogo ao "centro de massa":

$$
x=\frac{\sum_{i} F_{i} p_{i}^{x}}{\sum_{i} F_{i}} \quad, \quad y=\frac{\sum_{i} F_{i} p_{i}^{y}}{\sum_{i} F_{i}} .
$$

Deste modo, apenas o conhecimento das coordenadas das células de carga $\left(p_{i}^{x}, p_{i}^{y}\right)$ e dos valores análogos às forças $F_{i}$ são necessários para o cálculo das coordenadas de pressionamento, $(x, y)$.

\subsection{Experimento inicial}

A viabilidade de medida de força na escala de operação desejada foi testada com um primeiro experimento (Figura 4.2). O sensor de força é uma célula de carga com capacidade de $5 \mathrm{Kg}$, utilizada em balanças de cozinha domésticas digitais 3

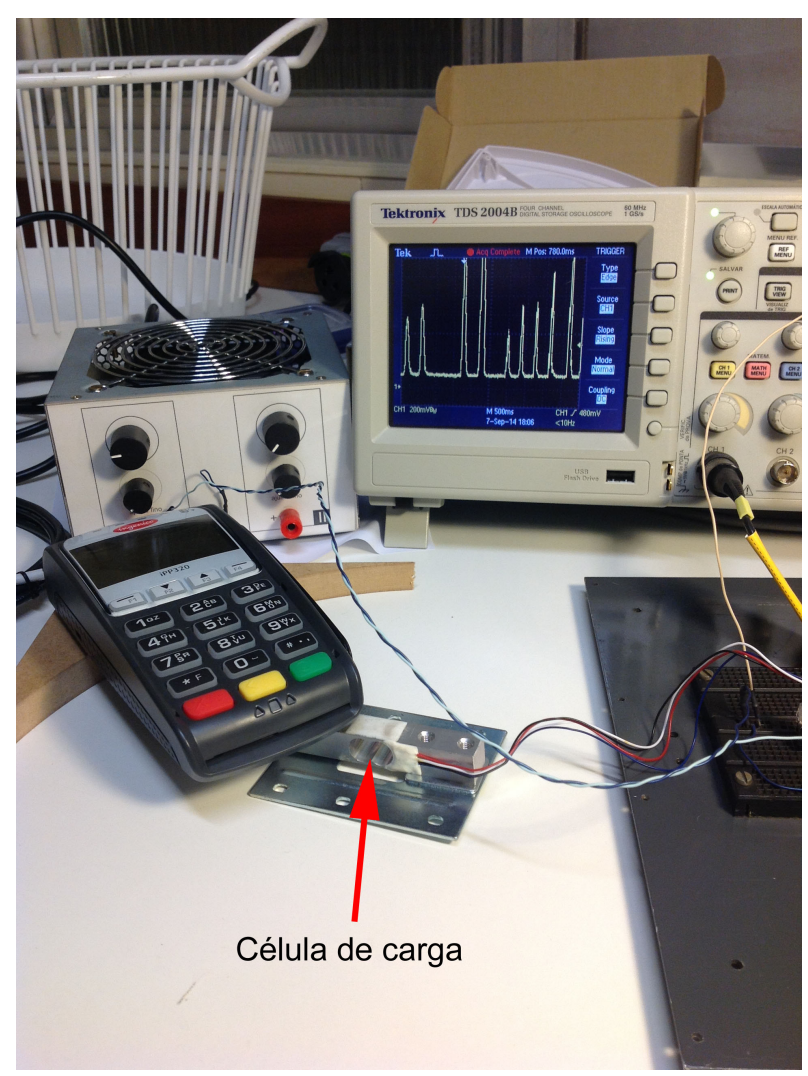

Figura 4.2: Primeiro experimento com células de carga. Os sinais do osciloscópio são de pressionamentos do PIN pad.

\footnotetext{
${ }^{3}$ Cinco balanças foram compradas para extração das células de carga, a um custo unitário de $\approx \mathrm{R} \$ 25$.
} 


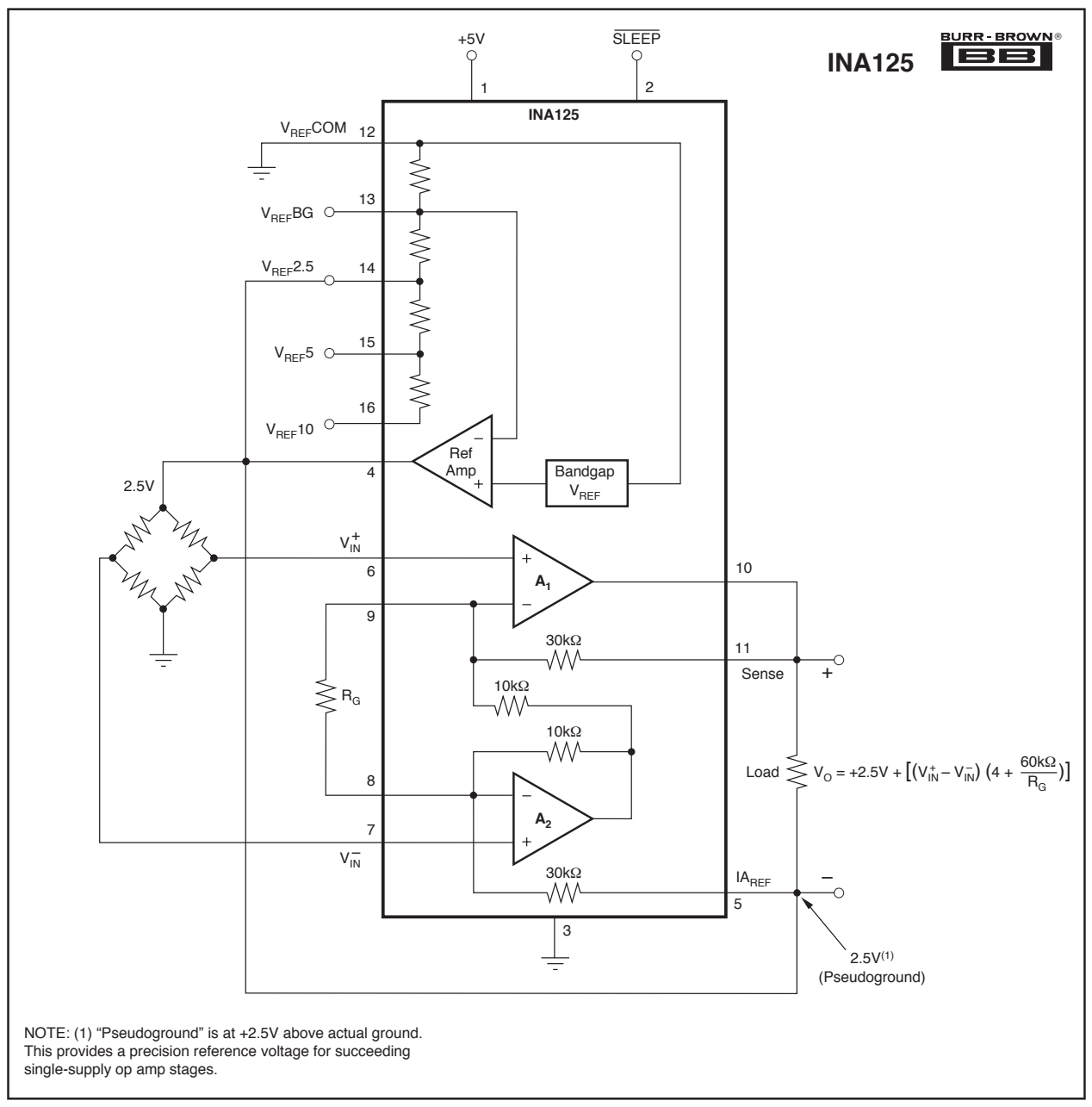

Figura 4.3: Diagrama do circuito amplificador do sinal das células de carga utilizado no experimento. $\mathrm{O}$ resistor de ganho $\mathrm{Rg} \approx 6 \Omega$ proporciona um ganho de $\approx 10.000$.

Células de carga são dispositivos dotados de strain gauges utilizados em medidas de força, torção, dilatação etc. Seu comportamento é essencialmente linear, baseado em elementos resistivos. Tais células de carga necessitam de um amplificador diferencial de alto ganho e alta $\mathrm{CMRR}_{4}^{4}$ para poder operar satisfatoriamente. A Figura 4.3 mostra o circuito do amplificador utilizado, em que a célula de carga é representada pelos quatro resistores em configuração ponte de Wheatstone, à esquerda. O ganho de tensão do amplificador para a escala de operação escolhida é de $\approx 10.000$ (80dB).

O sinal visto no osciloscópio da Figura 4.2 é aquisição de pressionamentos de teclas do PIN pad apoiado sobre a célula de carga. Uma vez que o experimento mostrou a viabilidade da medida de força com células de carga, projetei uma mesa em que quatro

\footnotetext{
${ }^{4}$ Common Mode Rejection Rate, Razão de Rejeição de Modo Comum é a taxa de rejeição de sinais comuns a ambas as entradas do amplificador diferencial, como ruídos da rede elétrica etc.
} 
células realizam a decomposição de forças de uma superfície acrílica, em que é apoiado o PIN pad.

\subsection{Extração de atributos}

Três tipos de atributos foram testados. Os dados brutos de força, os dados normalizados de força e as coordenadas calculadas pelo modelo da Equação 4.3 . Comum aos três atributos está o fato de tomarmos os valores de força no seu pico. O processo de descobrir os picos é trivial e descrito a seguir.

Sejam os vetores $z_{i}(t), 1 \leq i<4$ representando os valores de tensão elétrica correspondentes às forças adquiridos pela célula de carga $i$. O vetor de valores análogos às forças adquiridos nos picos é então calculado por:

1. Remova o valor de offset dos vetores $z_{i}(t)$, correspondendo ao repouso (sem pressionamento), gerando os vetores $\tilde{z}_{i}(t)$;

2. Calcule $Z(t)=\sqrt{\sum_{i=1}^{4} \tilde{z}_{i}(t)^{2}}$, correspondendo ao módulo das forças;

3. Descubra $M$ picos de $Z(t)$ com valor $>=\max (Z(t)) / k$, onde $k>1$ é a proporção entre o maior e o menor pico existentes. As posições dos picos serão então $t_{j}, 1 \leq j \leq M$. A restrição $t_{j+1}-t_{j}>=T_{i p}$, sendo $T_{i p}$ o tempo mínimo entre pressionamentos garante a aquisição nos máximos para cada pressionamento. Utilizamos $T_{i p} \approx 200 m s$.

\subsubsection{Atributo dados brutos de força}

O vetor de atributos de dados brutos de força, de dimensão $4 \times M$ será $F_{i j}=\tilde{z}_{i}\left(t_{j}\right)$.

\subsubsection{Atributo forças normalizadas}

Como o ato de pressionar as teclas gera um momento na plataforma, as forças nos quatro sensores devem ser decomposições da força do pressionamento, consideradas as posições relativas entre teclas e sensores. Desta forma, dado que as grandezas envolvidas são vetoriais, a idéia inicial razoável foi a normalização das forças medidas pelas 
células de carga. O vetor de atributos de forças normalizadas, de dimensão $4 \times M$ será $F_{i j}=\tilde{z}_{i}\left(t_{j}\right) / Z\left(t_{j}\right)$.

\subsubsection{Atributo modelo de coordenadas}

Os atributos gerados pelo modelo de coordenadas são calculados pelas Equações 4.3 . possuindo dimensão 2, correspondendo às coordenadas $x$ e $y$. Não se tratam de coordenadas absolutas pois não há processo algum de calibração envolvido: os sensores e amplificadores apresentam ganhos distintos, bem como não há aplicação de fator de conversão entre a tensão medida pelo sensor e seu valor em força.

\subsection{Mesa sensora I}

A mesa sensora (Figura 4.4) é composta por uma base acrílica colada em quatro parafusos afixados às células de carga.

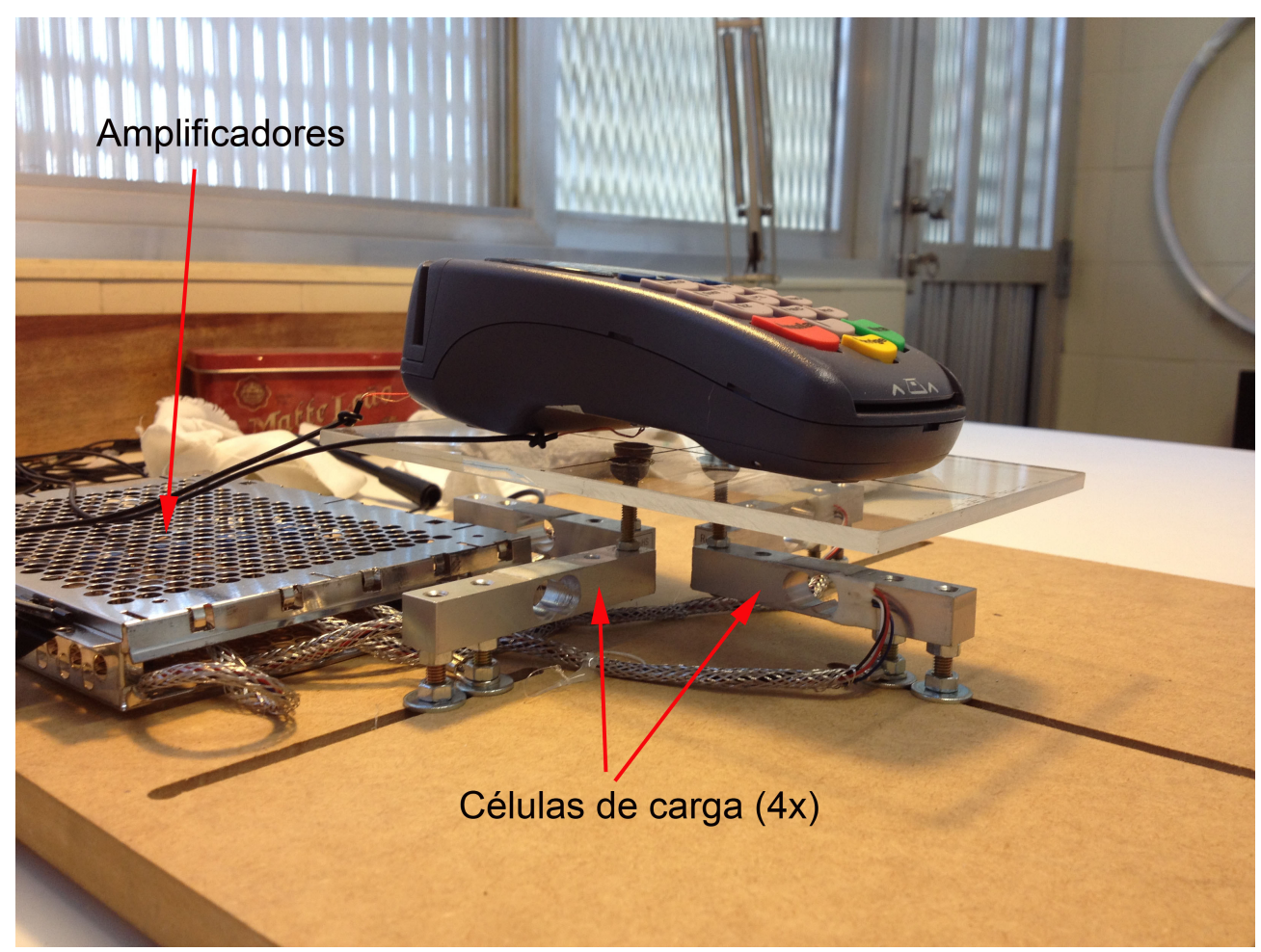

Figura 4.4: Protótipo da mesa. As células de carga são afixadas na placa acrílica com uso de pequenos pés de borracha.

O conjunto amplificador é formado por quatro circuitos idênticos ao do diagrama 
da Figura 4.3, blindados por uma caixa metálica. Tal blindagem foi necessária pois o simples movimento das mãos nas proximidades do circuito produzia oscilações indevidas nos sinais amplificados, devido ao alto ganho dos amplificadores.

\subsubsection{Resultados do experimento da Mesa I com PIN pad iPP320}

A Figura 4.5 (cima) apresenta os sinais brutos de forças e os atributos forças normalizadas correspondentes (baixo). Percebe-se uma boa invariância dos atributos (Figura) com relação à variações de amplitude dos sinais brutos de forças.
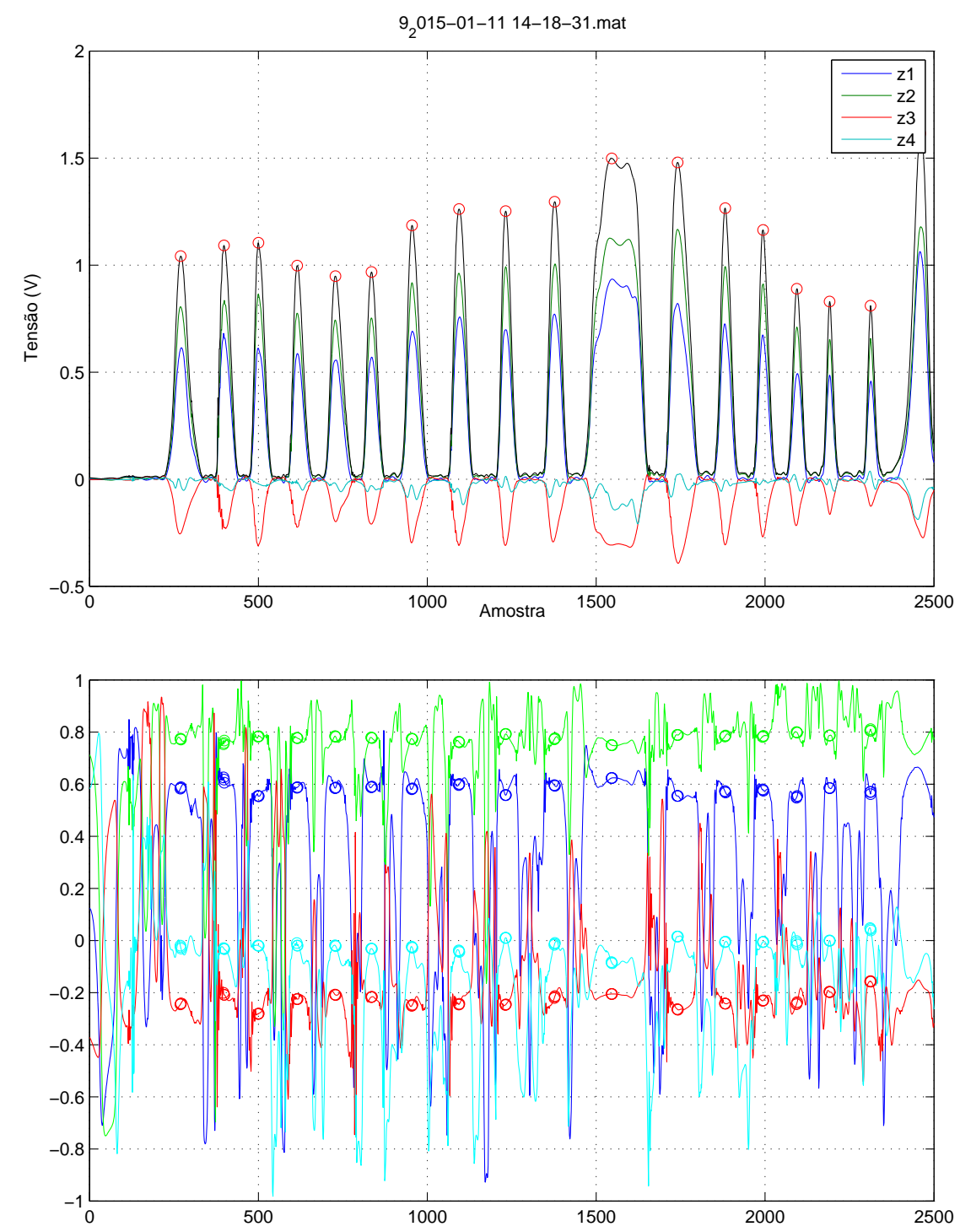

Figura 4.5: (Acima) Sinais de força obtidos no pressionamento da teclas para as quatro células de carga. (Abaixo) Atributos computados pela normalização euclideana $\left(\ell^{2}\right)$ dos valores das forças. 
A Figura 4.6 apresenta os atributos do tipo forças normalizadas para os dados de treino do experimento. Após a $\mathrm{PCA}^{5}$, observamos que embora o modelo tenha característica bidimensional, a 3a componente ainda colabora com alguma informação.

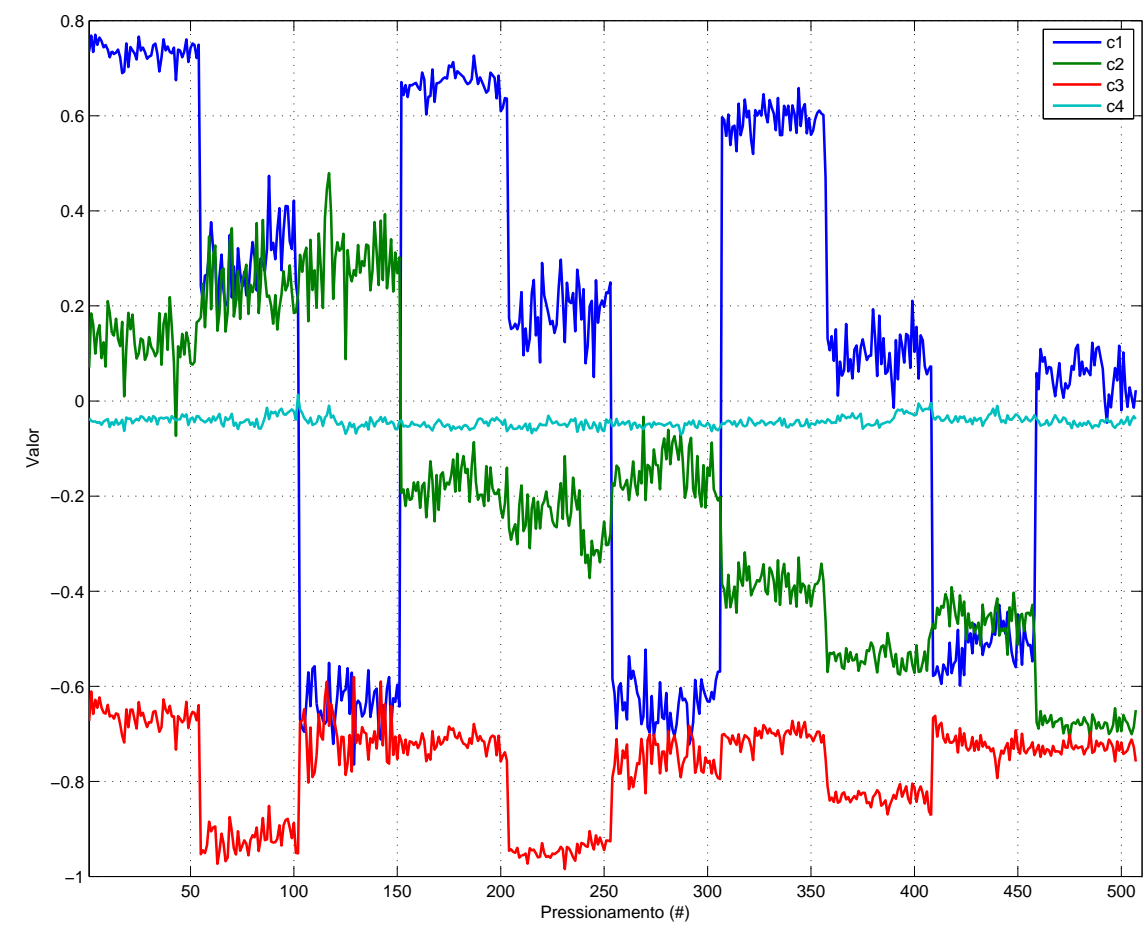

Figura 4.6: Atributos do tipo "forças normalizadas" após a PCA indicam que a informação necessária possui dimensão 3 .

A Figura 4.7 apresenta as posições estimadas relativas, com base no modelo de centro de força, dado pelas Equação 4.3. Nesta figura, dois aspectos de ordem prática precisam ser mencionados:

1. a medida de tensão elétrica correspondente à força aplicada não foi calibrada para equivaler corretamente a uma medida de força. Como consequência, $x$ e $y$ não correspondem à medidas de distância reais;

2. as constantes de amplificação não são iguais nas quatro células de carga, gerando distorção espacial.

O gráfico de posições estimadas evidencia o fato de que entre usuários há variação de posições de pressionamento, que, como veremos adiante, acarreta imprecisão na

\footnotetext{
${ }^{5}$ Uma descrição sucinta do método de redução de dimensionalidade é apresentada no Apêndice B.
} 
classificação. Tais variações são devidas ao modo como as pessoas pressionam as teclas.

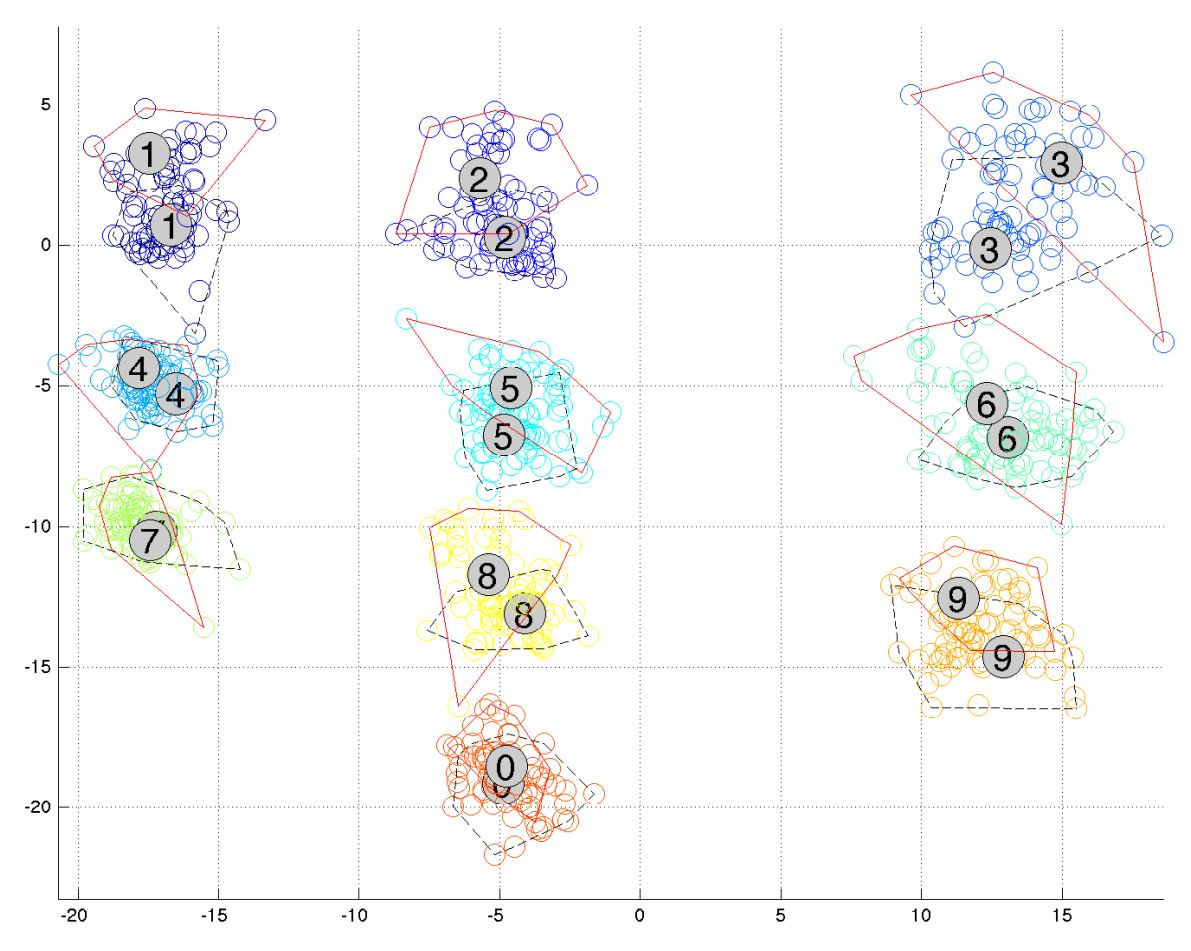

Figura 4.7: "Clusters" de coordenadas de pressionamentos de dois usuários para o experimento iPP320.

A Tabela 4.1 mostra os resultados de classificação para 3 tipos de atributos, 3 dimensões de vetores e dois classificadores. Os valores entre parênteses correspondem ao desvio padrão dos testes realizados. Os dados de treino e os dados de teste são de pessoas distintas. A rede neural possui uma camada oculta e 10 saídas, uma para cada tecla.

Observamos que o atributo "dados brutos de força" não apresenta bons resultados no geral. Os atributos "forças normalizadas" e "modelo de coordernadas" são razoalvelmente equivalentes em termos de resultados. A dimensão que obteve melhor classificação é 3, com classificador Naive Bayes e atributos "forças normalizadas". 
Tabela 4.1: Resultados de classificação - mesa sensora I

\begin{tabular}{lccccccc}
\hline & \multicolumn{3}{c}{ RNA } & & \multicolumn{3}{c}{ Naive Bayes } \\
\cline { 2 - 4 } \cline { 7 - 9 } Dim & $\mathbf{2}$ & $\mathbf{3}$ & $\mathbf{4}$ & & $\mathbf{2}$ & $\mathbf{3}$ & $\mathbf{4}$ \\
\hline Dados Brutos & $70 \pm 31$ & $89 \pm 10$ & $93 \pm 7$ & & $74 \pm 35$ & $77 \pm 33$ & $85 \pm 30$ \\
\hline Normalização & $90 \pm 12$ & $92 \pm 9$ & $91 \pm 9$ & & $93 \pm 14$ & $95 \pm 8$ & $93 \pm 14$ \\
\hline Modelo & $90 \pm 11$ & - & - & & $94 \pm 12$ & - & - \\
\hline
\end{tabular}

\subsection{Mesa sensora II}

De modo a isolar fatores adversos do experimento anterior, com vistas a melhores resultados de classificação, um novo protótipo de mesa sensora foi construído.

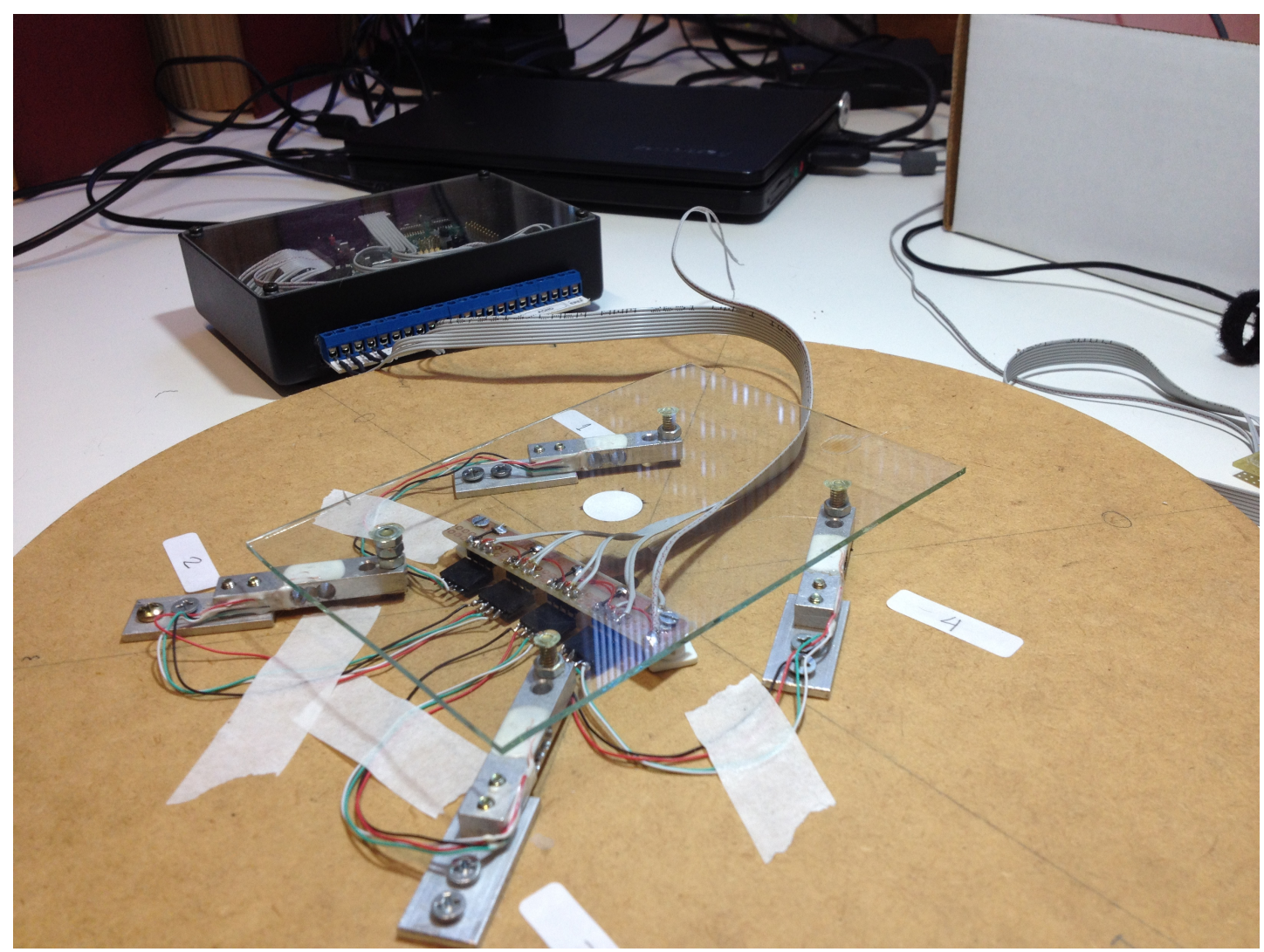

Figura 4.8: Protótipo da segunda mesa sensora com base de vidro. As tensões elétricas das células de carga de $500 \mathrm{~g}$ são medidas diretamente por um conversor A/D de 24 bits, sem uso de amplificador externo.

A segunda mesa sensora (Figura 4.8) difere da primeira nos seguintes aspectos:

- substitui a base de acrílico por vidro, de forma a reduzir possíveis flexões da mesma; 
- substitui as células de carga de $5 \mathrm{~kg}$ por células mais sensíveis, com fundo de escala de 500g;

- substitui o amplificador do sinal da célula por um conversor A/D de 24 bits com entradas diferenciais, operando na faixa $-2.5 \mathrm{~V}$ a $2.5 \mathrm{~V}$, de modo a reduzir interferências observadas devido ao alto ganho necessário na etapa amplificadora. A faixa dinâmica do sinal aumenta, trocando-se o oscilocópio de resolução em amplitude de 8 bits pelo conversor de 24 bits.

\subsubsection{Resultados do experimento da Mesa II com PIN pad iPP320}

A Figura 4.9 apresenta os atributos do tipo forças normalizadas para os dados de treino do experimento.

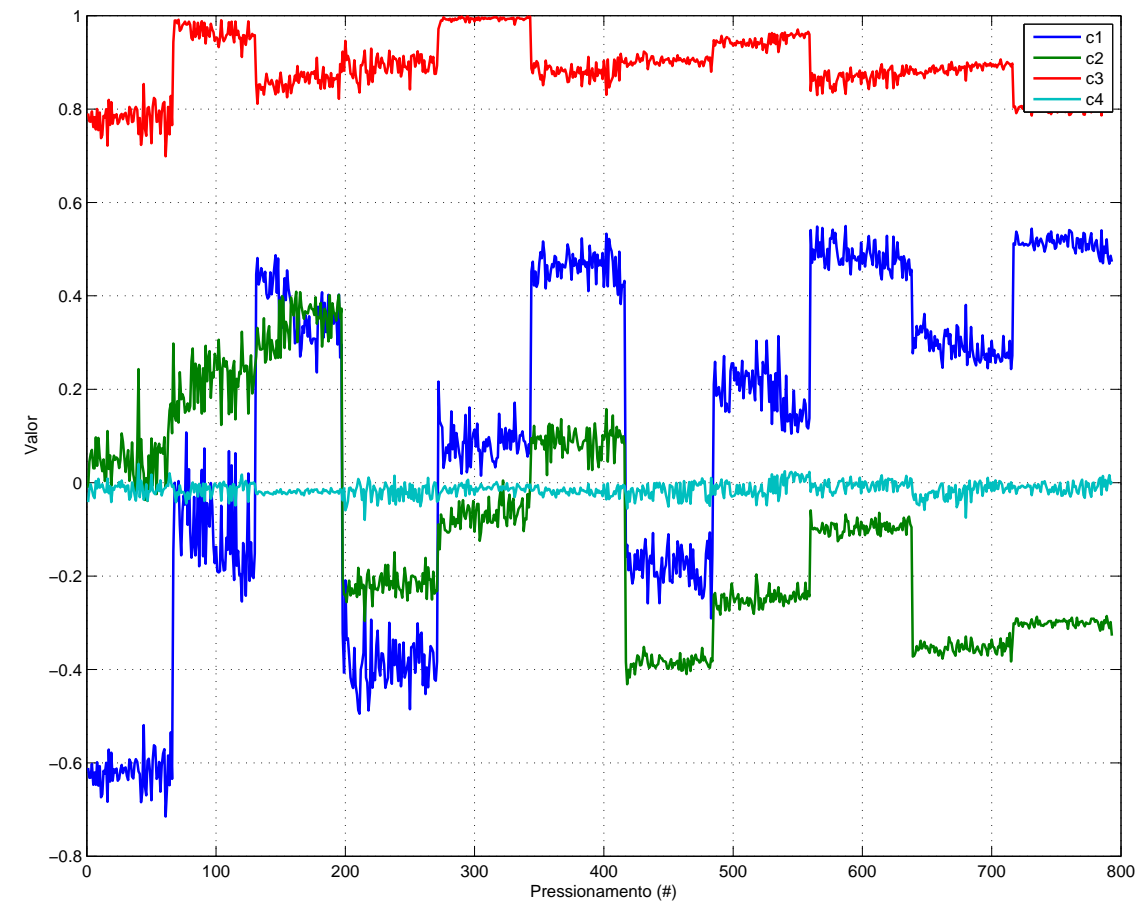

Figura 4.9: Atributos do tipo forças normalizadas após a PCA.

O experimento com o PIN pad iPP320 foi realizado na nova mesa e os resultados são apresentados na Tabela 4.2. Após a PCA, observamos que a dimensão que obteve melhor classificação é 2 , com a variância da 3 a componente sendo $2 \%$ do total. Neste experimento, o resultado de classificação para dimensão 2 é mais convincente do que para dimensão 3, pois o desvio padrão do resultado é menor para dimensão 2 (99 $\pm 1 \%$ 
vs. $99 \pm 8 \%$ ), sendo que os atributos de forças normalizadas e modelo de coordenadas ainda são equivalentes. É possível observar que de modo geral os resultados de classificação são melhores do que os obtidos anteriormente. A taxa de acertos geral aumenta de $95 \pm 8 \%$ (Mesa I) para $99 \pm 1 \%$ (Mesa II).

Tabela 4.2: Resultados de classificação - mesa sensora II

\begin{tabular}{lccccccc}
\hline & \multicolumn{3}{c}{ RNA } & & \multicolumn{3}{c}{ Naive Bayes } \\
\cline { 2 - 4 } \cline { 7 - 9 } Dim & $\mathbf{2}$ & $\mathbf{3}$ & $\mathbf{4}$ & & $\mathbf{2}$ & $\mathbf{3}$ & $\mathbf{4}$ \\
\hline Dados Brutos & $83 \pm 25$ & $96 \pm 4$ & $97 \pm 3$ & & $83 \pm 23$ & $85 \pm 20$ & $84 \pm 20$ \\
\hline Normalização & $95 \pm 6$ & $98 \pm 4$ & $97 \pm 3$ & & $99 \pm 1$ & $99 \pm 8$ & $98 \pm 2$ \\
\hline Modelo & $96 \pm 6$ & - & - & & $99 \pm 1$ & - & - \\
\hline
\end{tabular}

A Figura 4.10a mostra que há um deslocamento entre os grupos de pressionamentos, devido a fatores humanos, i.e., o modo como a tecla é pressionada tem grande importância no resultado da classificação. Tais fatores não foram modelados nos experimentos aqui desenvolvidos.

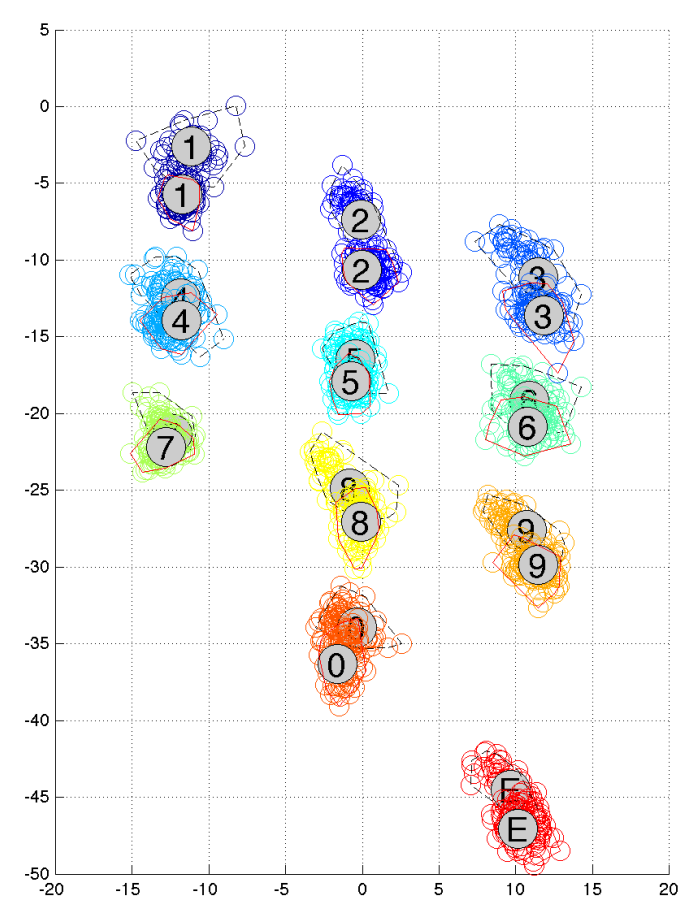

(a)

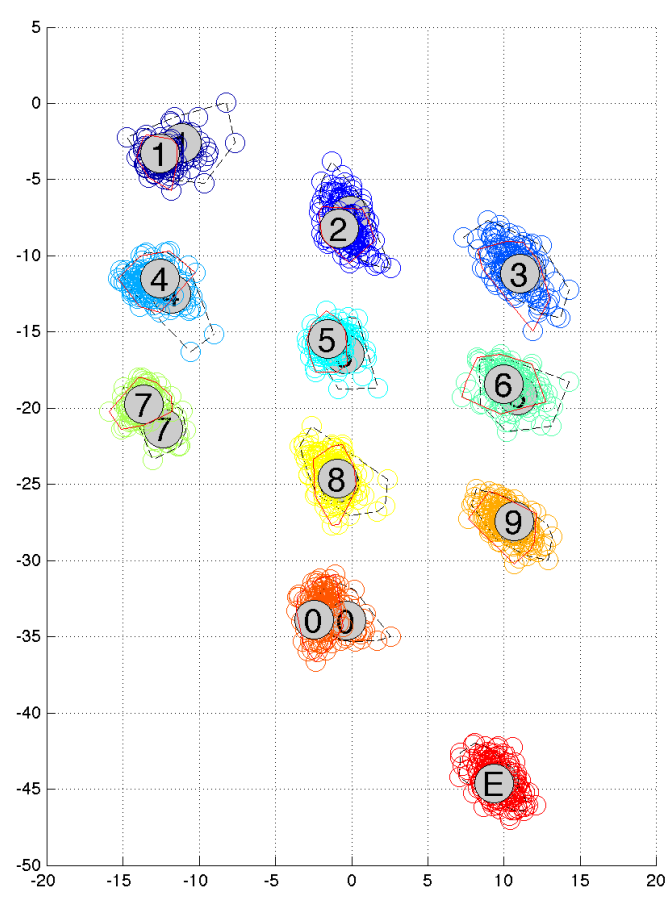

(b)

Figura 4.10: (a) As posições estimadas das teclas para dois usuários revela um deslocamento devido a fatores humanos. (b) Alinhamento a partir da tecla "E" (Confirma). 
Para comprovar o efeito de tais fatores, realizei um experimento para identificar a dependência do ângulo do dedo com que o usuário pressiona as teclas. A Figura 4.11a mostra a posição do pressionamento estimado quando o dedo é deixado pressionado e o ângulo do mesmo é alterado exageradamente em círculos. O contorno apresentado é a região convexa do trajeto realizado. Observamos que os domínios entre as teclas se sobrepõem em grande medida. A Figura 4.11bé o resultado quando o ângulo do dedo é variado apenas da direção latitudinal do equipamento, também de forma exagerada $\left(\approx 45^{\circ} \mathrm{a} \approx 90^{\circ}\right)$. O ângulo entre o dedo e a mesa acrescenta uma componente horizontal de força, alterando o centro resultante da mesma. Ou seja, o ângulo do dedo com que a pessoa pressiona a região influencia diretamente na localização do pressionamento, pois uma componente horizontal é adicionada, dividindo assim a força resultante com as células de forma distinta da de um pressionamento na normal.

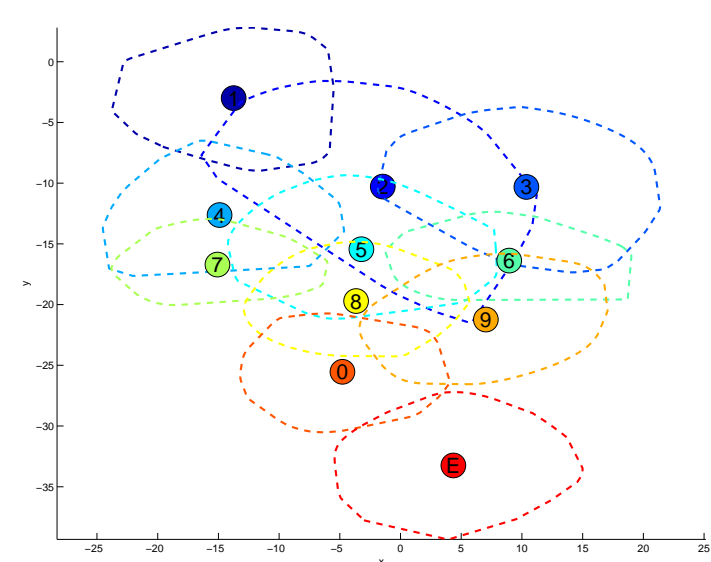

(a)

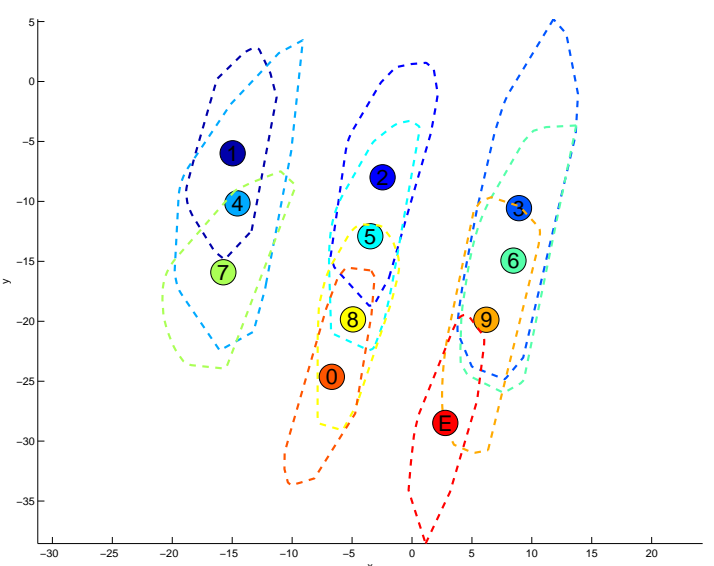

(b)

Figura 4.11: Domínios dos reconhecimentos para pressionamento (a) com o ângulo do dedo variando exageradamente em círculos (b) com o ângulo do dedo variando exageradamente apenas da direção latitudinal do equipamento.

A Figura 4.10b apresenta uma possível solução para o problema: o alinhamento de todos os pressionamentos a partir da posição da tecla "E" (enter ou confirma), dado que em toda operação esta tecla é pressionada ao final da entrada de dados, podendo ser utilizada como informação a priori . Neste caso, o resultado de classificação para o atributo "modelo de coordenadas" chega a 100\% para Naive Bayes e $99.8 \%$ para RNA. Obviamente, tal correção não resolve o problema do modo de pressionamento de forma geral. 


\subsection{Discussões e viabilidade do ataque}

A montagem da primeira mesa com os sensores aqui apresentada foi finalizada em setembro de 2014. Após quase dois anos, em abril de 2016, a empresa americana Maxim Integrated lançou um kit de desenvolvimento de GUI (Graphics User Interface) [50] (Figura 4.12) cujo princípio é o mesmo da mesa aqui descrita. O preço deste kit, no momento em que escrevo, é US\$100 FOB.

Este ataque suscita a necessidade de dois exercícios importantes, que concorreram para sua consecução. Em primeiro lugar, o exercício imaginativo da antecipação de possíveis desenvolvimentos da tecnologia e, um segundo exercício, de como a tecnologia desenvolvida para um uso específico - interface homem máquina - pode servir para outro uso, com pouca ou nenhuma alteração. A inovação é muitas vezes uma nova configuração gerada a partir do uso de blocos de soluções pré-existentes - inclusive no mundo do crime, onde se utilizam partes de eletrônica dos mais variados dispositivos, de celulares a MP3 players 6 .

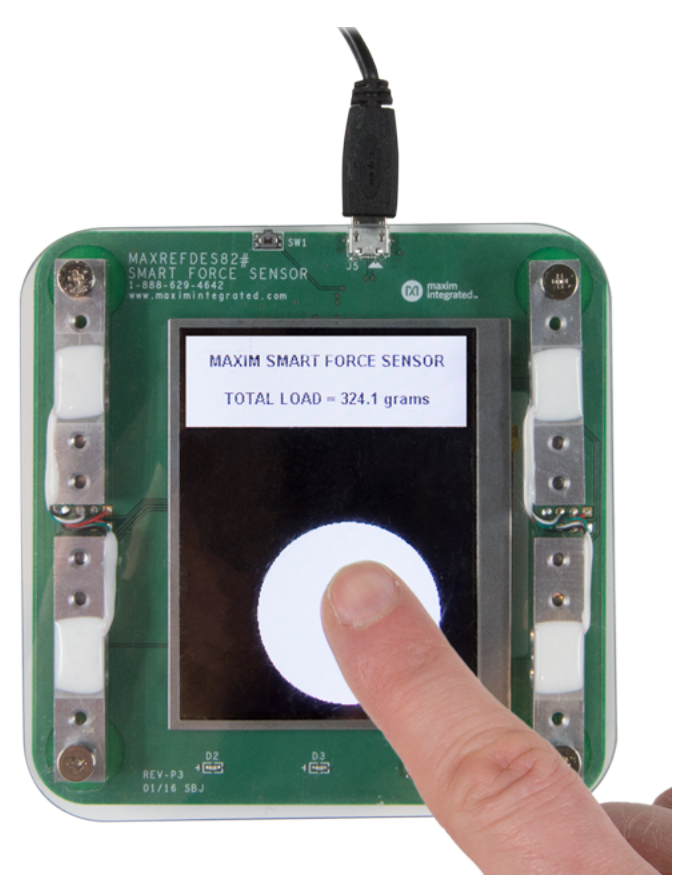

Figura 4.12: Kit de referência de projeto de interface de toque MAXREFDES82 da empresa Maxim.

\footnotetext{
${ }^{6}$ Para uma extensa galeria de skimmers veja "All about skimmers" em https://krebsonsecurity.com/all-about-skimmers/.
} 


\title{
Capítulo 5
}

\section{Normas e Processos de Certificação}

\author{
Segurança real e efetiva é ir além da conformidade [às normas] - fo- \\ cando na rápida detecção e resposta às intrusões e realizando constan- \\ temente "gap analysis" de modo a identificar e barrar vulnerabilidades \\ antes que os malfeitores possam se aproveitar delas.
}

— B. Krebs, Krebs on Security

Embora seja necessário projetar-se sistemas de segurança com muito mais cuidado, isto não é suficiente. Estes devem ser submetidos a testes hostis.

— R. Anderson e M. Kuhn, Tamper Resistance, a Cautionary Note

Este capítulo trata de aspectos normativos relevantes aos ataques realizados, baseados nas exigências do consórcio PCI (Payment Card Industry Security Standards), Common Criteria (Common Criteria for Information Technology Security Evaluation) e do padrão brasileiro Abecs (Associação Brasileira das Empresas de Cartões de Crédito e Serviços). Também trata do tema geral de “divulgação responsável de vulnerabilidades" e como esse procedimento foi adotado nas publicações das vulnerabilidades aqui relatadas. 


\subsection{A norma ISO 9564}

A norma internacional corrente que especifica princípios e técnicas de segurança mínimos de gerencimento de PIN é a ISO 9564-1:2011 "Financial services - Personal Identification Number (PIN) management and security - Part 1: Basic principles and requirements for PINs in card-based systems '11. É aplicável a instituições responsáveis por implementar mecanismos de segurança e proteção do PIN durante criação, emissão, uso e desativação. Igualmente, é dedicada a aspectos envolvendo outros equipamentos como ATMs, PIN pads, bombas de gasolina de autoatendimento etc. De qualquer forma, a consecução dos ataques aqui descritos levam à suposição de que se tratam de aspectos bastante gerais de segurança - assim como são os documentos disponíveis do PCI e Common Criteria.

\subsection{Padrões de certificação}

\subsubsection{Payment Card Industry - PCI}

De forma a padronizar práticas de segurança em sistemas e soluções de pagamento, as empresas American Express, Discover Financial Services, JCB International, MasterCard e Visa Inc. criaram o conselho denominado Payment Card Industry - Security Standards Council (PCI), que tem por propósitos manter, desenvolver e promover padrões de segurança de transações com cartãd ${ }^{2}$. Os objetivos se concretizam por meio de atividades que compreendem o desenvolvimento de requisitos técnicos para os vários e abrangentes programas de conformidade (compliance) existentes, para dispositivos de hardware e componentes de software. O PCI é responsável por certificar laboratórios responsáveis pelas análises técnicas e também por treiná-los conforme os requisitos do programa específico. Para os dispositivos alvo dos ataques aqui desenvolvidos, o programa PCI de nosso interesse é o PIN Transaction Security (PTS), ou PCI-PTS, que trata exclusivamente da segurança do PIN. O PCI mantém uma base online aberta de

\footnotetext{
${ }^{1} \mathrm{O}$ conteúdo completo da norma só é acessível mediante a compra do documento, sendo que seu custo (29 páginas, R \$627,90) http://www.abntcatalogo.com.br/norma.aspx?ID=86398 inviabilizou a possibilidade de uma análise pormenorizada. Obs.: Tal norma não consta da base conveniada USP/GEDWEB - Sistema de Gestão de Normas e Documentos Regulatórios.

${ }^{2}$ https://www.pcisecuritystandards.org/pci_security/. Acesso em 7 Abr. 2016.
} 
dispositivos certificados 3 Ambos os PIN pads aqui analisados constam como dispositivos homologados PCI.

No Brasil, um órgão representante de empresas de meios de pagamento, a Abecs mantém um programa de certificação nos moldes do PCI, possuindo uma pequena rede de laboratórios nacionais de certificação. É possível observar que os requisitos de segurança Abecs [32] são emprestados do PCI, embora com escopo reduzido apenas a equipamentos de captura de senha (terminais POS e PIN pad). Segundo o documento supracitado, a Abecs também realiza análise de conformidade de laboratórios participantes ou canditados da rede de certificação. Em suma, trata-se da associação responsável pela homologação PCI no Brasil.

\subsubsection{Common Criteria - CC}

O Common Criterid $\rrbracket^{4}$ é um corpo normativo formado por membros de vários países, cuja abrangência vai muito além do escopo do PCI, este último limitado apenas à indústria de sistemas de pagamento. Da mesma forma que o PCI, o CC possui uma coordenação no tocante à homologação de laboratórios de certificação. Dois aspectos do CC nos interessam, sendo estes alguns requisitos de teste e o cálculo de custos de ataques utilizado pelo PCI, originário do modelo CC. Uma análise da criação, escopo e limitações do Common Criteria é apresentada em [18, Cap.26].

\subsubsection{ITI/ICP-Brasil}

Os procedimentos de ensaio criados pelo órgão brasileiro Instituto Nacional de Tecnologia da Informação - IT 5 relativos à segurança física de dispositivos aplicáveis aos aqui atacados são dois: procedimentos de teste de leitoras de cartões (MCT-2) e procedimentos de testes de hardware seguro (MCT-7). Em tais documentos, recomendações de mitigação de ataques que se utilizam dos fenômenos aqui abordados são inexistentes.

\footnotetext{
${ }^{3}$ https://www.pcisecuritystandards.org/assessors_and_solutions/pin_transaction_devices

${ }^{4}$ https://www.commoncriteriaportal.org/ccra/. Acesso em 17 Jan. 2014.

5 http://www.iti.gov.br/servicos/homologacoes/85-servicos/1360-documentos. Acesso em 25 Set. 2016.
} 


\subsection{Análise dos custos dos ataques desenvolvidos}

Ambos os dispositivos utilizados nos ataques desta tese são certificados. A versão do PIN pad Ingenico iPP320 atacado é certificada de acordo com normas PCI-PTS versão 2.X (Figura 5.1] $]^{6}$ também de acordo com normas brasileiras da Abecs [32, Sec. 11.1].

\begin{tabular}{|c|c|c|c|c|}
\hline COMPANY & $\begin{array}{l}\text { APPROVAL } \\
\text { NUMBER }\end{array}$ & VERSION & $\begin{array}{l}\text { PRODUCT } \\
\text { TYPE }\end{array}$ & EXPIRY DATE \\
\hline \multicolumn{5}{|l|}{$\begin{array}{l}\text { Ingenico } \\
\text { www.ingenico.com }\end{array}$} \\
\hline \multicolumn{5}{|l|}{ iPP310, iPP320, iPP350 } \\
\hline $\begin{array}{l}\text { Hardware \#: IPP3xx-01Txxxxx } \\
\text { Firmware \#: 820305V01.xx, 820365V02.xx, } \\
\text { SRED (Non CTLS) :820157V01.xx } \\
\text { Applic \#: 820073V01.xx (OP) }\end{array}$ & 4-20142 & $2 . x$ & PED & 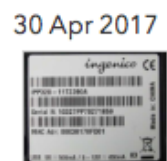 \\
\hline
\end{tabular}

Figura 5.1: Declaração de certificação PCI do equipamento iPP320.

O equipamento Gertec PPC9107 é certificado de acordo com PCI-PTS 2.X (Figura 5.2 5 , Abecs [32, Sec. 11.1] e EMV 2000 níveis 1 e 2.

\begin{tabular}{|c|c|c|c|c|}
\hline COMPANY & $\begin{array}{l}\text { APPROVAL } \\
\text { NUMBER }\end{array}$ & VERSION & $\begin{array}{l}\text { PRODUCT } \\
\text { TYPE }\end{array}$ & EXPIRY DATE \\
\hline \multicolumn{5}{|l|}{$\begin{array}{l}\text { Gertec Brasil Ltda } \\
\text { www.gertec.com }\end{array}$} \\
\hline \multicolumn{5}{|l|}{ PINPad Criptografado PPC910 } \\
\hline $\begin{array}{l}\text { Hardware \#: 700.xxxx.y, 700.xxxx.y Version } \\
1.4 \\
\text { Firmware \#: 0068_9063_008X_010Y, } \\
\text { 0080_0072_008X_01YY, } \\
\text { 0083_0074_008X_01YY } \\
\text { Applic \#: 001.ZZ AA/BB/CC }\end{array}$ & $4-20112$ & $2 . x$ & PED & 30 Apr 2017 \\
\hline
\end{tabular}

Figura 5.2: Declaração de certificação PCI do equipamento PP910.

Um requisito PCI relativo à segurança do PIN é descrito em [33, p. 14] (aqui em tradução livre):

\footnotetext{
${ }^{6}$ https://www.pcisecuritystandards.org/popups/pts_device.php?appnum=4-20142

7 http://www.gertec.com/produto.aspx/produtosdetalhe/57/PPC_910

8 https://www.pcisecuritystandards.org/popups/pts_device.php?appnum=4-20112
} 
Não deve haver um modo viável de determinar qualquer dígito do PIN inserido e transmitido internamente pela monitoração de som, emissões eletromagnéticas, consumo de energia ou qualquer outra característica externa disponível para monitoração - mesmo com a cooperação do lojista - sem que o mesmo requeira um potencial de ataque de ao menos 26 para identificação e exploração inicial e um mínimo de 13 para o uso final, como definido no Apêndice B. 9

Como citado acima, os requisitos PCI requerem que um ataque como os realizados somente seja possível a um custo igual a 26 para identificação e 13 para exploração. A metodologia de custo de testes é descrita em [33, Appendix B]. A Tabela 5.1] sumariza os fatores envolvidos nas duas etapas do ataque: "Identificação" que é a descoberta da possível vulnerabilidade e "Exploração" que é o uso do dispositivo alterado. Os fatores, comuns a ambas as etapas, são relativos a recursos humanos e materiais, como tempo do ataque, expertise etc., cada um possuindo uma faixa de valores fixos.

Tabela 5.1: Cálculo do custo dos ataques TDOA e DAA para um PIN pad

\begin{tabular}{lll}
\hline Fator & Identificação & Exploração \\
\hline Tempo do ataque & Além de 160 horas $=5.5$ & $\leq 1$ hora $=0$ \\
\hline Expertise & Expert $=4$ & Leigo $=0$ \\
\hline Conhecimento do PIN pad & Público $=0$ & Público $=0$ \\
\hline Acesso ao PIN pad & Amostras necessárias $=1$ & Amostras necessárias $=1$ \\
\hline Equipmento necessário para o ataque & Padrão $=1$ & Padrão $=1$ \\
\hline Peças específicas necessárias & Padrão $=1$ & Padrão $=1$ \\
\hline Custo total & $\mathbf{1 2 . 5}$ & $\mathbf{3}$ \\
\hline
\end{tabular}

Um requisito PCI que interessa diretamente é o TA4.9 [33, p. 15], que trata de roubo de PIN por meio de ataque acústico:

TA4.9 - O analista deverá utilizar um microfone para monitorar o sinal para cada um dos dez botões numéricos. Deverá também realizar análise de sinais e processamento de sinais para demonstrar que informação

\footnotetext{
${ }^{9}$ There is no feasible way to determine any entered and internally transmitted PIN digit by monitoring sound, electro-magnetic emissions, power consumption or any other external characteristic available for monitoring - even with the cooperation of the device operator or sales clerk - without requiring an attack potential of at least 26 for identification and initial exploitation with a minimum of 13 for exploitation, as defined in Appendix $B$.
} 
audível determinando os valores das teclas não é vazado pelo POI (equipamento). 10

Observamos que as recomendações são bastante gerais, cabendo ao laboratório certificador a tarefa de criar os ensaios específicos. Ocorre que tais ensaios são os ativos dos laboratórios, não sendo por isso divulgados e objeto de um maior escrutínio público, sendo mantidos normalmente em sigilo.

Embora os custos mínimos requeridos pelo PCI sejam 26 para identificação e exploração inicial e 13 para o uso final, os ataques TDOA (Capítulo2) e, principalmente, DAA (Capítulo 3) custam 12,5 para identificação e 3,5 para de exploração (Tabela 5.1). Uma ressalva é feita ao equipamento Gertec, cuja taxa de acerto não pode ser considerada satifatória em termos de comprometimento da confidencialidade do PIN. O ataque da mesa sensora, utilizando células de carga (Capítulo 4) não configura vulnerabilidade específica dos equipamentos, mas do ambiente operacional.

Um aspecto importante no cálculo de custo de um ataque pelo PCI é que, aparentemente, o mesmo não leva em conta o lucro potencial da exploração, isto é, um custo alto não significa necessariamante a inviabilidade do ataque, uma vez que o retorno do mesmo pode ser compensador com o passar do tempo, pagando os custos e entregando lucro. Em suma, é pouco provável que um criminoso não tenha em mente o retorno do investimento, aos moldes do que é utilizado no cálculo de finanças como Taxa Interna de Retorno, que estima a viabilidade de investimentos e projetos em geral.

O PIN pad iPP320 é certificado pelas normas do Common Criteria também. O CC possui uma nomenclatura peculiar, que será explicada na medida em que os termos próprios do CC apareçam no texto. Vários documentos utilizados no processo de certificação desse equipamento alertam contra ataques de emissão acústica, assim como o faz o PCI. Abordarei os requisitos relativos à essa vulnerabilidade, relevante ao ataque DAA. O documento Ingenico's Security Target Lite [39, sec. 4.1] é explícito no tocante a quais "ativos" devem ser certificados, sendo o PIN um destes, como esperado. É digno de nota que o nome original do documento contenha o termo Lite, ou seja, é uma versão "sanitizada", editada de forma a retirar informação considerada confi-

\footnotetext{
${ }^{10}$ TA4.9 - The tester shall use a microphone to monitor the signal for each of the ten numeric buttons. The tester shall perform signal analysis and signal processing as necessary to demonstrate that audible information determining key-press values is not leaked by the POI.
} 
dencial, como afirmado pelo próprio órgão responsável pelo processo [40, sec. 13]. Especificamente, a informação que o documento omite é relativa ao Protection Profile, que consite dos requisitos de segurança, suas razões e o nível de segurança devido (EAL). Um Security Target é o refinamento de um Protection Profile para um dado alvo de avaliação [18, p. 874].

Sobre esse grau de confidencialidade, Ross Anderson, afirma que um Protection Profile ou um Security Target sanitizados não são confiáveis, colocando o banco ou o correntista (potenciais vítimas em caso de fraude) em uma situação injusta, por não terem acesso ao que de fato foi certificado [55]. Ainda o documento Ingenico's Security Target Lite na seção 8.1.1.1 afirma:

O dispositivo sendo avaliado não deverá emitir:

- PCI A6: som, emissões eletromagnéticas, consumo de energia ou qualquer outra característica externa disponível para monitoração. 11

Há também um Security Objective que é item de uma hierarquia do Protection Profile utilizado [42] que reitera [39, sec. 5.1]:

O TOE deve prover a funcionalidade de proteger a confidencialidade do PIN durante sua inserção (p.e. contra manipulações do teclado do usuário, pressionamento sendo visto, sons do teclado sendo distinguidos ou emanações do teclado sendo distinguidas. ${ }^{12}$

O Relatório de Certificação [40, p. 27] afirma que um outro documento é utilizado no processo, o Joint Interpretation Library - Application of Attack Potential to POIs, apresentando os sons de teclado como vulnerabilidade [41, sec. 3.10]:

Um exemplo de ataque "Completo" seria a monitoração de sons do teclado pois este ataque compromente diretamente o PIN. .. ${ }^{13}$

\footnotetext{
${ }^{11}$ The TOE shall not emit:

- PCI A6: sound, electro-magnetic emissions, power consumption or any other external characteristic available for monitoring. O termo TOE significa Target of Evaluation, ou seja, o objeto sendo avaliado.

${ }^{12}$ The TOE shall provide the functionality to protect the confidentiality of the PIN during PIN entry (e.g. against manipulations of the Cardholder keypad, key presses being seen, key sounds being distinguished or key emanations being distinguished.

13 An example of a "Complete" attack would be to monitor keyboard sounds as this attack directly compromises the PIN...
} 
Dos documentos referenciados acima, podemos concluir que ataques baseados em emissões acústicas estão explicitamente cobertos por requisitos de ambos os corpos normativos, PCI e CC. O ataque de TDOA não consta do corpo de normas. Adicionalmente, podemos concluir também que os dispositivos atacados foram avaliados pelos órgãos de certificação de acordo com tais requisitos. No entanto, o processo de certificação falhou em identificar a vulnerabilidade aqui explorada pelo ataque DAA. Uma vez que não há relatórios públicos descrevendo quais técnicas foram aplicadas na avaliação de emissões acústicas, não temos como saber exatamente onde o processo falhou, em todos os laboratórios de certificação aos quais foi submetido, credenciados PCI, CC e Abecs.

\subsection{Divulgação responsável de vulnerabilidades}

A divulgação de vulnerabilidades é um aspecto crítico na área de segurança. A publicação de resultados, dependendo do impacto da descoberta, pode envolver as partes em situações delicadas até legalmente. A quem descobre, não é razoável ou suficiente adotar a postura que pode ser considerada ingênua-altruísta, ainda que ética, de que "divulgando a vulnerabilidade estarei auxiliando a melhoria do produto e isso é bom para todos, não há razão para preocupações”. Na verdade, há. Um caso que envolveu a academia e se tornou conhecido na área de segurança em 2010 foi a divulgação de uma vulnerabildade no protocolo EMV que levou representantes de bancos na Inglaterra a tentar retirar do site a dissertação de Mestrado do aluno da Universidade de Cambridge, Omar Choudary. A resposta foi dada no documento Responsible disclosure and academic freedom ${ }^{14}$. Felizmente, a universidade se opôs a tal tentativa.

O tópico "Divulgação Responsável de Vulnerabilidades" (Responsible Vulnerabilities Disclosure) vem justamente para tentar estabelecer boas práticas para esse processo. É um tema de intensa discussão no meio de segurança de sistemas. É relativo às práticas (legais inclusive) de divulgação de vulnerabilidades, uma vez descobertas. Um documento público em fase draft sobre o tema é a RFC Responsible Vulnerability Disclosure Process $\sqrt{15}$, de autoria de Steve Christey. Transcrevo o resumo deste

${ }^{14}$ http://www.cl.cam.ac.uk/ rja14/Papers/ukca.pdf Acesso em 20 Jun. 2015.

15 https://tools.ietf.org/html/draft-christey-wysopal-vuln-disclosure-00. Acesso em 30 Set. 2016. 
documento, pois este descreve de forma direta o propósito do tema:

Novas vulnerabilidades em produtos de software e hardware são descobertas e publicadas diariamente. A divulgação de informação de vulnerabilidades tem sido um tópico polêmico há anos. Durante o processo de divulgação, muitos fornecedores, pesquisadores em segurança e outros agentes seguem uma variedade de diretrizes informais e não escritas de como interagem e trocam informações. Alguns deles podem não estar cientes dessas diretrizes ou podem ignorá-las intencionalmente. Este estado de coisas pode tornar difícil a obtenção de um resultado satisfatório para quem usa ou é afetado por informação de vulnerabilidades. O propósito deste documento é descrever boas práticas para um processo de divulgação que envolva os divulgadores, os fornecedores ou mantenedores, terceiros, comunidade de segurança e, finalmente, clientes e usuários. ${ }^{16}$

Tal documento evoluiu gerando a norma ISO/IEC 29147:2014, que (tradução minha):

Oferece diretrizes para a divulgação de vulnerabilidades potenciais em produtos e serviços online. Detalha métodos os quais o fornecedor deva usar para tratar de assuntos relacionados à divulgação de vulnerabilidades.

É possível que tal norma seja um caminho a ser seguido por profissionais de segurança, sendo recomendado seu conhecimento. Entretanto, nesta tese, tal caminho não foi seguido, tendo sido adotada prática do Grupo de Segurança do Laboratório de Computação da Universidade de Cambridge, a mim recomendada pelo professor Ross Anderson:

\footnotetext{
${ }^{16} \mathrm{New}$ vulnerabilities in software and hardware products are discovered and publicized on a daily basis. The disclosure of vulnerability information has been a divisive topic for years. During the process of disclosure, many vendors, security researchers, and other parties follow a variety of unwritten or informal guidelines for how they interact and share information. Some parties may be unaware of these guidelines, or they may intentionally ignore them. This state of affairs can make it difficult to achieve a satisfactory outcome for everyone who uses or is affected by vulnerability information. The purpose of this document is to describe best practices for a responsible disclosure process that involves vulnerability reporters, product vendors or maintainers, third parties, the security community, and ultimately customers and users.
} 
O caminho correto para lidar com riscos legais é divulgar o artigo aos órgãos reguladores e não ao fabricante. Pessoalmente, eu enviaria uma cópia ao US Federal Reserve, à UK Financial Conduct Authority e talvez ao responsável local pelo sistema Common Criterid ${ }^{17}$

Não foi possível identificar a existência de um órgão responsável pela certificação Commom Criteria no Brasil. Deste modo, um email descrevendo o assunto com uma cópia do artigo Identification of Pressed Keys by Acoustic Transfer Function [5] foi enviado para os seguintes destinatários, incluindo uma cópia à autoridade bancária federal:

- Fed: Rick Sullivan <rick.j.sullivan@kc.frb.org>

- FCA: Sarah McKenzie <Sarah.McKenzie@fca.org.uk>

- Visa: Vaibhav Garg <me@ vaibhavgarg.net>

- Banco Central do Brasil: Stanislaw Zmitrowicz <stanislaw.zmitrowicz@ bcb.gov.br>

Tal comunicação com os órgãos reguladores tem o intuito de proteger o pesquisador/laboratório de possíveis sanções legais impetradas contra a divulgação das vulnerabilidades encontradas.

\footnotetext{
${ }^{17}$ R. Anderson, comunicação pessoal.
} 


\section{Conclusões}

As pessoas que lidam com gerenciamento de riscos levam em consideração apenas as coisas arriscadas que as prejudicaram no passado (dado seu enfoque em "evidências"), sem perceberem que, no passado, antes de aqueles eventos acontecerem, tais ocorrências prejudiciais não tinham qualquer precedente, escapando aos padrões.

— Nassim N. Taleb, Antifrágil, p.424

Nesta tese, demonstrei que o uso de ferramentas de aprendizado de máquina na análise de sinais de sensores tornam possíveis novos ataques a dispositivos de entrada de dados confidenciais. Para isso, vários fenômenos físicos foram explorados e diversos tipos de atributos derivados destes foram desenvolvidos e analisados, com vistas à sua capacidade de codificar informação. Mostrei que dispositivos complexos e possuidores de certificações podem ser vulneráveis a ataques físicos de naturezas distintas, via propagação de ondas mecânicas (ataque TDOA), via emanação acústica (ataques DAA e PSD) com resultados de reconhecimento de $100 \%$ em um modelo de equipamento, e por meio da análise de forças mecânicas (ataque por células de carga). Os experimentos demonstraram a factibilidade de novos ataques de baixo custo, contrastando com uma visão de que somente ensaios dependentes de equipamentos sofisticados permitem a obtenção de resultados importantes. Certamente, tal abordagem não pressupõe ser desnecessário o uso de equipamentos avançados para análise de segurança física. O que é demonstrado aqui é a possibilidade de laboratórios avançados negligenciarem ataques efetivos sem o uso de equipamentos elaborados. $\mathrm{O}$ ataque utilizando células de carga é um exemplo relevante sob este aspecto, no que mostra como a tecnologia desenvolvida para um uso específico - uma interface homem máquina - pode servir para outro uso, como ataque a um PIN pad, com pouca ou nenhuma alteração do dis- 
positivo. Esta é a razão principal do pré-requisito de baixo custo dos ataques aqui desenvolvidos, o exercício da imaginação.

Percebi que segurança da informação e "usabilidade" são aspectos extremamente importantes e, normalmente são mutuamente excludentes, gerando uma relação de compromisso aparentemente inescapável. Por si só, a modelagem de fenômenos físicos de dispositivos é bastante complexa e, se levarmos em conta a interação de dispositivos com seres humanos - que agem de forma naturalmente não determinística estamos frente a um grande desafio de projeto.

Ainda mais, a viabilização tecnológica da mobilidade traz o problema da segurança distribuída, isto é, garantir que a vulnerabilidade do dispositivo não aumente pelo fato deste estar sendo operado fora de um ambiente controlado ou monitorado, como uma agência bancária ou uma loja. Ainda que fosse possível um dispositivo perfeito, os resultados dos experimentos desenvolvidos mostram que a própria interação realizada com o dispositivo pode conter informação suficiente para inferir aquela que desejou-se transferir, em princípio, exclusivamente ao equipamento. $\mathrm{O}$ ataque utilizando células de carga é um exemplo, em grande medida, de independência do dispositivo.

Nesta tese, analisei apenas dispositivos de pagamento. Tal escolha deve-se ao fato destes serem de uso comum, operarem em ambiente não controlado e tratarem com informação de impacto direto nas vidas das pessoas, o dinheiro. Em processos litigiosos, a posse de certificações internacionalmente reconhecidas pode pesar contra a parte lesada, em favor do fabricante ou da empresa de meios de pagamento. Desta forma, é importante que informações de vulnerabilidade sejam publicamente conhecidas e expostas, de forma que a comunidade de pesquisadores, fabricantes, órgãos reguladores, certificadores e demais interessados adequem-se de acordo, uma vez considerada a falibilidade dos sistemas.

Os procedimentos de teste a que são submetidos os dispositivos normalmente não são acessíveis publicamente, pois tratam-se de ativos dos laboratórios que os realizam. Junta-se a isso o fato de que tais laboratórios manipulam informações de propriedade intelectual de fabricantes sob acordos mútuos de sigilo, conhecidos como nondisclosure agreements. Poderia-se questionar se tais informações deveriam ser públicas, tomando-se o princípio de Kerckhoffs como argumento principal. Na área de crip- 
tografia, um princípio bastante comum, enunciado em 1883 por Auguste Kerckhoffs afirma que "segurança por obscuridade" torna os sistemas menos seguros, isto é, os algoritmos criptográficos deveriam ser públicos e apenas a chave ser secreta. A razão seria de que tendo o algoritmo que ser sigiloso, tanto este como a chave deveriam ser mantidos em segredo e, quanto mais segredos, mais frágil o sistema se tornaria. A tendência é de que a simplicidade deste princípio seja aplicada a sistemas complexos, e não apenas a algoritmos criptográficos. Fôssemos aplicá-lo a nosso caso, os ensaios realizados pelos laboratórios deveriam ser todos divulgados, juntamente aos dados de projeto, restando apenas à(s) chave(s) criptográfica(s) do sistema a garantia de segurança. Bruce Schneier desenvolve essa linha argumentativa em [51], cuja conclusão é de que o princípio de Kerckhoffs é válido para aquilo a que se destina originariamente, ou seja, a algoritmos criptográficos, tratados como objetos matemáticos, não sendo diretamente generalizável a outros domínios.

Há muitos aspectos importantes deixados à margem ou brevemente citados nesta tese, por escolha temática. Tópicos importantes relativos a certificações são levantados apenas nos pontos em que falham, suscitando crítica. Área recente, em vias de sistematização e de extrema relevância como "Cyber Security Economics”, que analisa incentivos e desincentivos que tornam sistemas de informação mais seguros ou não, certamente desejam estudo atento dos agentes envolvidos em toda cadeia produtiva da tecnologia e da segurança de sistemas.

Deste modo, compete aos pesquisadores da área de segurança, sejam eles acadêmicos ou não, o exercício do "ensaio hostil" a que se refere Ross Anderson e Markus Kuhn em [52], onde a competição entre agências e/ou laboratórios pode ser um fator crucial para assegurar maior qualidade na segurança de sistemas que lidam com informação confidencial. 


\section{Referências Bibliográficas}

[1] G. S. Faria, H. Y. Kim, "Identificação das teclas digitadas a partir da vibração mecânica," in Anais do XXX Simpósio Brasileiro de Telecomunicações, 2012.

[2] G. S. Faria. "Identificação das teclas digitadas a partir da vibração mecânica." Dissertação (Mestrado em Sistemas Eletrônicos) - Escola Politécnica, Universidade de São Paulo, São Paulo, 2012. http://www.teses.usp.br/teses/disponiveis/3/ 3142/tde-19072013-115909/. Acesso em: 1 Ago. 2016.

[3] G. S. Faria and H. Y. Kim, "Identification of Pressed Keys From Mechanical Vibrations," IEEE T. Information Forensics and Security, vol. 8, no. 7, pp. 12211229, Jul. 2013.

[4] G. S. Faria and H. Y. Kim, "Identification of pressed keys by time difference of arrivals of mechanical vibrations," Computers \& Security, vol. 57, pp. 93-105, Mar. 2016.

[5] G. S. Faria and H. Y. Kim, "Identification of Pressed Keys by Acoustic Transfer Function," in Systems, Man, and Cybernetics (SMC), 2015 IEEE International Conference on, Hong Kong, pp. 240-245, 2015.

[6] P. Marquardt, A. Verma, H. Carter, and P. Traynor, “(sp)iPhone: decoding vibrations from nearby keyboards using mobile phone accelerometers," in Proc. 18th ACM Conf. on Computer and Communications Security, 2011.

[7] M. Hussain et. al., "The rise of keyloggers on smartphones: A survey and insight into motion-based tap inference attacks," Pervasive and Mobile Computing, vol. 25, pp. 1221-1229, Jan. 2016. 
[8] L. Zhuang, F. Zhou, and J. D. Tygar, "Keyboard acoustic emanations revisited," ACM T. Information and System Security, vol. 13, no. 1, pp. 3:1-3:26, Out. 2009.

[9] T. Schumacher, D. Straub, C. Higgins, “Toward a probabilistic acoustic emission source location algorithm: A Bayesian approach," J. Sound and Vibration, vol. 331, no. 19, pp. 4233-4245, 2012.

[10] M. Backes, M. Dörmuth, S. Gerling, M. Pinkal, and C. Sporleder, "Acoustic sidechannel attacks on printers." in Proc. of the 19th USENIX Conference on Security, pp. 307-322, 2010.

[11] Y. Berger, A. Wool, and A. Yeredor, "Dictionary attacks using keyboard acoustic emanations," in Proc. 13th ACM Conf. Computer and Communications Security, pp. 245-254, 2006.

[12] E. Tromer, "Hardware-based Cryptanalysis," Weizmann Institute of Science, Tese de Doutorado, 2007. http://tau.ac.il/ tromer/papers/tromer-phd.pdf, Acesso em Set., 2011.

[13] C. Wang, X. Guo, Y. Wang, Y. Chen, e B. Liu, "Friend or Foe?: Your Wearable Devices Reveal Your Personal PIN," in Proceedings of the 11th ACM on Asia Conference on Computer and Communications Security (ASIA CCS '16), New York, USA, pp. 189-200, 2016.

[14] L. Cai and H. Chen, "Touchlogger: inferring keystrokes on touch screen from smartphone motion," in Proc. 6th USENIX Conf. Hot Topics in Security, 2011.

[15] L. Cai, S. Machiraju, and H. Chen, "Defending against sensor-sniffing attacks on mobile phones," in Proc. 1st ACM Workshop on Networking, Systems, and Applications for Mobile Handhelds, pp. 31-36, 2009.

[16] D. Asonov and R. Agrawal, "Keyboard acoustic emanations," in Proc. IEEE Symp. Security and Privacy, pp. 3-11, 2004.

[17] M. G. Kuhn, "Compromising emanations: eavesdropping risks of computer displays," University of Cambridge, Computer Laboratory, Tech. Rep. UCAM-CLTR-577, 2003. 
[18] R. J. Anderson, Security Engineering: A Guide to Building Dependable Distributed Systems, Wiley Publishing, 2 ed., 2008.

[19] R. Duda, P. E. Hart e D. Stork Pattern Classification, John Wiley \& Sons, 2 ed., 2008 .

[20] A. Tarantola, Inverse Problem Theory and Methods for Model Parameter Estimation, SIAM, ch. 7, 2004.

[21] T. Halevi and N. Saxena, "A Closer Look at Keyboard Acoustic Emanations: Random Passwords, Typing Styles and Decoding Techniques," in Proc. of the 7th ACM Symposium on Information, Computer and Communications Security, pp. 89-90, 2012.

[22] G. H. John e P. Langley "Estimating continuous distributions in Bayesian classifiers," in Proceedings of the Eleventh Conference on Uncertainty in Artificial Intelligence, pp. 338-345, 1995.

[23] M. Ge, "Analysis of source location algorithms - Part I: Overview and noniterative methods," J. Acoustic Emission, vol. 21. http://www.ndt.net/article/jae/ papers/21-014.pdf, 2003. Acesso em: 26 Out. 2016.

[24] M. Ge, "Analysis of source location algorithms - Part II: Iterative methods," J. Acoustic Emission, vol. 21. http://www.ndt.net/article/jae/papers/21-029.pdf, 2003. Acesso em: 26 Out. 2016.

[25] K. C. Ho, Y. T Chan, "Solution and performance analysis of geolocation by TDOA," IEEE T. Aerospace and Electronic Systems, vol. 29, no. 4, pp. 13111322, Out. 1993.

[26] F. Gustafsson, F. Gunnarsson, "Positioning using time-difference of arrival measurements," IEEE International Conference on Acoustics, Speech, and Signal Processing, vol. 6, pp. 553-556, Abr. 2003.

[27] D. E. Manolakis, "Efficient solution and performance analysis of 3-D position estimation by trilateration," IEEE T. Aerospace and Electronic Systems, vol. 32, no. 4, pp. 1239-1248, Out. 1996. 
[28] W. C. Elmore, M. A. Heald, Physics of Waves, Dover, 1969.

[29] L. Meirovitch, Analytical Methods in Vibrations, Macmillan, 1967.

[30] A. V. Oppenheim, R. W. Schafer Digital Signal Processing, Prentice Hall, 1975.

[31] Freescale Semiconductor - MMA7361LC: $\pm 1.5 \mathrm{~g}, \pm 6 \mathrm{~g}, 3$-Axis Analog Output Acceleration Sensor. http://www.freescale.com/webapp/sps/site/prod_summary. jsp?code=MMA7361LC Acesso em 27 Out. 2016.

[32] Associação Brasileira das Empresas de Cartões de Crédito e Serviços (Abecs), “Certificação de Segurança para Dispositivos de Captura de Senhas".

http://www.abecs.org.br/app/webroot/files/media/e/5/a/ c2c7a3ec9f30c8885125ebde3dbec.pdf. Acesso em Jun. 2016.

[33] Payment Card Industry - Security Standards Council LLC, PIN Transaction Security (PTS) Point of Interaction (POI) Modular Derived Test Requirements 5.0, Set. 2016.

[34] S. Drimer, S. J. Murdoch and R. Anderson, "Thinking inside the box: systemlevel failures of tamper proofing," in Proc. IEEE Symp. on Security and Privacy, pp. 281-295, 2008.

[35] D. Havelock, S. Kuwano, M. Vorländer Handbook of Signal Processing in Acoustics, Springer, vol. 1, 2008.

[36] D. Havelock, S. Kuwano, M. Vorländer Handbook of Signal Processing in Acoustics, Springer, vol. 2, 2008.

[37] S. M Kay Modern Spectral Estimation - Theory \& Application, Prentice Hall, chap. 4, 1988.

[38] P. Stoica e R. L. Moses Spectral Analysis of Signals, Prentice Hall, 2005.

[39] Ingenico Group, "IPP3xx Security Target Lite - ICO-OPE-00719-V1-EN.” https://www.bsi.bund.de/SharedDocs/Downloads/DE/BSI/Zertifizierung/ Reporte/Reporte08/0859b_pdf.pdf?_blob=publicationFile\&v=2, Acesso em 27 Out. 2016. 
[40] BSI - Bundesamt für Sicherheit in der Informationstechnik, "Certification Report BSI-DSZ-CC-0859-2013 for Ingenico PIN Entry Device iPP320-11T and iPP350-11T with Software 820305.V02.01, 820365.V02.06 from Ingenico S.A." https://www.bsi.bund.de/SharedDocs/Downloads/DE/BSI/Zertifizierung/ Reporte/Reporte08/0859a_pdf.pdf?_blob=publicationFile\&v=2, Acesso em: Janeiro 2016.

[41] Joint Interpretation Working Group, “Joint Interpretation Library - Application of Attack Potential to POIs - Version 1.0 (for trial use) 9th June 2011." http://www.sogisportal.eu/documents/cc/domains/hardware_devices/poi/JILApplication-of-Attack-Potential-to-POIs-v1-0_2011_06_09-for_trial_use.pdf Acesso em 27 Out. 2016.

[42] Common Approval Scheme, "Point of Interaction Protection Profile, Version: 2.0, ANSSI-CC-PP-POICOMPREHENSIVE," 2010. http://www.ssi.gouv. fr/IMG/certificat/ANSSI-CC-cible_PP-2010-10en.pdf

[43] P. Kocher, J. Jaffe, B. Jun, "Differential Power Analysis," in Lecture Notes in Computer Science, vol. 1666, pp. 388-397, 1999.

[44] B.W. Lampson, "A note on the confinement problem" in Communications of the A.C.M., vol. 16, no. 10, pp. 613-615, Out. 1973.

[45] F. Koeune e F. Standaert, "A Tutorial on Physical Security and Side-channel Attacks," in Lecture Notes in Computer Science, vol. 3655, pp. 78-108, 2005.

[46] R. W. Shirey, RFC 4949, Internet Security Glossary, 2007. https://tools.ietf.org/ html/rfc4949. Acesso em: 1 Abr. 2016.

[47] G. Loukas, Cyber-physical attacks, Butterworth-Heinemann, 2015.

[48] A. Avizienis, J. C. Laprie, B. Randell and C. Landwehr, "Basic concepts and taxonomy of dependable and secure computing," in IEEE Transactions on Dependable and Secure Computing, vol. 1, no. 1, pp. 11-33, Jan.-Mar. 2004.

[49] G. Strang, Computational Science and Engineering, Wellesley-Cambridge, ch. 1, 2012. 
[50] Maxim Integrated, System Board 6266, MAXREFDES82\#: SMART FORCE SENSOR, 2016. https://www.maximintegrated.com/en/design/reference-designcenter/system-board/6266.html. Acesso em: 2016-04-26.

[51] Bruce Schneier, "Secrecy, Security, and Obscurity," 2002. https://www.schneier. com/crypto-gram/archives/2002/0515.html\#1, Acesso em 2016-09-26.

[52] R. Anderson e M. Kuhn, "Tamper Resistance, a Cautionary Note" in Proceedings of the 2Nd Conference on Proceedings of the Second USENIX Workshop on Electronic Commerce, vol. 2, pp 1-11., Nov. 1996.

[53] M. Wax and T. Kailath, "Detection of signals by information theoretic criteria," IEEE T. Acoustics, Speech and Signal Processing, vol. 33, no. 2, pp. 387-392, Abr. 1985.

[54] J. B. Allen and D. A. Berkley, "Image methods for efficiently simulating smallroom acoustics," J. Acoustic Soc. Am., vol. 65, no. 4, Abr. 1979.

[55] Ross Anderson, comunicação pessoal.

[56] A. Papoulis and S. Pillai, Probability, Random Variables and Stochastic Processes, McGraw-Hill, 2002. 


\section{Apêndice A}

\section{Correlação Cruzada Normalizada}

Seja o vetor $v$ com elementos $v_{i}, 0 \leq i<N$ representando os valores de aceleração adquiridos por um acelerômetro. $\mathrm{O}$ vetor de média nula $\tilde{v}$ tem elementos $\tilde{v}_{i}=v_{i}-\bar{v}$, onde $\bar{v}$ é a média de $v$. Nós utilizamos apenas vetores de média nula, pois não nos interessa componentes de aceleração estática devido à gravidade. O coeficiente de correlação entre os dois vetores é:

$$
\operatorname{corr}(\tilde{v}, \tilde{w})=\frac{\tilde{v} \cdot \tilde{w}}{\|\tilde{v}\|\|\tilde{w}\|}
$$

O coeficiente de correlação mede a similaridade linear entre os dois vetores, invariante à bias (porque os vetores tem a média subtraída) e variância (porque os vetores são normalizados).

A correlação cruzada normalizada (NCC) entre os vetores $v$ e $w$ é um vetor denotado como $\tilde{v} \otimes \tilde{w}$ cujos elementos são os coeficientes de correlação entre o vetores deslocados no tempo tempo, ignorando os elementos que não têm o par correspondente. Ele possui $2 N-1$ elementos:

$$
(\tilde{\mathbf{v}} \otimes \tilde{\mathbf{w}})_{n}= \begin{cases}\frac{\sum_{i=0}^{N-n-1} \tilde{v}_{i} \tilde{w}_{n+i}}{\sqrt{\sum_{i=0}^{N-n-1} \tilde{v}_{i}^{2} \sum_{i=0}^{N-n-1} \tilde{w}_{n+i}^{2}}}, & 0 \leq n<N \\ (\tilde{\mathbf{w}} \otimes \tilde{\mathbf{v}})_{-n}, & -N<n<0\end{cases}
$$


Note que $(\tilde{v} \otimes \tilde{w})_{0}=\operatorname{corr}(\tilde{v}, \tilde{w})$. NCC é uma medida utilizada na área de visão computacional para encontrar padrões pré-definidos em imagens, em uma operação chamada de "template matching". Utilizamos a função do MATLAB xcov ( $v, w$, ' coeff' ) para calcular a NCC. 


\section{Apêndice B}

\section{Principal Component Analysis (PCA)}

A análise de componentes principais é uma técnica amplamente utilizada que busca identificar as principais propriedades de um conjunto de dados mediante o critério de variância. Em um experimento com medidas, em princípio, pode ser difícil descobrir quais as propriendades mais importantes contidas nos dados adquiridos, devido a vários fatores. Os dados normalmente estão contaminados com ruído, podemos estar medindo mais variáveis (“dimensões”) do que o necessário para explicitar o fenômeno etc. A PCA busca identificar propriedades que sejam decorrelacionadas entre si, a partir de uma transformação linear dos dados ou medidas originais. É importante notar que a aplicação direta da técnica nem sempre é adequada em descobrir as direções de maior importância dos dados. Um exemplo clássico é quando a representação dos dados tem forma toroidal. Nesses casos particulares, alguma transformação prévia pode ser necessária. As três técnicas apresentadas nesta tese utilizam PCA como técnica de reducão de dimensionalidade. Este apêndice pretende explicar dois pontos importantes.

Primeiro ponto: o experimento do Capítulo 3, 'Ataque DAA' gerou vetores de dados brutos, ou atributos, de 512 pontos, originados pela resposta em frequência acústica. Foram criados aproximadamente 50 vetores para cada uma das 10 teclas, produzindo assim uma matriz de dimensão $512 \times 500$. Quando realizada a PCA desta matriz, apenas 9 autovalores se apresentaram relevantes, para os experimentos com os dispositivos Ingenico. Este número corresponde à quantidade de teclas menos um 11

\footnotetext{
${ }^{1}$ Tal fato é devido à extração da média dos dados no cálculo das covariâncias, perdendo assim um
} 


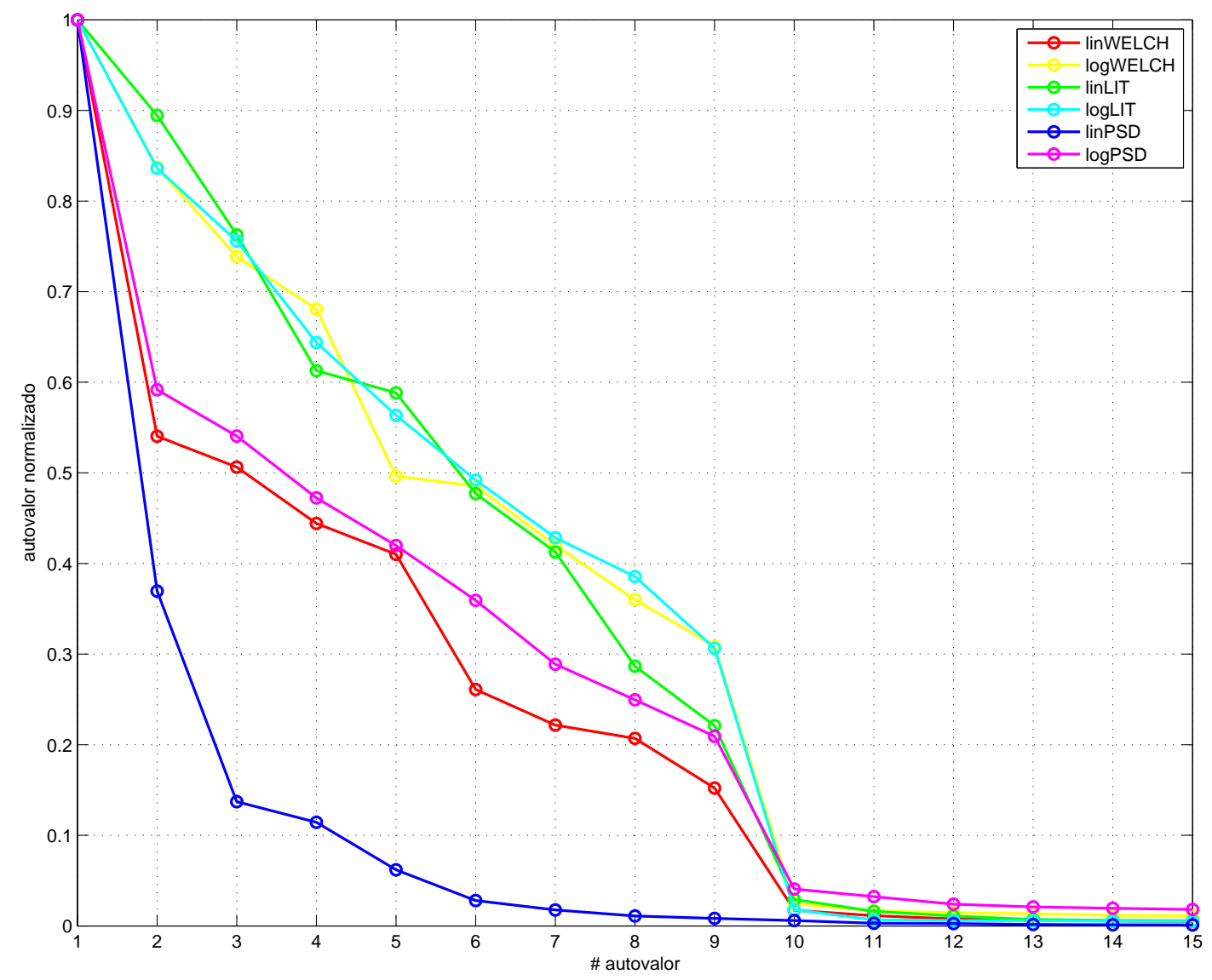

Figura B.1: Autovalores da família de dados de treino para o experimento "B".

A Figura B.1 apresenta os 15 maiores autovalores normalizados para os atributos do experimento "B" do Capítulo 3. Os atributos que possibilitaram uma classificação com acerto de $100 \%$ são os que possuem os primeiros 9 autovetores com autovalores bastante discerníveis dos subsequentes. Isto é, a diferença entre o 9ำ e 10ํa autovalores é acentuada. Apenas o atributo linPSD não satisfaz essa condição, e como consequência, não obtém boa taxa de classificação. É importante observar que nem sempre os 9 autovalores foram necessários para se obter classificação de $100 \%$, i.e., houve muitos casos em que apenas 4 componentes foram suficientes. No entanto, apenas os atributos que geraram os 9 principais autovalores bastante destacados permitiram isso.

Uma análise precipitada poderia induzir à suposição de que o número de "maiores componentes principais", ou seja, das componentes de maior autovalor, indicaria sempre a quantidade de classes de sinais existentes, neste caso, a quantidade de teclas, uma vez que cada tecla geraria atributos distintos.

grau de liberdade, ou dimensão. 
Os experimentos do Capítulo 2, 'Ataque TDOA' e Capítulo 4, 'Ataque utilizando células de carga ' geraram vetores de dados brutos de tamanho 4 e 3, respectivamente. A PCA indicou que apenas 2 atributos eram relevantes. Ou seja, neste caso, o número de classes não foi revelado pelo número de maiores autovalores. Tal fato é óbvio, dado que a dimensão inicial dos dados, 3 ou 4, já era menor do que o número de classes (=10). Este apêndice discute a razão de em um caso o número de teclas ser revelado pela PCA e em outro caso não.

Segundo ponto: haveria diferença relevante nos resultados de classificação quando a redução de dimensionalidade via PCA dos dados de teste é feita a partir dos autovetores calculados a partir dos dados de treino?

\section{B.1 O algoritmo}

Dada uma matriz $A_{m \times n}$, sendo $m$ a dimensão do vetor de atributos e $n$ a quantidade de medidas ou amostras, de média zero, a matriz de covariâncias é dada por:

$$
\Sigma_{n}=\frac{1}{n-1} A A^{\top}
$$

Realizando uma decomposição em valores singulares (SVD) de $\Sigma_{n}$ [49, p. 98], temos que os autovetores $u_{1}, u_{2}, \ldots, u_{n}$ de $\Sigma_{n}$ nos fornecem as combinações independentes de propriedades, ou atributos, em ordem de sua variância, ordenados por seus autovalores $\lambda_{1}, \lambda_{2}, \ldots, \lambda_{n}$ em ordem decrescente. Estes autovetores formam a melhor base no espaço de propriedades $\mathbb{R}^{m}$ pelo critério de minimização do erro quadrático médio. Isto significa que eles revelam a dimensão "real" do espaço das propriedades (o "posto" ou rank efetivo da matriz de covariâncias), descontando propriedades linearmente correlacionadas. Já os vetores $v_{1}, v_{2}, \ldots, v_{n}$ formam a melhor base no espaço de amostras $\mathbb{R}^{n}$. A combinação de propriedades dada pelo autovetor $u_{1}$ captura a maior variância dos dados, $\sigma_{1}^{2} /(n-1)$, correspondendo ao maior autovalor $\lambda_{1} /(n-1)$. Uma abordagem comum na escolha do número de autovalores para redução de dimensionalidade é considerar os autovetores cuja porcentagem da variância total capturada seja, 
digamos, $95 \%$, isto é, selecionar $m$ tal que

$$
\frac{\sum_{i=1}^{m} \lambda_{i}}{\sum_{j=1}^{n} \lambda_{j}} \approx .95
$$

Tal abordagem não foi utilizada aqui para "seleção de modelo" - utilizei o número de autovetores que geravam a maior taxa de acertos na classificação, via validação cruzada.

Quanto mais ruidosos os dados, menos discernível será o degrau dos autovalores que separa sinal do ruído, gerando uma matriz de covariâncias considerada de "posto completo" ou full rank [53, 49]. Neste caso é difícil identificar a dimensão efetiva do espaço. Métodos como AIC (Akaike Information Criteria) ou MDL, de Schwartz e Rissanen abordam este problema, embora obtendo resultados divergentes entre si [53].

O fato de o experimento do Capítulo 3 ter descoberto uma quantidade de autovetores com os maiores autovalores suficientemente discerníveis dos demais igual a 9 e o experimento dos outros capítulos uma quantidade igual a 2 indica que nestes últimos, a natureza dos dados permite representar todas as teclas em um espaço de dimensão 2, pois todas as amostras de forças ou atrasos das 10 teclas são combinações lineares neste espaço bidimensional. Para os experimentos de ataque acústico, a representação de cada tecla via resposta em frequência acústica (e mesmo baseada em espectro de frequências) gera seu próprio subespaço, não sendo possível descrevê-lo como combinação linear dos autovetores das outras teclas. Como forma de verificar o argumento, realizei cálculos da PCA para um conjunto de 5 teclas, obtendo os 4 maiores autovalores suficientemente discerníveis dos demais. Mas, como já afirmado, nem todas as $n-1$ componentes principais foram necessárias para uma classificação com $100 \%$ de acertos nos ataques acústicos, $\operatorname{com} n$ sendo o número de teclas.

\section{B.2 Aplicação}

Quando uma transformação linear PCA é utilizada com o objetivo de redução de dimensionalidade para classificação, um aspecto importante deve ser observado. Nos ataques aqui descritos, há sempre uma matriz de dados utilizada para treino mas nunca 
uma matriz de teste. Em uma situação real, não possuímos uma família de dados de pressionamentos da vítima do ataque, e sim apenas vetores de teste de dimensão 4 a 6, tamanhos comuns de PIN. Sendo $P$ a matriz formada pelos $n$ principais autovetores da matriz de covariâncias de treino $A A^{\top}$, a nova matriz de atributos de treino reduzida será dada por $X_{\text {treino }}=P A$. Se possuíssemos a matriz de autovetores da matriz de covariâncias de teste $B B^{\top}$, equivalentemente a nova matriz de atributos de teste reduzida será dada por $X_{\text {teste }}=Q B$. Ocorre que $P \neq Q$ e quando usamos $P$ em lugar de $Q$, os resultados da classificação podem ser bem distintos. Como exemplo, os resultados da aplicação da matriz $P$ gerou a Tabela 4.1, i.e., considerando que não possuímos uma família de dados de teste. Para o atributo "normalização" de dimensão 2, obtivemos resultados $90 \pm 12 \%$ para RNA e $93 \pm 14 \%$ para Naive Bayes. Se considerarmos todas as amostras de teste adquiridas (inexistentes em um caso de ataque real) e calculando $Q$, os resultados de classificação melhoram em valores absolutos e reduzem o desvio padrão, indo para $95 \pm 5 \%$ e $98 \pm 2 \%$, respectivamente. Não obstante, para o ataque DAA na situação real (de não possuir uma família de dados de teste), os resultados não foram prejudicados, indicando maior robustez dos atributos deste. 


\section{Apêndice C}

\section{Método do Periodograma Suavizado}

\section{de Welch}

\section{C.1 O algoritmo "tfestimate"}

A documentação do algoritmo de estimativa da função de transferência de um sistema linear, aqui utilizado via função do MATLAB tfestimate, afirma que "utiliza o método do periodograma suavizado de Welch'11 Na verdade, o método de Welch é utilizado para estimar as densidades espectrais de potência (PSD) $\hat{S}_{y x}(\omega)$ e $\hat{S}_{x x}(\omega)$, utilizadas na Equação 3.2, para cálculo de $\hat{H}(\omega)$. Já a estimação da resposta em frequência $\hat{H}(\omega)$ de um sistema linear via espectro cruzado (que é implementada por tfestimate) é conhecida na literatura pelos nomes "filtro de Wiener não causal", "estimação via erro quadrático médio" [56, Cap.13] e também como "equação de Wiener-Hopf" [38, Cap.1]. A derivação da estimação da resposta em frequência via espectro cruzado a seguir é baseada em [56, Cap.13].

Seja $y[n]$ um sinal cuja estimativa $\hat{y}[n]$ é saída de um filtro linear com entrada $x[n]$ :

$$
\hat{y}[n]=\sum_{k=-\infty}^{\infty} h[k] x[n-k] .
$$

O erro médio quadrático do estimador será mínimo se a entrada $x[n]$ for ortogonal ao erro de estimação $y[n]-\hat{y}[n]$,

${ }^{1}$ http://www.mathworks.com/help/signal/ref/tfestimate.html. Acesso em 4 Nov. 2015 


$$
E\left\{\left(y[n]-\sum_{k=-\infty}^{\infty} h[k] x[n-k]\right) x[n-m]\right\}=0,
$$

para todo $m$. Desenvolvendo o produto, chegamos a:

$$
r_{y x}[m]=\sum_{k=-\infty}^{\infty} h[k] r_{x x}[m-k] .
$$

onde $r_{y x}[m]$ é a função de correlação cruzada entre $y[n]$ e $x[n]$, e $r_{x x}[m]$ é autocorrelação de $x[n]$. Aplicando-se a transformada Z em ambos os lados da Equação C.3. chegamos à forma final $H(z)=\frac{S_{y x}(z)}{S_{x x}(z)}$. A mesma forma é observada para o caso contínuo $H(\omega)=\frac{S_{y x}(\omega)}{S_{x x}(\omega)}$. Tal equação poder suscitar o questionamento sobre a possibilidade de não haver excitação em alguma frequência no denominador, o que levaria à instabilidade de $H(\omega)$. Ocorre que os sinais medidos são naturalmente dotados de ruído. Deste modo, reescrevendo a Equação C.2 como um modelo de sinal e ruído branco aditivo $e_{x}$ de energia $\sigma_{x}^{2}$, presente na entrada $x$, e, reescrevendo a Equação C.2.

$$
E\left\{\left(y[n]-\sum_{k=-\infty}^{\infty} h[k]\left(x[n-k]+e_{x}[n-k]\right)\right)\left(x[n-m]+e_{x}[n-m]\right)\right\}=0
$$

para todo $m$. Desenvolvendo a Equação C.4. obtemos:

$$
r_{y x}[m]-\sum_{k=-\infty}^{\infty} h[k] r_{x x}[m-k]-\underbrace{\sum_{k=-\infty}^{\infty} h[k] r_{e_{x} e_{x}}[m-k]}_{h[m] \sigma_{x}^{2}}=0 .
$$

Que resulta em:

$$
H(\omega)=\frac{S_{y x}(\omega)}{S_{x x}(\omega)+\sigma_{x}^{2}}
$$

Portanto, concluímos que o próprio ruído existente no sinal $x$ limita uma possível descontinuidade em $H(\omega)$. 


\section{Apêndice D}

\section{O classificador Naive Bayes}

\section{D.1 O algoritmo Naive Bayes}

A redação deste capítulo é baseada parcialmente em [22, Sec. 2]. Seja $C$ uma variável aleatória representando a classe de uma instância e $\mathbf{X}$ um vetor de variáveis aleatórias representando valores de atributos observados. Ainda, seja $c$ o rótulo de uma dada classe e x um dado vetor de atributos observado. Dado o vetor $\mathrm{x}$ a ser classificado, utilizamos o teorema de Bayes para calcular a probabilidade de cada classe, dado o vetor de valores observados:

$$
p(C=c \mid \mathbf{X}=\mathbf{x})=\frac{p(C=c) p(\mathbf{X}=\mathbf{x} \mid C=c)}{p(\mathbf{X}=\mathbf{x})} .
$$

Na equação acima, $\mathbf{X}=x$ significa que $X_{1}=x_{1} \wedge X_{2}=x_{2} \wedge \ldots X_{k}=x_{k}$. A suposição de independência condicional entre atributos, daí o nome de "naive Bayes" permite a simplificação:

$$
p(\mathbf{X}=\mathbf{x} \mid C=c)=\prod_{i=1}^{k} p\left(X_{i}=x_{i} \mid C=c\right) .
$$

O termo $p(C=c)$ corresponde à probabilidade $a$ priori das classes. Em nosso caso, cada classe recebe a mesma probabilidade, ou seja, é não informativa. O termo $p(\mathbf{X}=\mathbf{x})$ garante que a probabilidade posterior seja unitária quando somada para todas as classes. Tal termo é irrelevante para o uso de classificação. Desta forma, a classe $c_{i}$ atribuída ao vetor de atributos $\mathrm{x}$ corresponde ao índice $i$ com o maior valor 
na Equação D.2

\section{D.2 Aplicação}

Em nosso caso, os atributos são do tipo real e as distribuições de probabilidade adotadas nos classificadores são Gaussianas. Para todos os experimentos desta tese, o procedimento computacional do MATLAB utilizado que implementa o algoritmo Naive Bayes é NaiveBayes. Tal procedimento possui duas funções, uma que realiza a estimativa dos parâmetros ${ }^{1}$ de cada classe fit (inputTreino, targetTreino) e outra que realiza a classificação predict (input Teste). Outros argumentos podem ser ajustados antes do treino, como por exemplo, o tipo de distribuição, além da normal (default).

De acordo com Duda et al. [19, p. 11], um processo ideal de extração de atributos deve tornar simples a tarefa de um classificador. De forma recíproca, um classificador poderoso não necessitaria de um método de extração de atributos sofisticado. A abordagem utilizada em todos os experimentos desta tese é a de não exigir muito do classificador, tentando entregar a este atributos já com boa capacidade discriminatória. Obviamente, tal abordagem exige um processo mais elaborado de representação e compreensão dos dados. Em vez da "inteligência" estar totalmente dependente do algoritmo de classificação, boa parte dela já é dada no processo de extração de atributos. Como exemplo, reproduzimos a seguir os gráficos dos atributos linPSD e logPSD (apenas 6 componentes principais), utilizados no ataque DAA. Para os atributos logPSD, os patamares de cada componente são praticamante constantes e com variância baixa, tornando bastante adequada a representação destes por uma distribuição normal, via uso de um classificador como Naive Bayes Gaussiano. O mesmo não ocorre para os atributos linPSD, que necessitariam de um classificador mais elaborado, e provavelmente não atingiria um resultado tão satisfatório. Os resultados de classificação correspondentes para o exemplo são 100\% de acerto para logPSD e $71 \pm 37 \%$ de acerto para linPSD.

\footnotetext{
${ }^{1}$ Para distribuições Gaussianas, apenas a média e variância são necessários.
} 


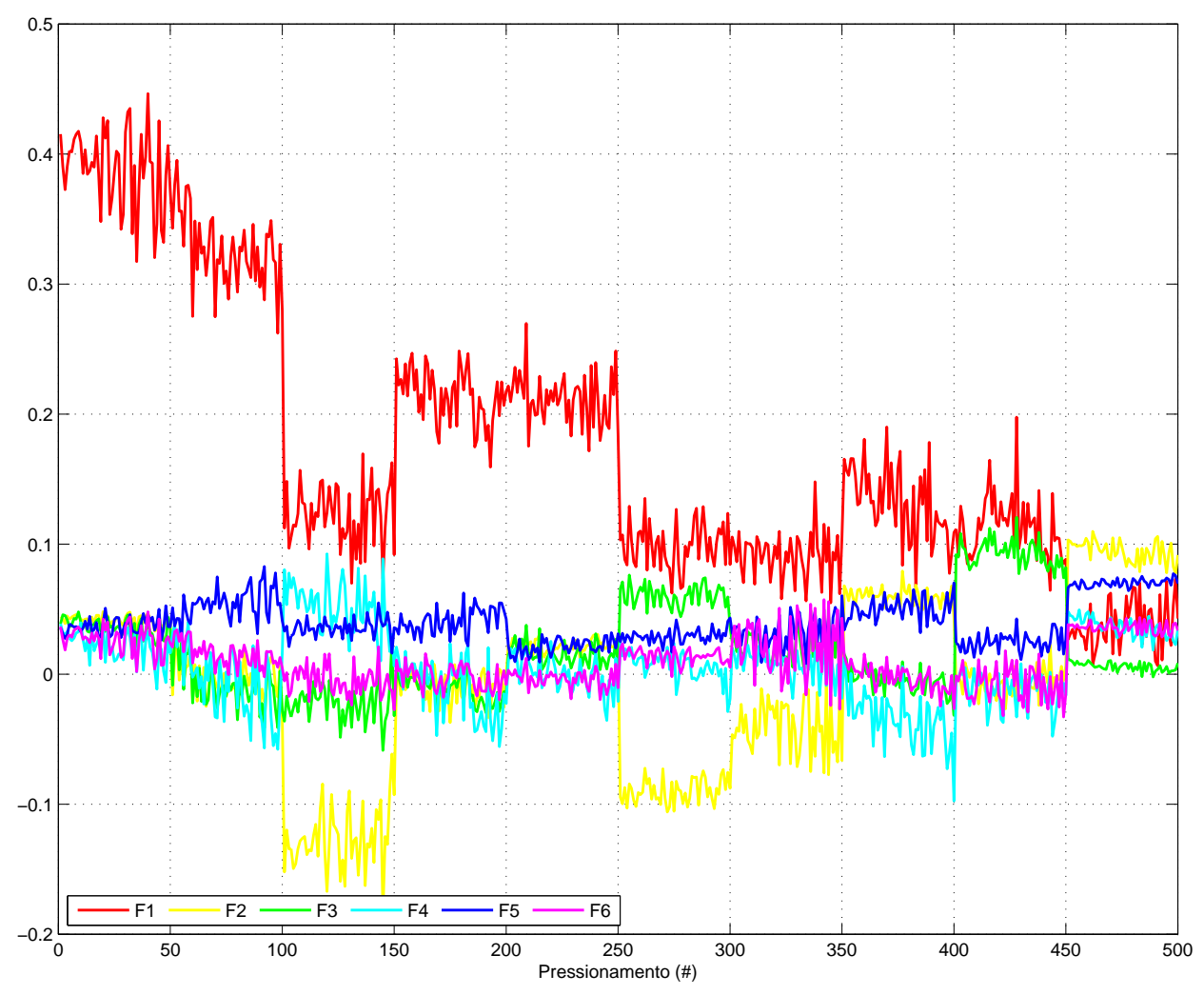

(a) linPSD

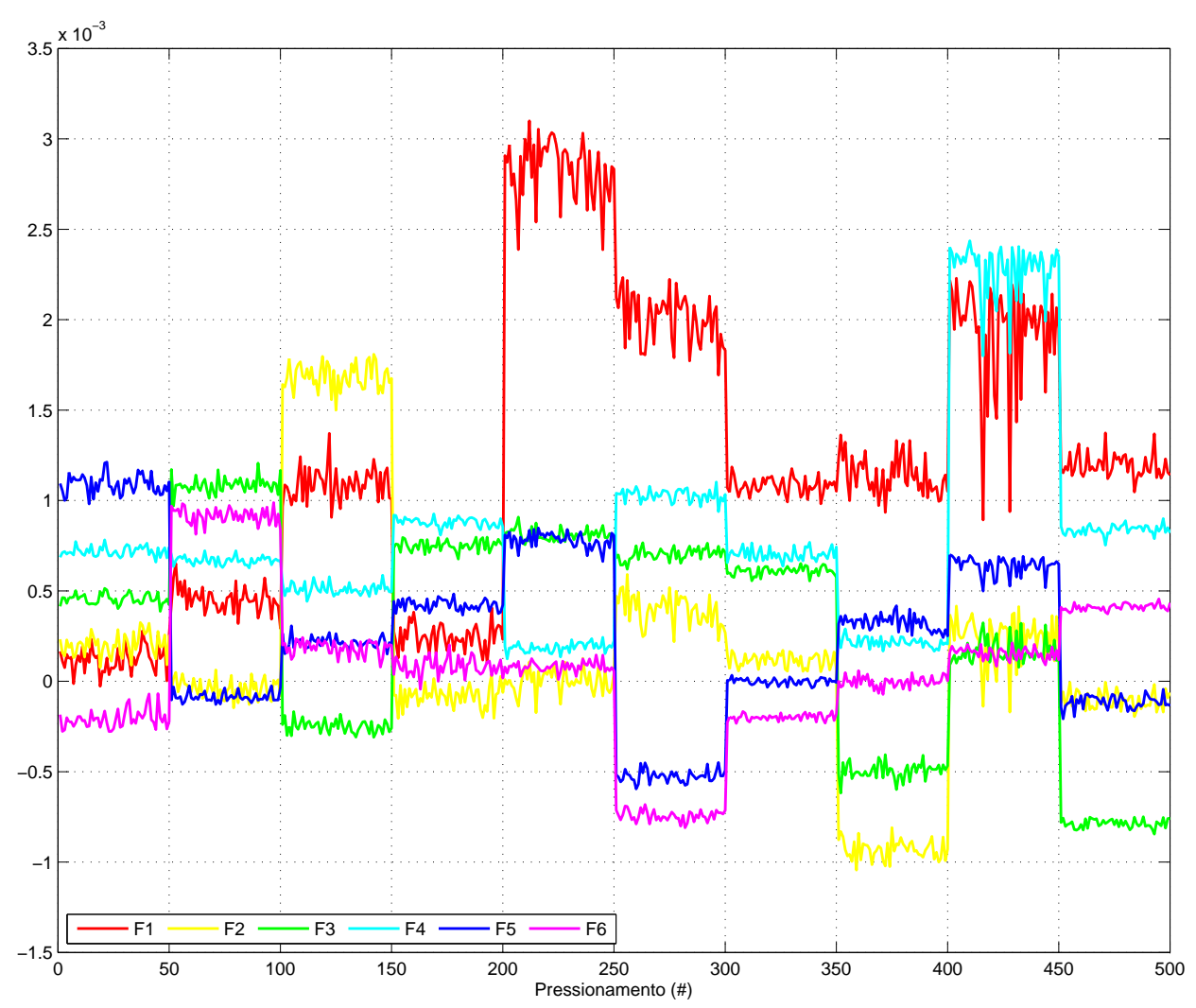

(b) $\log$ PSD 


\section{Apêndice E}

\section{Simulação do modelo DAA para uma}

\section{caixa fechada}

Como forma de verificar a capacidade de discriminação do modelo acústico via entradasaída, i.e., com que resolução o mesmo pode representar o fenômeno relativo à posição da fonte sonora, utilizei a Equação 3.1 para simular o comportamento acústico de uma caixa com uma fonte sonora e dois microfones, apresentada na Figura E.1.

$\mathrm{Na}$ figura, a linha azul sólida descreve o percurso realizado pela fonte sonora, que varia apenas na coordenada $x$ da caixa, na faixa de $20 \mathrm{~mm}$ a $80 \mathrm{~mm}$. Os pontos M1 e M2 descrevem as posições de dois microfones. Os valores das constantes da Equação 3.1 utilizados na simulação foram $c=340 \mathrm{~m} / \mathrm{s}$ e os coeficientes de reflexão $\beta=0.9$ para todas as paredes. As posições dos microfones são M1 = (20 25 25)mm, M2 = (80 25 25)mm e a dimensão da caixa é (100 50 50)mm. A frequência de amostragem é 96 $\mathrm{kHz}$.

A Figura E.2 representa a magnitude da função de transferência na forma de imagem. A abscissa corresponde à frequência; a ordenada corresponde à posição da fonte em $x$, na direção da linha sólida azul da Figura E.1; a cor representa a magnitude da função de transferência, numa escala linear em que valores menores de magnitude são azuis e valores maiores são vermelhos, correspondendo à escala à direita da imagem..$^{1}$

Caso a simulação indicasse grandes regiões espaciais com resposta em frequên-

\footnotetext{
${ }^{1}$ Para algumas posições da fonte sonora virtual, o cálculo da função de tranferência resultante a partir das duas funções de resposta impulsivas calculadas se mostrou instável.
} 


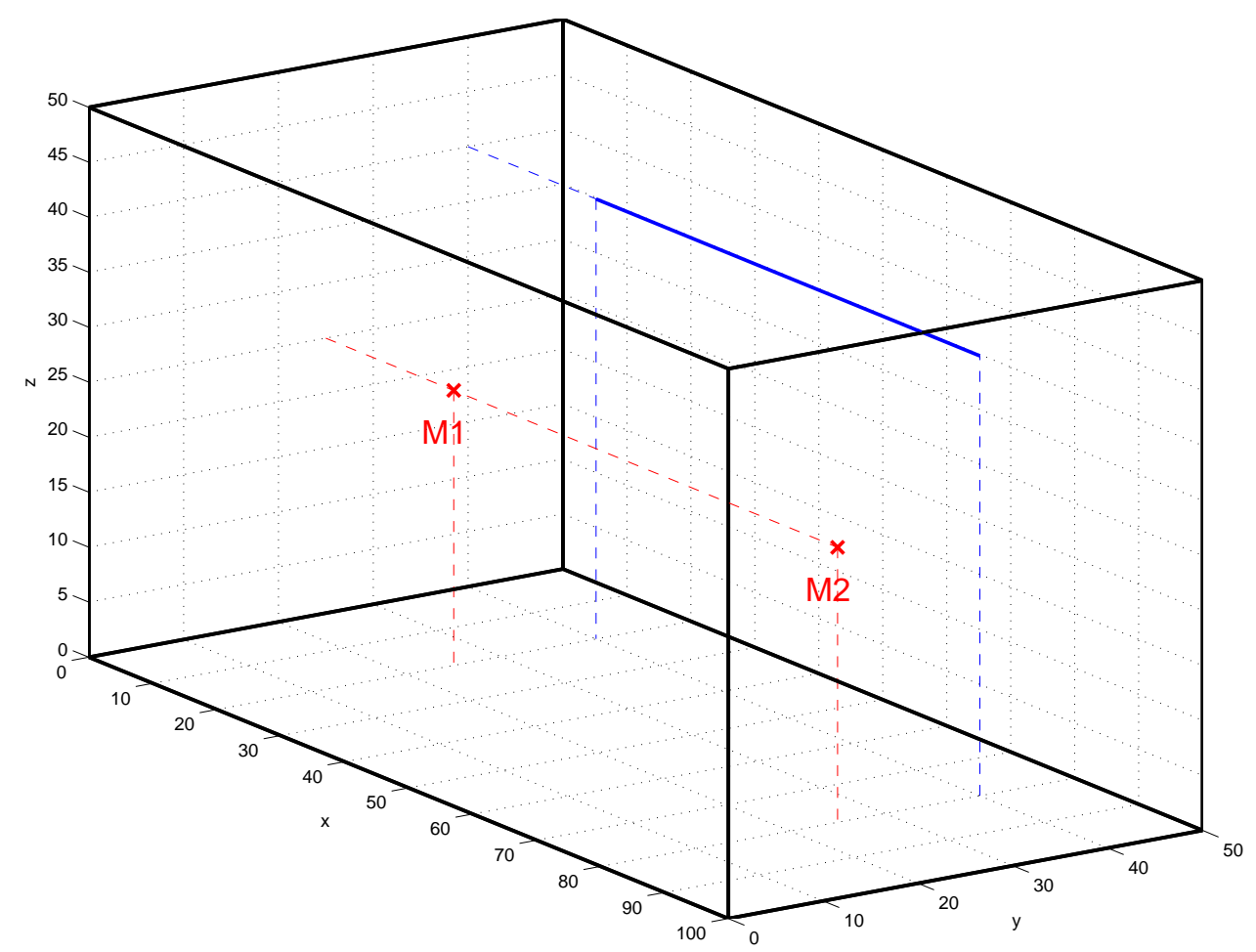

Figura E.1: Caixa utilizada na simulação do modelo entrada-saída. A linha azul sólida corresponde ao percurso da fonte sonora em que as funções de transferência foram calculadas. As posições dos microfones são M1 e M2.

cia muito semelhante, concluiríamos que a capacidade de distinguir acusticamente o espaço seria limitada, i.e., possuiria uma "baixa densidade" de características. Neste caso, poderíamos esperar uma maior confusão na classificação das posições. Mas o que observamos no mapeamento simulado realizado é que o modelo entrada-saída adotado possui um grau bastante elevado de discriminação, indicando teoricamente que o modelo permite a classificação espacial de forma acústica com boa resolução, pois percebemos que mesmo para pequenas variações em $x$ a resposta em frequência é bastante alterada, embora possa haver algumas pequenas "ilhas". Não é possível vislumbrar um padrão claro, exceto que a imagem é anti-simétrica no eixo $x=50 \mathrm{~mm}$. O gráfico da Figura E.3 mostra um recorte da imagem da Figura E.2 para os valores de $x=40,50$ e $60 \mathrm{~mm}$. Dada a simetria das posições, percebemos que a magnitude para a fonte em $40 \mathrm{~mm}$ e $60 \mathrm{~mm}$ são anti-simétricas como já mencionado, uma vez que $x=$ $50 \mathrm{~mm}$ está no plano de simetria dos microfones, apresentando ganho zero em todas as frequências.

Obviamente, a simulação realizada não considera fatores importantes presentes no 


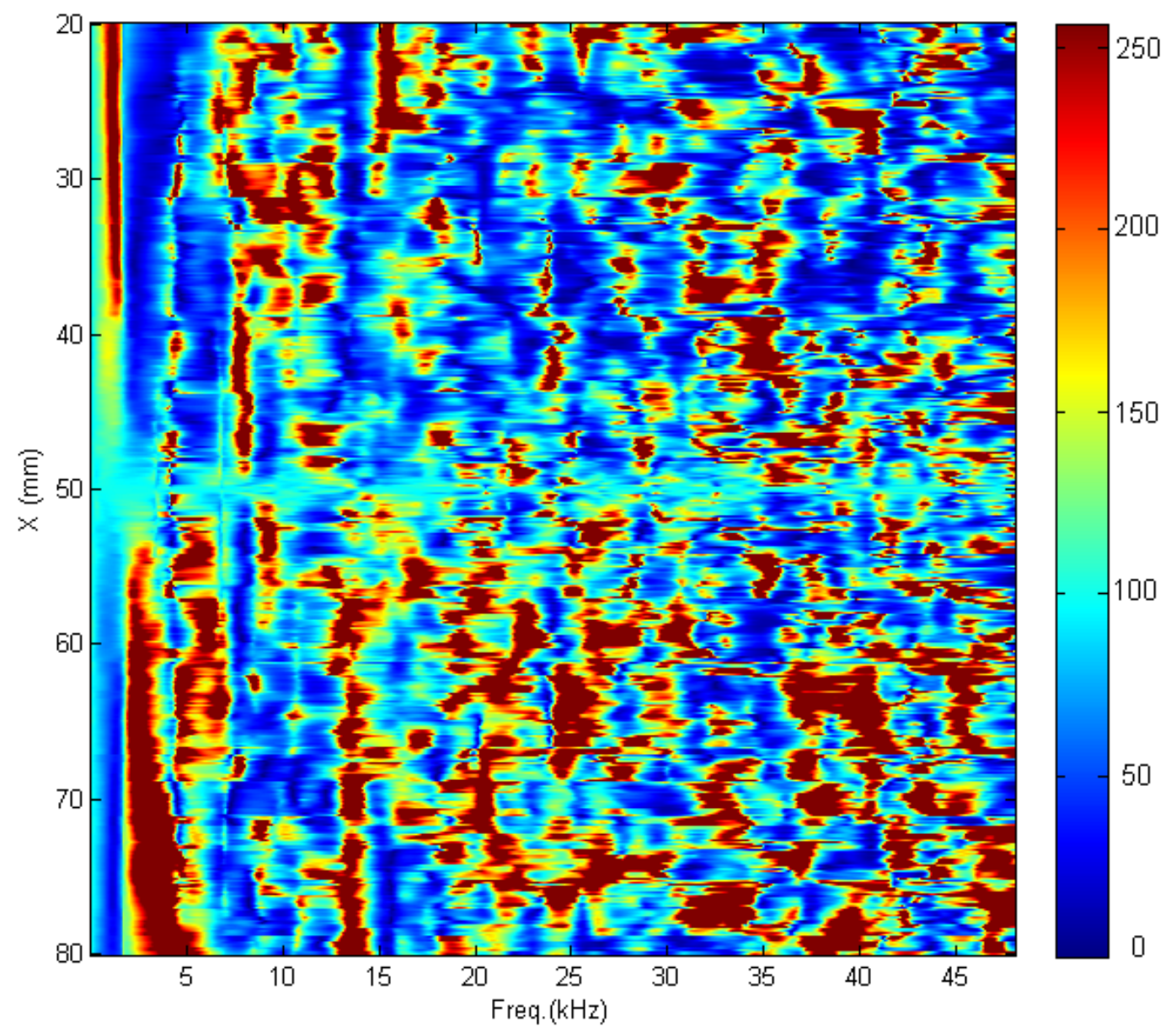

Figura E.2: Representação da magnitude da resposta em frequência para valores de $x$ entre $20 \mathrm{~mm}$ e $80 \mathrm{~mm}$.

ataque real a dispositivos físicos, e.g. a fonte sonora real não se encontra no interior da caixa, a fonte sonora e os microfones não são pontuais, o espaço real não possui paredes lisas e tampouco é retangular etc. Tais idealizações podem possuir importância menor em espaços maiores comparados ao compartimento do PIN pad. No entanto, isto não implica em afirmar que no caso real o modelo DAA é inadequado - o intento do método DAA não é, obviamente, modelar o espaço acústico. De fato, é ainda possível que tais características do caso real adicionem complexidades que auxiliem na distinção entre posições espaciais. 


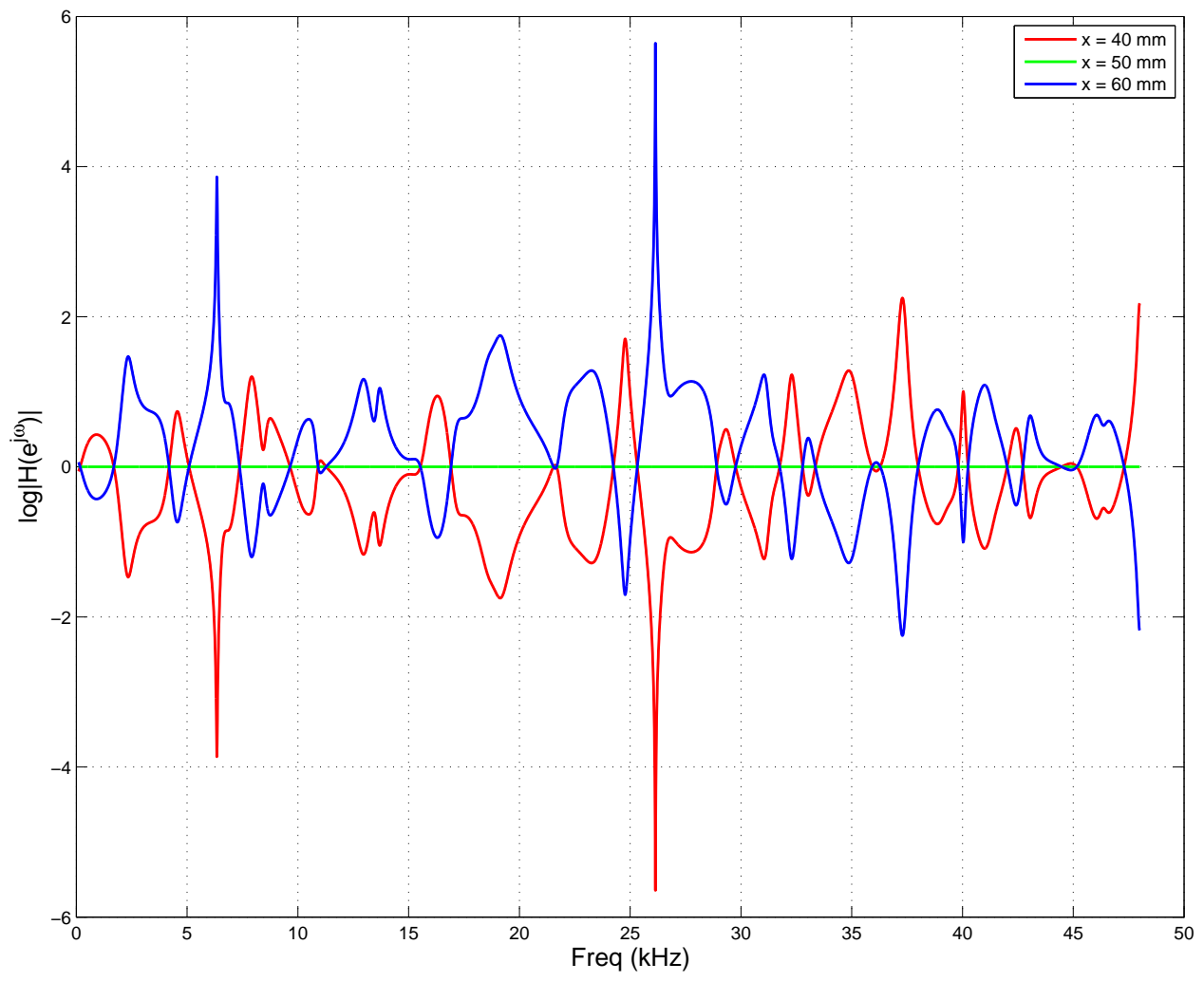

Figura E.3: Funções de transferência simuladas para a caixa da Figura E.1, para posições distintas de $x$. 


\section{Glossário 2}

\section{$\mathbf{A}$}

adversário 1. Uma entidade que ataca um sistema, [intruso] (Compare: cracker, hacker) 2. Uma entidade que é uma ameaça a um sistema. [46]

ataque Ato intencional pelo qual uma entidade intenta se evadir dos serviços de segurança e violar a política de segurança de um sistema. Isto é, uma violação de um sistema de segurança que deriva de uma ameaça inteligente. [46]

ataque de canal secundário Ataque no nível físico que pode revelar parcial ou totalmente a informação trafegada, de forma distinta da que foi protegida em princípio. $\mathrm{Na}$ área de segurança da informação e criptografia, tal "canal de vazamento" é denominado "secundário" ou "colateral", vindo do termo em inglês side-channel. O termo covert channel [44] (canal oculto) às vezes é utilizado na mesma acepção de "canal secundário", como canal não planejado para transferir informação, sendo que neste caso, pode haver intenção do [adversário] em sua criação ou manutenção. (Ver: canal secundário).

ataque invasivo vs. não-invasivo Ataques invasivos requerem alteração física do dispositivo de modo a obter informação, como por exemplo decapagem do chip para permitir acesso a seus componentes internos, desativação dos mecanismos de segurança (tamper detection) de um PIN pad e conexão de fios no barramento de dados para monitorar transferências dos mesmos. Um ataque não invasivo somente explora informação externamente disponível (emissão de algo que é frequentemente não intencional) como tempo de operação, consumo de energia, emissão acústica, vibração,

\footnotetext{
${ }^{2}$ Traduzido e adaptado pelo autor a partir das referências citadas nos verbetes.
} 
temperatura, emissão eletromagnética etc. Adaptado de [45].

atributo(s) Dados que representam um objeto formados a partir da seleção e/ou transformação de dados "originais" obtidos daquele objeto. É comum a distinção entre "espaço de atributos" e "espaço de dados", considerando-se este último como dados originais extraídos do objeto. A extração de atributos (features ou características) é etapa importante de um processo de classificação, devendo gerar atributos similares para objetos de mesma categoria e distintos para objetos de categorias diferentes. Um processo ideal de extração de atributos deve tornar simples a tarefa de um classificador. De forma recíproca, um classificador poderoso não necessitaria de um método de extração de atributos sofisticado. Adaptado de [19, p. 11].

attack potential (potencial de ataque) A probabilidade percebida de sucesso caso um ataque seja empreendido, expresso em termos da habilidade do [adversário] (i.e., expertise e recursos) e motivação [46]. O PCI adota uma metodologia para o cálculo dos custos em [33, Appendix B].

\section{B}

Big Data Nome atribuído intercambiavelmente aos dados gerados por todas as interações com dispositivos conectados à Internet, aos repositórios desses dados e à tecnologia para processá-los.

\section{$\mathbf{C}$}

canal secundário $\mathrm{O}$ meio físico pelo qual um dispositivo ou a interação humana com este gere sinais que, uma vez de codificados, forneçam informação imprevista a respeito desta interação. (Ver também [ataque de canal secundário]).

comprometimento de dados Um incidente de segurança no qual informação é exposta ao acesso potencialmente não autorizado, de modo que a divulgação, alteração ou uso não autorizado da informação possa ter ocorrido [46].

confidencialidade de dados A propriedade de que o dado não seja divulgado a entidades do sistema a menos que o mesmo tenha sido autorizado ao conhecimento do 
mesmo. (Compare: [privacidade]). [46]

contramedida Uma ação, dispositivo, procedimento ou técnica que se opõe a uma ameaça, uma vulnerabilidade ou a um ataque eliminando-os ou prevenindo sua ocorrência, por minimizar o mal que possam causar, ou por descobrir e relatar sua existência de modo que ações corretivas possam ser tomadas. [46]

cracker Alguém que tenta quebrar a segurança e ganhar acesso ao sistema de outrem, normalmente com intenção maliciosa. (Ver: adversário, intruso. Compare: [hacker]) [46]

\section{$\mathbf{F}$}

fallback (transação) Uma transação que é iniciada por um cartão com chip (smartcard) mas a tecnologia dochip não é utilizada e a transação é realizada via tarja magnética. 3

\section{$\mathbf{H}$}

hack 1a. /verbo/ Trabalhar sobre algo, especialmente um programa de computador. (Ver: [hacker]) 1b. /verbo/ Realizar algum tipo de traquinagem, especialmente para pregar uma peça, ou penetrar um sistema (Ver: [hacker], [cracker]) 2. /sm/ Um item de trabalho completo, ou uma solução para um problema, que não é generalizável, i.e., bastante específico a uma área de aplicação ou problema sendo resolvido. [46]

hacker A primeira definição contém o sentido do termo (circa 1960), então com uma conotação neutra ou positiva de alguém que "resolve problemas ou descobre as causas de um problema e faz coisas interessantes". Hoje em dia, o termo é mal utilizado especialmente por jornalistas, igualando-o à definição de [cracker]. [46]

\section{I}

intruso Ver: [adversário]

\footnotetext{
$\mathbf{P}$

${ }^{3}$ http://www.emv-connection.com/downloads/2015/05/EMF-Liability-Shift-Document-FINAL5052715.pdf. Acesso em 8 Ago. 2016.
} 
política de segurança Conjunto de regras (ou princípios) que direcionam como um sistema (ou organização) oferece serviços de segurança para proteger recursos sensíveis do sistema. [46]

privacidade $\mathrm{O}$ direito de uma entidade (normalmente uma pessoa), agindo em favor próprio, determinar o grau ao qual ela interage com o ambiente, incluindo o grau ao qual a entidade está disposta a compartilhar informações pessoais com os outros. Compare: [confidencialidade de dados]. [46]

\section{$\mathbf{S}$}

skimmer Dispositivo físico instalado em um leitor de cartões magnéticos ou com chip, que opera de forma secreta, cujo intuito é armazenar de forma ilegal dados do cartão e/ou do cliente, quando este realiza uma operação com o cartão. Tais dados podem ser recuperados junto ao dispositivo ou enviados ao [adversário], p.e. de modo wireless.

\section{$\mathbf{T}$}

True positive rate (TPR) Proporção de entidades corretamente classificadas em uma categoria. É dada por: TPR = corretamente classificadas / (corretamente classificadas + incorretamente classificadas).

\section{V}

vulnerabilidade 1 . Um defeito ou fraqueza no projeto de um sistema, implementação ou operação e gerenciamento que pode ser explorada para violar a política de segurança do sistema. [46] 2. Uma falha interna que permite que uma falha externa prejudique o sistema.[48] 


\title{
Índice Remissivo
}

\author{
Abecs, 76, 78, 83 \\ cepstrum, 36,43 \\ certificação Gertec PPC910, 79 \\ chupa-cabras, veja também skimmer,1 \\ certificação Ingenico iPP320, 79 \\ Common Criteria, 76, 78, 81, 83 \\ acelerômetro, 1, 16, 18, 21, 25, 28, 33 \\ contramedida \\ Freescale MMA7361, 18 \\ definição, 113 \\ adversário \\ definição, 111 \\ cracker, 5 \\ definição, 113 \\ ARMA \\ autoregressive moving average, 41 \\ ataque \\ definição, 111 \\ células de carga, 61 \\ DAA, 35 \\ definição, 113 \\ invasivo vs. não-invasivo, 111 \\ TDOA, 14 \\ atributo \\ definição, 112 \\ attack potential, 80 \\ definição, 112 \\ EMSEC, iv, 3 \\ EMV, iv, vi, 5, 8, 11, 79, 83 \\ fallback, 9 \\ FFT, 43 \\ Gertec, 56, 59, 79, 81 \\ GPS, 15 \\ GSM, 11 \\ hacker, 5 \\ definição, 113 \\ Big Data \\ definição, 112 \\ ICP-Brasil, 78 \\ Ingenico, 44, 48, 52, 59, 60, 79 \\ IoT, 2 \\ ISO 9564,77 \\ canal secundário, 5, 8, 10, 12, 14, 61 \\ definição, 111 \\ $\mathrm{CC}$, veja Common Criteria \\ Kerckhoffs \\ princípio de, 88
}




\title{
Identification of Pressed Keys by Time Difference of Arrivals of Mechanical Vibrations
}

\author{
Gerson de Souza Faria ${ }^{\mathrm{a}, 1, *}$, Hae Yong Kim ${ }^{\mathrm{a}, 1}$, \\ ${ }^{a}$ Departamento de Engenharia de Sistemas Eletrônicos, Escola Politécnica, Universidade de São Paulo, Av. Prof. Luciano \\ Gualberto, tr. 3, 158, CEP 05508-010, São Paulo, Brazil
}

\begin{abstract}
The possibility of finding the sequence of pressed keys in a mechanical keyboard is a serious security threat. In our previous work, we have shown that it is possible to identify, with high probability, the pressed key by analyzing the vibration generated by the keystrokes. At that time, we did not know the physical phenomenon responsible for leaking information as mechanical vibration. In this paper, we show that the TDOA (Time Difference of Arrivals) of the mechanical waves is the main culprit for leaking information. To demonstrate this hypothesis, we glued three accelerometers in a PIN-pad, collected the vibrations generated by the keystrokes and computed the relative delays of vibration arrival times in pairs of accelerometers. We show that it is possible to estimate the positions of the keys through simple difference of the delays. A simple classification scheme using the delays yielded $96.4 \%$ of recognition success rate. The same technique can be used to attack devices with touch-sensitive screen, identifying the region touched.
\end{abstract}

\section{1. Introduction}

Mechanical keypads are widely used for entering confidential data. Confidential passwords are typed in mechanical keypads in ATMs (Automatic Teller Machines) or PIN-pads (devices used in smart card

4 transactions to input the cardholder's Personal Identification Number). In some countries, including Brazil,

5 electors use electronic voting machines with mechanical keyboards to choose the candidate. Thus, the

6 possibility that someone finds out the sequence of pressed keys, without the user's knowledge or consent,

7 is a serious security threat. In card operations, the theft of card information in an otherwise legitimate

s transaction, known as "skimming", was responsible for $87 \%$ of attacks against ATMs in 2013, as reported 9 in [1].

10 In a previous work [2], we have shown that it is possible to identify the pressed key with high probability

11 by gluing accelerometers in the device, acquiring acceleration signals generated by keystrokes and analyzing 12 these signals. We called it "vibration attack".

Usually, modern ATM keypads are encrypted. They are sealed modules that encrypt the PIN soon after 14 the entry. So, non-encrypted PIN numbers are not meant to be accessible from outside either by physically 15 tapping onto wires or remotely sensing electromagnetic radiation. Any tampering of the keypad causes it to permanently disable itself. Similarly, PIN-pads are protected modules that permanently disable themselves if tampered. The possibility of identifying the sequence of pressed keys through mechanical vibrations is a serious security failure of secure keypads because they are designed to resist against any attempt of eavesdropping. The devices will continue functioning normally while passwords are stolen.

When we wrote our previous paper, we did the experiments without knowing the physical phenomenon responsible for the leak of information. We extracted a lot of features from the vibration signals (up to 165 features per keystroke) and fed machine learning algorithms with them in an attempt to identify the pressed

\footnotetext{
${ }^{*}$ Corresponding author

Email addresses: gerson.faria@usp.br (Gerson de Souza Faria), hae@lps.usp.br (Hae Yong Kim)
} 
key. This was enough to certify the existence of the problem, but without a satisfactory explanation of the underlying phenomenon.

In this work, we show that the propagation delay of the transverse wave generated by the keystroke is the main phenomenon responsible for the information leaking. With this knowledge, in this work we use much less features per keystroke (2 instead of up to 165) and less training data (100 or 200 keystrokes per experiment instead of up to 2400 keystrokes) and obtain similar classification success rates than in our earlier work. This result is somewhat surprising, because PIN-pad is far from being a homogeneous medium, and one would expect that the vibration propagation velocities were different in different regions of the device. To provide our technique a short name, we will call it "vibration delay attack".

It is also possible to estimate the position of the pressed key (the source of the wave) through a simple $2-\mathrm{D}$ trilateration of the relative delays of the signals captured by the accelerometers. This is a well known technique in a variety of fields by terms like TDOA (Time Difference of Arrivals) or simply "time of flight". For instance, the accurate measurement of these delays is the basis of GPS (Global Positioning System) and other geolocation systems. Geophysicists and seismologists also use it in order to locate the epicenters of earthquakes and of other seismic events [3]. In our case, the position of the key is analogous to the epicenter of an earthquake.

In the literature, there are some papers that identify the pressed key by sound, because each key usually emits a characteristic sound when pressed. Asonov and Agrawal [4] achieved $79 \%$ of key recognition success rate when identifying one out of 30 keys in a PC keyboard. Berger et al. [5] use keyboard acoustic emanations and a dictionary to recognize correctly $73 \%$ of the English words typed in a PC keyboard, without any training. Zhuang et al. [6] takes as input 10-minute sound recording of a user typing English text using a keyboard and recovers up to $96 \%$ typed characters. Halevi [7] uses keyboard acoustic emanations for eavesdropping over random passwords, without using dictionary, achieving $40 \%$ to $64 \%$ recognition rate per character.

Similarly to acoustic emission, each key seems to emit a characteristic mechanical vibration when pressed. However, this idea has been much less explored in the literature. Marquardt and Verma [8] use this idea to recognize keystrokes of a computer keyboard. They use the accelerometer of a smartphone placed near the computer's keyboard to capture the vibrations. They do not actually identify the pressed key. Instead, they classify keystrokes in "left" or "right" and pairs of keystrokes in "near" and "far". They achieved classification rates from $65 \%$ to $91 \%$ making those binary decisions.

The phenomenon identified in this work is of a different nature: even if it were possible to have all the keys emit exactly the same sound and the same mechanical vibration, it would be still possible to identify the pressed key by the arrival times of the vibration wave. Our purpose in this work is neither to select the most appropriate classifier nor to achieve extremely high recognition rates. Instead, our primary aim is to show that there is one more physical phenomenon that can be used to identify the pressed key by means of a simple location technique, but applied in a complex non-homogeneous medium. Most of location experiments use relatively homogeneous solids, like concrete, metal, glass, acrylic etc. and not composite ones, like a PIN-pad. We use in all experiments only the relative delays as features and a simple Naive Bayesian classifier. If we add other features and fine-tune the classifier, probably we would achieve higher success rates. Additionally, our finding also opens the possibility of attacking touch-screen devices, because the same phenomenon occurs when the user interacts with them. Note that touch-screen devices cannot be attacked using acoustic emanations.

The literature on trilateration comes from diverse fields of research. Maochen Ge discusses the source location theories and methods that are used for earthquake, microseismic and acoustic emission [9, 10]. He analyzes the principles of source location methods and mentions the main causes of inaccuracy, for instance, imprecision of sensor positions and errors in arrival time measuring. Geolocation methods based on measuring the time difference of arrivals (TDOAs) of signals received from several geostationary satellites are presented in $[11,12,13]$. Ho and Chan present a method that solves a set of nonlinear equations to estimate the location [11]. Gustafsson and Gunnarsson compare a Monte Carlo method and a gradient search algorithm [12]. Schumacher et al. propose a Bayesian approach for the problem of source location in the materials research [14]. Arun et al. [15] develop a location method based on Kullback-Leibler discrimination information criteria on spectra of acceleration signals, testing the method on a large aluminium plate. 
The rest of the paper is organized as follows. Basic theory on transverse waves is described in Section 2. ${ }_{76}$ We apply the vibration delay attack in two devices: a simple mockup keypad in Section 3 and a commercial 77 PIN-pad designed to be secure in Section 4. We make some considerations comparing the previous results 78 with the new ones in Section 5 and present our conclusions in Section 6. Appendixes present the definition 79 of normalized cross correlation (used to estimate the relative delay between two signals) and the source so location estimation method.

\section{2. Vibration of a Plate}

82 2.1. Theory

83 The behavior of a transverse wave in a bar or plate (with thickness) is considerably more complex than ${ }_{84}$ the classical transverse wave in a string or membrane (with negligible thickness). Plates and bars have 85 thickness, bringing properties as bending stiffness (also known as flexural rigidity) defined as the resistance 86 offered by the plate while undergoing bending or deflection.

87 The differential equation for the deflection of a one-dimensional string is [16]:

$$
\nabla^{2} y(x, t)=\frac{1}{c^{2}} \frac{\partial^{2} y(x, t)}{\partial t^{2}}, \quad c^{2}=\frac{T}{\rho}
$$

88 where $T$ is the tension and $\rho$ is the mass density of the material. All functions of the form $y(x, t)=$ 89 $F_{1}(x-c t)+F_{2}(x+c t), \forall F_{1}, F_{2}$, are its solutions, where $c$ is the constant velocity of the traveling wave 9o without shape deformation.

On the other hand, the simplified wave equation for the transverse vibration of a uniform bar is:

$$
\nabla^{4} y(x, t)=-\frac{1}{a^{2}} \frac{\partial^{2} y(x, t)}{\partial t^{2}}, \quad a^{2}=\frac{E I}{m}
$$

where $E$ is the modulus of elasticity of the material, $I$ is its moment of inertia and $m$ its total mass. Let us assume that a solution of Eq. 2 is a simple harmonic wave traveling with velocity $v$ :

$$
y(x, t)=A \cos \frac{2 \pi}{\lambda}(x-v t)
$$

Substituting Eq. 3 in Eq. 2, we obtain a velocity that depends on the wavelength, $v=a \frac{2 \pi}{\lambda}$. Note in the previous relation that $a$ does not possess dimensions of velocity, so it does not represent a velocity, instead of $c$ in Eq. 1 that is in fact a velocity.

In summary, the travelling velocity of a wave is constant in a string but, in a bar, it depends on the wavelength and consequently on the oscillation frequency, because the latter is a dispersive medium. A sinusoidal wave can travel in a dispersive medium without suffering deformation in its shape, but a wave packet will be deformed in such a medium since its components have, by construction, distinct wavelengths. In this case, each component will travel with a distinct velocity thus causing deformation $[16,17]$.

The same phenomenon occurs in plates, like the acrylic plate where we made the two initial experiments (Sections 2.2 and 3).

The dispersion and reflections make it difficult to accurately measure the delays in the arrival of mechanical vibrations, because different ways of pressing keys generate distinct spectra and so different delays between wavefronts and reflection occurrences. We measure the delays of wavefronts considering them as packets travelling with a group velocity. The group velocity of a wave is the velocity with which the overall shape of the wave's amplitudes propagates.

\subsection{Dispersion in Acrylic Plate}

In order to observe in practice the effect of medium dispersion and group velocity presented in Section 2.1, we made an experiment in an acrylic plate using two distinct sources of excitation: (i) touching the plate with the finger and (ii) touching it with the tip of a mechanical pencil. Fig. 1 depicts the assembly of the 


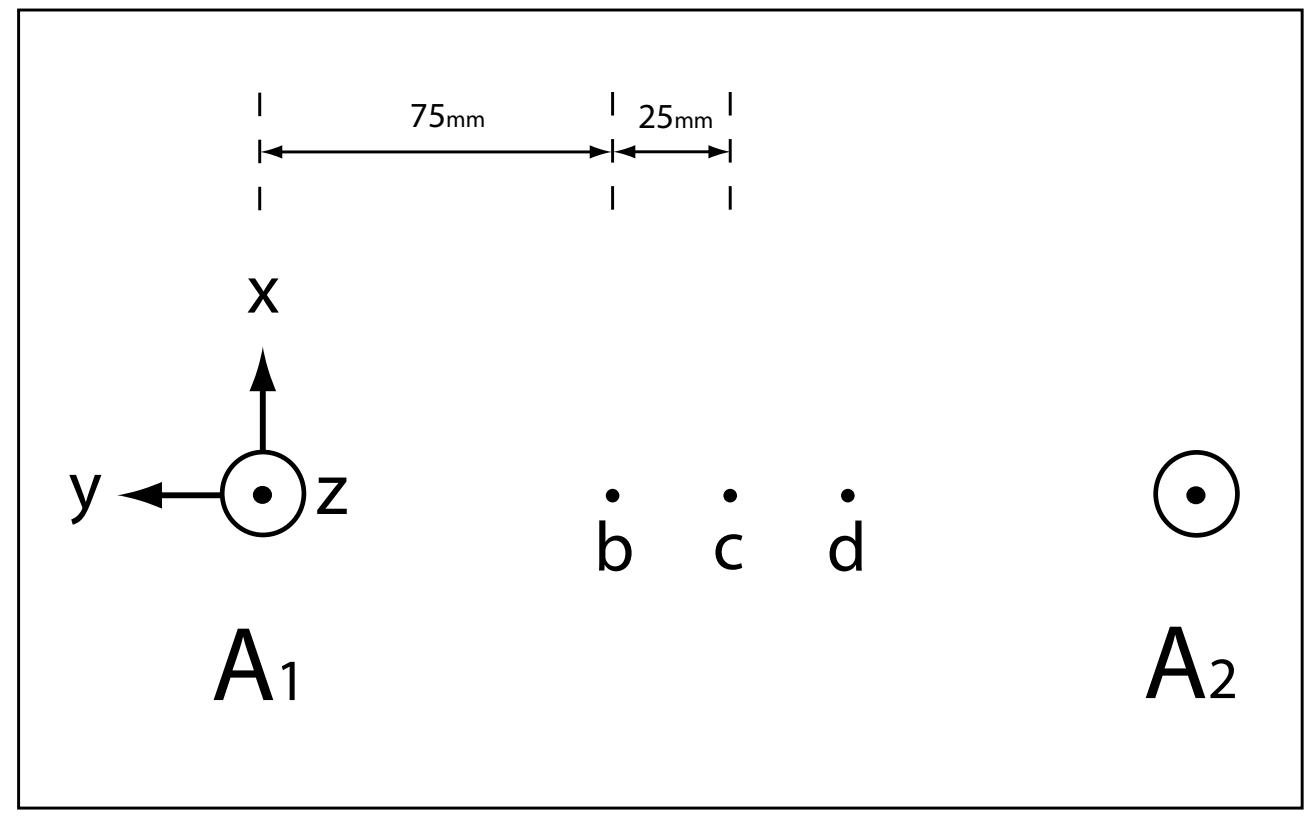

Figure 1: Assembly of the experiment to observe the medium dispersion in acrylic plate.

experiment. The dimensions of the plate are approximately $3 \mathrm{~mm} \times 640 \mathrm{~mm} \times 670 \mathrm{~mm}$. We mounted the two accelerometers over small metallic screws and glued them on the acrylic plate. $A_{1}$ and $A_{2}$ are the positions of the accelerometers.

In all the experiments, we use Freescale MMA7361 analog triaxial low-g accelerometers [18] operating in $\pm 1.5 \mathrm{~g}$ range and a Tektronix TDS-2004B digital oscilloscope to acquire the data. Each signal vector comprises 2500 points, the maximum allowed by the oscilloscope. The sampling rate varies from experiment to experiment. In this case, the sampling rate was $100 \mathrm{KS} / \mathrm{s}$ for the experiment touching the plate with the finger and $500 \mathrm{KS} / \mathrm{s}$ for touching it with a mechanical pencil.

The left column of Fig. 2 depicts the transverse $\vec{z}$ acceleration signals acquired by the accelerometers, touching the plate with the finger at points "b", "c" and "d". Longitudinal waves in $\vec{x}$ and $\vec{y}$ directions are much faster than transverse waves because they travel inside the material and not on its surface. So, we ignored the longitudinal signals, processing only surface transverse signals $\vec{z}$.

Obviously, a wavefront in a homogeneous and isotropic medium arrives first at the nearest accelerometer. Thus, the wavefront arrives first at $A_{1}$ when touching the point "b". The wave arrives first at $A_{2}$ touching point " $\mathrm{d}$ ". The wavefront reaches simultaneously at the two accelerometers pressing the middle point "c".

\subsection{Delay estimation via $N C C$}

We use normalized cross correlation (NCC) to compute the relative delay between the signals acquired by the two accelerometers (see Appendix A for the definition and computation of NCC). Suppose that the wavefront generated by a keystroke takes $n_{1}$ sampling periods to reach the accelerometer $A_{1}$ and takes $n_{2}$ sampling periods to reach the accelerometer $A_{2}$ (see Fig. 2). In this case, we will observe a peak in NCC between the acceleration values obtained by $A_{1}$ and those obtained by $A_{2}$, when the latter is shifted right $n_{1}-n_{2}$ positions. This difference is the estimated delay.

The right column of Fig. 2 depicts the NCC between the signals acquired by the two accelerometers touching the acrylic plate with the finger. Using the peaks in NCC we computed the group velocity, that was estimated as $\approx 45 \mathrm{~m} / \mathrm{s}$. Fig. 3 depicts the signals obtained and the NCC touching the plate with the tip of a mechanical pencil. The group velocity is more than twice faster, $\approx 95 \mathrm{~m} / \mathrm{s}$, because the frequency generated touching the plate with the pencil is higher than touching it with the finger. 

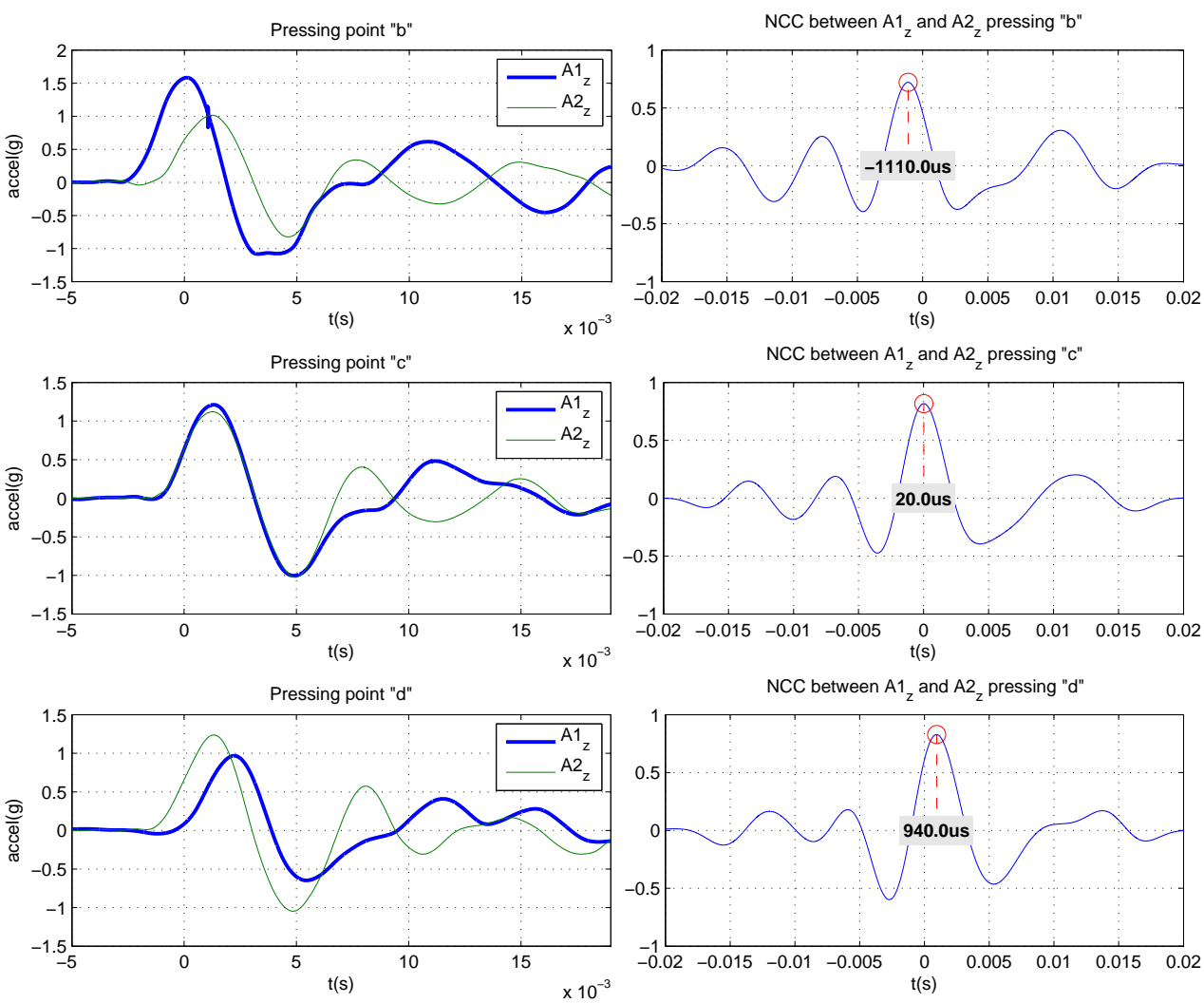

Figure 2: (Left) Acceleration signals obtained tapping the acrylic plate with finger at points 'b', 'c' and 'd'. (Right) Relative delay estimated using the position of the highest peak in NCC between $A 1_{z}$ and $A 2_{z}$.

The duration of the first semi-cycle of the signal $A 1_{z}$ tapping with the finger (Fig. 2) is $\approx 5 \mathrm{~ms}$, corresponding to frequency of $\approx 100 \mathrm{~Hz}$ (if considered cyclic). The duration of the first semi-cycle of the signal $A 1_{z}$ tapping with the pencil (Fig. 3 ) is $\approx 1 \mathrm{~ms}$, corresponding to frequency of $\approx 500 \mathrm{~Hz}$ (if considered cyclic).

\section{Acrylic Plate Mockup Keypad}

We constructed a mockup keypad using an acrylic plate to verify if the vibration delay can be used to identify the pressed key. We fixed a paper print of a keypad on the plate (Fig. 4), glued three accelerometers and touched inside each region emulating the keys. If we achieve a high accuracy in this test, it would be worth continuing the tests in real devices. We pressed 10 times each one of " 0 " to "9" virtual keys, generating 100 acquisitions.

Fig. 5 (top) depicts a typical keystroke captured by the three accelerometers. These signals are complex due to dispersion, reflections and many other wave phenomena. So, if we simply compute the NCC between a pair of these signals, the highest peak may not correspond to the relative delay. It is possible to remove the artifacts introduced by the reflections by analyzing only the first points in time of the signal, before the arrival of the reflections. To this end, we enveloped the signals with a Gaussian window with mean $\mu$ and standard-deviation $\sigma$. We compute the highest peak in the first $M$ points in each of the three original signals and then set $\mu$ as the average position of the three peaks, as shown in Fig. 5. The parameters $\sigma$ and $M$ depend on the experiment.

In this experiment, the sampling rate was $25 \mathrm{KS} / \mathrm{s}$ or $50 \mathrm{KS} / \mathrm{s}$. We used $\sigma=\frac{200}{\sqrt{2}}$ for sampling rate of $25 \mathrm{KS} / \mathrm{s}$ and $\sigma=\frac{100}{\sqrt{2}}$ for $50 \mathrm{KS} / \mathrm{s}$, and $M=1500$ for both. 

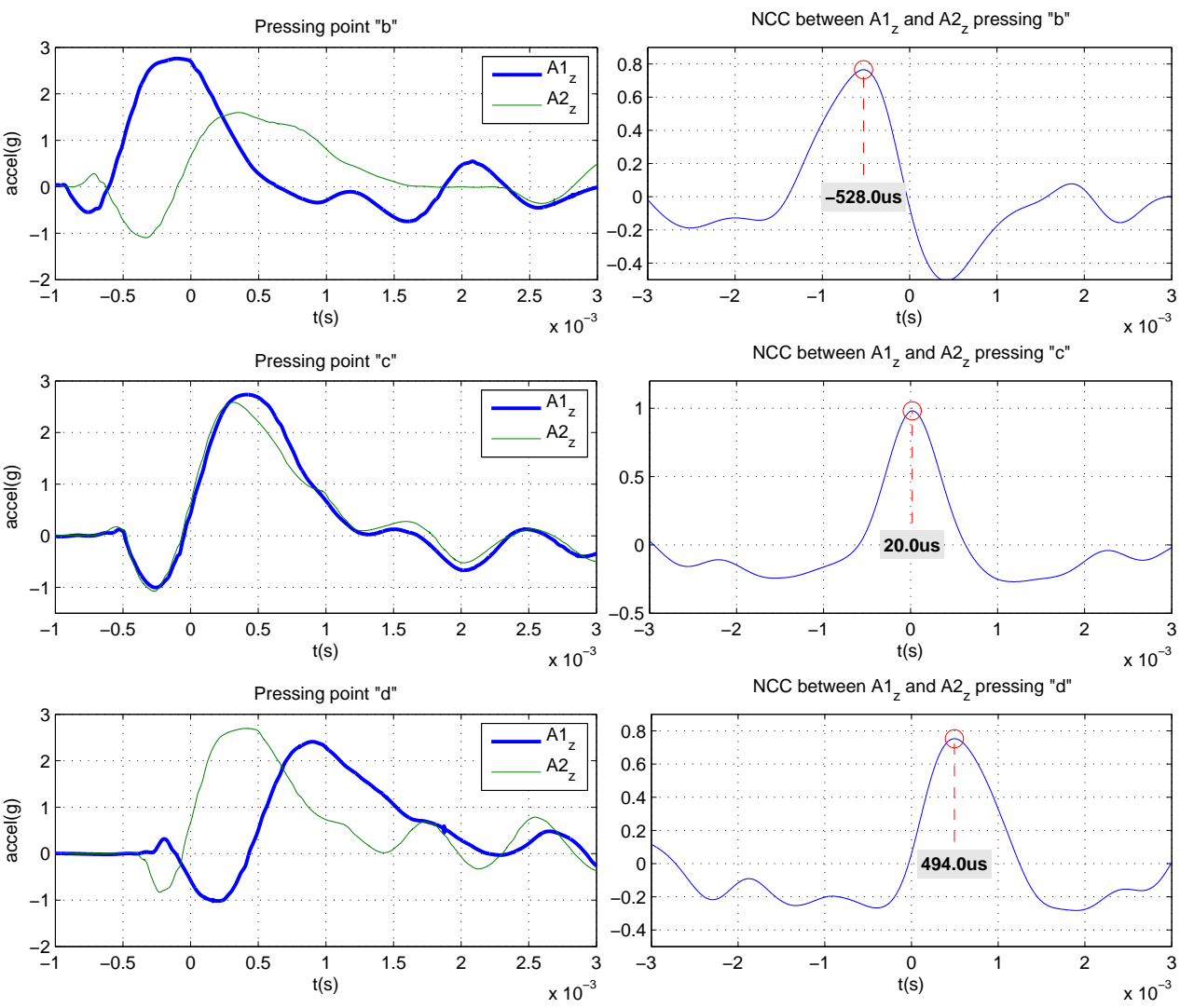

Figure 3: (Left) Acceleration signals obtained tapping the acrylic plate with a mechanical pencil at points 'b', 'c' and 'd'. (Right) Relative delay estimated using the position of the highest peak in NCC between $A 1_{z}$ and $A 2_{z}$.

After multiplying the three original signals with the Gaussian window, we take pairs of the enveloped signals and compute NCC between each pair. The position of the highest peak in NCC is considered the relative delay between the pair. As we have three original signals, we get three relative delays. However, we noted that only two out of these three relative delays are independent features, because the third can be obtained as a linear combination of the first two. See Appendix B for explanation.

In our previous paper [2], we extracted up to 165 features from each keystroke, instead of only two. The features were the values of NCC (instead of the position of the highest peak in NCC). In our very preliminary conference paper [19], we used many tentative features before choosing NCC. At those times, we made these choices because we had no clear idea of the underlying physical phenomenon.

We use in all experiments a simple Naive Bayes classifier with normal distribution. We took randomly $80 \%$ of all features as the training set and $20 \%$ as the test set, repeat this procedure 100 times and present the classification result as a confusion matrix.

In this "mockup keypad" experiment, we obtained $100 \%$ of correct classification rate (Table 1)! Evidently, this is an ideal situation. In order to visualize spatially the data, we used 2-D trilateration (Appendix B) to estimate the relative locations of keys (Fig. 6). The estimated positions closely resemble their actual positions. Moreover, the clusters of keys are clearly separated. This shows that the group velocity is constant throughout the acrylic plate, because it is a homogeneous and isotropic medium as we assumed in the source localization method. 


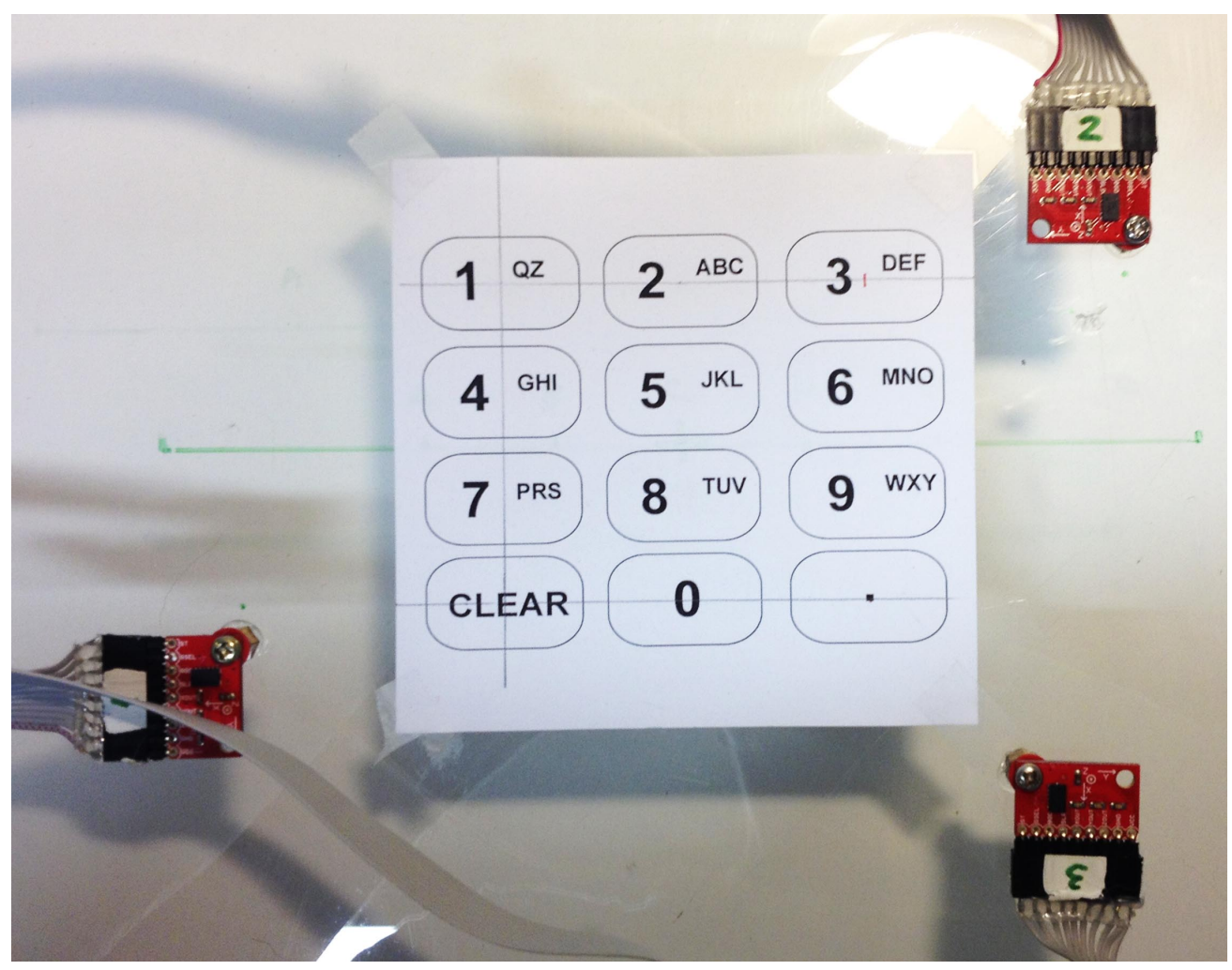

Figure 4: Keypad emulation on an acrylic plate. We tapped inside each virtual key to emulate keystrokes.

Table 1: Confusion Matrix of the Acrylic Plate Mockup Keypad Experiment

\begin{tabular}{|c|c|c|c|c|c|c|c|c|c|c|}
\hline Key & 1 & 2 & 3 & 4 & 5 & 6 & 7 & 8 & 9 & 0 \\
\hline 1 & 200 & & & & & & & & & \\
\hline 2 & & 200 & & & & & & & & \\
\hline 3 & & & 200 & & & & & & & \\
\hline 4 & & & & 200 & & & & & & \\
\hline 5 & & & & & 200 & & & & & \\
\hline 6 & & & & & & 200 & & & & \\
\hline 7 & & & & & & & 200 & & & \\
\hline 8 & & & & & & & & 200 & & \\
\hline 9 & & & & & & & & & 200 & \\
\hline 0 & & & & & & & & & & 200 \\
\hline
\end{tabular}

\section{PIN-pad}

After the experiment with the acrylic plate, we applied the vibration delay attack to a PIN-pad designed to deal with sensitive information in a secure way. Fig. 7 shows the device, an Ingenico iPP320 PIN-pad and the assembly of the experiment, where the three accelerometers were glued inside the SAM (Secure Access Module) card access compartment. This device is PCI-PTS compliant ${ }^{1}$, under 2.X and 3.X versions.

\footnotetext{
${ }^{1}$ PCI stands for Payment Card Industry. PTS stands for PIN Transaction Security, a set of requirements specific for PIN entry devices. Device compliance can be consulted at https://www.pcisecuritystandards.org/approved_companies_ providers/approved_pin_transaction_security.php
} 

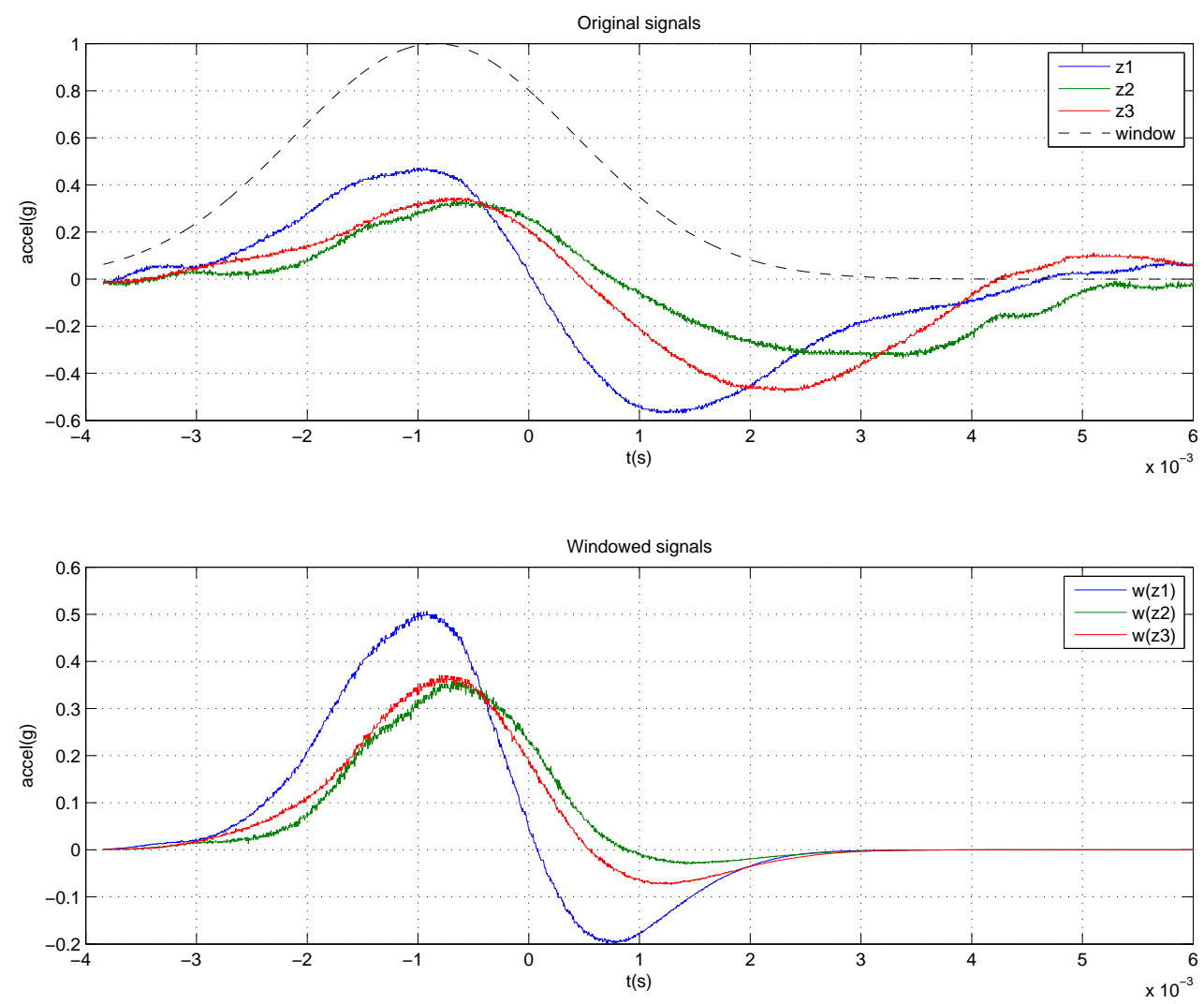

Figure 5: We apply a Gaussian window to attenuate the reflections and improve the delay estimation. (Top) the original acceleration signals took from the PIN-pad experiment, key "8". (Bottom) the windowed signals.

The choice of this model/brand was not guided by any prior vulnerability we could spot. We want to make it clear that most of PIN-pads with a SAM card compartment are potential targets of this attack and Ingenico's iPP320 is not a special case.

The SAM card compartment increases the vulnerability to vibration delay attack mainly because:

1. it provides room for implanting wiretap devices or "bugs", hidden within the compartment;

2. the compartment is normally located just below the keypad, the ideal place to capture the vibrations from the keystrokes;

3. the SAM slots can eventually provide electrical power for the "bugs".

Thus, the attack can be executed in real scenario in a noninvasive and undetectable way, without batteries and wires. We placed the accelerometers inside the SAM card compartment to simulate a real vibration delay attack. In a real attack, however, miniaturized bug devices may be placed inside this compartment.

The restricted space in the SAM card compartment does not allow us to place the accelerometers wherever we want. So, the triangle formed by the three accelerometers covered only a small portion of the area where the keys are located (Fig. 7 (a)). We used spacers between the device's chassis and the printed circuit boards of the accelerometers, to make the accelerometers feel the vibration of only a small area, hoping that this may improve the results.

We pressed 20 times each one of the "0" to "9" keys. As before, we enveloped the three signals with a Gaussian window with $\sigma=\frac{450}{\sqrt{2}}$ and $M=1500$. We used sampling rate of $250 \mathrm{KS} / \mathrm{s}$. 


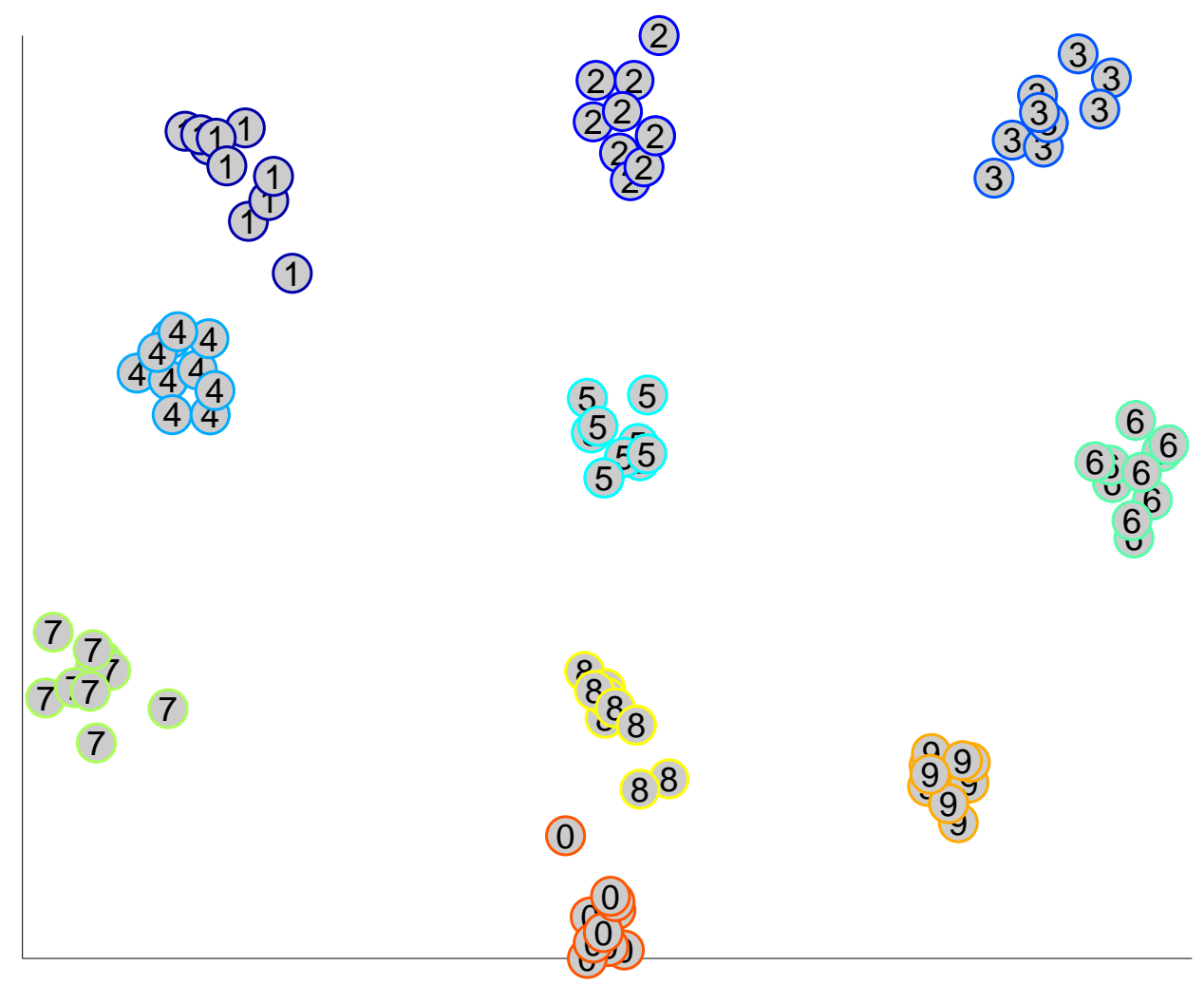

Figure 6: Estimation of the key positions of the acrylic keypad experiment.

\subsection{Features}

Fig. 8 depicts the obtained features. Each graph represents the delays between the signals obtained by a pair of accelerometers. The $x$ coordinate indicates the test number. For example, $x=1$ to 20 correspond to the 20 strokes of key "1", $x=21$ to 40 to key "2" and $x=181$ to 200 to key " 0 ". As before, we used only two features, $\Delta t_{1,2}$ and $\Delta t_{1,3}$.

Table 2 shows the confusion matrix. The recognition rate is very high $(96.4 \pm 6 \%)$, where 6 is the standard deviation of the 100 cross validations. The errors occur only between the neighboring keys. Moreover, excluding the key "0" (that seems to be a special case) the errors occur only between neighboring keys that belong to the same column. We observed similar results in [2]. Our hypothesis is that this happens because the distance between columns $(\approx 23 \mathrm{~mm})$ is almost twice the distance between rows $(\approx 13 \mathrm{~mm})$, making it easier to make row misclassifications.

In this experiment, the reconstruction of the key locations is also very good (Fig. 9) though the clusters are not so clearly separated as in the ideal case (Section 3). The keys are uniformly distributed in space with the exception of keys " 0 " and " 8 " that are partially mixed (in agreement with the confusion matrix in Table 2 and features in Fig. 8). These results show that the supposition of constant group velocity used in the source location method (Appendix B) is reasonable in practice, in spite of the apparent complexity of the medium. The observed localization errors may be due to: (a) the triangle formed by the accelerometers covers only a small part of the keypad; (b) the group velocity may not be constant throughout all the device; (c) the delay estimation method is not accurate enough; and (d) the medium is dispersive.

\subsection{From NCC to TDOA}

The instant of the peak in NCC can be used to estimate the delay between two similar signals (Section 2.3). In a previous work [2], we used the amplitudes of NCC as features to identify the pressed keys, 


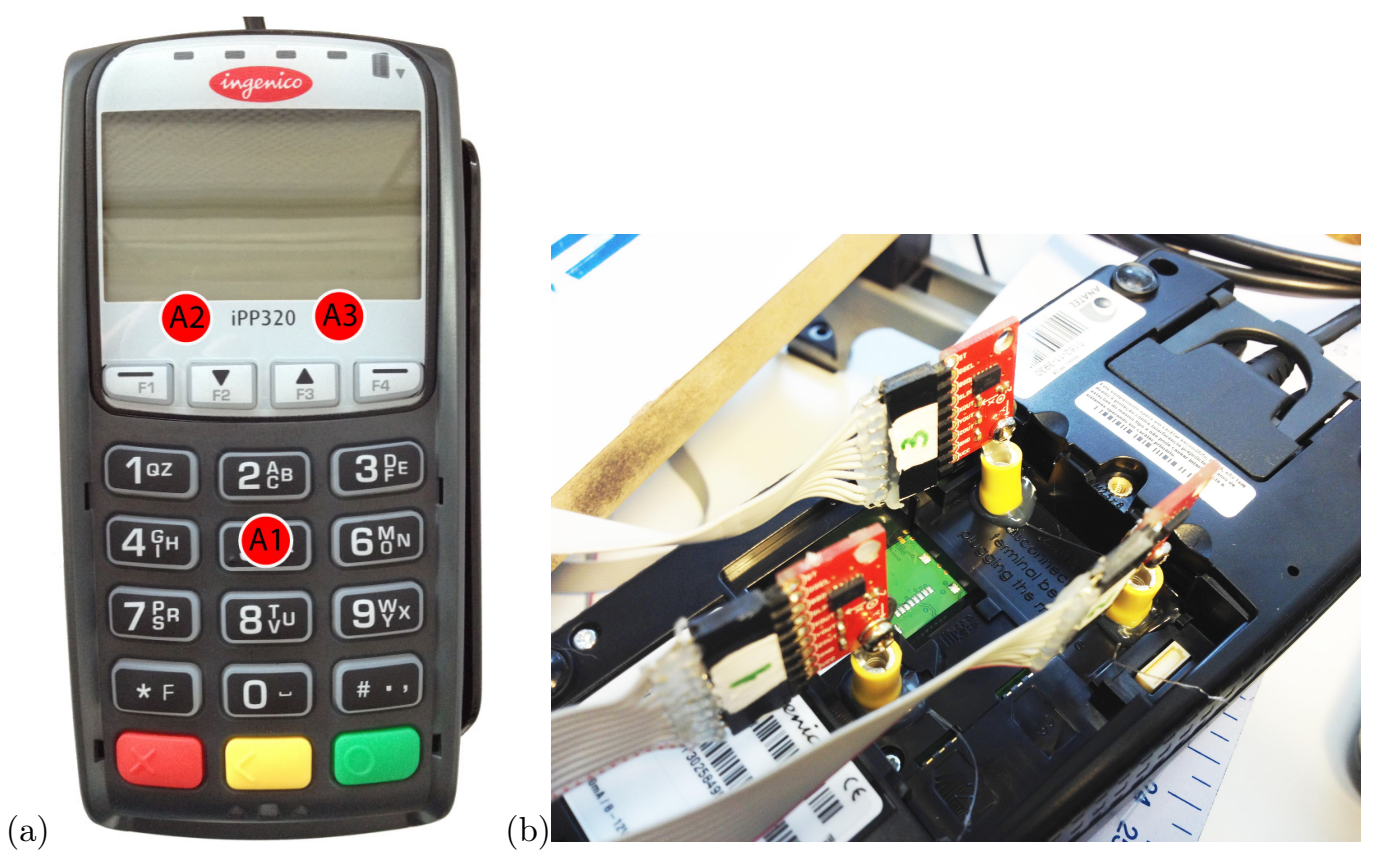

Figure 7: (a) PIN-pad used in the experiment with approximate locations of accelerometers. (b) The bottom view showing the SAM compartment with the implanted accelerometers.

Table 2: Confusion Matrix of the Pin-pad Experiment

\begin{tabular}{|c|c|c|c|c|c|c|c|c|c|c|c|}
\hline Key & 1 & 2 & 3 & 4 & 5 & 6 & 7 & 8 & 9 & 0 & Acc. $(\%)$ \\
\hline 1 & 400 & & & & & & & & & & 100.0 \\
\hline 2 & & 398 & & & 2 & & & & & & 99.5 \\
\hline 3 & & & 400 & & & & & & & & 100.0 \\
\hline 4 & & & & 400 & & & & & & & 100.0 \\
\hline 5 & & & & & 397 & & & 3 & & & 99.2 \\
\hline 6 & & & & & & 382 & & & 18 & & 95.5 \\
\hline 7 & & & & & & & 389 & & & 11 & 97.2 \\
\hline 8 & & & & & & & & 345 & & 55 & 86.2 \\
\hline 9 & & & & & & & & & 400 & & 100.0 \\
\hline 0 & & & & & & & 5 & 50 & & 345 & 86.2 \\
\hline
\end{tabular}

without computing the instant of the peak. This implied large feature vectors (up to 165 features), as opposed to small TDOA features here used (only 2 features). However, the dimension of NCC features can be reduced using some standard dimensionality reduction technique, as PCA (Principal Component Analysis). We used PCA to reduce NCC amplitudes into two main features. Fig. 10 shows that the two features so obtained are very well-correlated with the TDOA features we used throughout this paper. This clearly demonstrates the delay of arrival is the main physical phenomenon that identifies the pressed key.

Feeding the Bayes learning algorithm with the two features obtained by NCC-PCA, the obtained recognition rate was $95.1 \%$, very close to the $96.4 \%$ obtained with the TDOA features. Using the three most important features obtained by NCC-PCA, the recognition rate is $97.7 \%$, slightly higher than the rate obtained with the two TDOA features. This may indicate that there are other information (besides the time of arrival) in the NCC amplitudes that may help increasing slightly the recognition rate. Maybe the classifier is using specific vibration pattern of each key, wave reflections inside the device or some other complex phenomena to improve the key classification rate. If we use four features, the recognition rate decreases to $96.5 \%$. 


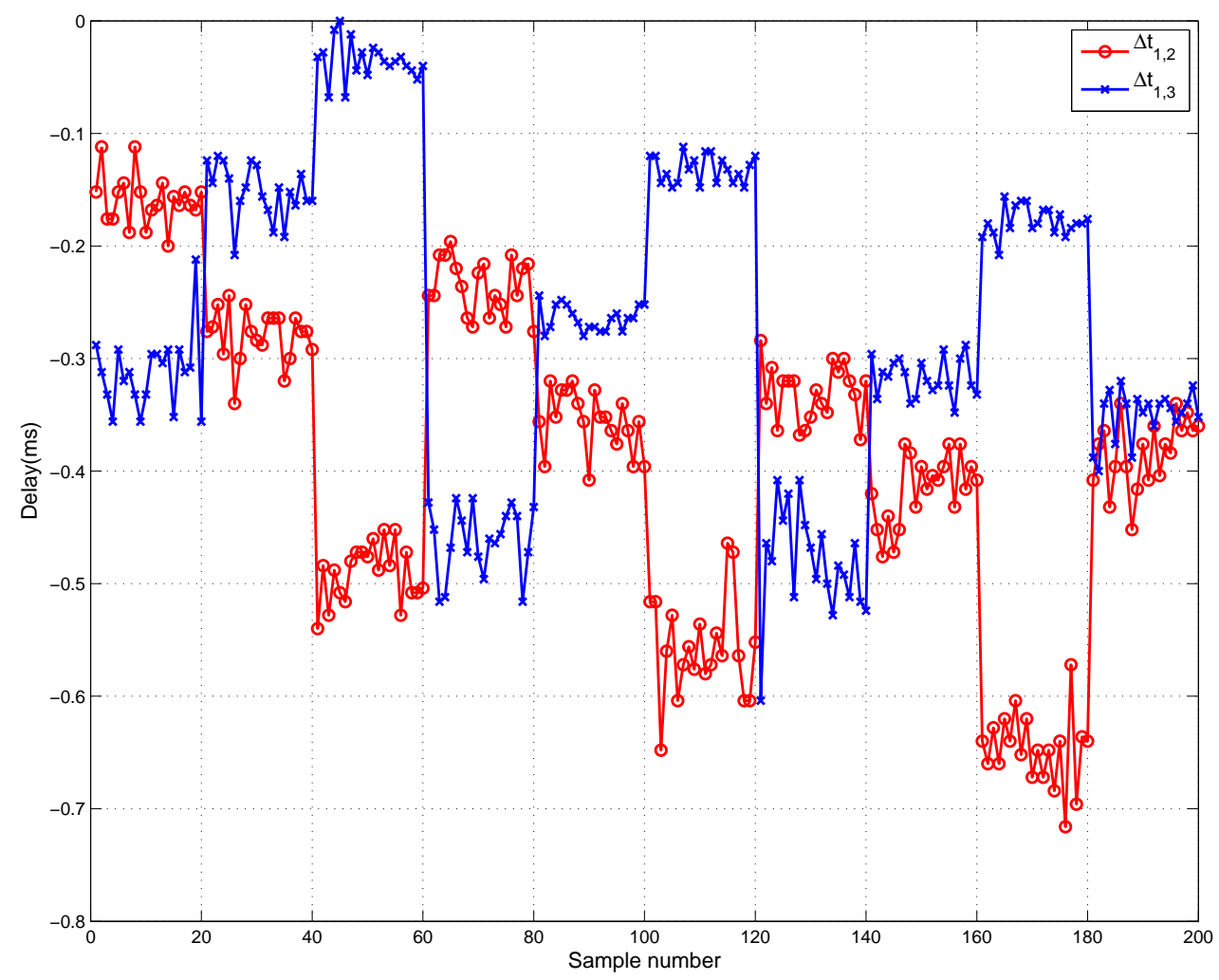

Figure 8: The features obtained in PIN-pad experiment. Each graph represents the delays between pairs of signals. X-axis is the test number, that is, $x=1$ to 20 correspond to key " 1 ", $x=21$ to 40 to key "2" and $x=181$ to 200 to key " 0 ". Only $\Delta t_{1,2}$ and $\Delta t_{1,3}$ were used. See text.

Table 3: Calculation of the Cost of PIN-pad Vibration Delay Attack

\begin{tabular}{lll}
\hline Factor & Identification & Exploitation \\
\hline Attack time & Beyond 160 hours $=5.5$ & $\leq 1$ hour $=0$ \\
\hline Expertise & Expert $=4$ & Layman $=0$ \\
\hline Knowledge of the PIN entry device & Public $=0$ & Public $=0$ \\
\hline Access to the PIN entry device & Mechanical Sample $=1$ & Mechanical Sample $=1$ \\
\hline Equipment required for the attack & Standard $=1$ & Standard $=1$ \\
\hline Specific parts required & Standard $=1$ & Standard $=1$ \\
\hline Total cost & $\mathbf{1 2 . 5}$ & $\mathbf{3}$ \\
\hline
\end{tabular}

\subsection{PCI Requirements}

237

PCI requires that an attack such as described in this work should be possible only with very high cost ${ }_{238}$ of 26 for identification and 13 for exploitation ${ }^{2}$. Nevertheless, the vibration delay attack to this PCI-PTS 239 compliant equipment costs only 12.5 for identification and 3.5 for exploitation (Table 3 ). The method used 240 to calculate the costs can be found in [20, p. 142]. 


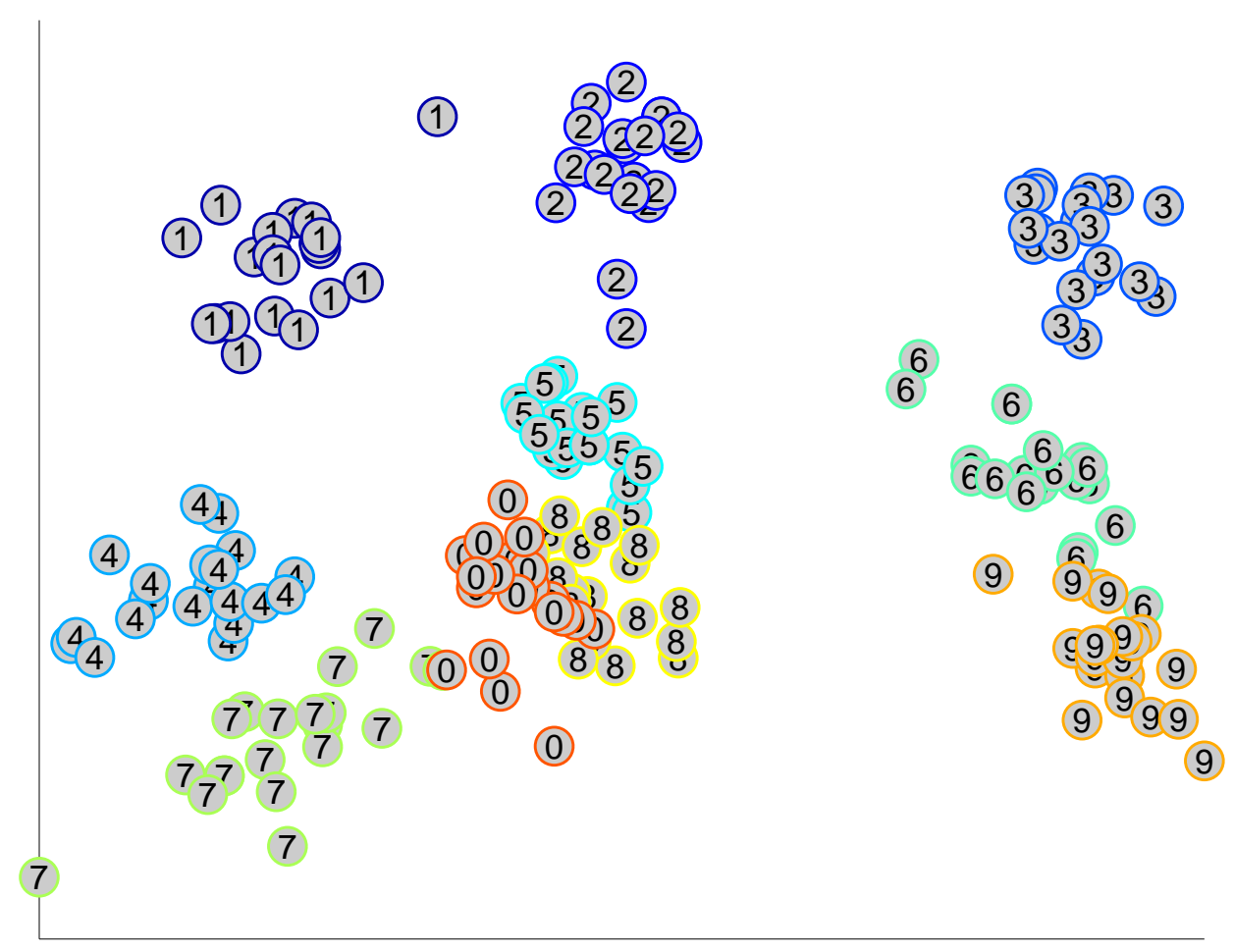

Figure 9: Estimation of the key locations of the PIN-pad experiment.

Table 4: Comparisons between the Main Experiments

\begin{tabular}{rcccc}
\hline & \multicolumn{2}{c}{ Previous work } & & This work \\
\cline { 2 - 3 } \cline { 5 - 5 } & ATM & PIN2 rigid & & PIN-pad \\
\hline Features per keystroke & 63 & 165 & & 3 \\
\hline Accelerometers & 3 & 2 & 3 \\
\hline Success rate & $98.4 \%$ & $76.7 \%$ & & $96.4 \%$ \\
\hline
\end{tabular}

\section{Considerations}

Table 4 compares the main experiments of our previous work [2] and of this work. Clearly, "PIN2 rigid mode" experiment of the previous work has the lowest success rate. As we now know the main physical phenomenon for leaking the information, we can explain the cause for this low rate. It is because in that experiment we used only two accelerometers. Thus, TDOA cannot uniquely determine the location of the vibration source.

The success rate of the ATM experiment of our previous work is slightly higher than PIN-pad experiment of this work. The recognition rates of the two experiments cannot be compared directly, because they are attacking two different devices (ATM keypad and PIN-pad). However, as we said in the last Section, it seems that there are other information (besides TDOA) in NCC amplitudes that may increase slightly the recognition rate.

2 "There is no feasible way to determine any entered and internally transmitted PIN digit by monitoring sound, electromagnetic emissions, power consumption or any other external characteristic available for monitoring - even with the cooperation of the device operator or sales clerk - without requiring an attack potential of at least 26 for identification and initial exploitation with a minimum of 13 for exploitation." [20, p. 16] 

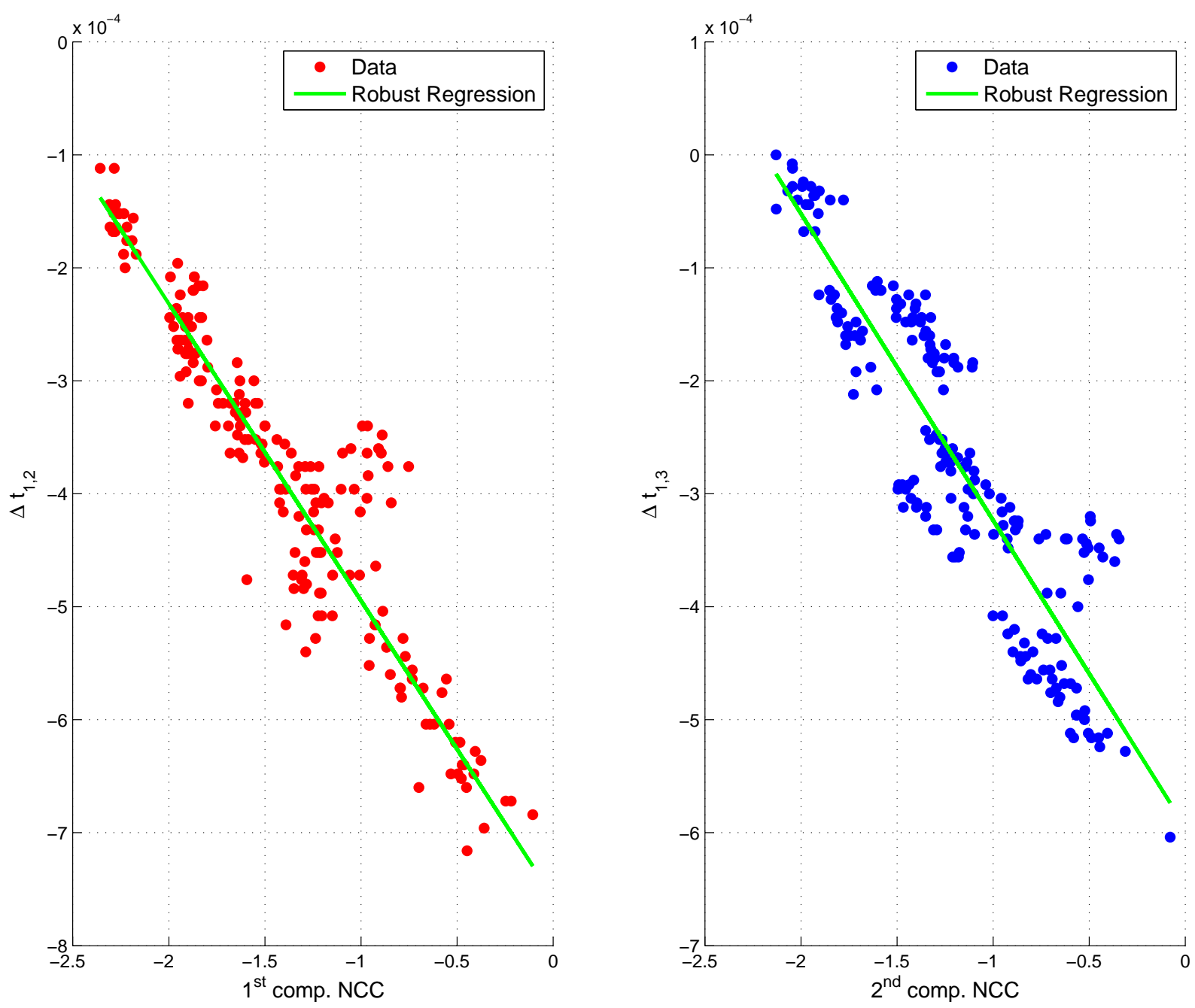

Figure 10: Comparison between the two main NCC-PCA components and the two TDOA features (the delays between the vibration signals). The pairs of features computed in different ways are highly correlated.

\section{Conclusion}

In this paper, we have demonstrated that the primary cause that makes it possible to identify the pressed key by monitoring the vibrations with accelerometers is the relative delays in the wavefront arrival times at different accelerometers located at different points. We have shown that the propagation delay of the wavefront generated by the keystroke makes each accelerometer feel similar vibrations at different moments. These relative delays is used in our "vibration delay attack". A simple classification scheme using the relative delays yielded $96.4 \%$ of key recognition success rate.

We also have shown that a PIN-pad, a device properly designed to counter side-channel attacks and PCI-PTS compliant is very vulnerable to the vibration delay attack. Clearly, the vibration delay attack can also be applied to touch screen devices.

Our finding indicates (i) the care that an engineer must have to design secure human-machine interface devices in the future and (ii) a new attack vector that certification processes must address hereafter. 

${ }_{287} P=\left(P^{x}, P^{y}\right)$ is: to compute NCC.

where $c_{1,2}$ is: (Fig. B.11).

Let the vector $v$ with elements $v_{i}, 0 \leq i<N$ represent the acceleration values captured by an accelerometer. The mean-corrected vector $\tilde{v}$ has elements $\tilde{v}_{i}=v_{i}-\bar{v}$, where $\bar{v}$ is the mean of $v$. We use only mean-corrected acceleration values, because we are not interested in the static acceleration of gravity. The correlation coefficient between the two mean-corrected vectors is:

$$
\operatorname{corr}(\tilde{v}, \tilde{w})=\frac{\tilde{v} \cdot \tilde{w}}{\|\tilde{v}\|\|\tilde{w}\|}
$$

Correlation coefficient measures the "similarity" between the two vectors, invariant to bias (because the vectors are mean-corrected) and to gain (because the vectors are divided by their norms).

Normalized cross correlation (NCC) between vectors $v$ and $w$ is a vector denoted as $\tilde{v} \otimes \tilde{w}$ whose elements are the correlation coefficients computed between time-shifted vectors, ignoring the elements that do not have the matching pair. It has $2 N-1$ elements:

$$
(\tilde{\mathbf{v}} \otimes \tilde{\mathbf{w}})_{n}= \begin{cases}\frac{\sum_{i=0}^{N-n-1} \tilde{v}_{i} \tilde{w}_{n+i}}{\sqrt{\sum_{i=0}^{N-n-1} \tilde{v}_{i}^{2} \sum_{i=0}^{N-n-1} \tilde{w}_{n+i}^{2}}}, & 0 \leq n<N \\ (\tilde{\mathbf{w}} \otimes \tilde{\mathbf{v}})_{-n}, & -N<n<0\end{cases}
$$

Note that $(\tilde{v} \otimes \tilde{w})_{0}=\operatorname{corr}(\tilde{v}, \tilde{w})$. NCC has been used for a long time in computer vision to find templates in search images, in an operation called template matching. We use Matlab function $x \operatorname{cov}(v, w$, 'coeff')

\section{Appendix B. Source location estimation}

We present here the technique used to estimate the positions of keys throughout this paper. Note that it is not necessary to know the spatial position of the pressed key in order to identify it. We suppose that the group velocity is constant throughout the device and consequently that the relative distances are roughly equivalent to the measured relative delays. For instance, we consider that the distance $d_{1}-d_{2}$ is approximately equal to the measured relative delay $\Delta t_{1,2}$ between accelerometers $A_{1}$ and $A_{2}$ (Fig. B.11). Similarly, we assume that $d_{1}-d_{3} \approx \Delta t_{1,3}$ and $d_{2}-d_{3} \approx \Delta t_{2,3}$.

The following reasoning demonstrates that only two time differences carry useful information. Consider $\Delta t_{1,2}=t_{1}-t_{2}$. Doing the same for $\Delta t_{1,3}$ and $\Delta t_{2,3}$, it is easy to see that $\Delta t_{2,3}=\Delta t_{1,3}-\Delta t_{1,2}$, a linear combination of the other two features, not carrying new information.

We estimate the source location $P$ by a simple numerical optimization, using Matlab function fminunc. We minimize the following functional:

$$
f=c_{1,2}+c_{1,3}
$$

$$
c_{1,2}= \begin{cases}{\left[d_{1}^{2}-\left(d_{2}+\Delta t_{1,2}\right)^{2}\right]^{2},} & \Delta t_{1,2} \geq 0 \\ {\left[d_{2}^{2}-\left(d_{1}+\Delta t_{1,2}\right)^{2}\right]^{2},} & \Delta t_{1,2}<0 .\end{cases}
$$

The cost $c_{1,3}$ is defined similarly. The distance $d_{i}$ from the accelerometer $A_{i}=\left(A_{i}^{x}, A_{i}^{y}\right)$ to the point

$$
d_{i}=\left\|A_{i}-P\right\|=\sqrt{\left(A_{i}^{x}-P^{x}\right)^{2}+\left(A_{i}^{y}-P^{y}\right)^{2}}
$$

If we substitute Eq. B.2 and B.3 in Eq. B.1 and minimize $f$, we get the approximate position of point $P$ 


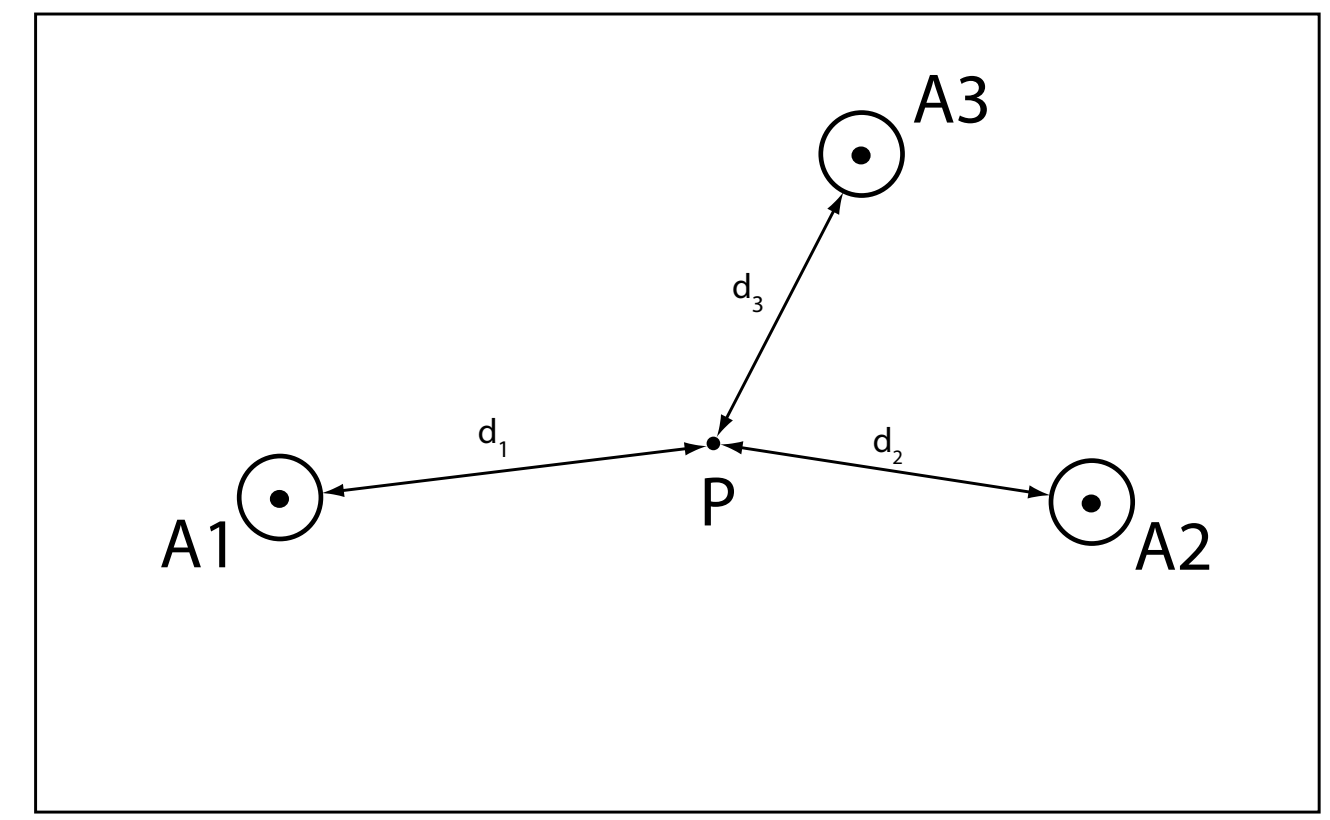

Figure B.11: Diagram of trilateration method.

\section{References}

[1] Verizon, Verizon 2014 Data Breach Investigations Report (2014). URL http://www . verizonenterprise.com/DBIR/2014/

[2] G. de Souza Faria, H. Y. Kim, Identification of pressed keys from mechanical vibrations, Information Forensics and Security, IEEE Transactions on 8 (7) (2013) 1221-1229. doi:10.1109/TIFS.2013.2266775.

[3] A. Tarantola, Inverse Problem Theory and Methods for Model Parameter Estimation, Society for Industrial and Applied Mathematics, 2005. arXiv:http://epubs.siam.org/doi/pdf/10.1137/1.9780898717921, doi:10.1137/1.9780898717921. URL http://epubs.siam.org/doi/abs/10.1137/1.9780898717921

[4] D. Asonov, R. Agrawal, Keyboard acoustic emanations, in: Security and Privacy, 2004. Proceedings. 2004 IEEE Symposium on, 2004, pp. 3-11. doi:10.1109/SECPRI.2004.1301311.

[5] Y. Berger, A. Wool, A. Yeredor, Dictionary attacks using keyboard acoustic emanations, in: In Proceedings of Computer and Communications Security (CCS, 2006.

[6] L. Zhuang, F. Zhou, J. D. Tygar, Keyboard acoustic emanations revisited, ACM Trans. Inf. Syst. Secur. 13 (1) (2009) 3:1-3:26. doi:10.1145/1609956.1609959. URL http://doi.acm.org/10.1145/1609956.1609959

[7] T. Halevi, N. Saxena, A closer look at keyboard acoustic emanations: Random passwords, typing styles and decoding techniques, in: Proceedings of the 7th ACM Symposium on Information, Computer and Communications Security, ASIACCS '12, ACM, New York, NY, USA, 2012, pp. 89-90. doi:10.1145/2414456.2414509. URL http://doi.acm.org/10.1145/2414456.2414509

[8] P. Marquardt, A. Verma, H. Carter, P. Traynor, (sp)iphone: Decoding vibrations from nearby keyboards using mobile phone accelerometers, in: Proceedings of the 18th ACM Conference on Computer and Communications Security, CCS '11, ACM, New York, NY, USA, 2011, pp. 551-562. doi:10.1145/2046707.2046771.

URL http://doi.acm.org/10.1145/2046707.2046771

[9] M. Ge, Analysis of source location algorithms - part i: Overview and non-iterative methods, J. Acoustic Emission 21. URL http://www.ndt.net/article/jae/papers/21-014.pdf

[10] M. Ge, Analysis of source location algorithms - part ii: Iterative methods, J. Acoustic Emission 21. URL http://www.ndt.net/article/jae/papers/21-029.pdf

[11] K. Ho, Y. Chan, Solution and performance analysis of geolocation by tdoa, Aerospace and Electronic Systems, IEEE Transactions on 29 (4) (1993) 1311-1322. doi:10.1109/7.259534.

[12] F. Gustafsson, F. Gunnarsson, Positioning using time-difference of arrival measurements, in: Acoustics, Speech, and Signal Processing, 2003. Proceedings. (ICASSP '03). 2003 IEEE International Conference on, Vol. 6, 2003, pp. VI-553-6 vol.6. doi:10.1109/ICASSP. 2003.1201741.

[13] D. Manolakis, Efficient solution and performance analysis of 3-d position estimation by trilateration, Aerospace and Electronic Systems, IEEE Transactions on 32 (4) (1996) 1239-1248. doi : 10.1109/7.543845.

[14] T. Schumacher, D. Straub, C. Higgins, Toward a probabilistic acoustic emission source location algorithm: A bayesian 
approach, Journal of Sound and Vibration 331 (19) (2012) 4233 - 4245. doi:http://dx.doi.org/10.1016/j.jsv.2012. 04.028.

URL http://www.sciencedirect.com/science/article/pii/S0022460X12003446

328 [15] K. Arun, E. Ong, A. Khong, Source localization on solids using kullback-leibler discrimination information, in: Information, Communications and Signal Processing (ICICS) 2011 8th International Conference on, 2011, pp. 1-5. doi:10.1109/ICICS. 2011.6174299

[17] L. Meirovitch, Analytical Methods in Vibrations, Macmillan, 1967.

18] Freescale Semiconductor - MMA7361LC: $\pm 1.5 \mathrm{~g}, \pm 6 \mathrm{~g}, 3$-Axis Analog Output Acceleration Sensor (February 2015). URL http://www.freescale.com/webapp/sps/site/prod_summary.jsp?code=MMA7361LC

335 [19] G. S. Faria, H. Y. Kim, Identificação das teclas digitadas a partir da vibração mecânica, in: Anais do 30o Simpósio Brasileiro de Telecomunicações - SBrT, 2012.

337 [20] Payment Card Industry - Security Standards Council LLC, PIN Transaction Security (PTS) Point of Interaction (POI) Modular Derived Test Requirements v4.0 (June 2013). 


\section{Identification of Pressed Keys by Acoustic Transfer Function}

\author{
Gerson de Souza Faria \\ Departamento de Engenharia de Sistemas Eletrônicos \\ Escola Politécnica \\ Universidade de São Paulo, Brazil \\ Email: gerson.faria@usp.br
}

\author{
Hae Yong Kim \\ Departamento de Engenharia de Sistemas Eletrônicos \\ Escola Politécnica \\ Universidade de São Paulo, Brazil \\ Email: hae@lps.usp.br
}

\begin{abstract}
The possibility of uncovering the sequence of pressed keys in a PIN-pad, ATM or other device with mechanical keyboard that processes sensitive information is a serious security threat. In this paper, we show that the Acoustic Transfer Function (ATF) of the device carries information that discloses the pressed key. To demonstrate this hypothesis, we glued two microphones in empty spaces of two different PIN-pads, collected the acoustic emission generated by the keystrokes and estimated the transfer functions of the system through the two acquired audio signals. A simple classification scheme using the ATFs yielded $99.6 \%$ of recognition accuracy in one device and $46 \%$ in the other. The results show that there are devices that can be easily attacked using ATF and those that are more difficult to attack using this technique. We analyzed again the data where we obtained $99.6 \%$ of accuracy, this time using the traditional frequency spectrumbased technique, obtaining only $52 \%$ of recognition rate. The results also show that the certification process has failed in identifying this vulnerability.
\end{abstract}

Keywords-information security, side-channel attack, acoustic emission, transfer function, smart card skimming, EMV, PCI, Common Criteria, ATM, PIN-pad.

\section{INTRODUCTION}

Mechanical keypads are widely used for entering sensitive data. Passwords are typed in mechanical keypads in ATMs (Automatic Teller Machines) or PIN-pads (devices used in card transactions to input the cardholder's Personal Identification Number, also known as PIN entry devices or PEDs). In some countries, electors use electronic voting machines with mechanical keypads to choose the candidate. Thus, the possibility that someone finds out the sequence of pressed keys, without the user's knowledge or consent, is a serious security threat.

In card operations, the theft of card information in an otherwise legitimate transaction, known as "skimming", was responsible for $87 \%$ of attacks against ATMs in 2013, as reported in [1]. Card issuers estimate that U.S. merchants will acquire 575 million new chip-enabled payment cards and terminals by the end of $2015^{1}$. All of these new terminals are required to be certified by laboratories following PCI-PTS-

${ }^{1}$ http://newsroom.mastercard.com/press-releases/nearly-half-u-s-merchantterminals-accept-chip-2015/\#prclt-sSxZ1V62

\section{$\mathrm{POI}^{2}$ and/or Common Criteria ${ }^{3}$ evaluation standards.}

In this work, we use Acoustic Transfer Function (ATF) to identify the pressed keys of PIN-pads. Let us call our new attack ATF attack. In a PIN-pad certified by both PCI and Common Criteria, we could identify the pressed keys with $99.6 \pm 0.8 \%$ of accuracy, where one person pressed the keys for the training and another person pressed the keys for the test, emulating a realistic attack scenario. Analyzing the same data with the traditional frequency spectrum-based technique, we obtained only $52 \%$ of recognition rate. However, in another PIN-pad (also certified by PCI and Common Criteria), we obtained only $48 \%$ of accuracy using ATF technique. The results show that there are devices that can be easily attacked using ATF and those that are more difficult to attack using this technique. We make some considerations for manufacturers to construct ATF attack-resistant devices.

Usually, modern ATM keypads are encrypted. They are sealed modules that encrypt the PIN soon after the entry. So, non-encrypted PIN numbers are not meant to be accessible from outside either by physically tapping onto wires or remotely sensing electromagnetic radiation. Any tampering of the keypad causes it to permanently disable itself. Similarly, PIN-pads are protected modules that permanently disable themselves if tampered. However, Drimer et al. [2] show cases where this mechanism fails. The possibility of identifying the sequence of pressed keys through acoustic emissions analyzed using ATFs is a serious security failure of secure keypads because they are designed to resist against any attempt of eavesdropping. The devices will continue functioning normally while confidential data are stolen. In the literature, there are some papers that identify the pressed key by sound, because each key usually emits a characteristic sound when pressed. Asonov and Agrawal [3] achieved 79\% of key recognition success rate when identifying one out of 30 keys in a PC keyboard. Berger et al. [4] use keyboard acoustic emanations and a dictionary to recognize correctly $73 \%$ of the English words typed in a PC keyboard, without any training. Zhuang

\footnotetext{
${ }^{2}$ PCI-PTS-POI stands for PIN Transaction Security - Point of Interaction, a set of requirements specific for PIN entry devices, proposed by the Payment Card Industry - PCI. Device compliance can be consulted at https://www.pcisecuritystandards.org/approved_companies_ providers/approved_pin_transaction_security.php

${ }^{3}$ The Common Criteria for Information Technology Security Evaluation is an international standard for computer security certification. http://www. commoncriteriaportal.org
} 
et al. [5] take as input 10-minute sound recording of a user typing English text using a keyboard and recovers up to $96 \%$ of typed characters. Halevi [6] uses keyboard acoustic emanations for eavesdropping over random passwords, without using dictionary, achieving $40 \%$ to $64 \%$ recognition rate per character

Similarly to acoustic emission, each key seems to emit a characteristic mechanical vibration when pressed. However, this idea has been much less explored in the literature. Marquardt and Verma [7] use this idea to recognize keystrokes of a computer keyboard. They use the accelerometer of a smartphone placed near the computer's keyboard to capture the vibrations. They do not actually identify the pressed key. Instead, they classify keystrokes in "left" or "right" and pairs of keystrokes in "near" and "far". They achieved classification rates from $65 \%$ to $91 \%$ making those binary decisions.

Faria and Kim [8] show that it is possible to identify the pressed key by gluing accelerometers in the device, acquiring mechanical vibration signals generated by keystrokes and analyzing them. They called it "vibration attack". They achieved 98.4\% of accuracy in identifying keystrokes in ATM keypad, $76.7 \%$ in PIN-pad resting on a hard surface and $82.1 \%$ in PINpad hold in hand.

The approach used in this work is of a different nature: even if it were possible to have all the keys emit exactly the same sound and vibration, it would be still possible to identify the pressed key by estimating the acoustic transfer function of the system. The acoustic transfer function depends on device's empty space, the audio source location (the pressed key) and the location of microphones.

Researchers in acoustics engineering [9, vol. 2, p. 1381] use transfer function to estimate spatial frequency responses of rooms, reverberation times and other characteristics. In our case, the "room" is basically the SAM (Secure Access Module) card access compartment located just below the keypad, where the sound waves interact.

In theory, since the transfer function is a characteristic of the system and not of the excitation source, the ATF attack will be user-independent - no matter who presses the key, it will be correctly identified.

The rest of the paper is organized as follows. We present the basic theory on acoustic model in Section II. We present our preliminary experiment to test our hypothesis in (Section III). We tested ATF attack in two commercial PIN-pads designed to be secure and present the results in Section IV and Section V. We make some considerations on the results and discuss the certification processes in Section VI. We present our conclusions in Section VII. Appendix presents the implementation details: audio segmentation, feature extraction and classification methods.

\section{Acoustic Model}

\section{A. Theory}

Let us denote the signal of a microphone measuring air pressure at time $t$ and position $\mathbf{r}$ as $y(t, \mathbf{r})$. Given some excitation $x(\tau, \boldsymbol{\rho})$ (also depending on time and position) and considering the system as linear, time invariant and spatially

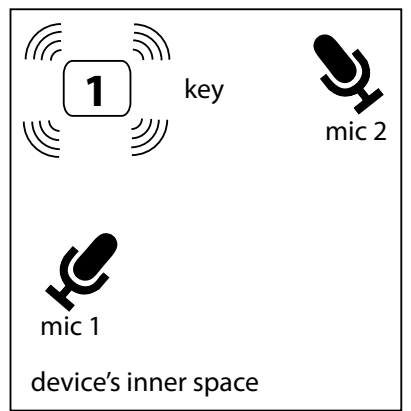

system ' 1 '

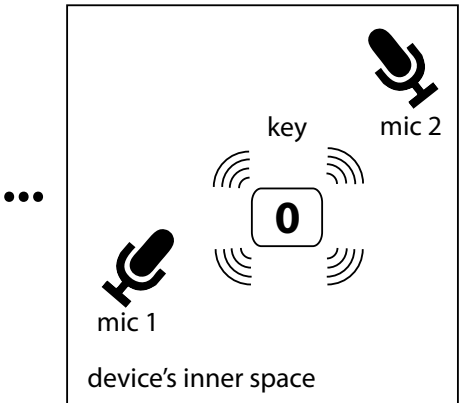

system ' 0 '
Fig. 1. The ensemble formed by the device's inner space, the position of the key and of the two microphones compose a system whose transfer function must be estimated. The keys are classified based on the transfer functions.

homogeneous, the response signal $y$ can be described through a generalization of convolution [9, vol. 1, p. 14]:

$$
y(t, \mathbf{r})=\iint h(t-\tau, \mathbf{r}-\boldsymbol{\rho}) x(\tau, \boldsymbol{\rho}) \mathrm{d} \boldsymbol{\rho} \mathrm{d} \tau .
$$

where $h(\cdot)$ is the impulse response of the entire system. The impulse response describes the linear transmission properties of any system able to transport or transform energy in a certain frequency range $([9$, vol. 1, p. 65$])$. If the system is nonlinear, the equation describing the response signal given an excitation is not of the form of Eq. 1.

Since the impulse response is dependent on the spatial position of both the source and the measure locations, if we maintain the latter (microphones) fixed in the space, the impulse response can be used as a signature of the position of the audio source, providing that it can be estimated with a reasonable accuracy. There are several methods for estimating the impulse response of an acoustic system. All of them use as excitation sources deterministic signals or noise, in order to cover some desired range of the frequency spectrum. In our case, the excitation sources are the audio provided by distinct keys being pressed by distinct persons. Since the transfer function is a characteristic of the system and not of the excitation source, the attack will be user independent, i.e., no matter who presses the key, it will be, in theory, successfully classified.

Fig. 1 depicts the attack model proposed. The positions of keys define each system, since other factors are fixed (inner space of the device and the positions of microphones put inside it). Therefore, we have one system for each key, described by the transfer function of the system. Each transfer function is estimated from the signals captured simultaneously by the microphones, one taken as system's "input" and other as system's "output".

\section{B. Transfer Function Estimation}

For a given spatial configuration, Eq. 1 can be expressed through convolution notation:

$$
y(t)=h(t) * x(t) .
$$


This relation has an equivalent representation in the frequency domain, as the product of the Fourier transforms of system's impulse response and input signal:

$$
Y(f)=H(f) \cdot X(f) .
$$

The term $H(f)$ is called the transfer function of the system. Discrete estimates of this function will be used as the features that will characterize our system. However, as we use only discrete positions (the positions of keys), we can rewrite the transfer functions expression as:

$$
H_{i}(f)=H\left(f, \mathbf{r}_{\mathbf{i}}\right) .
$$

As stated before, there are several methods for its estimation. Here we will use the classic nonparametric Welch method [10], that can be computed with the Matlab procedure tfestimate. Resulting vectors $H_{i}$ are used as features, through the method described in the Appendix. This method is not mandatory and other transfer function estimation methods can be used instead.

\section{BOX MODEL EXPERIMENT}

If different audio source locations generate distinct transfer functions, we can use these functions as "location signatures". So, in order to observe the behavior of distinct source positions in the transfer function, we made an experiment with a small acrylic box with three holes (Fig. 2), using an earphone as audio source but changing its location among the three holes. We stress that this experiment (and all the subsequent ones) does not use the true transfer functions between the earphone and the two microphones, because in an ATF attack the true sound emitted by the key is unknown. We estimate the transfer function from the signals captured simultaneously by the two microphones, one taken as system's "input" and other as system's "output".

The audio signal is captured by two condenser microphones placed inside the box. Two distinct excitation signals were used $^{4}$ : (i) $\approx 30$ s of white noise and (ii) $\approx 15 \mathrm{~s}$ of sinusoidal sweep increasing from $20 \mathrm{~Hz}$ to $20 \mathrm{KHz}$. $\mathrm{T}$ he dimensions of the box are approximately $40 \mathrm{~mm} \times 65 \mathrm{~mm} \times 85 \mathrm{~mm}$. The microphones used for recording have a pre-amplifier operating with gain of $50 \times$. The output of the pre-amplifiers are connected in the "line-in" input of a PC and recorded at $96 \mathrm{KS} / \mathrm{s}$ with the program "Audacity".

Fig. 3 depicts the absolute values (magnitudes) of the transfer functions for the three holes. The transfer functions are remarkably distinct between the different holes, and at the same time very similar using white noise or sweep tone, since the transfer function is a characteristic of the system and not of the excitation signal.

\section{INGENICO IPP320 PIN-PAD EXPERIMENT}

Fig. 4 shows the first PIN-pad we tested, an Ingenico iPP320, and the assembly of the experiment, where two condenser microphones were glued inside the SAM (Secure Access Module) card access compartment. We stress that a

\footnotetext{
${ }^{4}$ We used an iPhone application named "The Signal Generator" to generate the tones: https://itunes.apple.com/us/app/signal-generator-audiotest $/$ id543661843?mt=8
}

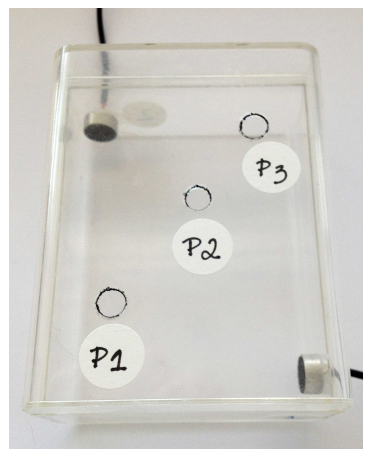

Fig. 2. An acrylic box was used to estimate three transfer functions, one for each position P1, P2, and P3. An earphone was used as excitation source playing tones through the holes, one hole at a time, keeping the others closed.
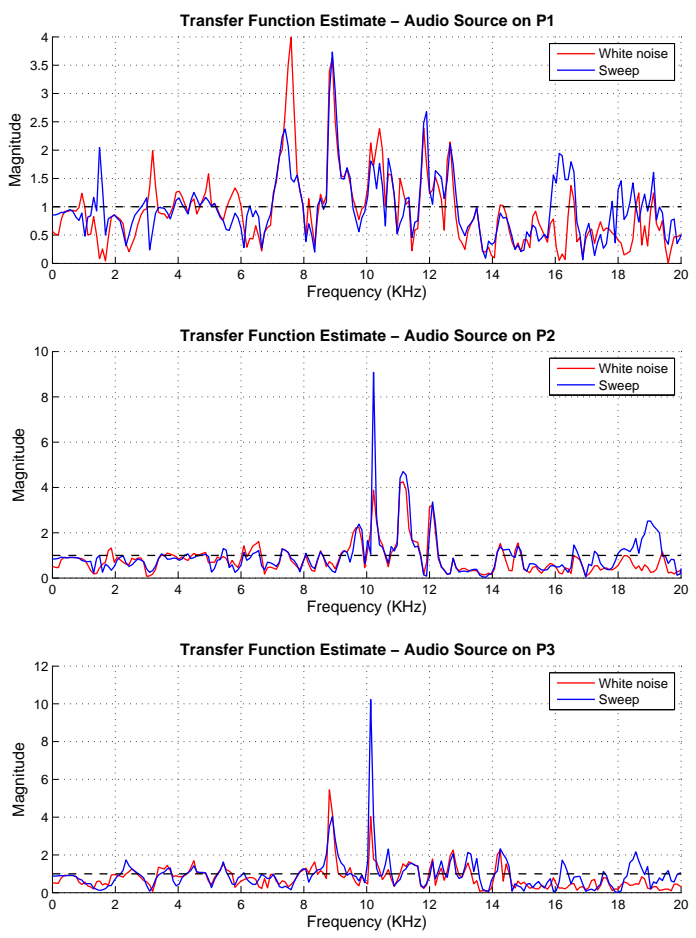

Fig. 3. The estimated transfer functions for the three holes of the box model. They are remarkably distinct between the different holes, but very similar using white noise or sweep tone as excitation source.

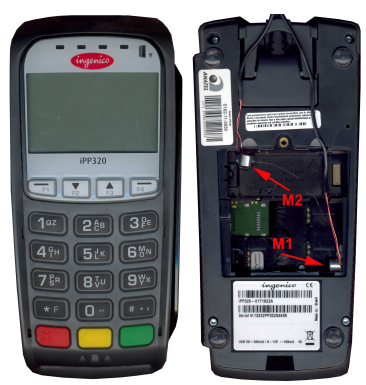

Fig. 4. (Left) Ingenico iPP320 PIN-pad used in the experiment. (Right) The bottom view showing the SAM compartment with the implanted microphones. 
PIN-pad is a tamper proof device and it permanently disables itself if opened. However, the space in the SAM card compartment is designed to be freely accessible.

Ingenico iPP320 is a widely used model in retail stores. This device is Common Criteria Certified ${ }^{5}$, PCI-PTS compliant, under 2.X and 3.X versions.

The choice of this model/brand was not guided by any vulnerability we could spot. We want to make it clear that most of PIN-pads with a SAM card compartment are potential targets of ATF attack and Ingenico iPP320 is not a special case. The SAM card compartment increases the vulnerability to ATF attack mainly because:

1) it provides room for implanting "hardware trojans" or "bugs", hidden within the compartment. ATF attack explores this space;

2) the compartment is normally located just below the keypad, the ideal place to capture the audio emanated from the keystrokes;

3) the SAM slots can eventually provide electrical power for the "bugs".

So, a hacker can put the microphones inside this compartment without disabling the device. A hacker can also easily put a wireless device to transmit the captured information. Thus, the attack can be executed in a undetectable way, without batteries and wires.

\section{A. Data Acquisition for Training and Testing}

To obtain the data sets for training and testing the system, one (training) person pressed 70 times each one of the " 0 " to "9" keys and both audio signals were recorded as a single stereo ".wav" file, with sampling rate of $96 \mathrm{KS} / \mathrm{s}$. Another (testing) person pressed the same keys 50 times. All pressings were done with PIN-pad's power off.

\section{B. Features and Model Evaluation}

Fig. 5 depicts the obtained features. Each color represents the "averaged" transfer function magnitude for the pressings of each user. They are very similar for the two users and distinct enough among keys, making them good features for the key identification.

Table I shows the confusion matrix. The recognition rate is extremely high $(99.6 \pm 0.8 \%)$, where 0.8 is the standard deviation of the 5 cross validations. See Appendix for the methods used for features extraction and classification.

\section{Comparison with the Frequency Approach}

In order to compare the ATF approach with the traditional frequency spectrum classification ${ }^{6}$, we used as features the estimated periodograms with normalization of total energy. We followed the same procedures used for the ATF feature dimensionality reduction and classification (See Appendix). This

\footnotetext{
${ }^{5}$ https://www.bsi.bund.de/SharedDocs/Downloads/DE/BSI/Zertifizierung/ Reporte08/0859a_pdf.pdf?_blob=publicationFile

${ }^{6}$ We did not reproduce faithfully Agrawal and Asonov's [3] experiment. We just used frequency spectrum as features, the approach these authors have introduced.
}
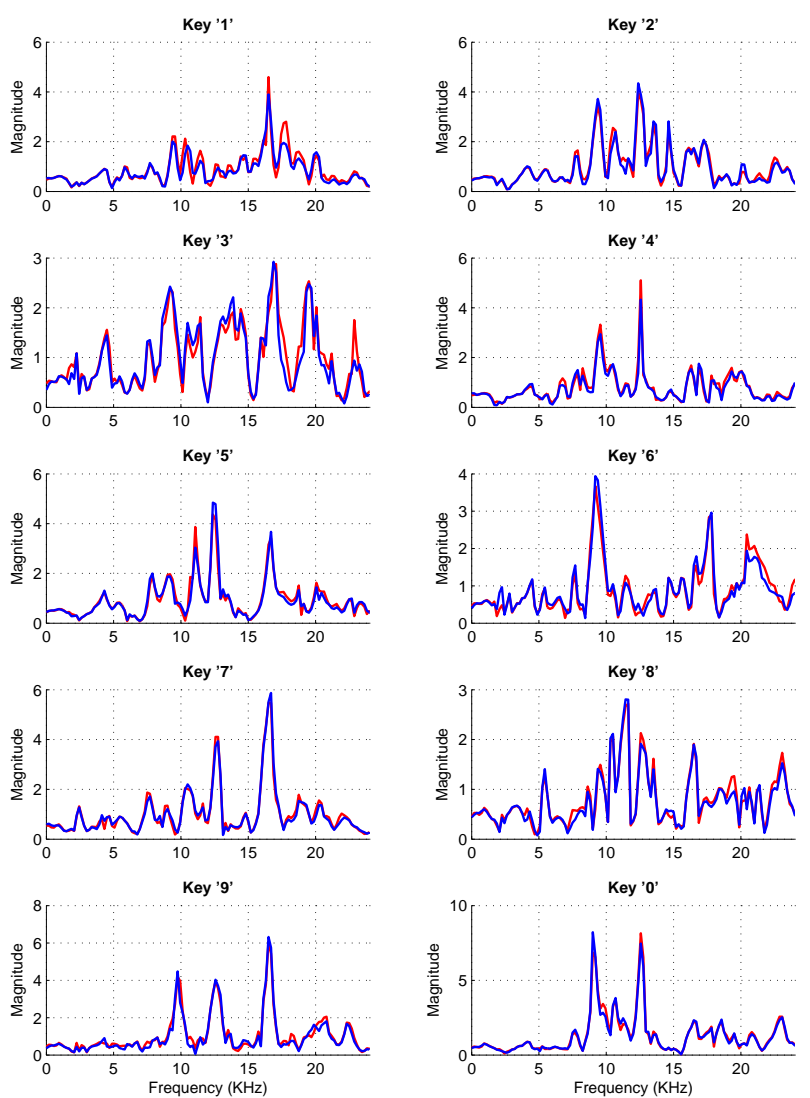

Fig. 5. The magnitudes of the transfer functions for each key obtained in Ingenico iPP320 experiment. Each color correspond to one user. The graphs show the averages for each key.

TABLE I. CONFusion Matrix OF THE IngEnico IPP-320 Transfer FUNCTION EXPERIMENT

\begin{tabular}{|c|c|c|c|c|c|c|c|c|c|c|c|}
\hline Key & 1 & 2 & 3 & 4 & 5 & 6 & 7 & 8 & 9 & 0 & Acc. $(\%)$ \\
\hline 1 & 244 & 1 & & & & & & & & & 99.6 \\
\hline 2 & & 245 & & & 1 & 3 & & & & 1 & 98.0 \\
\hline 3 & & & 230 & & & & & & & & 100.0 \\
\hline 4 & & & & 250 & & & & & & & 100.0 \\
\hline 5 & & & & & 205 & & & & & & 100.0 \\
\hline 6 & & & & & & 235 & & & & & 100.0 \\
\hline 7 & & & & & & & 240 & & & & 100.0 \\
\hline 8 & & & & & & & & 245 & & & 100.0 \\
\hline 9 & & 1 & & & 1 & 2 & 1 & & 245 & & 98.0 \\
\hline 0 & & & & & & & & & & 250 & 100.0 \\
\hline
\end{tabular}

approach uses only one microphone. The average recognition rate using periodogram was $(52 \pm 34 \%)$, a poor result.

\section{GERTEC PPC910 PIN-PAD EXPERIMENT}

Fig. 6 shows the other tested device, a Gertec PPC910 and the assembly of the experiment, where the microphones were glued in the back of the bottom cover of the SAM card access compartment. This device is PCI-PTS compliant, under 2.X and EMV 2000 Levels 1 and 2 compliant $^{7}$.

http://www.gertec.com/produto.aspx/produtosdetalhe/57/PPC_910 


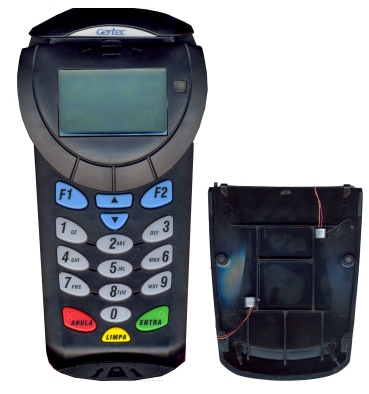

Fig. 6. (Left) Gertec PPC910 PIN-pad used in the experiment. (Right) The bottom cover with the implanted microphones.
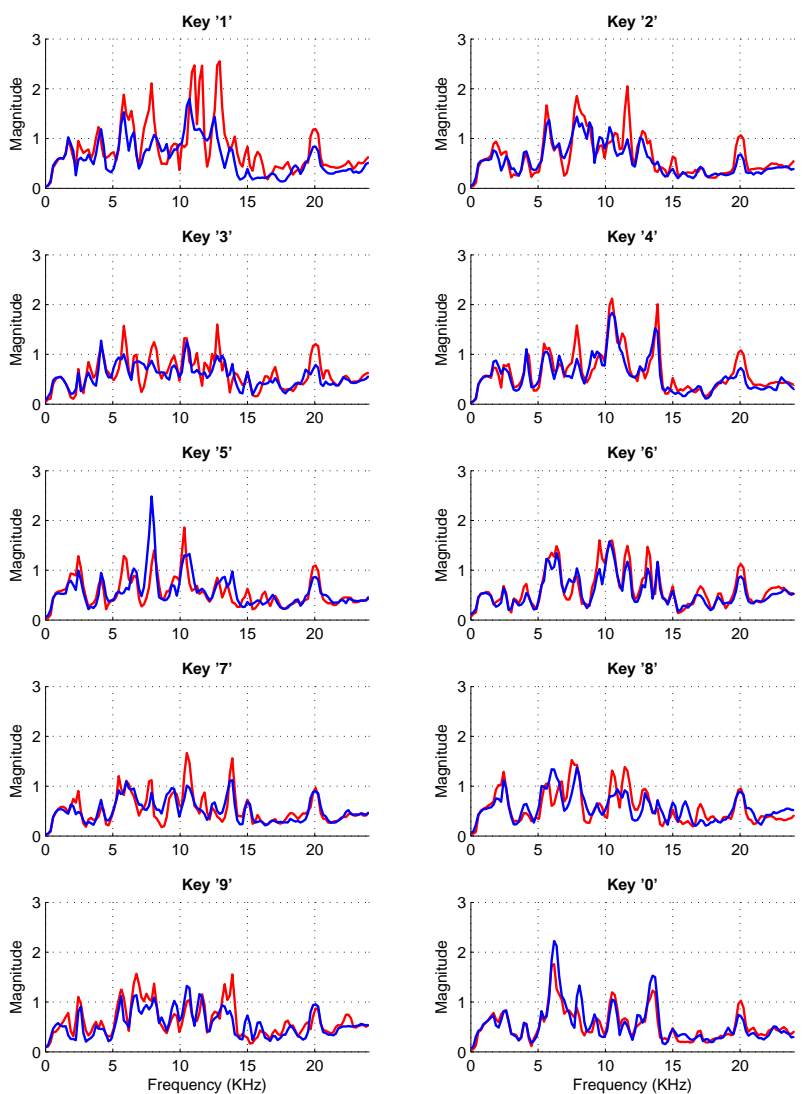

Fig. 7. The magnitudes of the transfer functions obtained in Gertec PPC910 experiment. Each color correspond to one user. The graph shows averages for each key. The transfer functions obtained from the keystrokes of the two users have poor agreement.

The signal acquisition process was the same as in the previous experiment, but not all the generated keystrokes were detected by our segmentation method because of the low acoustic energy emitted. Fig. 7 depicts the obtained features. As in the previous experiment, each color represents the "averaged" transfer function magnitude for the pressings of one user. Table II shows the confusion matrix. The average recognition rate is very poor $(46 \pm 22 \%)$. The real classification rate would be even lower if we consider that not all the generated keystrokes were detected by the segmentation method.
TABLE II. CONFUSION MATRIX OF the GERTEC PPC910 Transfer FUNCTION EXPERIMENT

\begin{tabular}{cccccccccccr}
\hline Key & 1 & 2 & 3 & 4 & 5 & 6 & 7 & 8 & 9 & 0 & Acc.(\%) \\
\hline 1 & 20 & 28 & 10 & 32 & 9 & 2 & 7 & & 21 & 1 & 15.4 \\
\hline 2 & 3 & 119 & & 13 & 11 & 7 & 6 & 7 & 26 & 13 & 58.0 \\
\hline 3 & & 3 & $\mathbf{4 1}$ & 11 & 8 & 1 & 1 & 4 & 12 & 9 & 45.6 \\
\hline 4 & 1 & 10 & & 128 & 9 & 1 & 3 & & 6 & 7 & 77.6 \\
\hline 5 & 3 & 8 & & 23 & $\mathbf{5 6}$ & 1 & 19 & 15 & 50 & 5 & 31.1 \\
\hline 6 & 1 & 14 & 2 & 11 & 5 & $\mathbf{1 0 3}$ & 9 & 3 & 7 & 10 & 62.4 \\
\hline 7 & & 17 & & 20 & 16 & 3 & 51 & 1 & 5 & 17 & 39.2 \\
\hline 8 & 1 & 14 & & 6 & 12 & 1 & 9 & 17 & 3 & 37 & 17.0 \\
\hline 9 & & 33 & 3 & 15 & 3 & 10 & 3 & 48 & $\mathbf{6 4}$ & 1 & 35.6 \\
\hline 0 & & 1 & & & 4 & 3 & & 1 & 16 & $\mathbf{7 0}$ & 73.7 \\
\hline
\end{tabular}

\section{CONSIDERATIONS}

\section{A. Qualitative observations}

We demonstrated experimentally that Ingenico iPP320 is much more vulnerable to ATF attack than Gertec PPC910. Even so, some keys have considerable recognition rates in Gertec's, deserving further analysis. Some qualitative observations regarding the operation of both equipments follow:

- Ingenico's keys leak an audible and inevitable "click". If, by one hand, this click is useful as acoustical and mechanical feedback for the operator, by the other hand it also furnishes acoustic information. Gertec's can be pressed in a way that no click is heard, so reducing the energy of the audio signal. We think this is the main cause of the low average classification rates for Gertec's.

- Ingenico's keys have a much more regular operation than Gertec's. The force used to press a key in Gertec's is greater and the key movement is very unstable.

- Gertecs's empty space are much more "corrugated" (see Fig. 6 right) and structurally complex than Ingenico's. This property can introduce nonlinearities affecting negatively the ATF linear model.

Another fact that may influence the success of the attack is how much dependent are the keys on a common support structure. If the keys are more closely dependent on a common structure (e.g. a loosely assembled printed circuit board where the contacts lie), it will be more difficult to distinguish systems for each key, because that structure may "blur" the origin of the sound source.

\section{B. PCI (Payment Card Industry)}

PCI requires that an attack such as described in this work should be possible only with very high cost of 26 for identification and 13 for exploitation [11, p. 16]. Nevertheless, the ATF attack costs only 12.5 for identification and 3 for exploitation (Table III). The method used to calculate the costs can be found in $[11$, p. 142].

\section{Common Criteria}

Many documents used in the certification process warn against acoustic emission attacks. Ingenico's Security Target 
TABLE III. CAlculation of the Cost of PIN-PAD ATF ATtack

\begin{tabular}{lll}
\hline Factor & Identification & Exploitation \\
\hline Attack time & Beyond 160 hours $=5.5$ & $\leq 1$ hour $=0$ \\
\hline Expertise & Expert $=4$ & Layman $=0$ \\
\hline Knowledge of the PIN entry device & Public $=0$ & Public $=0$ \\
\hline Access to the PIN entry device & Mechanical Sample $=1$ & Mechanical Sample $=1$ \\
\hline Equipment required for the attack & Standard $=1$ & Standard $=1$ \\
\hline Specific parts required & Standard $=1$ & Standard $=1$ \\
\hline Total cost & $\mathbf{1 2 . 5}$ & $\mathbf{3}$ \\
\hline
\end{tabular}

for iPP-320 states clearly which assets are being certified and PIN is one of them [12, sec. 4.1]. The same document [12, sec. 8.1.1.1] states that the device shall not emit sound, electromagnetic emissions, power consumption etc.

From the citations above, we can conclude that attacks based on acoustic emissions are explicitly covered by both PCI and Common Criteria requirements. And we can also conclude that the devices we attacked were evaluated and certified throughout these requirements. However, the certification process failed to identify the vulnerability explored in the ATF attack.

\section{CONCLUSION}

In this paper, we have demonstrated that the sound emitted by the keystrokes of a PIN-pad can be used to identify the sequence of pressed keys by analyzing the audio captured at two different points inside the device's SAM compartment. We have shown that the acoustic properties of the empty space, characterized by its acoustic transfer function (ATF), can be used as "location signatures". These signatures are used in our "ATF attack" to identify the pressed keys. In this preliminar research, a simple classification scheme using these signatures yielded $99.6 \%$ of key recognition success rate in one device and $46 \%$ in another one. This shows that there are some devices completely vulnerable to ATF attack, while others are less vulnerable. We made some considerations regarding what makes a device vulnerable to ATF attack. Our findings indicate that the certification process was not able to detect that sensitive information leaks from the device.

\section{ACKNOWLEDGEMENTS}

We would like to thank Ross A. Anderson for guidance on certification processes, specially Common Criteria, and also for information on responsible disclosure.

\section{APPENDIX}

We made the segmentation by (i) finding the $N$ highest peaks of $\sqrt{l^{2}(t)+r^{2}(t)}$, where $l(t)$ and $r(t)$ are respectively the audio signals of left and right channels; (ii) taking 4096 sample points, $80 \%$ after the peak, $20 \%$ before it; (iii) maintaining the segments with correlation coefficient between any pairs better or equal to $85 \%$, in order to avoid spurious signals. The audio segmentation is not the main focus of this work and other techniques can be used as well.

In the procedure tfestimate ${ }^{8}$, one can set the size of the FFT calculation in the power spectrum estimation. We set this value to 512 points for the PIN-pad experiments, generating a transfer function vector of 257 points. From these, the first 120 were chosen as features, representing a frequency range from 0 to $22.5 \mathrm{KHz}$. In order to reduce the dimensionality, we used the classic PCA (Principal Component Analysis) approach and selected the 30 eigenvectors with the largest eigenvalues, corresponding to $\approx 97 \%$ of the sum of all eigenvalues. More elaborate criteria for this procedure can be found in [13].

We used a standard artificial neural network for the classification. We used the configuration with input layer of size 30 , one hidden layer of size 50 and the output with size 10 , encoding the 10 keys.

In order to avoid overfitting, the data of one person was used exclusively for training the network and the data of another person was used for the testing, emulating a realistic attack scenario where the victim's pressing behavior is unknown. We repeated training/testing process 5 times, each time using a different training set and tested using all available testing data.

\section{REFERENCES}

[1] Verizon 2014 Data Breach Investigations Report. [Online]. Available: http://www.verizonenterprise.com/DBIR/2014/

[2] S. Drimer, S. J. Murdoch and R. Anderson, "Thinking inside the box: system-level failures of tamper proofing," in Proc. IEEE Symp. on Security and Privacy, pp. 281-295, 2008.

[3] D. Asonov and R. Agrawal, "Keyboard acoustic emanations," in Proc. IEEE Symp. Security and Privacy, pp. 3, 2004.

[4] Y. Berger, A. Wool, and A. Yeredor, "Dictionary attacks using keyboard acoustic emanations," in Proc. 13th ACM Conf. Computer and Communications Security, pp. 245-254, 2006.

[5] L. Zhuang, F. Zhou, and J. D. Tygar, "Keyboard acoustic emanations revisited," ACM T. Information and System Security, vol. 13, no. 1, pp. 3:1-3:26, Oct. 2009.

[6] T. Halevi and N. Saxena, "A Closer Look at Keyboard Acoustic Emanations: Random Passwords, Typing Styles and Decoding Techniques." [Online]. Available: http://eprint.iacr.org/2010/605.pdf, 2010.

[7] P. Marquardt, A. Verma, H. Carter, and P. Traynor, "(sp)iPhone: decoding vibrations from nearby keyboards using mobile phone accelerometers," in Proc. 18th ACM Conf. on Computer and Communications Security, 2011.

[8] G. S. Faria, H. Y. Kim, "Identification of Pressed Keys From Mechanical Vibrations," IEEE T. Information Forensics and Security, vol. 8, no. 7, pp. 1221-1229, July 2013.

[9] D. Havelock, S. Kuwano, M. Vorländer Handbook of Signal Processing in Acoustics, Springer, 2008.

[10] S. M Kay Modern Spectral Estimation - Theory \& Application, Prentice Hall, chap. 4, 1988.

[11] Payment Card Industry - Security Standards Council LLC, PIN Transaction Security (PTS) Point of Interaction (POI) Modular Derived Test Requirements 4.0, Jun 2013.

[12] Ingenico Group, "IPP3xx Security Target Lite - ICO-OPE-00719V1-EN.” [Online]. Available: https://www.bsi.bund.de/SharedDocs/ Downloads/DE/BSI/Zertifizierung/Reporte08/0859b_pdf.pdf?_blob= publicationFile

[13] M. Wax and T. Kailath, "Detection of signals by information theoretic criteria," IEEE T. Acoustics, Speech and Signal Processing, vol. 33, no. 2, pp. 387-392, Apr. 1985.

\footnotetext{
${ }^{8}$ http://www.mathworks.com/help/signal/ref/tfestimate.html
} 


\title{
Differential Audio Analysis: A New Side-Channel Attack on PIN pads
}

\author{
Gerson de Souza Faria ${ }^{\mathrm{a}, 1, *}$, Hae Yong Kim ${ }^{\mathrm{a}, 1,}$ \\ ${ }^{a}$ Departamento de Engenharia de Sistemas Eletrônicos, Escola Politécnica, Universidade de \\ São Paulo, Av. Prof. Luciano Gualberto, tr. 3, 158, CEP 05508-010, São Paulo, Brazil
}

\section{Abstract}

This paper introduces a low-cost side-channel attack that identifies the pressed key of tamper-proof mechanical keypads by exploiting the sound that emanates from the pressed key. Classical sound-based attacks usually identify the pressed key using the fact that each key emits a characteristic sound. These techniques use, for example, the frequency spectrum to identify the key. Instead, our attack (named DAA - Differential Audio Analysis) analyzes the differential characteristics of the sounds captured by two microphones placed inside the empty space of the device, expressed as the transfer function between the two signals. We applied our attack to two PIN Entry Devices - also known as PIN pads - of the same model and obtained classification rates of $100 \%$ in both devices, classifying correctly 600 keystrokes in each device. We also attacked the same PIN pads using the classical frequency spectrum technique, obtaining the average classification rate of only $78 \%$. This result shows clearly the superiority of the new technique. Some PIN pads do not emit sufficiently audible sound when a key is pressed. Evidently, these devices cannot be attacked analyzing audio emission. We applied our DAA attack to a device of this kind and obtained only $63 \%$ of classification success. This result shows that there are models quite vulnerable and models not as vulnerable to our attack. Finally, we present design suggestions in order to mitigate the vulnerabilities that make our attack

\footnotetext{
* Corresponding author

Email addresses: gerson.faria@usp.br (Gerson de Souza Faria), hae@lps.usp.br (Hae Yong Kim)
} 
possible. These vulnerabilities are present in many certified PIN pad models available currently in the worldwide market.

\section{Introduction}

Mechanical keypads are universally used for entering data, given their low cost and satisfactory usability. They are one of the most traditional ways of interfacing humans and machines. Passwords are typed in mechanical keypads like PIN pads (devices used in card transactions to input the cardholder's Personal Identification Number, also known as PIN entry devices or PEDs) and also in ATMs (Automatic Teller Machines). Many countries use electronic voting machines with mechanical keypads in the elections.

In card operations, the theft of card information from an legitimate transaction, known as "skimming", was responsible for $87 \%$ of attacks ${ }^{1}$ against ATMs in 2013 [1]. As the U.S. is migrating its card payment towards the EMV 2 specification, new integrated circuit cards and PEDs are being deployed in the country. One issuer states that 212 million cards were issued with EMV chips in the U.S. by Dec. 31, 2015, and more than 766,000 merchant locations accept EMV cards [2]. All these new PEDs are required to be certified by laboratories following PCI-PTS-POI ${ }^{3}$ and/or Common Criteria ${ }^{4}$ evaluation standards.

Usually, modern ATM keypads use encryption. They are closed, sealed and tamper-resistant modules that encrypt the data after the entry. So, nonencrypted PIN numbers are not supposed to be accessible from outside either

\footnotetext{
${ }^{1}$ Incidents where a skimming device was physically implanted in a device that reads magnetic stripe data from a payment card.

${ }^{2}$ EMV stands for Europay, MasterCard and Visa, the original developers of the platform that promotes hardware and software standards for electronic payments using smartcards.

${ }^{3}$ PCI-PTS-POI stands for Payment Card Industry - PIN Transaction Security - Point of Interaction, a set of requirements specific for PIN entry devices, proposed by the PCI. Device compliance can be consulted at https://www.pcisecuritystandards.org/approved_ companies_providers/approved_pin_transaction_security.php

${ }^{4}$ The Common Criteria for Information Technology Security Evaluation is an international standard for computer security certification. http://www.commoncriteriaportal.org
} 
by physically tapping into the connections or remotely sensing electromagnetic radiation. Tamper detection causes the permanent self-disabling of the keypad. Similarly, PIN pads are secure modules that disable themselves if tampering is detected. However, Drimer et al. [3] show cases where this tamper detection mechanism may fail.

The possibility of identifying the pressed keys through acoustic emissions is a severe vulnerability of secure keypads because they are designed to resist against attempts of eavesdropping. The devices will continue functioning normally while entered data are stolen.

In this work, we use signal processing and machine learning techniques on audio signals acquired by two small microphones installed inside the SAM (Secure Access Module) card compartment of PIN pads to identify the pressed key. Although PIN pads are protected, the free space in the SAM card and service compartment is designed to be freely accessible, without any tamper detection mechanism.

We tested our attack in two PIN pads of the same model, identifying correctly 600 keystrokes in each device, with accuracy of 100\%. The tested equipments are certified following Common Criteria and PCI standards. We trained the machine learning algorithm using data obtained from a person, and tested the system using data from another, emulating a realistic attack scenario.

We found that a PED from a different manufacturer did not emit an audible sound when a key was pressed. We obtained only $63 \%$ of accuracy trying to attack such a device. We tested our attack only in PIN pads, but this attack can be applied to other mechanical keyboards as well. A preliminary conference version of our work was published in Proceedings of Systems, Man, and Cybernetics (SMC) Conference 2015 [4]. In the literature, there are some papers that classify keystrokes by sound, because each key usually emits a typical sound when pressed. Asonov and Agrawal [5] achieved 79\% of success rate when classifying one out of 30 keys in a common PC keyboard. Berger et al. [6] use also keyboard acoustic emanations and a dictionary to recognize correctly $73 \%$ of English words typed in a PC keyboard, without prior training. Zhuang et al. [7] 
takes as input 10-minute sound recording of a person typing English text using a keyboard, recovering up to $96 \%$ of typed characters. Halevi [8] uses acoustic emanations from a keyboard for eavesdropping over alphanumeric random passwords, without using dictionary, attaining $40 \%$ to $64 \%$ classification success per character.

Similarly to acoustic emissions, each key produces a characteristic mechanical vibration when pressed. Marquardt and Verma [9] apply this principle to identify keystrokes of a computer keyboard, by using the accelerometer of a smartphone positioned near the computer's keyboard to acquire the vibrations. Instead of identifying the pressed key, they classify keystrokes in "right" or "left" directions and pairs of keystrokes in "near" and "far", achieving classification rates from $65 \%$ to $91 \%$ by means of those binary decisions. Faria and Kim [10] show that it is possible to identify the pressed key with high probability by fixing accelerometers in the device, acquiring signals generated by mechanical vibration from keystrokes and analyzing them. Faria and Kim demonstrate [11] that the differences of arrival times of vibrations is the main physical phenomenon responsible for leaking the information in the form of mechanical vibration. They obtained $96.4 \%$ of key recognition success rate, attacking a PIN pad.

The approach used in this work is of a different nature: We use the acoustic transfer functions between the audio signals captured by two microphones as the features to attack PIN pads. Researchers in acoustics engineering [12, p. 1381] use transfer function to estimate frequency responses, reverberation times and other characteristics of rooms. In our case, the "room" is the SAM card compartment's empty space located just below the keypad in a PIN pad, where the sound waves interact.

In this new attack we propose, even if all the keys could emit exactly the same sound and vibration, it would still be possible to identify the pressed key by estimating the acoustic transfer function of the system. Since the transfer function is specific to the system and independent of the excitation source, DAA attack will be, in theory, user-independent - the key will be correctly classified, no matter who presses it and how it is pressed. The experiments show that this 
statement is true, within certain limitations that we explain in Section 7.1.

DAA attack needs the contribution of the sales clerk, changing of the original device by a "bugged" one, like most other attacks at the physical layer.

The rest of the paper is organized as follows. We present basic acoustic theory in Section 2. We describe our experiments attacking two distinct models of PIN pads in Sections 3 and 4. We describe our experiment to analyze the dependency between recognition rate and the positions of microphones in Section 5. We make additional tests with PIN pad lying on soft surface, with background noise, and with debit/credit card inserted in the card slot in Section 6. We make some considerations on the obtained results, suggest ways to mitigate the found vulnerabilities and discuss the certification process in Section 7. We present our conclusions in Section 8. Appendix presents implementation details of audio segmentation.

\section{Acoustic Model}

\subsection{Theory}

Let us denote the electric signal of a microphone measuring air pressure at time $t$ and position $\mathbf{r}$ as $y(t, \mathbf{r})$. Given some excitation $x(\tau, \boldsymbol{\rho})$ (also depending on time and position) and considering the system as linear, time-invariant and spatially homogeneous, the response signal $y(t, \mathbf{r})$ can be described through a generalization of convolution [13, p. 14]:

$$
y(t, \mathbf{r})=\iint h(t-\tau, \mathbf{r}-\boldsymbol{\rho}) x(\tau, \boldsymbol{\rho}) \mathrm{d} \boldsymbol{\rho} \mathrm{d} \tau .
$$

where $h(\cdot)$ is the impulse response of the system. In our application, we do not have direct access to the excitation signal $x$ of Eq. 1, because we cannot measure the keystroke sound at the exact position of the key. We have, instead, two signals captured by the two microphones. So, we consider the signal from one microphone as the input and the signal from the other as the output of the system. The impulse response $h(\cdot)$ relates the two signals captured by the two microphones. 
The impulse response depends on the device's empty space, on the spatial positions of sound source and microphones, and on the microphones themselves. The empty space, the positions of microphones and their constitutions are fixed, only the position of the sound source varies. So, the impulse response can be used as the signature of the position of the pressed key.

Since the impulse response is a characteristic of the system and not of the excitation source, in theory, the key will be successfully classified no matter how the key is pressed, as long as the keystroke generates a detectable sound. Consequently, DAA attack is user-independent, within certain limitations. The frequency spectrum of the sound of a keystroke has non-uniform energy distribution and so the estimated characteristics of the channel are limited to the range of frequencies generated by the keystrokes.

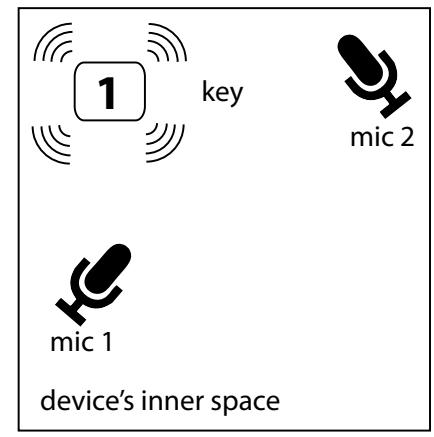

system ' 1 '

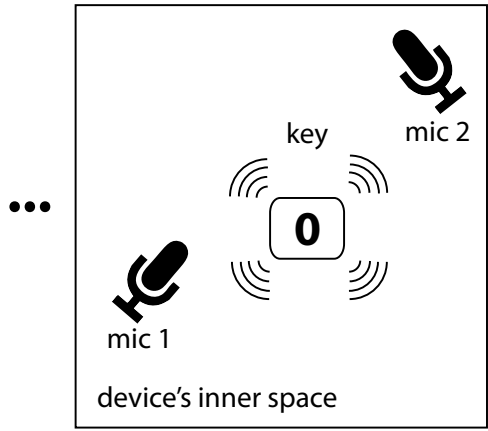

system ' 0 '

Figure 1: The ensemble formed by the device's inner space, the position of the key and of the two microphones compose a system whose transfer function must be estimated. The keys are classified based on the transfer functions.

Fig. 1 depicts the proposed attack. There is one system for each key, described by its transfer function. Each transfer function is estimated from the signals captured simultaneously by the two microphones, one taken as system's "input" and the other as "output". One keystroke sample is presented in Fig. 2. 

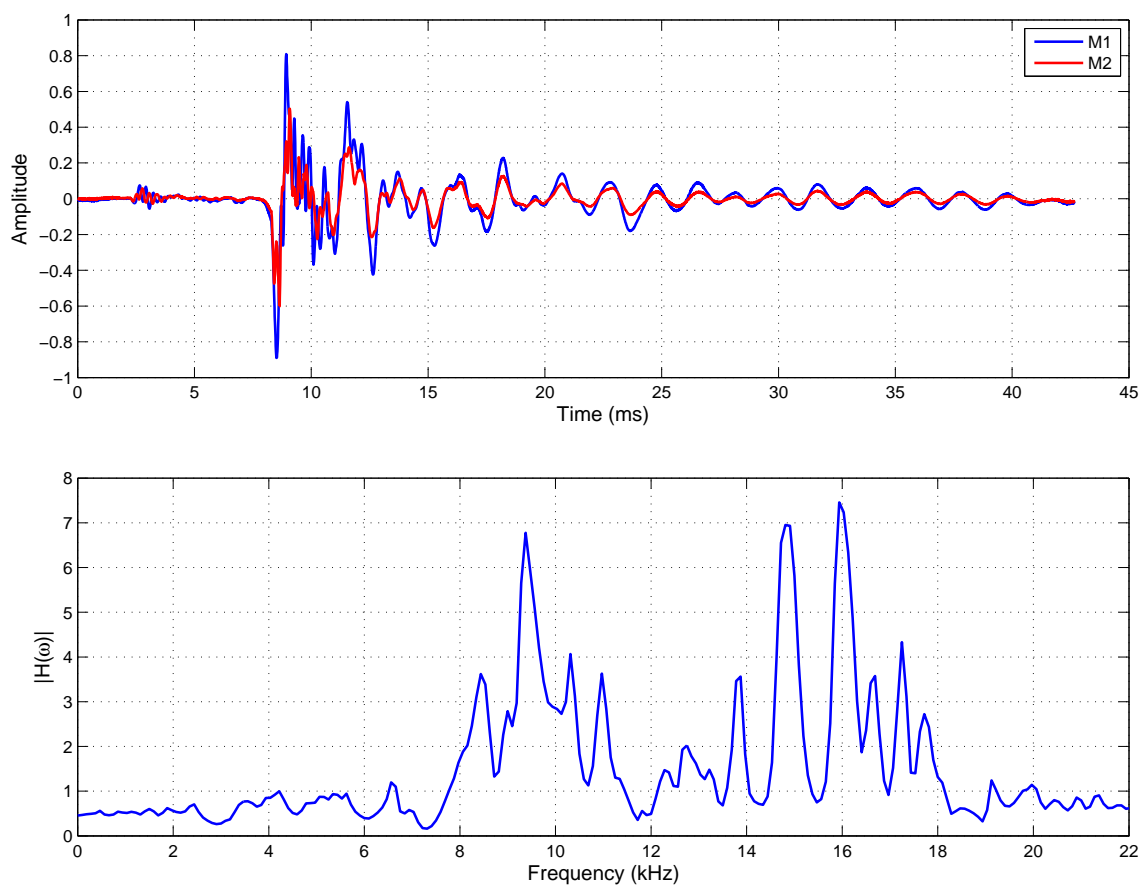

Figure 2: (Top) One keystroke of Ingenico PIN pad captured by the two microphones. Microphone signal 1 in blue and 2 in red. (Bottom) The estimated transfer function that transforms the signal 1 to 2 . Looking at Fig. 5, we can identify this transfer function as corresponding to key " 2 ".

\subsection{Transfer Function Estimation}

We consider the signal $x$ from microphone 1 as input and the signal $y$ from microphone 2 as output. So, we have $K$ single input single output linear systems, one for each key $k=1 \ldots K$. They can be expressed through the convolution notation:

$$
y(t)=h_{k}(t) * x(t) .
$$

This relation has an equivalent representation in the frequency domain, obtained by applying Fourier transforms to $y, h_{k}$ and $x$ :

$$
Y(\omega)=H_{k}(\omega) \cdot X(\omega) .
$$


The term $H_{k}(\omega)$ is the transfer function of the system $k$. Discrete estimates of this function will be used as features that characterize key $k$. There are several methods for estimating the transfer function of an acoustic system [13, p. 66]. Here we tested two methods: (i) classic nonparametric Welch's averaged periodogram method and (ii) parametric Yule-Walker autoregressive all-pole method.

\subsection{Welch's Averaged Periodogram Method}

The transfer function estimation based on Welch's method [14, 15] can be described as:

$$
\hat{H}(\omega)=\frac{\hat{P}_{y x}(\omega)}{\hat{P}_{x x}(\omega)}
$$

where $\hat{P}_{y x}(\omega)$ is the cross power spectral density between the input-output signals and $\hat{P}_{x x}(\omega)$ is input's power spectral density. It can be computed using Matlab procedure tfestimate. The magnitudes $\left|\hat{H}_{i}\right|$ of the resulting complex vector are used as features after dimension reduction using PCA (Principal Component Analysis).

\subsection{Yule-Walker Autoregressive All-Pole Method}

Let us consider $s(n)$ as an excitation source, not directly measurable, but common to both microphones, as depicted by Fig. 3(a). Also, consider two linear systems, described by $H_{x}(z)$ and $H_{y}(z)$, corresponding to the systems that transform the source signal $s(n)$ to signals $x(n)$ and $y(n)$ captured by the two microphones. We can model both systems as autoregressive processes, representing them by all-pole, IIR filters, one for the "input" $H_{x}(z)=1 / A_{x}(z)$ and other for the "output" $H_{y}(z)=1 / A_{y}(z)$, by using the Yule-Walker method $[14,15]$.

The following system relates the two signals captured by the two microphones: $H(z)=Y(z) / X(z)=A_{x}(z) / A_{y}(z)$. Fig. 3(b) depicts the input-output model adopted. We estimated autoregressive all-pole filters $A_{x}(z)$ and $A_{y}(z)$ using Matlab function aryule (x, order), obtaining the estimated filters $\hat{A}_{x}$ and 


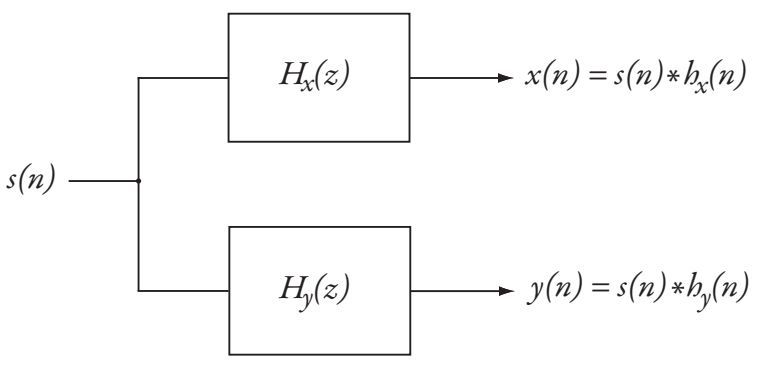

(a)

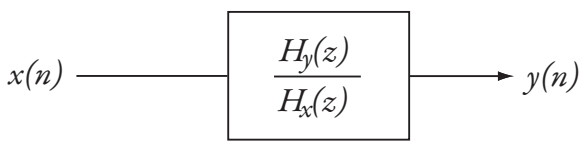

(b)

Figure 3: (a) The responses of the two microphones $x$ and $y$ are described by two linear time-invariant systems, with a common (unknown) excitation source $s$. (b) The resulting system, independent from the knowledge of the excitation source, is estimated considering an input-output model.

$\hat{A}_{y}$. System frequency response is obtained by making $z=e^{i \omega}$ :

$$
H\left(e^{i \omega}\right)=\frac{A_{x}\left(e^{i \omega}\right)}{A_{y}\left(e^{i \omega}\right)}
$$

We used Matlab function $\hat{H}=\mathrm{freqz}\left(\hat{A}_{x}, \hat{A}_{y}, \mathrm{n}\right)$ to estimate the frequency response vector, with $\mathrm{n}=512$ points of evaluation. Like the previous method, the magnitudes $\left|\hat{H}_{i}\right|$ of the resulting complex vector are used as features, after dimension reduction using PCA.

\section{Ingenico iPP320 Experiment}

Fig. 4 shows the first PIN pad we attacked, an Ingenico iPP320, and the assembly of the experiment, where two condenser microphones were glued inside the SAM (Secure Access Module) card access compartment. We tested two devices of this model, naming them "A" and "B". Ingenico iPP320 is a widely used 


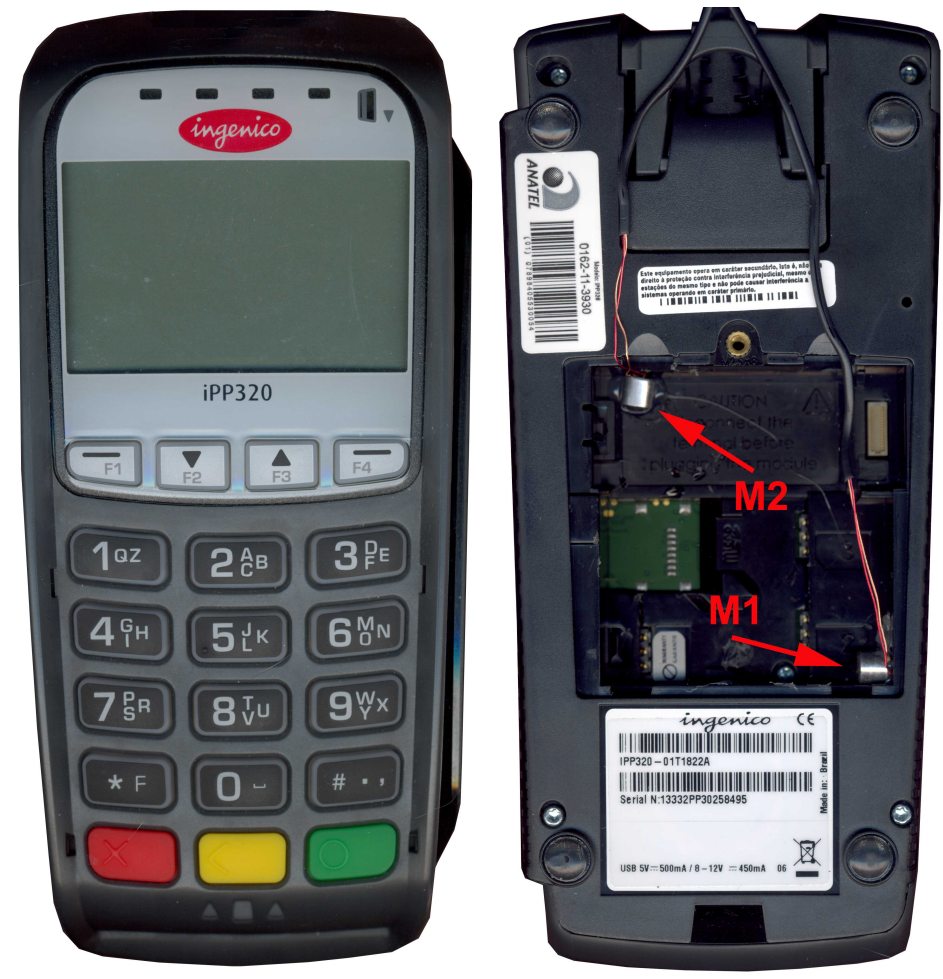

Figure 4: (Left) Ingenico iPP320 PIN pad used in the experiment. (Right) The bottom view showing the SAM compartment with the implanted microphones. Two devices of same model were attacked.

model in the payments market. This device is PCI-PTS compliant ${ }^{5}$, under 2.X level. The iPP320 device is also certified by Common Criteria [16], although the certified device (IPP320-11Txxxxx) is a slightly newer version of the device we tested (IPP320-01Txxxxx). We stress that a PIN pad is a tamper proof device and it permanently disables itself if opened. However, the SAM card compartment is designed to be freely accessible, without tamper proofing mechanisms. The SAM card compartment increases the vulnerability to DAA attack because:

\footnotetext{
${ }^{5}$ https: $/ /$ www. pcisecuritystandards .org/popups/pts_device $\cdot$ php?appnum=4-20142
} 
1. It provides sufficient space for implanting microphones, hidden within the compartment. DAA attack explores this space.

2. The compartment is normally located just below the keypad, the ideal place to capture sounds emanated from the keystrokes.

3. The SAM slots can provide electrical power for the listening devices that can transmit the captured information wirelessly.

Thus, the attack can be executed in real scenario in a undetectable way, without batteries and wires, by embedding off-the-shelf communication modules [17].

\subsection{Data Acquisition}

To obtain the data, a (training) person pressed 70 times each of the " 0 " to " 9 " keys and another (testing) person pressed the same keys 60 times. We recorded the audio signals from the two microphones as a single stereo "wav" file, with sampling rate of $96 \mathrm{kS} / \mathrm{s}$.

Our attack does not depend whether the device is powered or not, because there is no acoustic interference when the device is turned on. So, we maintained it powered off during the tests. ${ }^{6}$

\subsection{Features and Model Evaluation}

Fig. 5 depicts the features obtained from PIN pad "A". In all experiments, we used Yule-Walker method, because it presented a higher accuracy than Welch's method. We justify our decision to use the Yule-Walker method in Section 7.1. Each color represents the average magnitudes of the transfer function of a user. They are very similar for the two users, but quite distinct between the keys, making them good features for key classification. The recognition rates in both PIN pads, using the best parameters, were $100 \%$.

\footnotetext{
${ }^{6}$ Most PIN pads can be configured to emit a feedback "beep" when a key is pressed. This sound can be easily identified and removed from the signal, because it begins only after the "click" finishes. If the "beep" sound interferes with the attack (which is unlikely), then this sound can be turned off by the sales clerk (who is supposedly collaborating with the attack).
} 

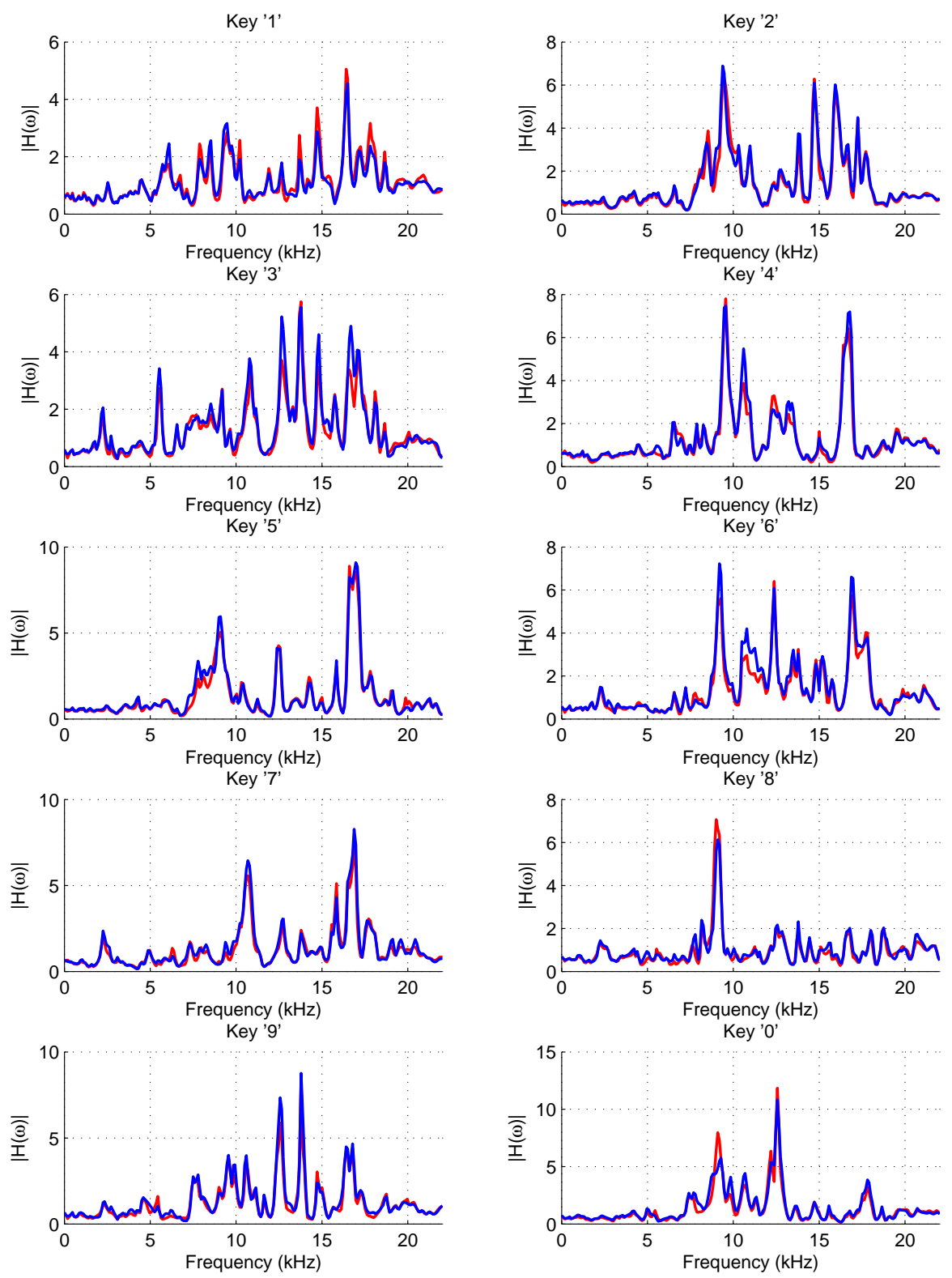

Figure 5: The average magnitudes of the transfer functions of each key, obtained in Ingenico "A". Each color corresponds to a user. 
We used Gaussian Naive Bayes as the training algorithm and tested a range of parameters: the AR filter order (10 to 250) and the dimension of feature vectors (4 to 20). There are many parameter combinations that achieve $100 \%$ of correct classification for both PIN pads. Among them, the smallest AR filter order was 41 and the smallest dimension of feature vectors was 9 .

\subsection{Comparison with the Frequency Spectrum Attack}

In order to compare the DAA attack with the traditional frequency spectrum attack by Asonov and Agrawal [5], we repeated the experiments using as features the estimated frequency spectra with normalization of total energy. We followed the same procedure used in the DAA feature dimension reduction and classification. In this case, signals from only one microphone were used, as the method requires.

The best classification rate was $(72 \pm 29) \%$ for Ingenico "A" and $(85 \pm 30) \%$ for Ingenico "B", where the 72 and 85 values are the average recognition rates of the ten keys and the 29 and 30 values are the standard deviations.

Figure 6 shows that two different keys can have similar frequency spectra, leading to classification confusion in frequency spectrum attack. However, these two keys have very different transfer functions, leading to correct classification in DAA attack.

\section{4. "Cloning" the attack}

An important characteristic of an attack is its scalability, i.e., if the attack can be replicated to other devices with little or no rework. We tested if DAA attack can be "cloned", that is, if the attack can be trained in a device ("master") and applied to another device ("copy") of the same model without retraining the machine learning algorithm. To this end, we trained the machine learning algorithm using keystroke sounds captured from "master" Ingenico "A" and applied the obtained algorithm to classify keystroke sounds of "copy" Ingenico "B".

We obtained very poor results, with key recognition rate of only $6 \pm 7 \%$. We observed that some keys have very distinct transfer functions depending 

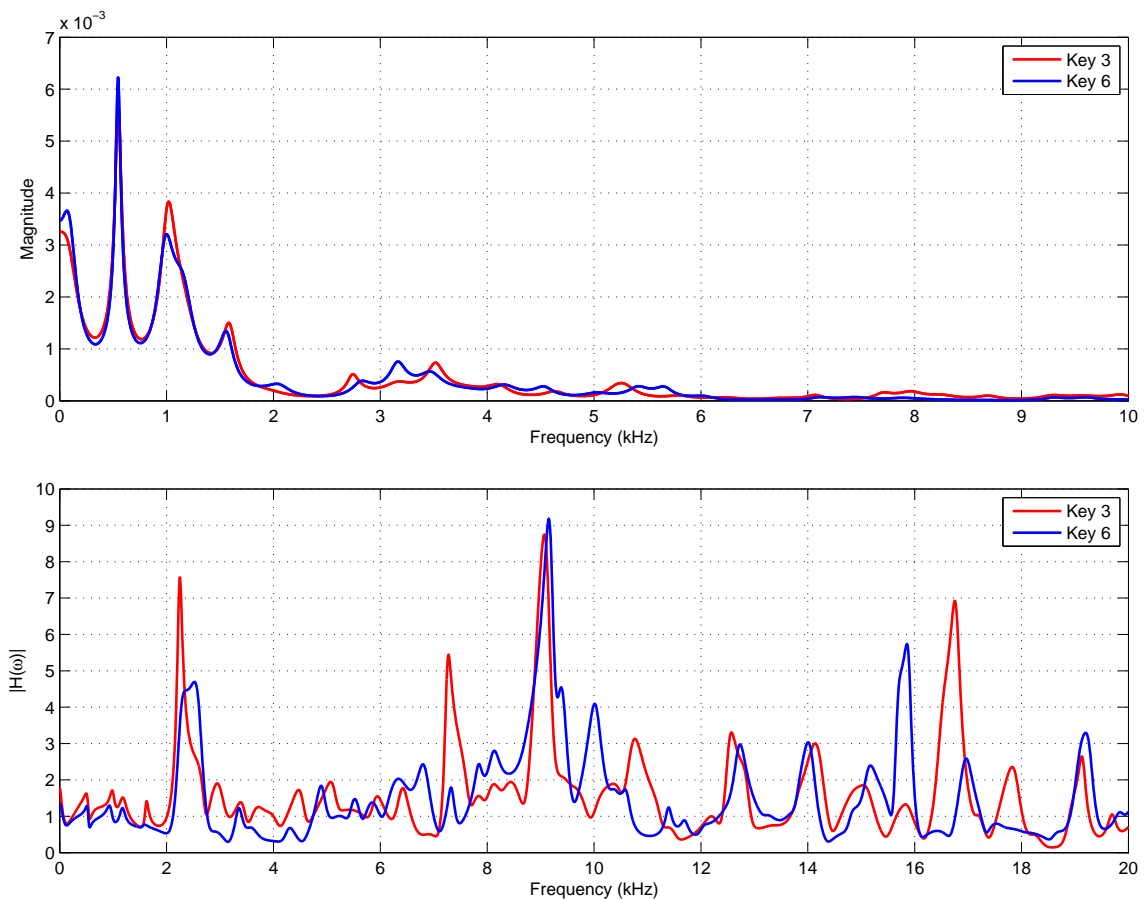

Figure 6: (Top) Frequency spectra of keys "3" (red) and "6" (blue) are very similar, leading to classification confusion in frequency spectrum attack. (Bottom) The corresponding transfer functions are very different, leading to the correct classification in DAA attack.

on the device. For example, Fig. 7 depicts the transfer functions of key " 3 " in Ingenico "A" (red) and "B" (blue). The two functions are very different. This phenomenon prevents "cloning" the DAA attack, because the transfer function seems to be specific to each device. We conclude from the experimental data that it is not possible to clone the DAA attack.

\section{Gertec PPC910 Experiment}

Fig. 8 shows the other attacked device, a Gertec PPC910. We glued the two microphones in the back of the bottom cover of the SAM card access compartment. This device is PCI-PTS compliant under 2.X, and also EMV 2000 levels 


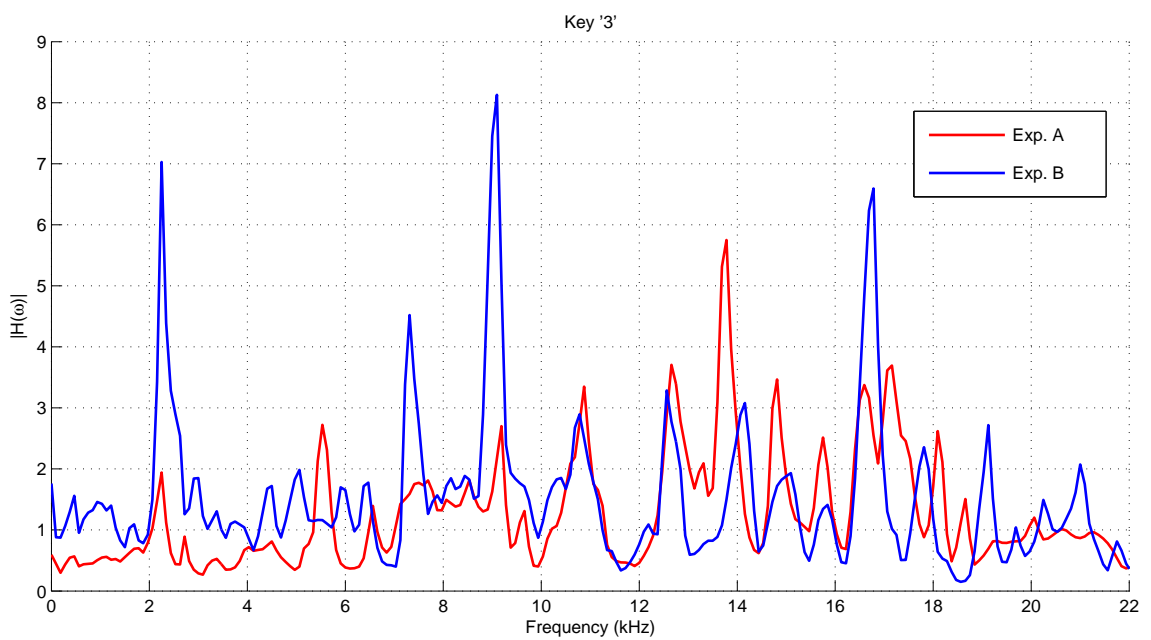

Figure 7: The average magnitudes of the transfer functions of experiments "A" (red) and "B" (blue) of key "3". The two functions are very different, showing that the transfer functions are specific to each device.

1 and 2 compliant ${ }^{7}$.

A person pressed 70 times each of the key '0' to '9' and the other pressed 50 times each key. We used the data from a person solely for the training and from the other exclusively for the test. Not all keystrokes were detected by our segmentation method because sometimes this device does not emit a "click" sound with sufficient energy when a key is pressed. As before, all keys were pressed with the PIN pad turned off.

Fig. 9 depicts the obtained features. Like in the previous experiment, each color represents the average magnitudes of the transfer function of a user. Note that the transfer functions of the two users can be very different.

The average recognition rate is very low $(63 \pm 23 \%)$, where 23 is the standard deviation. In fact, the actual key recognition rate would be even lower, considering that not all keystrokes were detected by the segmentation method.

\footnotetext{
${ }^{7}$ http://www.gertec.com/produto.aspx/produtosdetalhe/57/PPC_910
} 


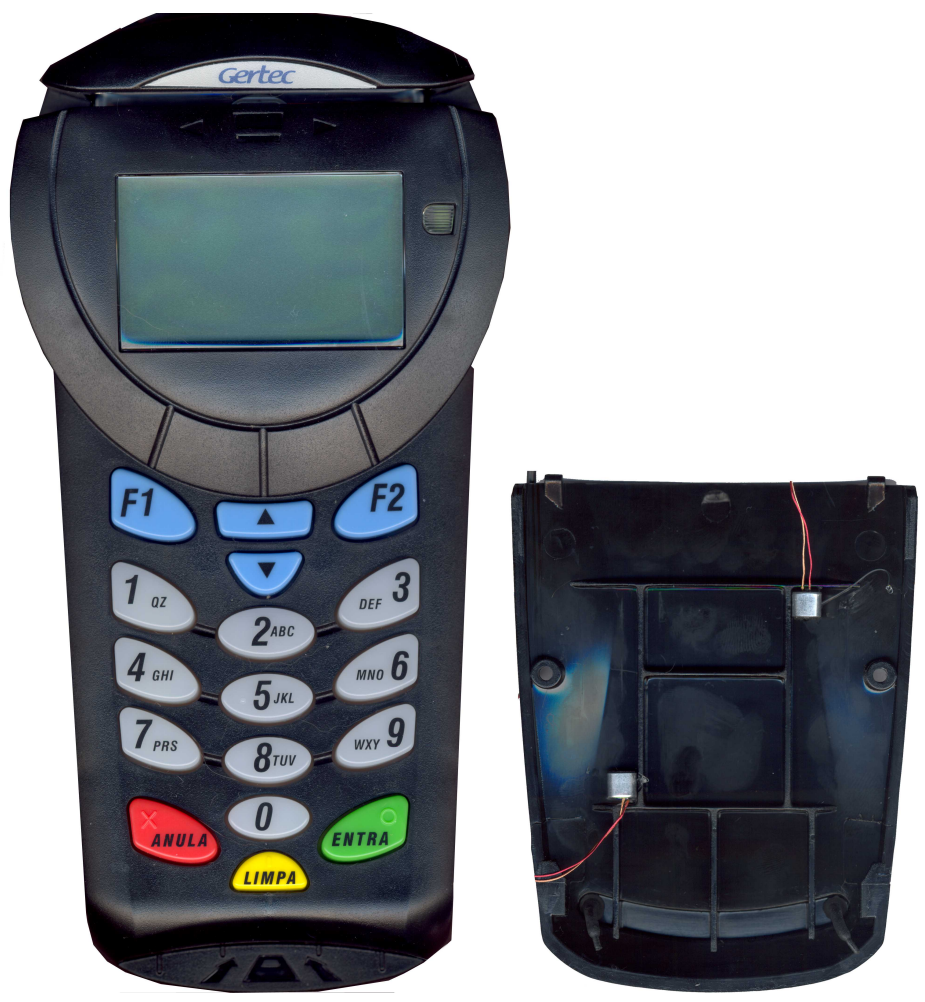

Figure 8: (Left) Gertec PPC910 PIN pad used in the experiment. (Right) The bottom cover with the implanted microphones.

\section{Microphone Positioning Experiment}

We made an experiment to find out if classification rates are related to the positions of microphones inside the equipment. For this, we placed 4 microphones inside the iPP-320 device, as shown in Fig. 10, acquired the audio of keystrokes of 4 persons pressing 30 times each key and trained the systems for the 6 possible pairs formed by the 4 microphones. The training was done by taking data from 3 out of 4 persons, leaving out one person for testing. This procedure was repeated 4 times, one for each person used for testing.

We validated the system performance by varying the 3 parameters: AR filter order (10 to 250), dimension of feature vectors (4 to 20), and the pair of microphones $\{(1,2) ;(1,3) ;(1,4) ;(2,3) ;(2,4) ;(3,4)\}$. The total number of tests 

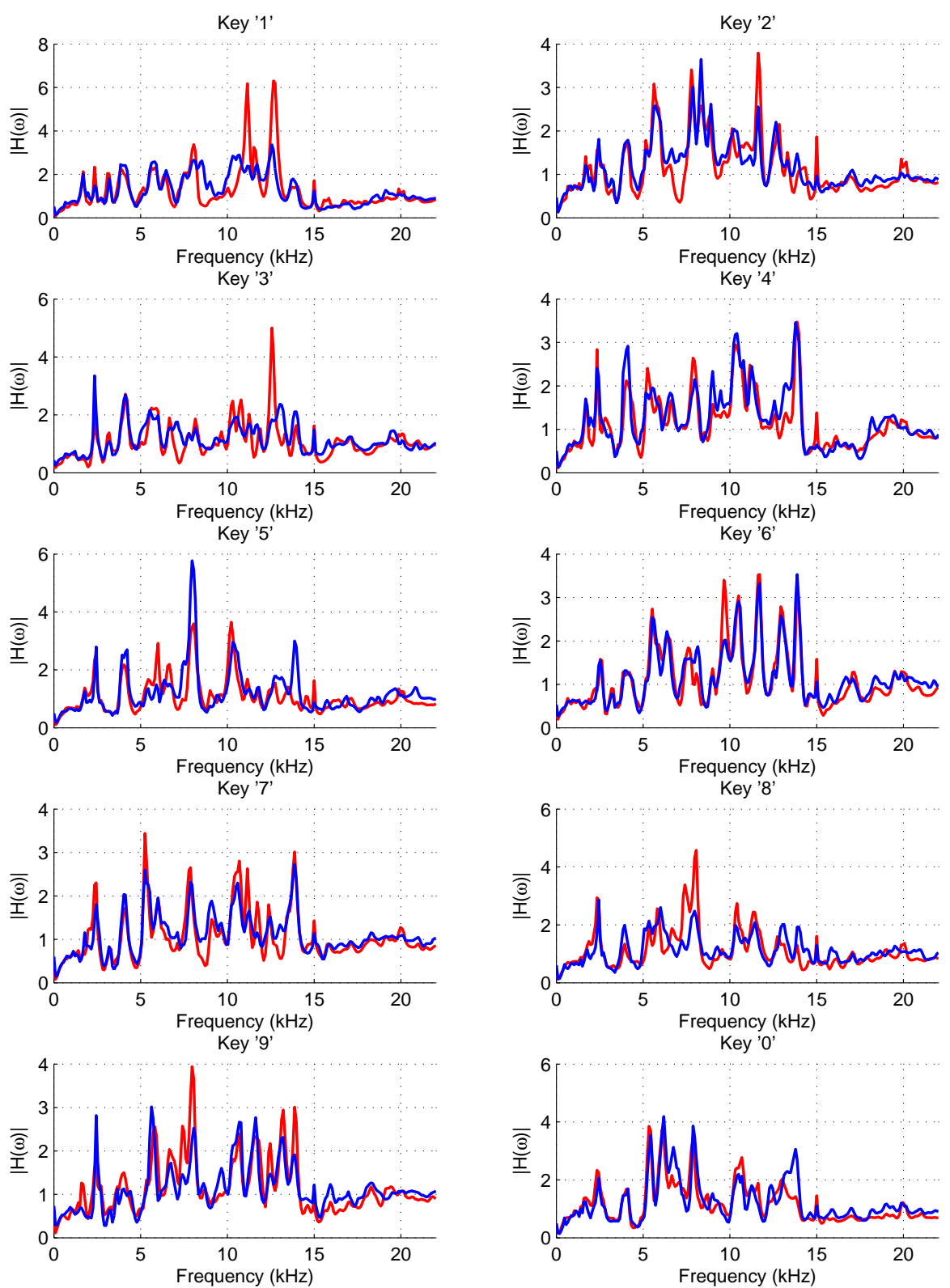

Figure 9: The average magnitudes of the transfer functions of each key, obtained in Gertec PIN pad. Each color corresponds to a user. Transfer functions of the two users do not match. 
per pair of microphones was $16,388(241 \times 17 \times 4)$. Fig. 11 shows the percentage of tests that achieved $100 \%$ of correct classification. For instance, pair $(1,2)$ reached 11,967 full correct classifications out of 16,388 tests, approximately $73 \%$. Two observations follow: (i) all pairs of microphones produce $100 \%$ classification using adequate parameters and (ii) there are 2 preferential pairs that produce full correct classification for a wider range of parameters: $(1,2)$ and $(3,4)$.

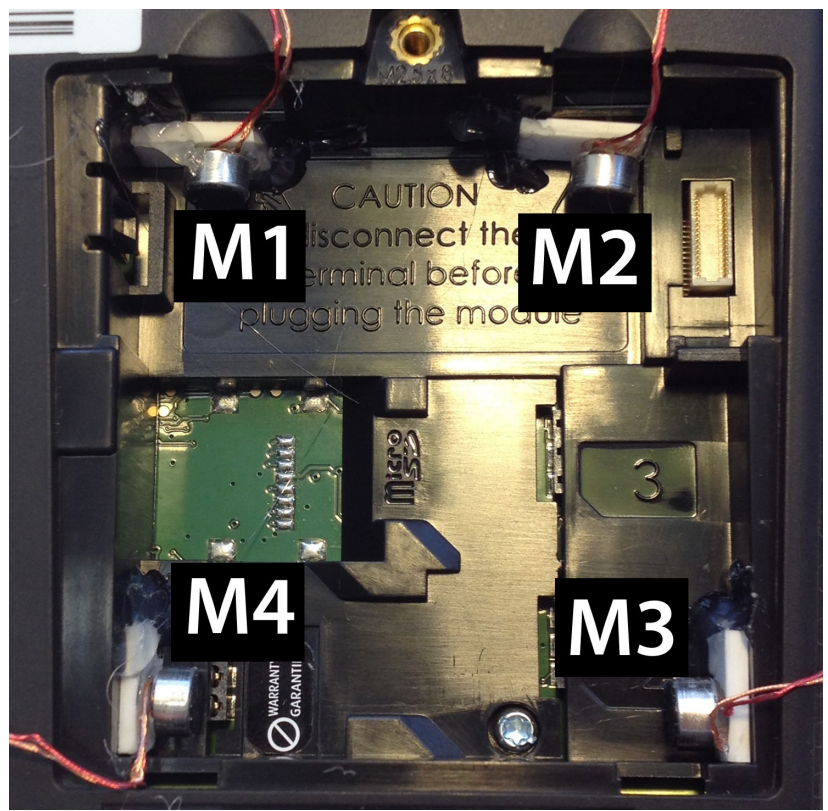

Figure 10: Bottom view of Ingenico iPP320 PIN pad used in the experiment showing the SAM compartment with the implanted microphones. Pairs (M1,M2) and (M3,M4) are preferable in the attack.

We used omni-directional microphones, what makes our tests orientationindependent. Moreover, according to the experiments we carried out in this Section, we conclude that DAA has good tolerance to the locations of the microphones, because all the six combinations produced $100 \%$ correct classification using adequate parameters. As the six combinations of microphones have different orientations, we can conclude that DAA has good tolerance to the microphone orientations as well. 


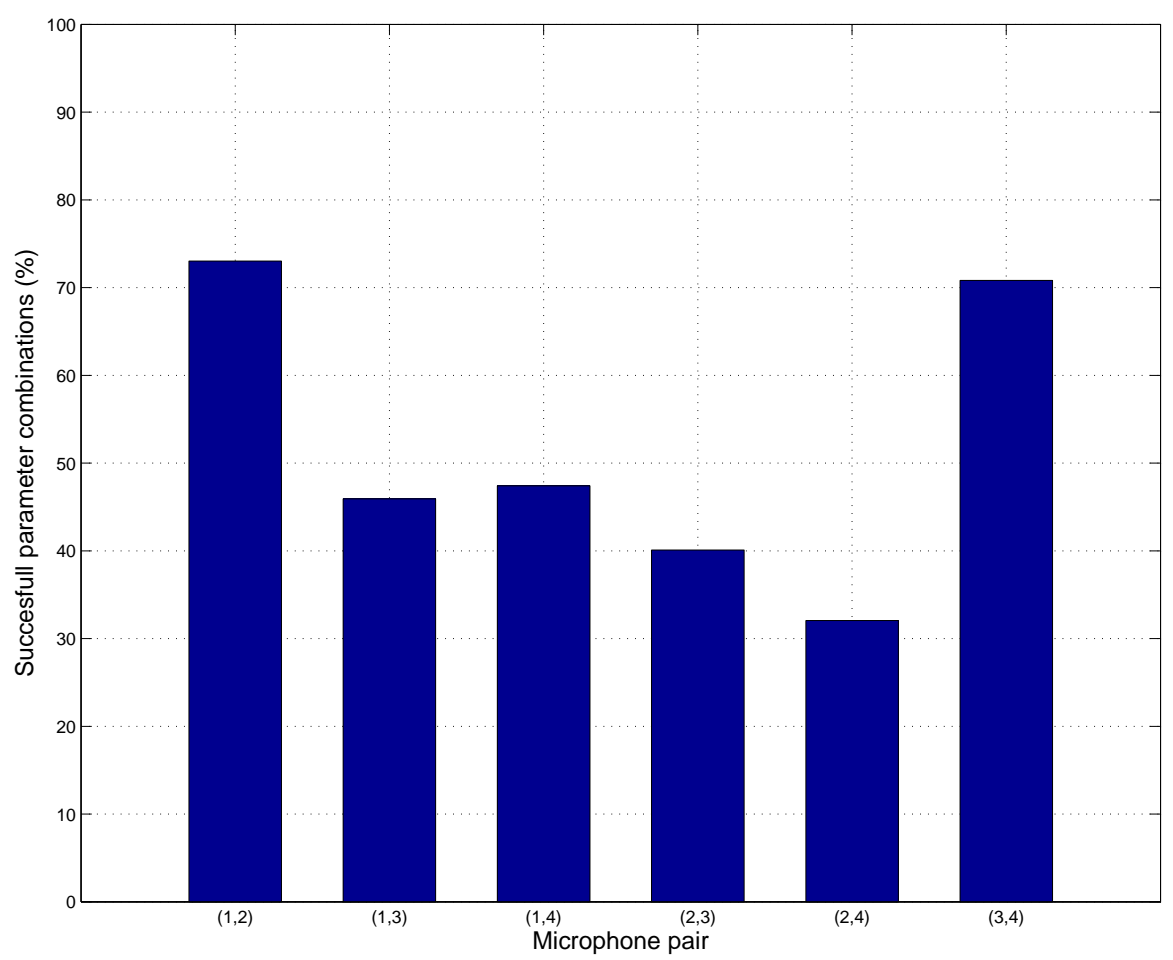

Figure 11: Percentage of parameter combinations that achieved $100 \%$ correct classification versus pair of microphones.

\section{Background Noise, Soft Surface and Inserted Card}

We made additional experiments to test the robustness of the attack against noisy environment and the softness of the surface where the PIN pad is placed. We tested the Ingenico device with the best microphone configuration according to Section 5, i.e., the pair $(1,2)$. One person pressed the keys 50 times in a silent environment on a rigid surface. This data was used as the training data. A second person pressed the keys 50 times in three conditions: (i) in a silent environment with PIN pad placed on a hard surface, (ii) in a silent environment on a soft surface (a rubber mouse-pad) and (iii) in a noisy environment on a rigid surface. The noise consisted of continuous pop/rock music played close to the PIN pad. Figure 12 presents the sound levels measured without and 
with music ${ }^{8}$. The sound level (70 80 dB on average) is normally categorized as "moderate". We tested only Yule-Walker method. The classification rate of "silent-hard" experiment was $100 \%$. The classification rate of "silent-soft" experiment was also $100 \%$, showing no dependence on the surface hardness. Only the experiment "noisy-hard" showed a slight decrease in classification rate, achieving $99.6 \pm 1.3 \%$.

We made another experiment in order to test the influence of the card presence in the card slot. We acquired the training and test data with a debit/credit card inserted in the slot and achieved $100 \%$ of classification rate, in silent environment.

\section{Considerations}

\subsection{Comparison of the Attacks}

Table 1 compares the key recognition rates obtained by frequency spectrum attack, DAA attack using Welch method, and DAA attack using Yule-Walker method. The classification algorithm was Gaussian Naive Bayes. In order to reduce the dimension of the feature vectors, we used the classic PCA (Principal Component Analysis) method and selected a number of eigenvectors with the largest eigenvalues. In all the experiments, DAA attacks have considerably higher accuracy than the frequency spectrum attack (see Section 3.3 for a explanation of why this occurs).

Comparing the two DAA attacks, Yule-Walker method always presents slightly higher accuracy than Welch's (that never reaches 100\% of successful classification). Additionally, Yule-Walker method reaches $100 \%$ of classification success in a large number of tests and within a wide range of parameters, as shown in Section 5. This is the reason why we have presented only the results of DAA Yule-Walker attack throughout this paper.

\footnotetext{
${ }^{8}$ The audio level was measured through the iPhone application "Decibel 10th" https: //itunes .apple.com/br/app/decibel-10th-professional/id448155923?mt=8
} 


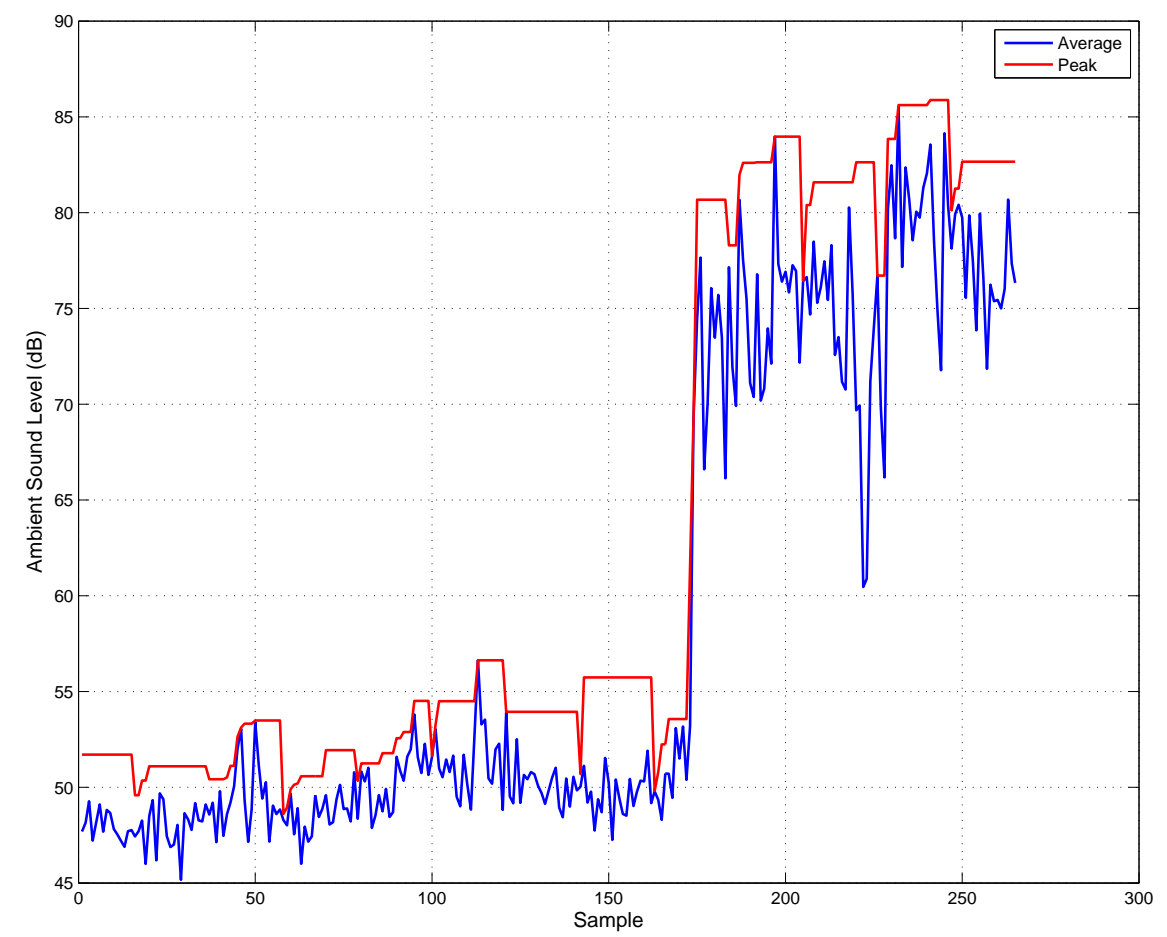

Figure 12: Sound level measured near the PIN pad. The left plateau corresponds to the ambient level without music, the right plateau with music.

Table 1: Accuracy of the Attacks

\begin{tabular}{lccc}
\hline & Freq. Spectrum & DAA Welch & DAA Yule-Walker \\
\hline Ingenico "A" & $72 \pm 29 \%$ & $99 \pm 1 \%$ & $\mathbf{1 0 0 \%}$ \\
\hline Ingenico "B" & $85 \pm 30 \%$ & $99 \pm 3 \%$ & $\mathbf{1 0 0 \%}$ \\
\hline Gertec & $46 \pm 30 \%$ & $47 \pm 26 \%$ & $\mathbf{6 3} \pm \mathbf{2 3 \%}$ \\
\hline
\end{tabular}

In our early research, we used Welch method because it is a generic nonparametric method that can be applied to any linear time-invariant system. Later, we noticed that the signals from each microphone can be modeled as an AR (Auto-Regressive) process, i.e., the equivalent to an IIR (Infinite Impulse Response) filter. Yule-Walker method is a parametric method that assumes that the system to be estimated is AR. So, one would expect that Yule-Walker 
works better than Welch in our problem, which was confirmed by our experiments. Non-parametric Welch method smooths spectrum. Meanwhile, YuleWalker method defines spectrum with sharp peaks.

\subsection{Considerations on DAA Attack}

As we said, DAA attack is user-independent within certain limitations. Figures 5 and 9 show the average transfer functions of each key, where each color corresponds to a user. The transfer functions of the two users are very similar in Fig. 5 (Ingenico), what makes it possible to identify the pressed keys in this device with $100 \%$ of success. However, the red and blue graphs do not match well in all subfigures of Fig. 9 (Gertec). If DAA were completely independent of the way the keys are pressed, the transfer functions of different users would be the same even in this device. Perhaps DAA is really independent of the user. But as Gertec sometimes emits a very low sound, it may be that the low signal to noise ratio does not allow properly estimate the transfer function, resulting in low success rates.

It seems that the speed at which a user presses one key after the other does not affect the effectiveness of the attack, because the pressing sound fully decays in about $45 \mathrm{~ms}$, much shorter than the pauses between two fast pressings (at least 200ms).

\subsection{Qualitative Observations and Countermeasures}

We experimentally demonstrated that Ingenico iPP320 is much more vulnerable to DAA attack than Gertec PPC910. Some qualitative observations that may explain this fact follow:

- Ingenico's keys inevitably leak an audible "click" when pressed. In turn, Gertec's keys can be pressed in a way that no click can be heard. We think this is the main cause for the low classification rates of Gertec device. It is not possible to classify the keys by sound if no sound can be identified. 
- Gertecs's empty space is much more "corrugated" (see Fig. 8 right) and structurally complex than Ingenico's. This property may introduce nonlinearities that invalidate the assumed DAA linear model.

The SAM compartment has enough space for installing all the necessary hardware for a real DAA attack. Krebs provides [17] an example of a compromised PIN pad that uses Bluetooth technology installed in SAM compartment to send the stolen data wirelessly. In a real DAA attack, the training should be done after mounting all electronic components, to take into account the sound propagation characteristics changed by them. A safer design should completely eliminate this compartment, using other ways to access SAM cards. Also, a secure keypad should not emit any audible sound when pressed. We have already observed that it is difficult to attack Gertec PPC910 using DAA attack because this device has silent keys.

It is noteworthy that many other PIN pad models also have the same design characteristics that led to the vulnerabilities described above. For instance, the Ingenico models Desk/3200, iCT220, iCT250 and all the iPP300 series have the keypad system and the SAM compartment closely resembling the model successfully attacked here.

\subsection{Certification Process}

PCI (Payment Card Industry) requires that an attack such as described in this work should be possible only with very high cost of 26 for identification and 13 for exploitation [18, p. 16]. Nevertheless, the DAA attack costs only 12.5 for identification and 3 for exploitation (Table 2). The method used to calculate the costs can be found in [18, p. 182].

Many documents used in the certification process warn against acoustic emission attacks. Ingenico's Security Target for iPP-320 states clearly which assets are being certified and PIN is one of them [19, sec. 4.1]. The same document [19, sec. 8.1.1.1] states that the device shall not emit sound, electromagnetic emissions, leak information through power consumption, etc. 
Table 2: Calculation of the Cost of PIN pad DAA Attack

\begin{tabular}{lll}
\hline Factor & Identification & Exploitation \\
\hline Attack time & Beyond 160 hours $=5.5$ & $\leq 1$ hour $=0$ \\
\hline Expertise & Expert $=4$ & Layman $=0$ \\
\hline Knowledge of the PIN entry device & Public $=0$ & Public $=0$ \\
\hline Access to the PIN entry device & Mechanical Sample $=1$ & Mechanical Sample $=1$ \\
\hline Equipment required for the attack & Standard $=1$ & Standard $=1$ \\
\hline Specific parts required & Standard $=1$ & Standard $=1$ \\
\hline Total cost & $\mathbf{1 2 . 5}$ & $\mathbf{3}$ \\
\hline
\end{tabular}

From the citations above, we can conclude that attacks based on acoustic emissions are explicitly covered by both PCI and Common Criteria requirements. The devices we attacked were evaluated and certified throughout these requirements (the model we tested is still on the market, is certified by PCI, but is a slightly earlier version of the model actually certified by Common Criteria). However, the certification process failed to identify the vulnerability explored in the DAA attack.

\section{Conclusion}

In this paper, we have demonstrated that the sound emitted by the keystrokes of a PIN pad can be used to identify the sequence of pressed keys by analyzing the audio captured at two different points inside the device's SAM compartment. We have shown that the acoustic properties of the empty space, characterized by its acoustic transfer function, can be used as location signatures. These signatures are used in our Differential Audio Analysis (DAA) attack to identify the pressed keys. A simple classification scheme using these signatures yielded $100 \%$ of key classification rates in two PIN pads of the same model and $63 \%$ in another model. This shows that there are some devices completely vulnerable to DAA attack, while others are less vulnerable. Two simple countermeasures may mitigate the possibility of this attack: (i) The devices should not have a service compartment where bugs can be embedded. (ii) The keystrokes should not emit audible "clicks". Our finding also indicates that the certification pro- 
cess was not able to detect information leakage from the device in the form of audible sound.

\section{Appendix A. Audio segmentation}

We segmented the captured audio files by (i) finding $N$ highest peaks of $\sqrt{l^{2}(t)+r^{2}(t)}$ that are separated by at least $200 \mathrm{~ms}$, where $N$ is the number of keystrokes in the audio file, and $l(t)$ and $r(t)$ are respectively the audio signals of left and right channels; (ii) taking 4096 sample points around each peak, 80\% of the samples after the peak position, and $20 \%$ before it. We used this simple approach because the audio segmentation is not the main focus of this work. Other techniques can be applied.

\section{References}

[1] Verizon, Verizon 2014 Data Breach Investigations Report (2014). URL http: //www. verizonenterprise.com/DBIR/2014/

[2] American Banker, How the Shift to EMV Is Faring (So Far) (April 2016). URL http: //www . americanbanker.com/gallery/ how-the-shift-to-emv-is-faring-so-far-1080295-1.html

[3] S. Drimer, S. J. Murdoch, R. Anderson, Thinking inside the box: systemlevel failures of tamper proofing, in: Security and Privacy, 2008. SP 2008. IEEE Symposium on, IEEE, 2008, pp. 281-295.

[4] G. S. Faria, H. Y. Kim, Identification of pressed keys by acoustic transfer function, in: Systems, Man, and Cybernetics (SMC), 2015 IEEE International Conference on, 2015, pp. 240-245. doi:10.1109/SMC. 2015.54.

URL http://dx.doi.org/10.1109/SMC.2015.54

[5] D. Asonov, R. Agrawal, Keyboard acoustic emanations, in: Security and Privacy, 2004. Proceedings. 2004 IEEE Symposium on, 2004, pp. 3-11. doi:10.1109/SECPRI . 2004.1301311. 
[6] Y. Berger, A. Wool, A. Yeredor, Dictionary attacks using keyboard acoustic emanations, in: In Proceedings of Computer and Communications Security (CCS, 2006.

[7] L. Zhuang, F. Zhou, J. D. Tygar, Keyboard acoustic emanations revisited, ACM Trans. Inf. Syst. Secur. 13 (1) (2009) 3:1-3:26. doi:10.1145/ 1609956.1609959.

URL http://doi.acm.org/10.1145/1609956.1609959

[8] T. Halevi, N. Saxena, A closer look at keyboard acoustic emanations: Random passwords, typing styles and decoding techniques, in: Proceedings of the 7th ACM Symposium on Information, Computer and Communications Security, ASIACCS '12, ACM, New York, NY, USA, 2012, pp. 89-90. doi:10.1145/2414456.2414509.

URL http://doi.acm.org/10.1145/2414456.2414509

[9] P. Marquardt, A. Verma, H. Carter, P. Traynor, (sp)iphone: Decoding vibrations from nearby keyboards using mobile phone accelerometers, in: Proceedings of the 18th ACM Conference on Computer and Communications Security, CCS '11, ACM, New York, NY, USA, 2011, pp. 551-562. doi:10.1145/2046707.2046771.

URL http://doi.acm.org/10.1145/2046707.2046771

[10] G. S. Faria, H. Y. Kim, Identification of pressed keys from mechanical vibrations, Information Forensics and Security, IEEE Transactions on 8 (7) (2013) 1221-1229. doi:10.1109/TIFS. 2013.2266775.

URL http://dx.doi.org/10.1109/TIFS.2013.2266775

[11] G. S. Faria, H. Y. Kim, Identification of pressed keys by time difference of arrivals of mechanical vibrations, Computers \& Security 57 (2016) 93 105. doi:http://dx.doi.org/10.1016/j.cose.2015.11.002.

URL http://dx.doi.org/10.1016/j.cose.2015.11.002

[12] D. Havelock, S. Kuwano, M. Vorländer, Handbook of Signal Processing in Acoustics, Vol. 2, Springer, 2008. 
[13] D. Havelock, S. Kuwano, M. Vorländer, Handbook of Signal Processing in Acoustics, Vol. 1, Springer, 2008.

[14] S. M. Kay, Modern Spectral Estimation - Theory \& Application, Prentice Hall, 1988.

[15] P. Stoica, R. L. Moses, Spectral Analysis of Signals, Prentice Hall, 2005.

[16] Certification report bsi-dsz-cc-0859-2013 for ingenico pin entry device (April 2013).

URL https://www.bsi.bund.de/SharedDocs/Downloads/DE/BSI/ Zertifizierung/Reporte/Reporte08/0859a_pdf.pdf?__blob= publicationFile\&v $=2$

[17] Krebs On Security - Pro-Grade Point-of-Sale Skimmer (February 2013). URL http://krebsonsecurity.com/2013/02/ pro-grade-point-of-sale-skimmer/

[18] Payment Card Industry - Security Standards Council LLC, PIN Transaction Security (PTS) Point of Interaction (POI) Modular Derived Test Requirements v4.0 (June 2013).

[19] Ingenico Group, IPP3xx Security Target Lite - ICO-OPE-00719-V1-EN. (January 2016).

URL https://www.bsi.bund.de/SharedDocs/Downloads/DE/BSI/ Zertifizierung/Reporte/Reporte08/0859b_pdf.pdf?__blob= publicationFile\&v $=2$ 